\title{
DOENÇAS RESPIRATÓRIAS ASSOCIADAS À MINERAÇÃO DE CARVÃO \\ - ESTUDO DE COORTE DE 5 ANOS -
}

\author{
Tese de doutoramento apresentada \\ ao Departamento de Saúde Ambiental da Faculdade \\ de Saúde Pública da Universidade de São Paulo. \\ para a obtenção do Título de Doutor \\ em Saúde Pública.
}

ORIENTADOR: Prof. Dr. DIOGO PUPO NOGUEIRA 


\section{ERRATA}

pq 11: Na 15- lintia do item 2, aonde se le:

$$
\begin{gathered}
\text {...como o declinio do Vefizzo... } \\
\text { leia-se } \\
\text {...como o declínio do Vef } 1224 \ldots
\end{gathered}
$$

pq 30: a texto do primeiro box a esquerda foi invertido

$$
\begin{aligned}
& \text { leia-se } \\
& 915 \\
& \text { Mineiros elegiveis para } \\
& \text { o exame de } 1989
\end{aligned}
$$

Pg 67: TABELA 3.24 - Fumantes com PB- $\quad(n=127)$

pg 80: TAFELA 3.37 - a probabilidade associada ao IT nao e significante.

pg 119: Uitimo parágrafo

...isto tendera a aumentar a especificidade... leia-se

...isto tenderá a aumentar a sensibilidade...

Pg 134: Sequndo parágrafo

...ou fibrose intersticial (R10)

$$
\text { leia-se }
$$

...ou fibrose intersticial4 


\section{EDUARDO ALGRANTI}

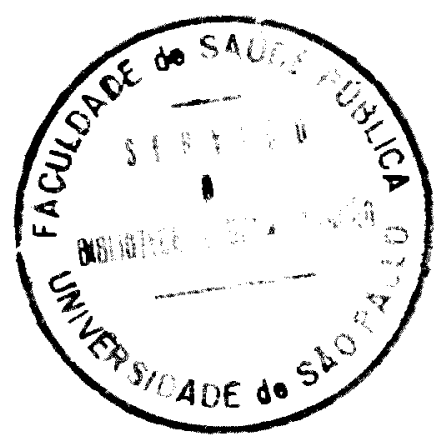

\section{DOENÇAS RESPIRATÓRIAS ASSOCIADAS À MINERAÇĀO DE CARVÃO \\ - ESTUDO DE COORTE DE 5 ANOS -}

Tese de doutoramento apresentada 20 Departamento de Saúde Ambiental da Faculdade de Saúde Páblica da Universidade de São Paulo, para a obtenção do Título de Doutor em Saú de Pública.

ORIENTADOR: Prof. Dr. DIOGO PUPO NOGUEIRA

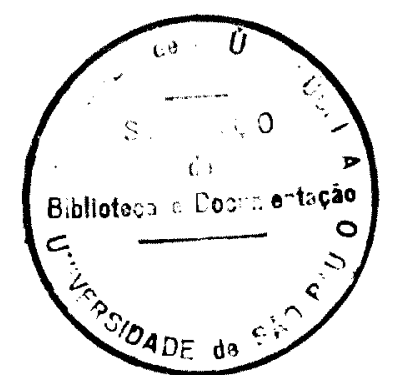

SÃo PAULO, 1991 
Trabalho financiado pelas seguintes entidades:

- CNPq (processo no 410010/89.8)

- FAPESP (processo no 88/4337-6)

- FUNDACENTRO (projeto 03.01.03/1989) 
"Most pathological changes in tissues can be prevented if the environmental milieu of the cells is constantly rich in oxygen. The ammount of oxygen the circulation supplies to the tissue is largely controlled by respiration.

To ensure healthy lungs, the inner ambient must be in harmony, and so also must be the outer environment. If the air we breathe is polluted it will disrupt the ecology of the lungs just as it disrupts the ecology of any forest"

("Boa parte das alterações nos tecidos podem ser evitadas se o meio ambiente das células é rico em oxigênio. A quantidade de oxigênio suprida aos tecidos pela circulação é em grande parte controlada pela respiração.

Yara que os pulmōes mantenham-se sadıs, o ambiente interno deve estar em harmonia, assim como o meio ambiente externo. Se o ar que respiramos é poluído, ele desequilibará a ecologia dos pulmões, da mesma forma que desequilibra a ecologia de qualquer mata".)

In: David Hoffmann - The New Holistic Herbal 3rd.ed. Element Books Ltd, UK. 


\section{AGRADECIMENTOS}

Este trabalho foi possível graças ao apoio financeiro do $\mathrm{CNPq}$, FAPESP, FUNDACENTRO e CAPES a quem sou grato. As nossas "promessas de projeto", quando candidato a estes auxílios, puderam ser quase todas cumpridas na gestāo da pesquisa.

Ao meu orientador, Prof. Dr. Diogo Pupo Nogueira, um reconhecido agradecimento pela sua disponibilidade, presteza, confiança e orientação durante meu período de pós-graduaçāo.

Um projeto desta envergadura depende de uma série de pessoas em seus diversos estágios. À Dra. Elisabete Medina C. Mendonça devo boa parte deste trabalho por sua ativa participação no desenvolvimento de metodologias, trabalho de campo e leitura minuciosa do texto final. A Dra. Rita de Cássia Cruz da Silva participou do desenvolvimento de metodologias e do trabalho de campo. Juntos, desenvolvemos atividades na área de doenças ocupacionais respiratórias e eu me considero um indivíduo privilegiado em participar deste trio de trabalho. Em Criciúma, a aconchegante recepção dos Drs. Albino José de Souza Filho e Rui José de Luca foram fundamentais nas inúmeras vezes que lá estivemos. Além disso, eles atuaram como leitores das radiografias.

A organização do trabalho de campo contou com a eïcaz colaboração do Sr. Antonio Cunha e do Eng. Dorival Barreiros (coordenador do trabalho) em 1984, e em 1989 do Dr. Anderley Antonelli e Roberto Lodetti, da Subdelegacia Regional do Trabalho de Criciúma, nos contatos com as empresas mineradoras, sindicatos dos trabalhảdores e órgãos de comunicação locais. Roberto Lodetti e Urlete Goulart foram os incansáveis técnicos do trabalho de campo que, além de serem responsáveis pela coleta de dados, encarregavam-se do agendamento dos mineiros. Agradeço a Irmã Dionê Rocha Rodrigues, Diretora do Hospital São José, Criciúma, pela sua colaboração na cessão gratuita do espaço físico para o exame dos mineiros.

Tive a felicidade de contar com o estatístico Antonio de Castro Bruni para a análise e interpretacãó de dados. Com sua competência e vaciência em 
responder às minhas dúvidas, pude (assim espero) transformar números em palavras. O estatístico Marco Antonio Bussacos foi também solícito e extremamente interessado durante a redação final do trabalho. Meus agradecimentos também à física Regina Bitelli Medeiros da Escola Paulista de Medicina pelos testes dos nebulizadores.

A Biblioteca da Faculdade de Saúde Pública, USP, foi um local de agradável trabalho durante os últimos anos. Agradeço a Daisy Pires Noronha, Angela Maria B. Cuenca e Raquel Noronha M. Braga pelo auxílio prestado na tarefa de levantamento bibliográfico e na orientação quanto as citaçōeś.

Com a nova sistemática de apresentação de teses, adotada pela Faculdade de Saúde Pública, o contato com os membros da banca examinadora foi extremamente importante para a versāo final deste trabalho. Sou grato a Dra. Sabina Lea Gottlieb, Jorge da Rocha Gomes e Nelson Morrone pelos valiosos comentários do texto. Ao leitor posso garantir que esta é uma edição polida e enriquecida do trabalho originalmente apresentado.

O texto foi competentemente datilogrado por Edmilson Sousa dos Santos e as figuras são de autoria de Lourenil Aparecido Ferreira.

Às minhas filhotas Claudia e Bruna, um beijo especial, pela compreensão nas minhas frequentes ausências neste período. Tenho a convição que transmiti uma relação saudável com o trabalho e elas souberam captá-la.

À Leila, minha mulher, pela sua intuição e ato cavalheiresco em não permitir a redação simultânea de duas teses debaixo do mesmo teto e pelo constante carinho e suporte de todos esses anos. Posso garantir que estou feliz em poder oferecer a contrapartida neste momento. 


\section{ABREVIATURAS UTILIZADAS}

AM - Anos-Maço

ATS - American Thoracic Society

BC-Bronquite Crônica

CPT - Capacidade Pulmonar Total

CVF - Capacidade Vital Forçada

DL - Declínio Lento

$\mathrm{DP}_{15}$ - Dose Provocativa que causa uma queda de $15 \%$ no VEF$_{1}$

$\mathrm{DP}_{20}$ - Dose Provocativa que causa uma queda de $20 \%$ no VEF$_{1}$

DR - Declínio Rápido

DT - Diâmetro Traqueal

$D_{\text {DEF }}$ - Declínio Longitudinal do VEF,

EF - Ex-fumante

EM - Enfisema Pulmonar

EP - Erro-Padrão

F - Fumante

$\mathrm{FEF}_{25-75}$ - Fluxo Expiratório Forçado entre $25 \%$ e $75 \%$ da Capacidade Vital

FMP - Fibrose Maciça Progressiva

GB - Grã-Bretanha

GL - Graus de Liberdade

HRB - Hiperreatividade Brônquica

IOM - Institute of Occupational Medicine

IR - Índice de Regularidade

IT - Indice de Tiffeneau

NCB - National Coal Board (GB)

NF - Não-fumante

OR - Odds ratio

PB - Provocação Brônquica

$\mathrm{PC}_{20}$ - Concentraçāo Provocativa que causa uma queda de $20 \%$ no VEF,

PFR - Pneumoconiosis Field Research

PR - Razão de Prevalência

PMC - Pneumoconiose de Mineiros de Carvão

PRU - Pneumoconiosis Research Unit

SANO - Soma de Anos de Exposição 
SANOAJ - Soma de Anos de Exposição Ajustada $\mathrm{VEF}_{1}$ - Volume Expiratório Forçado no $1^{\circ}$ segundo VEF 1 \% - Relaçāo entre Volume Forçado no $1^{\circ}$ segundo Observado/ Predito $\mathrm{VEF}_{1} \mathrm{AJ}$ - Volume Expiratório Forçado no $1^{\circ}$ segundo Ajustado para Altura 


\section{RESUMO}

Este trabalho é um estudo híbrido, prospectivo e transversal, de uma coorte de 280 mineiros de carvão de subsolo, selecionados por possuirem espirometrias aceitáveis nas investigações de 1984 e 1989. Em ambas as ocasiōes, êles responderam a questionários de sintomas respiratórios e exposições ocupacionais, fizeram espirometrias, e foram submetidos a uma radiografia do torax. Em 1989, em adição, fizeram um teste de provocação brônquica inespecífica.

Os métodos de análise empregados foram: análises descritivas, medidas de associação, análises de variância, e modelos de regressão logística e linear.

Em 1989, as médias e os desvios-padrão de idade e de anos de subsolo era de $34,9 \pm 5,1$, e $10,4 \pm 3,9$, respectivamente. Todos os mineiros eram do sexo masculino e 252 (90\%), brancos. A tosse, e o catarro foram os sintomas predominantes em ambas as ocasiões. No seguimento, $27,9 \%$ dos mineiros apresentavam sintomas compatíveis com bronquite crônica. $O$ chiado foi $o$ único sintoma a evoluir significativamente durante o período de observação. A tosse, 0 catarro e a bronquite crônica, foram fundamentalmente dependentes do tabagismo e reversíveis com o abandono do hábito, ao passo que a dispnéia e o chiado associaram-se à exposiçāo ocupacional. Dezoito por cento dos mineiros tinham sintomas compatíveis com asma, em 1989 , enquanto $12,1 \%$ referiram sintomas compatíveis com asma ocupacional. Destes últimos, 44,1\% apresentaram hiperreatividade brônquica.

A prevalência de pneumoconiose foi de 5,4\% em 1984, e 7,9\% em 1989. A incidência anual de PMC foi de 11,4/1.000 mineiros expostos. A progressão radiológica associou-se significativamente à exposição ajustada, tabagismo, ao componente sinérgico entre exposição e tabagismo, e a um VEF mais baixo. Mineiros com opacidades irregulares ao $\mathrm{Rx}$ tenderam a apresentar uma pior funçāo pulmonar.

Houve um discreto crescimento da CVF média da coorte durante os 5 anos. $\mathrm{OVEF}_{1}$ e o IT declinaram no mesmo período. $\mathrm{OVEF}$ identificou 
apenas 2,5\% mineiros com valores anormais, enquanto que o IT identificou $15,7 \%$. O tabagismo foi o principal fator associado a alterações espirométricas. Em relação ao IT, houve ainda um efeito significante do componente sinérgico da exposição e do tabagismo. A hiperreatividade brônquica associou-se significativamente a resíduos negativos do $\mathrm{VEF}_{1}$ e do IT. $O$ declínio longitudinal do $\mathrm{VEF}_{1}$ foi superior ao calculado transversalmente, em 1984 e 1989, e superior ao declínio previsto em indivíduos normais. A hiperreatividade brônquica associou-se, também, a um declínio acelerado do $\mathrm{VEF}_{1}$.

Concluimos que os resultados aqui descritos' são uma estimativa conservadora dos efeitos reais da exposição ocupacional, devido à seleção da coorte, e também a outros vieses. Há fortes indícios da presença de asma ocupacional neste grupo, assim como uma elevada incidência de PMC, e um declínio acelerado do $\mathrm{VEF}_{1}$. O tabagismo foi o principal fator de risco relacionado à deterioração funcional, em mineiros de carvão ativos, com uma média de 10 anos de subsolo, porém houve um efeito potencializador da exposição ocupacional. 


\section{SUMMARY}

This is a hybrid study in a cohort of $\mathbf{2 8 0}$ coalminers, with both prospective and cross sectional components. They were selected when they succeded in having acceptable spirometries and attended the 1984 and 1989 investigations. On both occasions they were submitted to a questionnaire of respiratory symptoms and occupational exposures, spirometry, and a chest x-ray. In addition, in 1989, they had a nonspecific bronchial challenge test.

The statistical methods included, descriptive analysis, measures of association, analysis of variance, and logistic and linear regression models.

In 1989 , the mean age and the mean number of years of exposure were, $34.9 \pm 5.1$, and $10.4 \pm 3.9$, respectively. All miners were male, and $252(90 \%)$ white. Cough and phlegm were the most prevalent symptoms. In the follow up, $27.9 \%$ had symptoms of chronic bronchitis. Wheezing was the only symptom that increased significantly during the observation period. Cough, phlegm and chronic bronchitis were basically associated with smoking, and reversible upon the cessation of the habit, whereas breathlessness and wheezing were associated with dust exposure. In $1989,18 \%$ of the miners had asthma symptoms, and $12.1 \%$ had symptoms compatible with occupational asthma. Forty-four percent of the later had bronchial hyperresponsiveness.

The prevalence of pneumoconiosis was $5.4 \%$ in 1984 , and $7.9 \%$ in 1989. The annual incidence of CWP was $11.4 / 1,000$ miners at risk. Radiological progression was significantly associated with adjusted exposure, smoking, an interacion term involving exposure and smoking, and a low $\mathrm{FEV}_{1}$. Irregular opacities on the $x$-ray were non-significantly associated with a worse pulmonary function.

During those 5 years there was a discrete growth in the mean FVC. The $\mathrm{FEV}_{1}$ and the $\mathrm{FEV}_{1} / \mathrm{FVC} \%$ declined in the same period. The $\mathrm{FEV}_{1}$ identified only $2.5 \%$ miners with abnormal results, whereas the $\mathrm{FEV}_{1} / \mathrm{FVC} \%$ identified $15.7 \%$. Smoking was the main variable associated with spirometric abnormalities. The interaction term of exposure and smoking was also significantly associated with an abnormal $\mathrm{FEV}_{1} / \mathrm{FVC}$. Bronchial hyperresponsiveness was 
significantly associated with negative $\mathrm{FEV}_{1}$, and $\mathrm{FEV}_{1} / \mathrm{FVC} \%$ residuals. The longitudinal decline of the FEV, was greater than the cross-sectional decline, both in 1984 and 1989, and also greater than the predicted decline in normal adults. Bronchial hyperresponsiveness was also associated with a rapid decline in FEV,

We conclude that these findings are an underestimate of the real effects of the dust exposure, because of the cohort selection, and also because of other bias. There are strong evidences of the ocurrence of occupational asthma, of a high incidence of CWP, and of a rapid decline the FEV, in this cohort. Smoking was the main factor linked to functional deterioration in active coalminers with a mean of 10 years of exposure, but there was a synergistic effect of dust exposure. 
SUMÁrIO

PX̃oIm

SEÇÃO 1. INTRODUÇÃO

1.1. Breve Histórico das Doenças Respiratórias

Associadas à Mineração de Carvão............... 01

1.2. Estado Atual das Doenças Associadas à

Exposição a Poeiras na Mineração de Carvão......... 02

1.2.1. Exposição a Poeiras e Papel da SIlica....... 03

1.2.2. Fibrose Maciça Progressiva............ 05

1.2.3. Bronquite Crốnica e Limitação Crônica ao

Fluxo Aéreo: Importancia Relativa da

Exposição a Poeiras e Tabagismo........... 06

1.2.4. Comentários Gerais................... 10

1.3. A Mineração de Carvão no Brasil.............. 12

1.3.1. Dados Históricos, Geológicos e Indústria

Extrativa........................ 12

1.3.2. O Contexto Social da Mineração de Carvão..... 15

1.3.3. As Doenças Respiratórias Associadas à

Mineração de Carvão no Brasil............. 17

1.4. A Investigaçåo Proposta.................. 19

1.4.1. As Implicações do Estudo de $1984 \ldots \ldots \ldots \ldots \ldots 19$

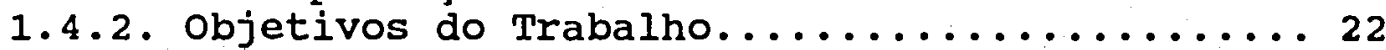

1.4.3. A Investigação Epidemiológica........... 23

SEÇÃO 2. MÉTODOS

2.1. População Estudada..................... 25

2.2. Questionarios......................... 32

2.3. Exposição Ocupacional.................... 37

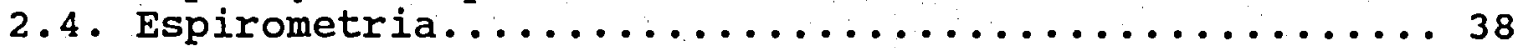

2.5. Provocação Brônquica...................... 39

2.5.1. Aspectos Técnicos.................. 40

2.5.2. Equipamentos e Calibração.............4 41

2.6. Radiologia......................... 43

2.7. Computação e Análises Estatísticas.............. 45

\section{SEÇÃo 3. RESULTADOS E COMENTÁRIOS}

3.1. Dados Gerais........................4 48

3.2. Sintomas Respiratórios.................. 50



3.2.2. Fatores Relacionados com o Desenvolvimento

de Sintomas Respiratórios............ 56

3.2.3. Efeitos da Exposição Ocupacional e do

Tabagismo......................... 59

3.2.4. Reatividade Brônquica, Exposições de Risco

e Sintomas Respiratórios..............66 66

3.2.5. Ocorrência de Asma Brônquica...........6.68

3.3. Radiologia.......................... 70

3.3.1. Prevalência de Pneumoconiose........... 70

3.3.2. Progressão Radiológica.............. 73 
3.3.3. Indice de Regularidade.............. 77

3.3.4. Diametro Traqueal.................. 79

3.3.5. Fatores Associados à Presença de Pneumoconiose...................... 80

3.4. Função Pulmonar.........................

3.4.1. Dados Descritivos dos Parámetros Funcionais...83

3.4.2. Dimensōes de Vias Aéreas e Espirometria......90

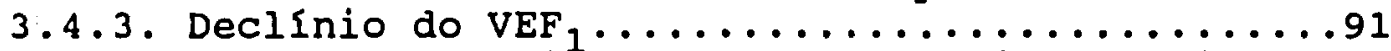

3.4.4. Obstrução de Vias Aéreas, Bronquite Crônica, Exposição ocupacional e Tabagismo..........97

3.4.5. Provocação Brônquica..................101

3.4.6. Modelos de Relações de Efeitos-Análise de

Residuos.........................102

\section{EÇÃo 4. DISCUSSÃo}

4.1. Aspectos Relativos ao Desenho Epidemiológico e à

Amostra................................109

4.2. Alguns Pontos Referentes aos Instrumentos de

Investigação.........................113

4.2.1. Questionarios.......................113

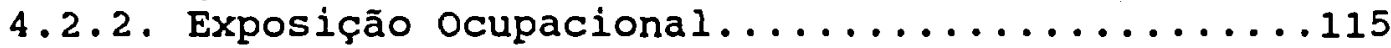

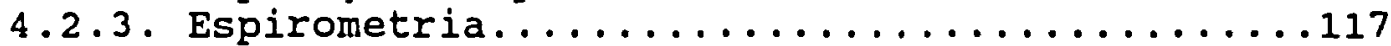

4.2.4. Provocação Brônquica..................118

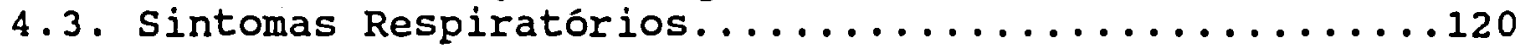

4.4. Reatividade Brônquica e Asma....................... 124

4.5. Prevalência de Pneumoconiose, Evolução

Radiológica e Fatores de Risco..................129

4.6. Espirometria e Dimensões de Vias Aéreas...........134

4.7. Efeitos da Exposição Ocupacional e do Tabagismo,

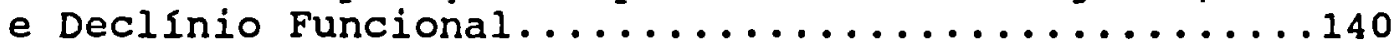

SEÇĀo 5. CONCLUSÕES E RECOMENDAÇõES

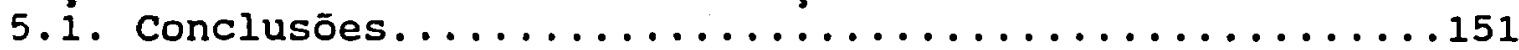

5.2. Recomendações........................... 154

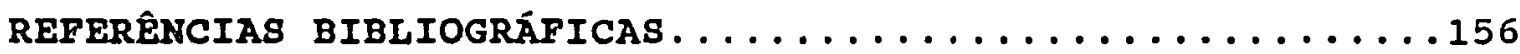

ANEXOS

ANEXO 1: Funções no Subsolo: Agrupamentos e Códigos

ANEXO 2: Questionário de Sintomas Respiratórios e Exposições Inalatórias Ocupacionais-1984

ANEXO 3: Questionário de Sintomas Respiratórios e Exposições Inalatórias Ocupacionais -1989

ANEXo 4: Folha de Resultados de Provocação Brônquica Alc

ANEXO 5: Folha de Leitura Radiológica 
SEÇÃO 1

INTRODUÇĀO 


\section{INTRODUCÃO}

\subsection{Breve Histórico das Doenças Respiratorias Associadas à Mineração de Carvão}

A atividade de extração do carvão mineral causa danos distintos ao sistema respiratório. Esta característica é comum a outras atividades extrativas minerais, envolvendo a exposição ocupacional a diferentes composiçōes de partículas e/ou fibras respiráveis. Historicamente, a mineração de carvão foi o segmento industrial responsável pelo intenso desenvolvimento de pesquisas relacionadas às doenças ocupacionais pulmonares, uma vez que despertou um crescente interesse pela importância da ocupação em relação à morbidade e mortalidade por doenças respiratórias.

A Pneumoconiose de Mineiros de Carvão (PMC) é conhecida do ponto de vista clínico e anatomo-patológico há cerca de $160 \operatorname{anos}^{82}$. O fato da PMC não se associar com frequência à tuberculose, levou, provavelmente, a um certo descaso em relação a seus efeitos respiratórios no começo deste século. HALDANE, um dos precursores da fisiologia respiratória, declarou em 1923 que "a inalação de poeiras de carvão não causa danos, e ao contrário, protege contra o desenvolvimento da tuberculose..."(HALDANE, J.S. citado por FLETCHER ${ }^{82}$ )

Na década de 30 , na Grắ-Bretanha, uma avalanche de casos de PMC, notadamente no País de Gales, exigiu das autoridades de saúde, providências no sentido de estudar-se o fato. Estes trabalhos iniciaram-se em 1937 e os primeiros resultados foram publicados em $1942^{155}$. Desde 1943, a PMC é reconhecida como uma doença distinta da silicose para fins de benefício previdenciário na Grã-Bretanha ${ }^{216}$. Em 1945 o "Medical Research Council", GB, criou a "Pneumoconiosis Research Unit" (PRU), com a finalidade de desenvolver estudos sobre diferentes aspectos da $\mathrm{PMC}^{82}$.

Em 1947, com a estatização das minas de carvão na Grã-Bretanha, o National Coal Board iniciou uma série de estudos prospectivos envolvendo cerca de 30.000 mineiros em 25 minas britânicas, com duas finalidades básicas: determinar as relações quantitativas e qualitativas das poeiras de carvão que levam às doenças e, estabelecer os níveis de poeira adequados para a proteção respiratória dos mineiros de carvão ${ }^{216}$. Estes estudos foram centralizados no "Institute of Occupational Medicine" (IOM) na Escócia. 
Destas duas instituições (PRU e.IOM) surgiu uma série de trabalhos abordando aspectos de higiene, epidemiológicos e clínicos que se constituem na espinha dorsal do conhecimento destas doenças. Os trabalhos do IOM levam a vantagem adicional de conterem medidas quantitativas sobre a exposição ocupacional, o que possibilitou a construção de curvas de probabilidade de se adquirir pneumoconiose $113,114,200,223$.

Ao longo do trabalho do "National Coal Board", foram estabelecidas medidas destinadas a diminuir a poeira respirável, através de melhoria de ventilação, umidificação, além de modificação no processo extrativo, o que levou paulatinamente a uma redução no registro anual de casos novos de $\mathrm{PMC}^{178}$.

A prevalência pontual de PMC varia de acordo com o tipo de carvão minerado, sendo que a antracita, que tem um conteúdo de carbono elevado, produz maior quantidade de partículas respiráveis, que são eliminadas mais lentamente dos pulmões, quando comparada ao carvão betuminoso ${ }^{40}$. Em 1983, 1,9\% dos mineiros ativos com menos de 60 anos apresentavam PMC na Grã-Bretanha ${ }^{178}$. Nos EUA, na mesma época, a prevalência era de $4,5 \%^{14}$. No Brasil, a prevalência foi calculada em 5,6\% em $1984^{4}$.

Além da PMC, mineiros de carvão estão em risco de desenvolver Fibrose Maciça Progressiva (FMP) ${ }^{43,109}$, Bronquite Crônica (BC) $)^{105,152,197,198,204}$ e Enfisema Pulmonar (EM) 46, 206,210

\subsection{Estado Atual das Doenças Associadas à Exposição a Poeiras na Mineração de Carvão}

Alguns tópicos referentes às doenças pulmonares associadas à exposição a poeiras de carvão continuam sendo objeto de investigaçõ̀es, ou porque não estão bem esclarecidas, como por exemplo a FMP, ou apresentam um comportamento mutável, dependente das condições ocupacionais e ambientais, como por exemplo a limitação crônica ao fluxo aéreo. Certos aspectos serão abordados nesta seção por sua relevância intríseca, ou por sua direta relação com este trabalho. 


\subsubsection{Exposição a Poeiras e Papel da Ślica}

As patologias até aqui mencionadas são ocupacionais (PMC e FMP), ou podem ter um componente ocupacional ponderável em sua etiologia (BC e EM). Dados originados do estudo prospectivo do "National Coal Board"113,114,223 e também da Alemanha ${ }^{199,200}$ mostram uma nítida relação dose-resposta para a PMC. Estes estudos, embora utilizando-se de metodologias distintas para expressar os resultados de exposição quantitativa, chegam a resultados semelhantes: a ocorrência da PMC é dose dependente, e a melhor forma de expressar-se a dose é através da concentração de massa respirável cumulativa ${ }^{114}$. As análises de conteúdo mineral pulmonar em autópsias de mineiros de carvão com diferentes categorias radiológicas de PMC também confirmam estes dados ${ }^{205}$.

Atualmente os limites permissíveis de poeira em minas britânicas é $4,5 \mathrm{mg} / \mathrm{m}^{3}$ (média), medidos com o equipamento de deposição gravimétrica -MRE- ${ }^{114}$. Nas minas dos E.U.A. este limite é de $2 \mathrm{mg} / \mathrm{m}^{3}$, medidos através de coletores individuais de ciclone que equivalem a $2,8 \mathrm{mg} / \mathrm{m}^{3}$ do $\mathrm{MRE}^{7}$. Ambos os limites não são associados com probabilidade nula de PMC. O limite britânico, por exemplo, preve uma probabilidade de adquirir PMC categoria 2, de 4,4\% após 35 anos de trabalho de subsolo ${ }^{111}$. Utilizando-se dados radiológicos para avaliar a efetividade dos limites propostos nos E.U.A., as taxas de prevalência de PMC foram concordantes com as predições de probabilidade britânicas, porém as taxas de progressão radiológicas para mineiros com $\mathrm{Rx}$ inicial lido como $0 / 1$ ou mais foram inferiores às taxas preditas 5 .

A exposição a poeiras nas minas de carvão relaciona-se com os valores da $\mathrm{VEF}_{1}$. Nas minas britânicas o termo "exposição", expresso através do índice cumulativo gramas.hora. $\mathrm{m}^{-3}$, possui significância estatística nas equações de regressão

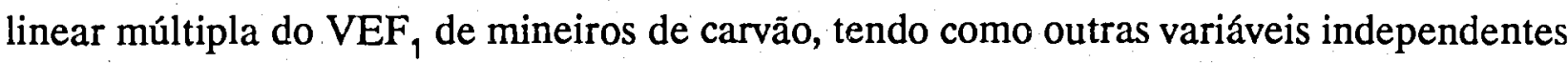
a altura e a idade ${ }^{149}$. Alguns mineiros, expostos a níveis moderados ou altos de poeira, estão sujeitos a uma queda anormal do $\mathrm{VEF}_{\mathfrak{1}}$ ao longo dos anos, levando a uma repercussão clínica importante ${ }^{111}$. Paralelamente, sintomas de BC estão significativamente associados a níveis crescentes de poeiras ${ }^{197,204}$. Estudos anatomo-patológicos efetuados nas vias aéreas de mineiros de carvão demonstraram uma associação significativa entre a relação glândulas: parede (Indice de Reid), tabagismo e exposição cumulativa a poeiras ${ }^{66}$. 
Há evidências anatomo-patológicas que mostram a relação entre a exposiçāo a poeiras em minas de carvão e a presença de Enfisema Pulmonar. O primeiro trabalho publicado foi um estudo de necrópsias de mineiros de carvão, sem um grupo controle, mostrando uma prevalência alta de enfisema centriacinar ${ }^{210}$. Estas evidências ficaram claras em 1982 com a publicação de estudo envolvendo mineiros e grupo controle $e^{46}$. A ocorrência de enfisema aumenta à medida que aumenta a severidade das alteraçōes anatomo-patológicas devidas ao acúmulo de poeiras e a presença de enfisema centriacinar aumenta quanto maior a quantidade de poeira retida nos pulmöes ${ }^{206}$. A presença de retenção preferencial de cinzas (que inclui o quartzo) reduz a probabilidade destes achados em autópsias ${ }^{206}$.

O potencial fibrogênico de poeiras de carvão depende, entre outras coisas, da concentração de sílica livre cristalina (quartzo). O elemento carbono possui um potencial citotóxico mínimo ${ }^{51,99}$, e quando depositado na região alveolar causa apenas uma discreta proliferação de reticulina. Uma poeira mista de carvão contendo $5 \%$ de quartzo já causa a deposição de colágeno nos pulmões de ratos ${ }^{150}$. Estudos epidemiológicos em minas britânicas mostram que, quando a concentração de quartzo não excede um limite de 7,5\%, as curvas de probabilidade de PMC, baseadas em concentração de massa respirável total, não são afetadas ${ }^{111,241}$. Uma incidência anômala de casos de PMC, ou taxas de progressão radiologica elevadas, em um intervalo de tempo conhecido, podem ser sinais indicativos de altas concentraçōes de quartzo na fraçāo respirável de poeiras em minas de carvão ${ }^{217}$.

Certos tipos de função na mineraçāo de carvão podem apresentar um risco elevado de exposiçāo ao quartzo, como os furadores, por exemplo. Assim, casos de silicose e silicose aguda já foram descritos em furadores de superfície ${ }^{16}$. Em um estudo caso-controle foi notado uma prevalência maior de FMP em mineiros de carvão expostos a uma maior quantidade de quartzo ${ }^{115}$. Estudos anatomo-patologicos indicam um aumento progressivo da retenção pulmonar dos contaminantes do carvão, à medida em que aumenta a severidade das lesões, especialmente do quartzo ${ }^{59}$. 


\subsubsection{Fibrose Macica Progressiva}

A FMP é uma consequência direta da exposição a poeiras de carvão. É diagnosticada pela radiografia do tórax através da presença de opacidades maiores do que $1 \mathrm{~cm}$ de diametro, normalmente localizadas nos campos médios e superiores. A etiologia da FMP ainda é especulativa. Uma revisão concisa sobre o tema encontra-se no excelente livro texto de PARKES ${ }^{189}$. Aparentemente a causa mais importante da FMP é a exposição cumulativa a poeiras ${ }^{109}$, embora já se saiba que também ocorre em mineiros com graus moderados de exposição. Mineiros com FMP acumulam mais poeira nos seus pulmões do que mineiros sem FMP e exposições semelhante ${ }^{67}$.

A importancia da FMP justifica-se porque ela se associa à dispnéia, alteraçōes funcionais respiratórias ${ }^{90}$ e mortalidade aumentada ${ }^{42,44}$.

Estudos iniciais mostraram que o excesso de mortalidade limitava-se as categorias B e C de FMP $\mathrm{P}^{44}$. Estes dados foram confirmados em um seguimento posterior do mesmo grupo ${ }^{15}$, porém limitados à regiāo do sul do País de Gales. Estudos mais abrangentes, envolvendo minas de toda Grã-Bretanha, demonstram que mesmo a FMP categoria $\mathrm{A}$ associa-se à mortalidade significativamente aumentada ${ }^{160} . \mathrm{O}$ problema destes estudos, em relação à mortalidade e categoria de FMP, é que o diagnóstico radiológico foi estabelecido no início do seguimento da coorte, e as publicações de ATUHAIRE $^{15}$ e MILLER $^{160}$ referem-se a seguimentos de 30 e 22 anos respectivamente. Espera-se que nestes intervalos de tempo, tenha ocorrido progressão radiológica das lesões e este fator, que provavelmente é relevante para o estudo da mortalidade, não foi considerado. Além disto, as variações regionais de morbidade devem conferir traços característicos a cada local examinado. A influência do tabagismo nestes estudos ${ }^{15,160}$ também não foi analisada, o que impossibilita a análise de riscos competitivos em maior detalhe ${ }^{170}$.

A prevalência da FMP vem caindo progressivamente: 0,7\% em 1963 a $0,2 \%$ em $1981^{179}$. Quanto maior a categoria radiológica de pneumoconiose, maior a prevalência de FMP ${ }^{43}$. A incidência de FMP foi maior em ex-mineiros, 41 por 1.000, comparada a mineiros, 20 por 1.000 de faixas etárias similares, seguidos radiológicamente nos mesmos intervalos de tempo ${ }^{146}$. Isto demonstra claramente a necessidade de um seguimento radiológico contínuo para ex-mineiros, o que normalmente é feito somente quando são portadores de pneumoconiose ao deixar a mina. 
Mineiros e ex-mineiros portadores de FMP apresentam alterações funcionais com maior frequência que os portadores de pneumoconiose simples. Desde que não haja outra doença respiratória associada, a incapacidade funcional dos mineiros é limitada a casos que apresentem FMP categoria B e $C^{54}$. As alterações funcionais da FMP não guardam uma boa correlação còm as alteraçōes radiológicas. São em grande parte determinadas pelo volume e localização anatômica das massas ${ }^{189}$. De maneira geral, a Capacidade Vital e a Capacidade Vital Forçada estão reduzidas ${ }^{244}$, há limitaçāo ao fluxo aéreo e há o aumento da diferença alvéolo-arterial de $\mathrm{O}_{2}$ em repouso e exercício ${ }^{174}$. A diminuição do leito vascular pulmonar pode levar ao aparecimento de hipertensão pulmonar em fases avançadas da doença ${ }^{180}$.

\subsubsection{Bronquite Crônica e Limitação Crônica ao Fluxo Aéreo: Importância Relativa da Exposicão a Poeiras e Tabagismo}

A BC e a Limitação Crônica ao Fluxo Aéreo (LCFA) são duas entidades distintas, podendo ou não estar relacionadas ${ }^{83}$. Até o trabalho de FLETCHER ${ }^{84}$, frequentemente a BC e a LCFA eram utilizadas como sinônimos, ou consideradas como estreitamente correlacionadas. A principal causa de ambas é, sem dúvida, o tabagismo, que agride tanto grandes vias aéreas, preferencialmente acometidas na $\mathrm{BC}$, como as pequenas vias aéreas,preferencialmente acometidas na LCFA.

Indivíduos expostos a poeiras minerais apresentam alterações anatomo-patológicas a nível de pequenas vias aéreas (bronquíolos respiratórios), que são supostamente características ${ }^{38}$, e morfologicamente distintas das alterações provocadas pelo tabagismo. Há uma associação significativa entre alteraçōes estruturais e função pulmonar, na presença destas lesões ${ }^{37}$. Esta correlação não aparece quando se compara indivíduos expostos/não expostos baseados em dados de história ocupacional apenas, sem o critério estrutural ${ }^{127}$. Estes estudos mostram uma nítida ocorrência de alteraçōes anatômicas a nível de pequenas vias aéreas em pacientes expostos a poeiras ${ }^{37}$ ou poeiras e fumos ${ }^{127}$, porém deve-se considerar que como estes trabalhos são originários da mesma população constituída por indivíduos submetidos à toracotomia por lesões nodulares de pulmão, houve uma seleção inicial funcional, ou seja, indivíduos com função pulmonar ruim foram excluídos do tratamento cirúrgico, além do que o número de casos no estudo de KENNEDY e col. ${ }^{127}$ foi relativamente pequeno. Há grande probabilidade de que esta 
seleçāo esteja apenas subestimando as correlaçōes clínicas, funcionais e anatômicas no grupo de indivíduos expostos.

$A$ associação entre $\mathrm{BC}$ e exposição a poeiras é de aceitação relativamente recente. No início do ano de 1966, um comitê criado pelo "Medical Research Council" da Grā-Bretanha, formado com o intuito de esclarecer se havia ou não associaçāo entre BC e exposição a poeiras, particularmente na mineração de carvão, concluiu que não havia evidências suficientes para que a exposiçāo a poeiras pudesse ser considerada como um fator determinante da $\mathrm{BC}^{154}$. Esta preocupação fundamentava-se no fato de que apenas a pneumoconiose era passível de concessão de benefícios previdenciários. Em 1970, GILSON $^{89}$, que havia participado do grupo anteriormente referido ${ }^{154}$, já aceitava indícios de um aumento de morbidade respiratória, incluindo sintomas de tosse e catarro crônicos e déficits funcionais, em grupos expostos a poeiras, porém este excesso de morbidade era de magnitude de duas vêzes apenas. Um fator confusional, na época, era o fato de que não havia associaçāo entre a presença de pneumoconiose e $\mathrm{BC}$, já que a presença de pneumoconiose era assumida como um espelho da exposição a poeiras. Este aspecto foi posteriormente esclarecido através de estudos de deposição de partículas nas vias aéreas, que mostraram que os locais de acometimento de pneumoconiose são periféricos, e causados pela inalação de partículas menores, ao passo que os sintomas de BC originam-se preferencialmente de vias aéreas mais centrais, aonde depositam-se partículas de maior tamanho ${ }^{176}$. Revisões sobre a associação causal entre exposição a poeiras e $\mathrm{BC}$ foram publicadas por MORGAN ${ }^{171}$ e SOUTAR ${ }^{222}$, com base nos trabalhos que surgiram neste período.

Reportando-se à mineração de carvão, esta associação causual ficou clara no início dos anos 70, quando começaram a surgir estudos longitudinais do "Pneumoconiosis Field Research-National Coal Board". RAE e col. ${ }^{197}$ apresentaram dados de uma crescente prevalência de $\mathrm{BC}$ em mineiros jovens, à medida que aumentava a exposição cumulativa. Este mesmo efeito foi também mostrado em relação à categoria radiológica de pneumoconiose, em oposição aos achados de GILSON ${ }^{86}$. MINETTE ${ }^{161}$ demonstrou a importância do número de anos de exposição em relação à $\mathrm{BC}$, após controlar para idade e tabagismo, em mineiros de carvão da Bélgica. HIGGINS ${ }^{104}$, resumindo uma série de estudos de comunidades mineiras, concluiu que mineiros e exmineiros de carvão tinham mais sintomas compatíveis com $\mathrm{BC}$ do que os controles. A categoria radiológica de pneumoconiose não exerceu influência sobre estes achados, e o efeito de anos de exposição também foi inconsistente nestas investigações. KIBELSTIS e 
col. ${ }^{129}$, em um estudo de mais de 8.000 mineiros de carvão betuminoso, concluiram que a exposiçāo ocupacional era responsável principalmente por sintomas de BC, porém o efeito do tabagismo sobre as alterações funcionais encontradas foi superior ao efeito da exposiçāo a poeiras.

Um estudo envolvendo o total de mineiros de carvão na Austrália mostrou os efeitos aditivos de 3 fatores: local de trabalho, tabagismo e consumo de bebidas alcólicas na prevalência de $\mathrm{BC}$ simples (BC com $\mathrm{VEF}_{1}$ maior que $80 \%$ do previsto) e $\mathrm{BC}$ obstrutiva (BC associada a um $\mathrm{VEF}_{1}$ menor do que $80 \%$ do previsto) ${ }^{139}$. Em uma publicação recente, o efeito da exposiçāo quantitativa a poeiras foi considerado aditivo aos efeitos do tabagismo em relação à prevalência de BC simples e BC obstrutiva, e as estimativas de prevalência da $\mathrm{BC}$ por exposição cumulativa mostraram curvas paralelas (com a mesma inclinaçāo) em fumantes e não fumantes, estes últimos num patamar mais baixo $^{149}$.

Níveis mais baixos de função pulmonar são consistentemente encontrados em mineiros e ex-mineiros de carvão, quando comparados a populaçōes nāo expostas de referência, e independem da presença de pneumoconiose ${ }^{104}$. ROGAN e col. ${ }^{204}$ mostraram uma queda do $\mathrm{VEF}_{1}$ médio em mineiros agrupados por faixas etárias, relacionada a exposiçōes cumulativas crescentes. Estes achados não tinham relação com a categoria radiológica de pneumoconiose, porém, tinham com a presença uma prevalência crescente de BC. KIBELSTIS e col. ${ }^{129}$ estudaram a prevalência de $\mathrm{BC}$ e índices de obstrução das vias aéreas, $\mathrm{VEF}_{1}, / \mathrm{CVF}, \mathrm{VEF}_{1}$ e CVF. Neste trabalho, que envolveu 8.000 mineiros, não havia dados de exposição cumulativa e, consequentemente, os mineiros foram divididos em trabalhadores de frente, transporte, manutenção, miscelânea $e$ superfície. Os 3 índices analisados mostraram-se significativamente inferiores em fumantes, comparados a não fumantes, sendo que em relação ao $\mathrm{VEF}_{1}$, entre os não fumantes havia uma diferença significativa entre mineiros de subsolo e de superfície. Um achado interessante foi o do grupo dos ex-fumantes, que não se comportou de forma semelhante aos não fumantes em relação aos índices funcionais, porém foi semelhante em relação à prevalência de sintomas respiratórios, o que demonstra que os sintomas são dependentes da categoria de tabagismo a que pertenciam no momento da investigação. Este trabalho gerou a informação, muito debatida posteriormente ${ }^{171}$, de que o efeito do tabagismo sobre as alteraçōes funcionais $\left(\mathrm{VEF}_{1}\right)$ é cerca de 5 vezes maior do que a exposiçāo a poeiras. 
LYONS e col. ${ }^{145}$, estudando mineiros e ex-mineiros de carvão em seguimento por benefício previdenciários em uma análise retrospectiva, demonstraram que o conceito das alterações funcionais pontuais de importância ocorrerem somente quando é alcançada a categoria radiológica $B$ (grande opacidade), não é verdadeiro. Mineiros que durante o período de estudo evoluiram para categoria $B$ apresentaram uma velocidade de queda do VEF, superior aos mineiros que não progrediram. Este trabalho, embora pouco comentado, é um dos precursores dos estudos de acompanhamento funcional longitudinal de mineiros de carvão.

HANKINSON e col..$^{95}$, estudando as relações fluxo $\mathrm{x}$ volume em mineiros de carvão ativos, demonstraram uma diminuição nos fluxos em volumes pulmonares altos, relacionada a anos de exposição. Estes achados foram independentes da categoria radiológica de pneumoconiose. Como estas alterações são devidas à resistência em vias aéreas altas, os autores as atribuiram à $\mathrm{BC}$, e não a lesões a nível de pequenas vias aéreas.

Em anos mais recentes, foram publicados dois estudos similares, analisando as relações entre exposição, tabagismo e queda longitudinal do $\mathrm{VEF}_{1}$ em mineiros de carvão. No primeiro deles, LOVE e col. ${ }^{142}$ demonstraram um excesso médio anual de queda do $\mathrm{VEF}_{1}$ de $87 \mathrm{ml}$, num período de observação de 11 anos e uma exposição cumulativa média de $245 \mathrm{mg} / \mathrm{m}^{3}$. ATTFIELD ${ }^{13}$, fez uma análise similar em mineiros dos EUA, demonstrando um excesso médio de queda anual do $\mathrm{VEF}_{1}$ de $84 \mathrm{ml}$, para um período de observação e uma exposição semelhante. $O$ efeito do tabagismo no primeiro estudo $^{142}$ foi cerca de 3 vezes superior à magnitude das perdas devidas exclusivamente à exposição e, no segundo estudo, foi 2,6 vezes superior. Ambos mostraram uma baixa explicação pelos fatores componentes das equações de regressão, $6 \%^{142}$ e $12 \%^{13}$, o que faz supor que o erro intrínseco das variáveis independentes é grande.

BATES e col. ${ }^{18}$ analisaram o declínio funcional de 397 mineiros de carvão, retirados retrospectivamente de uma coorte em acompanhamento por suspeita radiológica de pneumoconiose, ou queixas de dispnéia. Após um período médio de seguimento de 18 anos, a queda anual média do $\mathrm{VEF}_{1}$ variou de $46 \mathrm{ml}$ em mineiros não fumantes, vivos ao final do período de observaçāo, a $73 \mathrm{ml}$ em mineiros fumantes, falecidos (vide TABELA 4.3). A curva de queda do $\mathrm{VEF}_{1}$ não se alterou após a aposentadoria dos participantes deste estudo. Apesar de ser um trabalho retrospectivo, em que algumas variáveis não foram quantificadas, como o fumo, ou qualificadas como a dispnéia, a 
informação de queda acelerada do $\mathrm{VEF}_{1}$ independente de exposição é interessante, embora não tenham citado dados sobre o tempo de exposição deste grupo.

A relação entre a queda de $\mathrm{VEF}$, e a exposiçāo cumulativa a poeiras foi estudada por SOUTAR e col. ${ }^{224}$. As perdas estimadas foram de $68 \mathrm{ml} \mathrm{VEF} / 100 \mathrm{~g} / \mathrm{m}^{3}$ para mineiros e $89 \mathrm{ml} \mathrm{VEF}, 100 \mathrm{~g} / \mathrm{m}^{3}$ em ex-mineiros.

Finalmente, alguns indivíduos podem apresentar uma queda excessivamente acelerada do $\mathrm{VEF}_{1}$, devida à poeira, levando a uma redução funcional pulmonar severa e incapacidade clínica. Foram estimados, conservadoramente, perdas funcionais de $2 \mathrm{ml} \mathrm{VEF}, / \mathrm{g} / \mathrm{m}$ em um grupo de 199 mineiros de carvão, correspondentes a $5 \%$ de uma coorte originária do estudo do $\mathrm{NCB}^{110}$. Estes ex-mineiros tiveram uma exposição cumulativa média semelhante a outros ex-mineiros, ou mineiros, sendo que havia apenas mais fumantes, comparativamente aos outros grupos. Apesar das análises não justificarem porque estas alteraçōes eram devidas à exposiçāo ocupacional e não ao fumo, efetivamente é possível que alguns indivíduos tenham uma susceptibilidade aumentada em relação às poeiras inaladas, traduzindo-se por um declínio funcional acelerado.

\subsubsection{Comentários Gerais}

Há um consenso de que a exposição a poeiras na mineração de carvão leva a um aumento na prevalência de BC e EM. Há dados indicativos que também a função pulmonar é afetada. Ambos os efeitos aparecem mesmo após ajustes para o tabagismo, indicando que a exposição ocupacional é responsável por uma parcela destas alteraçōes. A importância relativa do tabagismo parece ser maior que a exposição a poeiras de carvão, e estes agressores do sistema respiratório atuam de forma aditiva, e não sinérgica. Hoje em dia, na Grã-Bretanba, as atuais condiçōes na mineraçāo de carvão levam a crer que o tabagismo é o fator preponderante em relação a morbidade e mortalidade respiratória ${ }^{72}$. Há dados mostrando também que, em uma proporção pequena de mineiros de carvāo, os efeitos funcionais e clínicos da exposição a poeiras podem ser desastrosos $^{224}$, de uma forma semelhante ao que ocorre com o tabagismo, onde apenas uma proporção limitada (em torno de 10 a 15\%) apresentam efeitos funcionais e clínicos importantes ${ }^{84}$.

Os estudos comentados nas seções anteriores, embora abordando temas semelhantes, utilizaram metodologias, populaçōes, variáveis e formas de análise 
distintas, o que faz com que seja difficil compará-los. Alguns pontos merecem citação, pois podem ter influenciado os resultados discutidos acima:

1. Boa parte dos estudos não diferenciou mineiros provenientes de minas de carvão antracitoso ou betuminoso. O carvão antracitoso associa-se com uma maior prevaléncia de pneumoconiose ${ }^{172,210}$, e a relaçāo de concentração de massa $x$ efeito orgánico é melbor do que para o carvão betuminoso ${ }^{114}$. Estes fatos levam a crer que a fragmentação mineral, no processo produtivo do carvão em minas de antracita, gera uma maior quantidade de partículas abaixo de 5 um de diåmetro aerodinâmico. Isto parece ser mais importante do que as diferenças químicas existentes entre eles, isto é, a antracita é um carvão mais puro, contendo maior quantidade do elemento carbono.

2. As populaçōes estudadas foram distintas: mineiros ativos ${ }^{13,95,129,139,142,149,197,204}$, ex.mineiros $^{110}$, comunida-des ${ }^{104}$, mineiros falecidos ${ }^{46,206}$ e miscelânea ${ }^{18,145,161}$. Embora não seja o objetivo deste trabalho fazer uma análise aprofundada do problema de seleção em estudos de saúde ocupacional, não se pode deixar de mencioná-los de uma forma breve. $O$ trabalho em mineração de carvão, principalmente de subsolo, de maneira geral, é uma atividade que exige uma condição física adequada para a sua realização, particularmente os postos de frente de serviço. Ao mesmo tempo que seleciona os mineiros mais saudáveis, estes postos de trabalho são os de maior exposição a poeiras e gases. Por este motivo, estudos transversais, e mesmo estudos longitudinais que se restrinjam a mineiros ativos, tendem a subestimar alguns dos efeitos devidos a exposição, pois os mineiros que não se adaptam ao trabalho migram para atividades mais leves, ou saem da indústria. Alguns estudos publicados com dados gerados no "Pneumoconiosis Field Research-National Coal Board", mostraram que a prevalência de pneumoconiose em mineiros e ex-mineiros é semelhante ${ }^{223}$, porém a FMP $^{146}$ e os efeitos respiratórios não pneumoconióticos, como o declínio do $\mathrm{VEF}_{1}{ }^{225}$, são mais prevalentes e acentuados em ex-mineiros que pediram demissãa antes da idade de aposentadoria. Além disso, estudos transversais de mineiros ativos (assim como outros grupos ocupacionais expostos a riscos respiratórios) são pouco sensíveis para a deteç̧āo de anormalidades funcionais respiratórias, pois referem-se a uma população fisicamente selecionada. Boa parte dos estudos comentados na seção anterior puderam demonstrar tais efeitos, pois referiam-se a uma população muito grande $^{129,139}$ ou possuiam dados de exposição cumulativa a poeiras, que permitiam análises mais detalhadas ${ }^{149,204}$. 
3. A caracterização da $\mathbf{B C}$ foi variável. Alguns autores aceitavam que a presença de catarro persistente era suficiente ${ }^{95,129}$, outros adotaram a definição de BC, sem o critério de tempo $139,149,197,204$. As análises de alterações funcionais restringiram-se ao $\mathrm{VEF}_{1}$ em alguns trabalhos ${ }^{13,18,110,142,145,204}$, incluiram o IT em outros ${ }^{129}$ ou mesmo dados da curva fluxo X volume ${ }^{95}$. Os critérios de exposição também foram distintos, desde anos de subsolo 95 , 139, 161 , grupos de atividades no subsolo ${ }^{129}$, exposição média ${ }^{13}$, e exposição cumulativa $^{149,197,204}$.

4. Os estudos comentados nas seções anteriores, referem-se à minerações de carvão na Europa, Estados Unidos, e Austrália. Neste locais, dificilmente a porcentagem média do quartzo na fraçāo respirável ultrapassa 7,5\%. Nestes níveis, as relaçōes entre exposição a poeiras $X$ pneumoconiose são particularmente bem descritas pela exposição cumulativa $\mathrm{em} \mathrm{mg} / \mathrm{m}^{3}{ }^{114}$ ou pelo conteúdo de poeira total no pulmão e categoria radiológica ${ }^{205}$, o que não é nítido em situaçōes em que a porcentagem de quartzo é maior, envolvendo o risco de silicose.

\subsection{A Mineração de Carvão no Brasil}

\subsubsection{Dados Históricos, Geológicos e Indústria Extrativa}

As jazidas de carvāo brasileiras foram descobertas no ano de 1792 na região de Curral Alto, hoje pertencente ao município de Butiá, no Rio Grande do Sul ${ }^{27}$. A exploração comercial teve início no começo do século XIX no Rio Grande do Sul, e por volta de 1830 em Santa Catarina ${ }^{147}$.

A utilização do carvão foi destinada inicialmente à indústria cafeeira, notadamente quando se iniciou a mecanização do processo de beneficiamento do café, e a extensāo da malha ferroviária nacional ${ }^{147}$. A Primeira Grande Guerra foi um impulso na indústria extrativa, devido a dificuldades de importação do carvão estrangeiro. $\mathrm{Na}$ época, o Rio Grande do Sul respondia por cerca de $80 \%$ da produção nacional, voltada para aplicações energéticas. Em 1931, através do Decreto-Lei 20.089, todos os importadores nacionais de carvão foram obrigados a adquirir $10 \%$ de seu consumo em carvão brasileiro. Em 1937 esta porcentagem foi elevada a 20\% pelo Decreto-Lei 1828. Em 1940, através do Decreto-Lei 2667, uma série de medidas destinadas a melhorar o beneficiamento do carvão mineral, assim como adequar o maquinário industrial à queima do carvão brasileiro 
e tributar as importaçōes de petróleo, associadas ao início do processo de industrialização no país, impulsionaram a indústria carbonífera nacional ${ }^{147}$

Nesta época, com a criação da Companhia Siderúrgica Nacional, o carvão catarinense ganhou importância pelas suas características de coqueificação e poder calorífico específico. Paulatinamente, sua exploração comercial sobrepujou a do estado do Rio Grande do Sul, e ao final da Segunda Grande Guerra, o estado de Santa Catarina era o principal produtor nacional.

Esta situação foi mantida até a crise do petróleo na década de 70 , quando o uso do carvāo energético, notadamente para o abastecimento de usinas termoelétricas, deu novo impulso à exploração deste tipo de carvão. $O$ atual modelo energético brasileiro prevê uma maior diversificaçāo de fontes energéticas. Assim, na década de 80, parte do consumo de petróleo foi substituído pelo carvão mineral, álcool, carvão vegetal e xisto, aliado a um aumento na produção de petróleo.

As reservas de carvằo brasileiras estão localizadas nos estados do Rio Grande do Sul, Santa Catarina, Paraná e São Paulo. Cerca de $90 \%$ estão localizadas no primeiro estado citado. (TABELA 1.1).

TABELA 1.1: Recursos Identificados de Carvāo no Brasil (em milhōes de toneladas).

$\begin{array}{lrrr} & \text { RESERVAS } & \begin{array}{r}\text { *RESERVAS } \\ \text { MARGINAIS }\end{array} & \begin{array}{r}\text { RECURSOS } \\ \text { TOTAIS }\end{array} \\ \text { São Paulo } & 4,50 & 4,00 & 8,50 \\ \text { Paraná } & 105,54 & 2,65 & 108,19 \\ \text { Sta. Catarina } & 2.461,80 & 1.041,40 & 3.503,20 \\ \text { R.G. do Sul } & 14.667,14 & 14.159,30 & 28.826,44 \\ \text { TOTAL } & 17.238,98 & 15.207,35 & 32.446,33\end{array}$

Fonte: 165

Reservas Marginais correspondem a reservas identificadas porém sem condiçס̄es de extração no momento 
O carvão nacional é fundamentalmente do tipo betuminoso, ou seja, com um conteúdo de carbono inferior ao antracitoso. O poder calorífico varia de 2500 a $6500 \mathrm{KCal} / \mathrm{kg}$, sendo que o de Santa Catarina é o unico que apresenta características coqueificáveis*. Possuem alto teor de enxofre, sob a forma de pirita, e de cinzas (contaminantes minerais associados ao carvão), que variam de 30 a $50 \%{ }^{147}$.

O carvão coqueificável é destinado ao uso em siderurgia, sendo conhecido como carvāo metalúrgico, e o não coqueificável é destinado a geração de calor, sendo conhecido como carvão energético. A produção de carvão vendável, tanto do tipo metalúrgico como energético, caiu em cerca de $10 \%$ do ano de 1985 para o ano de 1987 , porém os números de 1978 a 1987 mostram um aumento relativo da produção de carvão energético em relação ao metalúrgico ${ }^{165}$. Nesta mesma época, a participaçāo da indústria extrativa brasileira no consumo interno de carvão metalúrgico passou de $22,5 \%$ a $7,9 \%{ }^{165}$.

A força de trabalho empregada nos anos de 1985 a 1987 pode ser vista na TABELA 1.2.

TABELA 1.2: Número de Mineiros Empregados nas Carboníferas; 1985-1987, segundo Estados.

$\begin{array}{lcccr}\text { ANO } & \text { SC } & \text { RS } & \text { PR } & \text { TOTAL } \\ 1985 & 10.536 & 2.470 & 975 & 13.981 \\ 1986 & 9.794 & 2.986 & 999 & 13.779 \\ 1987 & 9.129 & 2.510 & 783 & 12.422\end{array}$

Fontes : $165,166,167$.

Se, por um lado há uma tendência à busca de fontes energéticas alternativas ao petróleo, por outro há a realidade da indústria carbonífera nacional. $O$ carvão aqui produzido é muito rico em cinzas, o que equivale a dizer que, em certas áreas, é necessária a mineração de 2 toneladas para a obtenção de 1 tonelada de carvão. Os métodos de mineração são arcaicos, comparáveis aos existentes nos Estados Unidos e

\footnotetext{
- Propriedade de diminuir os componentes voláteis do carväo, tomando-o mais rico em Carbono por peso e aumentando sua capacidade redutora.
} 
Europa há cerca de 40 anos. A política do carvão é um espelho das práticas políticas brasileiras: não há qualquer tipo de planejamento a médio e longo prazo, as importações de equipamentos são problemáticas, não há estímulo para o desenvolvimento de tecnologias nacionais, e a política de preços é aleatória. Por estes motivos, o futuro da indústria carbonífera é imprevisível, como tudo neste país.

\subsubsection{O Contexto Social da Mineracão de Carvão}

As jazidas de carvão estendem-se por toda região sul do Brasil, particularmente no Rio Grande do Sul. Apesar disso, a maior atividade mineira concentrase no Sul de Santa Catarina, na região dos municípios de Criciúma e Siderópolis, devido às características fisicoquímicas do minério. A principal utilização do carvão catarinense é na indústria-siderúrgica nacional.

No momento, há cerca de 13.000 mineiros oficialmente engajados na atividade. Oitenta porcento encontram-se nos municípios acima citados. Destes, calcula-se que $80 \%$ trabalhem no subsolo. Estima-se que nesta região cerca de 100.000 pessoas dependam direta ou indiretamente da indústria.

A força de trabalho mineira em geral é não especializada. Frequentemente vemos a famflia com duas a três geraçōes de mineiros, que guardam com orgulho esta herança de ofício. O aprendizado é prático, pode ser iniciado aos 18 anos, e a idade mínima para o início do serviço é de 21 anos (Portaria 3214, NR22 de 08/06/83). A renda média de um mineiro está em torno de 2 a 3 salários mínimos, dependendo de sua função específica. Em $2 / 3$ das famílias mineiras, esta é a única fonte de renda, pois menos do que $10 \%$ das esposas possuem emprego fixo ${ }^{240}$.

Mineiros de frente de lavra de subsolo tem aposentadoria especial após 15 anos de atividade (Decreto 83.080 de 24/01/79 - Regulamentação dos Benefícios da Previdência Social). Para as funções restantes, o tempo de aposentadoria é 25 anos. $O$ afastamento do subsolo se dá somente quando o mineiro atingir Categoria 2 da classificação radiológica da $\mathrm{OIT}^{112}$, e a compensaçāo previdenciária oficialmente contempla casos apenas em que há uma alteração funcional associada à pneumoconiose. Felizmente estas normas oficiais do INSS, nos dias de hoje, são rotineiramente aplicadas de forma diferente do texto oficial no estado de Santa Catarina. Portanto, é comum na 
regiảo encontrarmos homens aposentados antes dos 40 anos de idade, muitos dos quais inválidos por acidentes de trabalho típicos ou doenças profissionais.

O controle médico dos mineiros dá-se de maneira insatisfatória. As empresas mineradoras dispõem de serviços de saúde ocupacional, previstos por lei, que, com raras excessões, limitam-se à prática da medicina assistencial. As exigências legais de controle radiológico dos expostos são cumpridas, porém sem que haja um critério uniforme da qualidade técnica e das interpretações dos exames radiológicos. $O$ município de Criciúma dispõe de serviços de radiologia de bom padrāo na rede particular, e é um dos escassos locais do Brasil onde os radiologistas aplicam rotineiramente a classificação internacional das pneumoconioses. A rede pública não dispōe de recursos de radiologia para oferecer às empresas mineradoras. Não há exploração funcional pulmonar de rotina na população exposta. A Subdelegacia Regional do Trabalho (atual INSS) de Criciúma é a responsável pela fiscalização dos locais de trabalho, e do cumprimento das normas regulamentadoras, possuindo 1 médico e 1 engenheiro para atuar em toda região, que além de mineração tem uma atividade enorme no ramo de cerâmica e, em menor escala, vestuário.

Nos municípios de Criciúma e Siderópolis, os problemas ambientais, causados direta ou indiretamente pela mineração de carvão, são estarrecedores. Os grandes depósitos de rejeitos (cinzas) e pirita, a céu aberto, formam um cenário de devastação. As minerações a céu aberto dão lugar ao que se chama de "paisagem lunar", pela presença de enormes crateras e montes de rejeitos.

A pirita, que é o rejeito rico em enxofre, reage com o oxigênio e a água, formando entre outros o Dióxido de Enxofre $\left(\mathrm{SO}_{2}\right)$ e o Ácido Sulfúrico $\left(\mathrm{H}_{2} \mathrm{SO}_{4}\right)$. Este último contamina e acidifica as águas para onde é drenado, tanto que a fauna aquática nos rios da região é mínima. $\mathrm{O} \mathrm{SO}_{2}$ é um potente irritante de vias aéreas. Embora não haja dados oficiais publicados sobre a morbidade e a mortalidade respiratória na região, por diversas vezes ouvimos dos médicos da área, comentários sobre o grande número de casos de sinusite, asma, e infecçōes pulmonares na prática do dia a dia.

As opções de mercado de trabalho para o mineiro são escassas. A principal delas é a indústria cerâmica, que no momento emprega mais trabalhadores do que a mineração. A segunda opção seria a atividade agrícola, que é caracterizada pela 
presença de pequenos produtores agropecuários ${ }^{240}$. Embora não haja dados concretos, há uma forte tendência à emigração de mão de obra não especializada da região.

\subsubsection{As Doencas Respiratórias Associadas à Mineracão de Carvão no Brasil}

As doenças ocupacionais pulmonares no Brasil têm um número de publicações científicas paupérrimo. Isto se afirma baseado na magnitude que este capítulo da preumologia representa em termos de Saúde Pública nos país. Tomando como exemplo a excelente revisão bibliográfica do tema feita por MENDES em $1979^{156}$, são listadas 84 referências bibliográficas, das quais 30 referem-se a revisões genéricas sobre alguma doença ocupacional pulmonar, 21 são relatos de casos, 8 são revisões sobre condições de trabalho e condiçōes sociais, 11 são indefinidas e 14 são trabalhos epidemiológicos. Das 84 publicações, algumas referem-se ao mesmo material, publicado em diferentes veículos.

Especificamente em relação à mineração de carvão, são referidos 8 trabalhos, dos quais 3 merecem menção por sua vinculação mais direta com este trabalho. Em 1941, GIGLIO no Paraná descreveu o primeiro caso de PMC ${ }^{88}$. Em 1943, PEREIRA e FIRMEZA ${ }^{191}$ escreveram um relatório sobre as condições de trabalho e saúde na mineraçāo de carvão do Rio Grande do Sul. MOREIRA ${ }^{61}$ foi o primeiro autor a publicar um inquérito epidemiológico limitado em mineiros de carvão de Santa Catarina; de 51 trabalhadores radiografados foi diagnosticado 1 caso de pneumoconiose.

TSCHIEDEL e col, apresentaram no Congresso Brasileiro de Pneumologia e Tisiologia em $1980^{234}$ um trabalho de correlação clínica, radiológica e funcional em 63 mineiros de carvão, sugerindo que as variáveis de maior confiabilidade para o diagnóstico precoce da PMC eram a gasometria arterial e o Rx de torax.

Em 1981, SOUZA F e col. ${ }^{225}$ publicaram uma detalhada descrição de 536 casos de PMC diagnosticados na regiāo carbonífera de Santa Catarina entre 1969 e 1979. Embora haja uma menção de prevalência "em torno de 5 a $8 \%$ ", não há dados no trabalho que objetivem esta afirmação. A média do tempo de exposição foi 10 anos. Este trabalho traz ainda uma minuciosa descrição clínica da PMC, gerada da experiência clínica dos autores e também uma descrição anatomo-patológica. Esta última é um misto de experiência pessoal com literatura, o que deixa o leitor na dúvida sobre possíveis narticularidades da PMC em nosso meio. 
TSCHIEDEL em $1982^{233}$ enfocou o valor da gasometria em mineiros ae carvao com e sem pneumoconiose provavelmente utilizando-se da mesma população de TSCHIEDEL e col. ${ }^{235}$. Os resultados mostraram que as alteraçōes radiológicas correlacionaram-se significativamente com a pressāo parcial do oxigênio no sangue arterial $\left(\mathrm{PAO}_{2}\right)$ e com o gradiente alvéolo-arterial de oxigênio $\left(\mathrm{D}(\mathrm{A}-\mathrm{a}) \mathrm{O}_{2}\right)$. Neste estudo dois pontos chamam a atenção. $O$ primeiro quanto à seleção da população estudada: dos 65 casos, 31 foram retirados retrospectivamente de um arquivo de serviço de Cardiopneumologia. Embora não haja no texto dados para melhor análise, é de se supor que estes mineiros foram encaminhados por suspeita de doença, ou por queixas clínicas. Esta impressão é reforçada pela presença de alterações radiológicas em $87 \%$ dos mesmos. Quanto aos 34 casos restantes, não há dados de como foram selecionados. Fica claro que a amostra (restrospectiva) não é representativa para tais conclusōes e, embora estes achados tenham sido encontrados isoladamente no grupo prospectivo, a falta de dados de seleção sobre este último grupo no texto impede de aceitar-se estas "conclusões como cientifícamente válidas. O segundo ponto refere-se aos métodos de leitura radiológica, que diferiram nos dois grupos, embora este fato não deva ter influenciado os resultados.

Em 1983 o Ministério do Trabalho dotou uma verba à FUNDACENTRO*, destinada ao estudo das condições de trabalho na mineração de carvão, envolvendo aspectos de higiene, segurança e de saúde (contrato MTb/SSMT 014/83). Foi escolhida a bacia carbonífera catarinense para estes estudos, por tratar-se da principal região produtora e pelo fato da PMC estar assumindo proporçōes epidêmicas na região. Coletou-se entre outros dados, poeiras respiráveis de 6 minas de subsolo, representativas de 3 métodos distintos de mineração, semi-manual, semi-mecanizada e mecanizada, englobando diferentes funçōes no subsolo. Do total de 92 amostras, 48 $(52,2 \%)$ apresentaram níveis de poeira total acima do equivalente a $4,3 \mathrm{mg} / \mathrm{m}^{3}$ pelo método britânico e $62(67,4 \%)$ acima de $2,0 \mathrm{mg} / \mathrm{m}^{3}$. Das 92 amostras, 79 foram submetidas à determinação da porcentagem de quartzo por espectrofotometria de infravermelho, sendo que em $32(40,5 \%)$ a concentração de quartzo ultrapassou $10 \% 235$.

O estudo médico limitou-se apenas aos efeitos respiratórios da exposição a poeiras e constituiu-se no primeiro trabalho epidemiológico sobre o tema no

\footnotetext{
- FUNDACENTRO - Fundação Jorge Duprat Figueiredo de Segurança e Medicina do Trabalho. É uma fundação pública, vinculada ao Ministério do Trabalho que tem por finalidades básicas fazer estudos e pesquisas sobre condiçōes de trabalho, e, fornecer assessoria técnica, notadamente a entidades públicas.
} 
país. Através de uma amostragem que envolveu 956 mineiros (cerca de $10 \%$ de mineiros de subsolo do país), foi encontrada uma taxa de prevalência pontual de PMC de 5,6\% Apesar desta taxa ser comparável a outros países, a média de exposição foi de 8,4 anos. Este estudo abrangeu também a presença de sintomas respiratórios, alterações funcionais espirométricas, e tabagismo. A CVF média observada/esperada (O/E) foi de $102 \%$, o $\mathrm{VEF}_{1}$, médio $\mathrm{O} / \mathrm{E}$, de $95 \%$. A associação entre exposição ocupacional (medida através de anos de subsolo) e tabagismo mostrou um efeito significante em relação ao $\mathrm{VEF}_{1}$ e à CVF, em contraste com os efeitos isolados de cada uma das variáveis. Um modelo de regressão por probitos mostrou que o número de anos de subsolo, a presença de dispnéia, um IT elevado e um $V_{E F}$ baixos eram significativamente associados a probabilidade de ocorrência de pneumoconiose.

Em um estudo caso-controle do mesmo material ${ }^{2}$, as variáveis associadas à presença de PMC foram analisadas. A presença de tosse e catarro foi

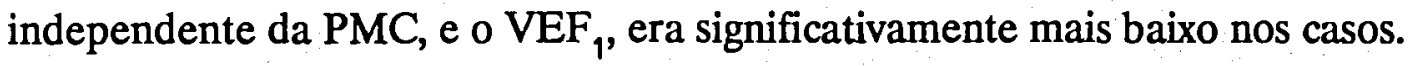

Estes estudos apresentaram uma série de problemas em sua execução. Inicialmente, na parte metodológica, não foi dada a devida importância ao treinamento em espirometria para os pesquisadores de campo. Isto resultou em cerca de $30 \%$ de espirometrias invalidadas, por não obedecerem aos critérios de aceitabilidade da $\mathrm{ATS}^{8}$. As radiografias ficaram a cargo das próprias empresas, o que resultou na perda de $20 \%$ delas, entre chapas não enviadas e chapas de qualidade inadequadas para interpretação. $\mathrm{Na}$ análise de resultados, utilizou-se o nomograma de predição de normalidade para o $\mathrm{VEF}_{1} \mathrm{e}$ CVF de KAMBUROFF e col. ${ }^{118}$, uma referência pouco empregada na literatura.

\subsection{A Investigação Proposta}

\subsubsection{As Implicações do Estudo de 1984}

O estudo transversal efetuado em $1984^{2,4}$ teve por natureza um caráter eminentemente descritivo, de conhecimento e caracterização da população exposta. Através de métodos estatísticos apropriados, pode-se fazer algumas análises de relação entre variáveis, como os fatores associados à presença de PMC, e a influência da exposição, medida em anos de subsolo, e do tabagismo, em relaçāo aos sintomas respiratórios e espirometria. As duas grandes limitações deste estudo foram: 
- a inexistência de um grupo controle adequado, para se comparar as prevalências de sintomas respiratórios, alteraçōes funcionais e tabagismo.

- por ser um estudo transversal, há o risco de seleção na população investigada. Em outras palavras, uma população de indivíduos resistentes às condições adversas de trabalho.

Três aspectos chamaram $\mathrm{a}$ atenção nos resultados:

a) apesar da prevalênicia de PMC ser baixa, o tempo médio de exposição de mineiros pneumoconióticos era de apenas 8 anos. Como já mencionado anteriormente, mineiros de subsolo de frente de serviço, que estão sujeitos a maior exposição a poeiras e gases, tem aposentadoria especial após 15 anos. Isto leva a duas suposições:

- A exposição a poeiras respiráveis é excessiva; apesar do número de amostras de poeira colhidas não ter sido grande, isto foi comprovado ${ }^{235}$.

- Deve haver um enorme contingente de ex-mineiros que já apresentam, ou desenvolverão alteraçōes radiológicas após a aposentadoria.

b) O carvão brasileiro é rico em cinzas ${ }^{165}$, e as análises de quartzo realizadas nas amostras de poeira respirável colbidas em 1984, indicaram que em $40 \%$ delas a porcentagem foi superior a $10 \%{ }^{235}$. Portanto, a exposição a poeiras em mineração de carvão no Brasil deve apresentar relações dose $x$ resposta diferentes de outros locais em que a quantidade de quartzo na fração respirável é mais baixa.

c) Com base nos resultados das análises log-lineares do estudo de $1984^{4}$, a magnitude da importância da exposiçāo a poeiras, aparentemente, é semelhante à do tabagismo em relação ao $\mathrm{VEF}_{\text {, }}$ e a CVF, (apesar de se admitir que a medida de exposição, em anos de subsolo, é um índice tosco). Pode-se supor que:

- foi uma referência pontual, não representativa dos efeitos reais do tabagismo e exposição.

- o fato da exposição a poeiras ser grande, modifica as relaçōes de efeito do fumo e da poeira.

- o fato da exposição ao quartzo ser grande modifica estas relações (reportando-se ao trabalho de ELMES ${ }^{72}$, o único ramo de atividades estudado em que a importância da exposição a poeiras foi semelhante ao tabagismo foi a mineração de ardósia, cujo risco pneumoconiótico é de silicose).

Afora estes achados objetivos, há uma outra variável que merece citação, embora não haja dados mensuráveis. A presença de gases em mineração de carvão é universal; eles são gerados na própria camada de carvão, em motores de combustão 
interna (veículos e máquinas de subsolo) e pelos explosivos. Os gases em mais temidos são o Metano, pela sua explosividade e o Monóxido de Carbono, pela sua toxicidade. Acidentes com estes gases costumam ser fatais*. Do ponto de vista de dano respiratório crônico, há especial interesse nos Óxidos de Nitrogênio ( $\mathrm{NO}$ e $\mathrm{NO}_{2}$ principalmente, que serão referidos como NOx daqui em diante), provenientes das camadas minerais, e principalmente provenientes dos explosivos, e no Dióxido de Enxofre $\left(\mathrm{SO}_{2}\right)$, também proveniente das camadas minerais, e dos motores a diesel no subsolo. Durante a investigação de 1984, os técnicos da Higiene fizeram mediçōes com tubos detectores instantâneos de gases, e rotineiramente estes gases encontravam-se acima do limite de tolerância ${ }^{235}$. Os $\mathrm{NOx}$, notadamente o $\mathrm{NO}_{2}$, são pouco solúveis em água e exercem sua ação principalmente na região periférica do pulmão, sob a forma de $\mathrm{HNO}_{2}$ e $\mathrm{HNO}_{3}$, levando a dois quadros principais: pneumonia química ${ }^{196}$ e edema pulmonar ${ }^{196,227}$ (que provavelmente representam fases distintas do mesmo processo). Exposiçōes de curta duraçāo a níveis ambientais baixos de $\mathrm{NO}_{2}$ potenciam o efeito broncoconstritor do carbacol em testes de provocação brônquica ${ }^{186}$. Na mineração de carvão, KENNEDY sugeriu que a exposição crônica ao NOx poderia ser a causa de enfisema pulmonar encontrado em mineiros ${ }^{124,125,126}$. Ao contrário dos $\mathrm{NOx}, \mathrm{SO}_{2}$ é hidrossolúvel e irritante de vias aéreas superiores. Em um estudo comunitário, em 4 localidades com níveis ambientais distintos de $\mathrm{SO}_{2}$ e sulfatos em suspensão, a prevalência de tosse e catarro crônicos na população associou-se significativamente com concentrações crescentes destes poluentes ${ }^{36}$. Estudos mais recentes demonstraram que a inalação de concentrações baixas de $\mathrm{SO}_{2}$ podem causar broncoconstriçāo sintomática em asmáticos submetidos a exercício $^{219,220 .}$

Estes dados citados indicam que, além da poeira respirável, a presença de gases na mina tem o potencial de exercer uma ação deletéria na função de vias aéreas, principalmente em mineiros com hiperreatividade brônquica.

Todos estes fatos, objetivos, analíticos, ou subjetivos, apontaram para uma necessidade de se prosseguir com as investigações iniciadas em 1984, com o intuito de recuperar dados clínicos, como a presença de $\mathrm{BC}$, melhorar os dados sobre o chiado e sua relação temporal com a exposição ocupacional (o que não foi analisado na ocasião), e se

\footnotetext{
- No ano de 1984, durante a realizaçāo do trabalho de campo, em uma mina de subsolo de uma das mineradoras participantes de trabalho, houve uma explosão seguida de incèndio, causada pela presença de Metano, com 34 mortes. Este foi o maior desastre di história da mineraçăo de carvão no país. Em 1989, também durante o trabaiho de campo, dois furadores de frente morreran asfixiados por $\mathrm{CO}$. Um deles fazia parte da coorte deste estudo.
} 
estudar com dados longitudinais o comportamento da espirometria e da radiologia torácica em função de uma série de variáveis. Havia também uma necessidade verbalizada pela comunidade mineira e pela comunidade médica local, de avaliar, com mais detalhes, o problema da asma relacionada ao trabalho.

\subsubsection{Objetivos do Trabalho}

Objetivo Geral

Estudar os efeitos da exposição a poeiras e outros riscos respiratórios em mineiros de carvão de subsolo através de dados longitudinais e transversais, reexaminando clínica, funcional e radiológicamente mineiros avaliados em 1984, que na ocasião possuíam uma espirometria válida e/ou uma radiografia de tórax interpretada.

Objetivos Específicos

Determinar os efeitos respiratórios da exposição a poeiras em mineiros de subsolo com aproximadamente 10 anos de exposiçăo.

Determinar a contribuição relativa da exposição a poeiras e do tabagismo, em relação aos sintomas respiratórios e ds alterações funcionais.

.Determinar de forma transversal e longitudinal o declínio anual do VEF, na população exposta e nos ex-mineiros.

.Investigar se os efeitos das variáveis determinantes do $\mathrm{VEF}$, tem ajustes lineares ou exponenciais em relação ao declínio deste índice.

.Determinar o padrão de progressão radiológica da PMC no Brasil.

.Investigar a prevalência de hiperreatividade brônquica inespecífica, suas relaçōes com os sintomas respiratórios e índices funcionais, em mineiros e exmineiros. 
Recuperar informações, parcialmente ou nāo utilizadas em 1984, como Bronquite Crônica e o Chiado, respectivamente.

\subsubsection{A Investigacão Epidemiológica}

A investigação proposta neste trabalho segue em linhas gerais os fundamentos clássicos de um estudo epidemiológico em doenças respiratórias ocupacionais crônicas ${ }^{86}$. Através da aplicação de um questionário de sintomas respiratórios, da execuçāo de espirometria forçada, e da obtenção de uma radiografia de tórax, geram-se dados comparáveis com os dados de 1984. Desta forma há a possibilidade de se proceder a análises transversais (1984 e 1989) e longitudinais (1984-1989), de acordo com o tópico em estudo. $O$ teste de Provocação Brônquica (PB) será incluído com uma dupla finalidade:

- O estudo de asma na mineração de carvão

- As relaçōes entre a reatividade brônquica, a presença de sintomas e o declínio funcional respiratório.

O tipo de estudo descrito pode ser considerado como híbrido ${ }^{130}$, pois inclui aspectos prospectivos, e ao mesmo tempo aspectos tranversais. $O$ estudo original de 1984 foi tipicamente um estudo descritivo que gerou dados e conhecimentos apropriados para a sua continuação. $O$ estudo de coorte, é uma análise prospectiva de uma parte dos mineiros vistos em 1984, com uma restrição: que tivessem uma espirometria tecnicamente válida na ocasiāo ${ }^{8}$. Esta decisão foi definida, visando-se ter um grupo consistente em relação às análises estatísticas e também, pelo fato de se enfocar preferencialmente os efeitos não pneumoconióticos da exposição ocupacional.

Cabe aqui algumas considerações sobre as análises dos fatores relacionados ao comprometimento respiratório. Primeiramente, a dicotomia Exposto/Não Exposto, que é a tônica de trabalhos prospectivos, aplica-se de forma peculiar, uma vez que todos os mineiros da coorte foram expostos a poeiras. Eles serão tratados como Mais Expostos e Menos Expostos, baseados em índices de exposição. $O$ tabagismo, como outro fator de risco, será também analisado juntamente com a exposição. Não houve a possibilidade de analisar a exposição aos $\mathrm{NO}_{x}$ e ao $\mathrm{SO}_{2}$ por motivos de ordem técnica e econômica, porém, apesar do critério de multicausalidade das doenças ficar 
comprometido, com o uso de técnicas de análise adequadas, os efeitos dos dois fatores analisados, que indiscutivelmente são os mais importantes, poderāo ser ponderados.

O componente transversal do trabalho pode ser exemplificado nas análises da BC, reatividade brônquica e asma, que foram feitas somente em 1989, pois os resultados de 1984 mostraram pontos carentes de um melhor tratamento.

As técnicas necessárias para medir os riscos respiratórios são diferenciadas, já que vai-se abordar a pneumoconiose, os sintomas respiratórios e a LCFA. Os instrumentos de análise que serão utilizados ao longo do trabalho nos parecem adequados para obter-se respostas aos objetivos específicos desta investigação.

O período de 5 anos entre as duas avaliações foi estipulado com base no fato de que a média de anos de subsolo nos participantes de 1984 era de 5,8 anos ${ }^{4}$ e, portanto, em 1989 teriam por volta de 10 anos de exposição, em média. Caso se optasse por um tempo de seguimento mais longo, boa parte dos mineiros já estariam aposentados ou próximos à aposentadoria, e um eventual seguimento posterior ficaria muito dificultado. Caso a escolha recaísse em um tempo inferior a 5 anos, não se conseguiria observar a progressão radiológica da PMC, que se constitui em um dos objetivos específicos deste trabalho. O plano de trabalho original incluía a reavaliação tanto de mineiros ativos em 1989 (cerca de 50\%) como de ex-mineiros, para um estudo comparativo. Infelizmente, devido à baixíssima resposta dos ex-mineiros, este objetivo não pôde ser cumprido e o estudo será referente apenas a mineiros que continuavam na indústria em 1989. As consequências deste fato serão discutidas no momento oportuno. 
SEÇÃO 2 MÉTODOS 


\section{METODOS}

\subsection{Populaçāo Estudada}

Como já mencionado no subitem 1.3.3, o Ministério do Trabalho destinou uma verba para estudos atualizados das condições de higiene, segurança e saúde dos trabalhadores de minas de carvão (Contrato SSMT/MTb 014/83) em 1983. Estes estudos foram conduzidos pelas Divisões de Higiene, Segurança e Medicina do Trabalhc da FUNDACENTRO, durante os anos de 1984 e 1985. A participação médica limitou-se ao estudo das doenças respiratórias, que sem dúvida são as mais problemáticas neste tipc de atividade.

Por ocasiāo do planejamento do trabalho havia 16 empresas na mineração de carvão na bacia carbonifera brasileira. Apenas 8 foram consideradas de grande porte por possuirem mais de 500 funcionários (6 em Santa Catarina e 2 no Ric Grande do Sul). Devido aos custos do projeto e por problemas de integração de investigação nas áreas de higiene, segurança e medicina, optou-se por limitar o trabalho a Santa Catarina.

As 6 empresas catarinenses possuiam na ocasião 16 minas em operação. Decidiu-se avaliar apenas as minas de subsolo representativas dos 3 principais métodos de mineração (manual, semi-mecanizada e mecanizada), o que resultou na escolha de 6 minas de 6 empresas distintas (TABELA 2.1). 
TABELA 2.1: Minas de Subsolo Investigadas, Métodos de Mineração e Número de Mineiros.

$\begin{array}{cccc}\text { EMPRESA } & \text { MINA } & \text { *METODO } & N^{\circ} \text { DE } \\ \text { A } & 1 & \text { SM } & 191 \\ \text { B } & 2 & \text { M } & 250 \\ \text { C } & 3 & \text { M } & 595 \\ \text { D } & 4 & \text { SM } & 598 \\ \text { E } & 5 & \text { SM } & 267 \\ \text { F } & 6 & \text { Ma } & 233\end{array}$

* $M a=$ manual, $S M=$ semi-mecanizada,$M=$ mecanizada

Na sequência, a referência a cada uma das minas será feita por sua numeração na TABELA 2.1.

Inicialmente, foi solicitado d̀s empresas que enviassem uma relação das funções no subsolo. Havia denominações diferentes para funções semelhantes entre as empresas, assim como funçōes distintas em cada uma delas, na dependência do método de mineração utilizado. Através de contatos pessoais com o pessoal de produção, as funçōes de subsolo foram agrupadas em 3 grandes grupos: supervisão, produção e manutençāo e 0 grupo de produção foi subdividido em 22 subgrupos, baseados na descrição de suas atividades. O ANEXO 1 traz a relação de funções no subsolo, na forma em que foram agrupadas.

O tamanho da amostra foi inicialmente definido calculando-se um erro de estimativa de 5\%(Alfa) e um erro padrão de 2,5\%. Porém, ao se iniciar o trabalho de campo, devido a modificações nos quadros de funcionários das empresas, decidiu-se que seria prudente aumentar o tamanho da amostra. Das listagens de mineiros atualizada de cada uma das minas, foram amostrados sistematicamente $50 \%$ dos operários de subsolo (produção, manutençâo e supervisão), dentro de cada uma das funções descritas, através de sorteio (pares ou ímpares). A TABELA 2.2 resume a amostragem. 
TABELA 2.2: Resumo da Amostragem de Mineiros e Porcentagem de Resposta.

\begin{tabular}{lcccc}
\hline MINA & $N^{\circ}$ DE MINEIROS & AMOSTRA & $\begin{array}{c}N^{\circ} \text { DE MINEIROS } \\
\text { INVESTIGADOS }\end{array}$ \\
\hline 1 & 191 & 93 & 73 & 78 \\
2 & 250 & 128 & 122 & 95 \\
3 & 595 & 306 & 260 & 85 \\
4 & 598 & 299 & 274 & 92 \\
5 & 267 & 135 & 130 & 96 \\
6 & 233 & 102 & 97 & 95 \\
\hline TOTAL & 2134 & 1063 & 956 & 90
\end{tabular}

Os motivos que levaram ao não comparecimento de $10 \%$ da amostra foram férias (4\%), afastamento por doença (5\%) e recusa em participar do trabalho (1\%). Como o tamanho da amostra foi grande não houve a preocupação em repô-los.

Para o seguimento de 1989 adotou-se como premissas básicas que os mineiros tivessem ou uma espirometria considerada como aceitável em 1984, ou uma radiografia interpretada em 1984. Novecentos e quinze mineiros preencheram estes requisitos. No primeiro semestre de 1989, enviamos às 6 empresas as listagens dos mineiros elegíveis; 416 (45\%) permaneciam ativos nas empresas. Como estratégia para recuperar os 499 restantes, editou-se uma listagem com os nomes e as empresas em que os mesmos se encontravam em 1984. Esta listagem foi afixada nos 3 sindicatos dos trabalhadores mineiros, na estação rodoviária, e publicados na imprensa local, convocando-os para um reexame gratuito. Adicionalmente, foram feitas entrevistas em 3 rádios regionais, na televisão local, divulgação dos nomes nas paróquias de bairros operários, assim como a cada um dos mineiros que compareciam para o reexame pois a maioria tinha conhecimento de nomes da lista. Finalmente, divulgou-se a convocação através do sistema de som do estádio de futebol de Criciúma durante o jogo final do campeonato catarinense de 1989. 
$O$ resultado aestas iniciativas tol inesperadamente desanimador. Havia uma previsão inicial de recuperar cerca de $2 / 3$ da amostra elegível, o que não foi conseguido. A TABELA 2.3 mostra os resultados finais da amostra.

TABELA 2.3: Mineiros que Compareceram ao Follow-up de 1989.

\begin{tabular}{|c|c|c|c|c|c|}
\hline \multirow[t]{2}{*}{ MINA } & \multirow{2}{*}{$\begin{array}{l}\text { MINEIROS } \\
\text { ELEGIVEIS }\end{array}$} & \multicolumn{3}{|c|}{ MINEIROS QUE COMPARECERAM-1989 } & \multirow{2}{*}{$\begin{array}{l}\text { COMPARE- } \\
\text { CIMENTO }\end{array}$} \\
\hline & & Ativos* & Aposentados & Demitidos & \\
\hline 1 & 73 & 38 & - & - & 52 \\
\hline 2 & 115 & 39 & 1 & - & 35 \\
\hline 3 & 247 & 123 & 6 & 3 & 49 \\
\hline 4 & 263 & 123 & 2 & 3 & 49 \\
\hline 5 & 128 & 30 & - & 1 & 24 \\
\hline 6 & 89 & 34 & - & 1 & 38 \\
\hline TOTAI & 915 & 387 & 9 & 8 & 44 \\
\hline
\end{tabular}

* Entre 08387 mineiros ativos, 7 encontravam-se na superfície.

Tinha-se a informação que 4 mineiros faleceram no período 19841989 e dos 507 restantes se obteve poucas informações. Provavelmente a maior parte deles ainda se encontrava na regiāo, apesar da contração da indústria carbonífera e consequente dispersão regional da mão de obra. Os motivos que levaram ao não comparecimento são especulativos e consequentemente desprovidos de validade de menção no texto.

Como consequência da fraca resposta ao reexame havia duas preocupações. A primeira, foi a inviabilidade de cumprir um dos objetivos específicos do projeto inicial: comparar-se mineiros que permaneceram ativos neste período com mineiros que deixaram a indústria. Como pode ser visto na TABELA 2.3 apenas 17 exmineiros (aposentados ou demitidos) compareceram ao reexame. A segunda, seria a análise da representatividade dos respondentes. A TABELA 2.4 responde a estas questões. 
TABELA 2.4: Características Descritivas, Antropométricas, Clínicas, Funcionais e Radiológicas dos Respondentes $(n=404)$ e Não Respondentes $(\dot{n}=511)$. Dados de 1984 .

\begin{tabular}{|c|c|c|c|}
\hline Idade & $30,2 \pm 5,3$ & $31,3 \pm 6,0$ & $\mathrm{p}<0,001$ \\
\hline Altura & $170,2 \pm 6,5$ & $170,8 \pm 5,9$ & NS \\
\hline Tosse $(q) \star$ & 35,6 & 34,0 & NS \\
\hline Catarro $(\%) *$ & 40,3 & 38,9 & NS \\
\hline Dispnéia $(q)$ * & 14,6 & 13,6 & NS \\
\hline Chiado $(q)$ * & 16,6 & 12,8 & NS \\
\hline Fumantes + Ex-Fumantes (q) & 70,7 & 76,7 & - \\
\hline $\mathrm{VEF}_{1}$ & $3,93 \pm 0,61$ & $3,87 \pm 0,66$ & NS \\
\hline Pneumoconiose $(z) \star \star$ & 5,6 & 5,7 & NS \\
\hline Anos de Subsolo & $6,0 \pm 4,2$ & $5,7 \pm 4,8$ & NS \\
\hline
\end{tabular}

\section{e $R=$ Respondente \\ $\mathrm{NR}=$ Não Respondente}

* Porcentagens referentes a Tosse, Catarro, Dispneia e Chiado referem-se a respostas positivas em relaço aso questós $4,8,11$ e 14 do questionário de Sintomas Respiratorios exposiçס̄es Inalatórias Ocupacionais de 1984 ANEXO 2 .

* Porcentagem de Pneumoconlose refere-se ao número de casos cuja mediana de 3 leituras fol considerada como sub-categoria $1 / 0$ ou malor.

Pelos dados da TABELA 2.4 nota-se que os mineiros respondentes eram significativamente mais jovens e tinham um pouco mais de sintomas que os mineiros não respondentes. Este último achado, embora o excesso seja muito discreto, foi inesperado em relação à expectativa. A média do $\mathrm{VEF}_{1}$ e a prevalência de pneumoconiose dos dois grupos foi semelhante.

Uma vez que este trabalho teve como objetivos preferenciais o estudo dos efeitos não pneumoconióticos da exposição a poeiras, a coorte foi restrita apenas aos mineiros que comparaceram à avaliação de 1989 e possuíam uma prova funcional válida em $1984^{8}$. Duzentos e oitenta mineiros atenderam a estes requisitos e compuseram a coorte que será analisada daqui em diante. A FIGURA 2.1 ilustra de forma esquemática os números da investigação. A TABELA 2.5 mostra as informações disponíveis para esta coorte. 





TABELA 2.5: Informaçōes Disponíveis para os Mineiros Participantes da Coorte $(n=280)$.

Historia Ocupacional

280

280

sintomas Respiratórios

280

280

Espirometria

280

280

Broncoprovocação

$-\quad 268$

Rx de Torax *

224

277

* Para o estudo da Progressão Radiológica há 223 pares de radiografias disponiveis

Os efeitos da seleção da coorte em relação aos 404 mineiros examinados em 1989 encontra-se na TABELA 2.6. Os mineiros excluídos $(n=124)$ apresentavam uma prevalência significativamente maior de tosse e dispnéia grau 3 , e um $\mathrm{VEF}_{1}$, médio significativamente maior do que os da coorte (mesmo quando ajustado por altura). 
TABELA 2.6: Efeitos da Seleção de Mineiros Reexaminados em 1989 com Espirometrias Válidas em $1984(n=280)$ e Invalidadas $(n=124)$.



* p significante

\subsection{Questionários}

A avaliação dos sintomas respiratórios, das exposições ocupacionais a riscos respiratórios e do tabagismo, foi feita com o auxílio de questionário em 1984 e 1989.

O questionário de 1984 (ANEXO 2) obedeceu à tradução do questionário de sintomas respiratórios do Medical Research Council (versão de 1976, Grã Bretanha) em sua quase totalidade ${ }^{86}$, incluindo-se a parte de identificação. $O$ espaço para a história ocupacional atual foi aumentado devido às características deste trabalho. Foram omitidas as questōes originais $7 \mathrm{a}$ e $7 \mathrm{~b}$, pois pareceu que estas se sobrepunham às questôes 11a, 11b e 11c, que foram mantidas. A questão original de Dispnéia, 8a, foi desdobrada em 2 questōes, 9 e 10. Foi acrescentada a questāo 16 referente a "Chiado" para melhor avaliação deste sintoma em relação ao trabalho. As questōes 17 a 20 também foram acrescentadas ao questionário visando-se estudar populações expostas ao asbesto, e não 
serão consideradas nesta investigação. As questões 40 a 52 também foram elaboradas para caracterizar-se outras exposiçōes de risco respiratório.

O questionário de 1989 (ANEXO 3) seguiu a mesma estrutura básica do questionário de 1984. Foi omitida a palavra "inverno" das questões referentes a Tosse e Catarro devido a sua utilização ter parecido de pouca valia dentro das condições climáticas do país. Foi acrescentada uma questão específica em relação à Tosse e Catarro (questão 3.1) para se poder caracterizar casos de Bronquite Crônica de acordo com sua definição oficial ${ }^{39}$. Voltou-se à tradução do texto original para as questões referentes à Dispnéia, que caracterizam os graus 2, 3 e 4 da classificação de Dispnéia da Pneumoconiosis Research Unit $^{213}$. As questões 5.5 a 5.8 referentes a "Chiado" foram reelaboradas devido à falta de consistência das respostas à pergunta 16 do questionário de 1984. Elas foram colocadas de forma aberta deliberadamente, e codificadas posteriormente às entrevistas. A questão 5.5 (referente às relações entre exposição e sintomas) também mostrou-se inconsistente por problemas de colocação da questão, assim como das respostas obtidas e não será analisada. As questōes referentes ao Tabagismo (8.1 a 8.6) também foram alteradas, com a inclusão de uma medida quantitativa de fumo (anos-maço), questão 8.5, e foram eliminadas as questões específicas referentes a charutos, cachimbo, e cigarros feitos a mão, os primeiros devido a ausência deste hábito na classe operária brasileira, e o último sendo transformado em cigarros, calculando-se a equivalência de $1 \mathrm{~g}$ de tabaco para 1 cigarro. As questões $9.1 \mathrm{e}$ 9.2 simplificam as questões 40 a 52 do questionário de 1984.

A aplicação do questionário em 1984 ficou a critério de 3 médicos participantes do projeto, de um enfermeiro e um supervisor de segurança. Com excessão da Mina 6, que foi a última a ser feita, em janeiro/85, em todas as outras trabalhou-se em duplas ( 1 médico e 1 enfermeiro ou supervisor de segurança). $O$ treinamento da aplicaçāo do questionário deu-se através de um folheto de instruções de preenchimento, e de testes piloto realizados sob a supervisão de um dos médicos participantes (EA) Não houve a tentativa de medir-se a validade do instrumento por tratar-se da tradução com pequenas modificações de questionário amplamente utilizado e já testado em uma série de $\operatorname{aspectos}^{211}$.

A aplicação do questionário de 1989 foi feita por 3 médicos, 1 supervisor de segurança e 1 técnica de laboratório de função pulmonar. $O$ treinamento deu-se da mesma forma, através da leitura das instruçōes de preenchimento e de testes piloto sob a supervisão de um dos médicos participantes (EA). 
Os critérios de análise da presença de sintomas respiratórios e tabagismo, em 1984 e 1989, foram semelhantes, ou seja:

Tosse: O sintoma Tosse foi considerado como presente em cada análise transversal somente quando a questão 4 (1984) e a questão 1.3 (1989) eram afirmativas.

Catarro: Analogamente à questão Tosse, nos casos das questões 8 (1984) e 2.3 (1989), serem afirmativas.

Dispnéia: O sintoma Dispnéia foi considerado como presente em cada análise transversal apenas quando a questões 11(1984) e 4.2 (1989) foram respondidas de forma negativa. Isto corresponde a dispnéia grau $3^{213}$ (impossibilidade de acompanhar o passo de pessoas de constituição física e idade semelhante, andando no plano). Notamos que houve um número muito elevado de respostas positivas às questões 9 (1984) e 4.1 (1989) devido a uma característica peculiar. A palavra "plano" para o mineiro de carvão tem uma conotação própria: o "plano inclinado" que normalmente é a rampa de acesso à galerias subterrầneas. No fraseamento da questão $4.1 \mathrm{em} 1989$ teve-se o cuidado especial de colocar a pergunta corretamente, porém, isto aparentemente não se traduziu em resultados práticos.

Chiado: Consideramos presente apenas quando as questões 14 (1984) e 5.2 (1989) foram afirmativas. A positividade às questões 13 (1984) e 5.1 (1989) foi alta em ambos os estudos, e relacionada principalmente a infecções inespecíficas das vias aéreas superiores.

Tabagismo: Foram considerados fumantes todos os indivíduos que afirmaram ter fumado um cigarro por dia por pelo menos um ano e que continuavam a fumar na época da entrevista. Indivíduos que pararam de fumar há até 6 meses foram também considerados fumantes. No questionário de 1984, o cálculo de Anos-Maço* foi feito com auxílio do computador. Em 1989 este dado foi diretamente incluído no questionário (questão 8.5, ANEXO 2).

\footnotetext{
- A variável Anos-Maço é uma forma quantitativa de se expressar tabagismo. Ela é calculada multiplicando-se o número de maços consumidos por dia (ou entāo fraçōes ou múltiplos), pelo número de anos de tabagismo, conforme os exemplos abaixo:

-1 maço por dia por 16 anos $=1 \times 16=16 \mathrm{AM}$

$-1 / 2$ maço por dia por 4 anos e 1 maço por dia por 3 anos $=(1 / 2 \times 4)+(1 \times 3)=5 \mathrm{AM}$

-4 cigarros ao dia por 10 anos $=1 / 5 \times 10=2 \mathrm{AM}$

- 3 maços por dia por 30 anos $=3 \times 30=90 \mathrm{AM}$
} 
Para algumas análises específicas os mineiros foram reunidos em 4 grupos de sintomas, com base nos dados do questionário de 1989, da seguinte forma:

Assintomáticos: Mineiros sem tosse ou catarro presentes, sem dispnéia e sem chiado. Mineiros com questōes afirmativas à tosse e/ou catarro que não obedeceram ao critério de inclusão nos outros 3 grupos também foram aqui incluídos.

Bronquíticos: Mineiros com tosse e catarro presentes por 2 ou mais anos. Neste grupo estão incluídos os mineiros bronquíticos que apresentavam dispnéia associada.

Chiadores: Mineiros com chiado presente (questão 5.2 - ANEXO 3), podendo em associação serem bronquíticos e/ou dispneicos, isto é, prevaleceu a resposta afirmativa à questão 5.2 para a inclusão neste grupo.

Dispneicos: Mineiros com dispnéia presente porém sem bronquite crônica e sem chiado.

Observe-se que estes 4 grupos são mutuamente excludentes : cada mineiro foi classificado em apenas um deles. O sintoma chiado prevaleceu sobre bronquite e dispnéia.

Como um dos objetivos desta investigação era de estudar a ocorrêncıa de asma entre os mineiros, e como o instrumento de análise foi epidemiológico e não clínıco, optou-se por classificar o indivíduo como asmático somente no caso da questão 5.2 ser positiva em associação com menções às questōes 5.6 e 5.8 (1989), ou seja, com a evidência de crises de broncoespasmo associadas a agentes específicos. É óbvio que este tıpo de interpretação é simplista e incorre na perda de indivíduos que referem broncoespasmo sem fatores desencadeantes evidentes, o que é relativamente frequente em asma, porém, como não se tratou de uma investigação clínica, de casos individualizados. pareceu que desta forma a chance de erro seria abrandada.

A TABELA 2.7 mostra a frequência de sintomas respiratórios e tabagismo mencionados nas investigaçōes de 1984 e 1989. A TABELA 2.8 mostra o número de indivíduos classificados dentro de cada grupo de sintomas. 
TABELA 2.7: Número e Porcentagem de Mineiros Segundo a Manifestação de Sintomas Respiratórios e Tabagismo em 1984 e $1989(\mathrm{n}=280)$.

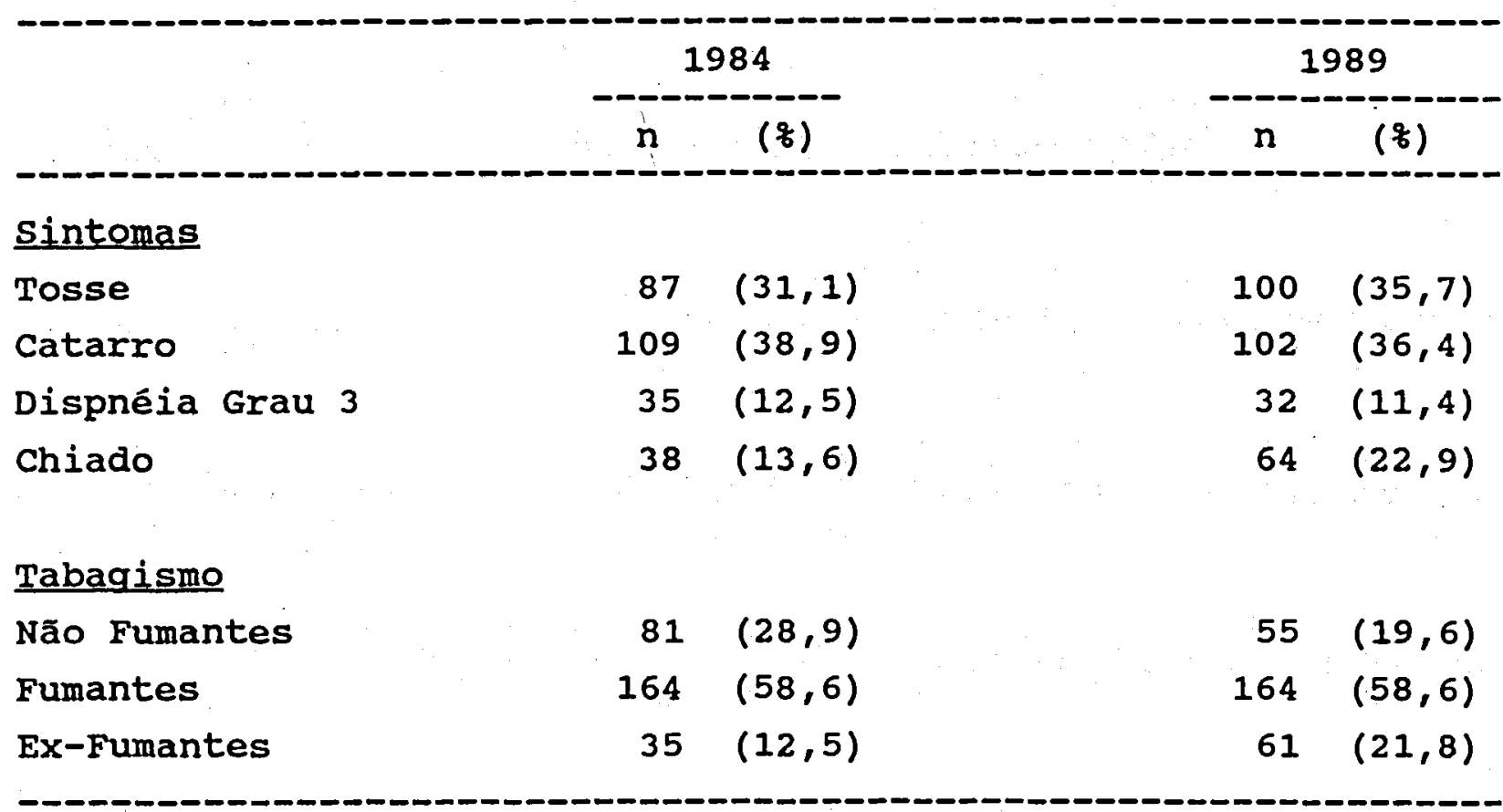

TABELA 2.8: Distribuição do Número e Porcentagem de Mineiros Classificados de Acordo com os Grupos Sintomáticos (1989).

\begin{tabular}{lcc} 
& GRUPOS & $(8)$ \\
\hline Assintomaticos & 158 & $(56,4)$ \\
Bronquiticos & 45 & $(16,1)$ \\
Chiadores & 66 & $(23,6)$ \\
Dispneicos & 11 & $(3,9)$ \\
& & \\
TOTAL & 280 & $(100)$
\end{tabular}




\subsection{Exposicão Ocupacional}

A exposição ocupacional foi derivada da história profissional na mineração de carvão (primeira folha dos questionários, ANEXOS 2 e 3). Calculou-se para cada mineiro, a soma de anos de subsolo em uma ou mais funções (SANO).

Como não se obteve dados quantitativos de exposição cumulativa por função, optou-se por criar um índice ponderado de exposição, o qual denominamos de soma de anos de subsolo ajustada (SANOAJ). Este índice foi derivado de duas fontes:

- dos resultados das análises pontuais de poeiras respiráveis efetuadas em $1984^{235}$

- de informações subjetivas de técnicos de fiscalização de ambientes de trabalho e dos próprios mineiros.

Utilizando-se então os 3 grupos de funçōes e suas subdivisōes (ANEXO 1), adotou-se o seguinte critério:



Apesar da subjetividade do índice ponderado, esta era uma forma possível de buscar um índice um pouco mais fiel do que a simples SANO. Além disto, apenas $88(31,4 \%)$ dos 280 mineiros tiveram o registro de somente uma função.

- A média do número de vezes em que a concentração de sílica ultrapassou o limite de tolerância foi de 26,1, no agrupamento de funçōes com fator de ponderaçăo 4, e de 4,4 no agrupamento com fator de ponderaçáo $1^{235}$. A relaçăo certa seria de 1:5,9, porém como a primeira média foi "puxada" por valores altos dos furadores de frente, que é uma atividade que causa exposição em picos, optou-se, empiricamente, por reduzir a relação para 1:4. 


\subsection{Espirometria}

Os testes de função pulmonar limitaram-se a análises de curvas forçadas de volume versus tempo, incluindo o cálculo do Volume Expiratório Forçado no $1^{0}$ segundo $\left(V_{E F}\right.$ ), da Capacidade Vital Forçada (CVF), da relação VEF 1 /CVF x 100 (Indice de Tiffeneau ou IT) e no reexame de 1989 acrescentando-se o Fluxo Expiratório Forçado Médio entre $25 \%$ e $75 \%$ da Capacidadé Vital $\left(\mathrm{FEF}_{25-\pi}\right)$.

As avaliações de 1984 e 1989 foram feitas com equipamentos secos de fole de 7 litros de capacidade. Em 1984 utilizaram-se 2 espirômetros Vitalograph (Vitalograph Limited, Buckinghan, UK). Os resultados foram calculados manualmente. A calibraçāo do equipamento foi efetuada no início do trabalho e a cada mobilização do equipamento, com uma seringa de calibração de 3 litros.

Em 1989 utilizaram-se 3 espirômetros Pulmonaire (Jones, USA) acoplados a microprocessadores Datamite III (Jones, USA). Os resultados dos valores obtidos eram automaticamente impressos, com a escolha final dos melhores valores do $\mathrm{VEF}_{1}$ e da CVF. A calibração do equipamento foi efetuada duas vezes ao dia com uma seringa de calibração de 3 litros.

Os critérios da espirometria foram os mesmos nas duas avaliações ${ }^{8}$. Obteve-se um mínimo de 3 curvas reprodutíveis (variação máxima de $5 \%$ entre os valores do $\mathrm{VEF}_{1}$ e da CVF após curvas de treinamento iniciais). O tempo zero para o cálculo dos volumes foi determinado por extrapolação retrógrada. $\mathrm{O} \mathrm{VEF}_{1}$ e a CVF aceitos foram os melhores valores de cada mineiro, mesmo se de curvas diferentes. $\mathrm{OFEF}_{25-75}$ foi derivado da curva com maior soma do $V_{E F}$, com a CVF. Não se utilizaram clips nasais. Os mineiros foram examinados em pé. As recomendações para critérios de espirometria da American Thoracic Society de $1987^{\circ}$ referem-se principalmente à calibração, a aceitabilidade de espirômetros e não trazem modificaçōes quanto aos critérios adotados em nosso trabalho.

Os volumes obtidos em ATPS foram transformados em BTPS. Em 1984 foi utilizada uma fórmula de correçāo ${ }^{183}$ ao passo que em 1989 utilizou-se apenas um fator de correção ${ }^{183}$. Isto se justifica pois em 1984 as espirometrias foram efetuadas nas minas e, embora a variação de altitude fosse pequena ( 0 a $400 \mathrm{~m}$ ), optou-se por corrigir pela pressão barométrica efetiva. Em 1989 todos os mineiros foram avaliados ao nível do 
mar. Provavelmente ocorreram variaçōes pressóricas além da faixa $750-770 \mathrm{mmHg}$, porém a sua influência em relação a correção dos volumes foi considerada desprezível.

Os exames em 1984 e 1989 foram efetuados pelas mesmas equipes que aplicaram os questionários. Dos 404 mineiros reexaminados, $280(69,3 \%)$ tinham provas aceitáveis em 1984, e 402 (99,5\%) tiveram provas aceitáveis em 1989. Isto reflete de forma clara que o treinamento para a realização de espirometrias em 1984 foi inadequado, e resultou em um número anormal de espirometrias rejeitadas.

As equaçōes de regressão de referência para valores normais utilizadas foram as de KNUDSON e col. ${ }^{131}$. Esta opção foi baseada em dois aspectos, o primeiro deles objetivo: a equação de regressão do VEF, dos dados de 1989 aproximava-se mais dos valores de KNUDSON. O segundo aspecto é o da presença de critérios de normalidade/anormalidade baseados no $95^{\circ}$ percentil em relação aos valores previstos para cada um dos parâmetros funcionais ${ }^{131}$. Assim, o critério para se classificar um indivíduo como normal/anormal será tratado neste trabalho de acordo com o $95^{\circ}$ percentil, e não com o critério habitual de uma variação de $20 \%$ em relação aos valores previstos.

Em uma série de análises, o $\mathrm{VEF}_{1}$ foi ajustado para altura, pelo cálculo $\mathrm{VEF}_{1} /$ altura $^{2}$. Esta fórmula de ajuste é a que melhor corrige para o efeito altura, quando comparada a $\mathrm{VEF}_{1} /$ altura ou $\mathrm{VEF}_{1} /$ altura $^{3}{ }^{63}$. Para tornar o valor mais familiar, multiplicou-se 0 ajuste por $1,69^{2}$, que foi a altura média da população analisada ( $\left.V E F, A J\right)$.

A variação temporal do $\mathrm{VEF}_{1}\left(\mathrm{DVEF}_{1}\right)$ foi expressa pelo cálculo

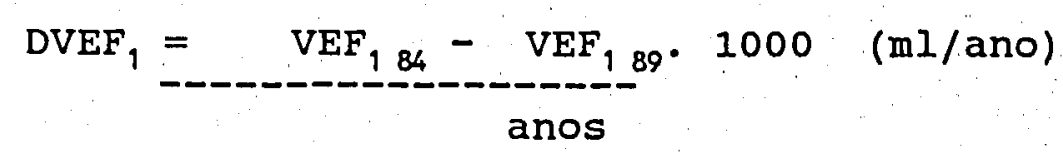

O período entre as duas observações variou de 56 a 68 meses, portanto o denominador do cálculo, transformado em anos, variou de caso a caso.

\subsection{Provocação Brônquica}

No reexame de 1989 os mineiros submeteram-se a um teste de provocação brônquica inespecífica (PB) após consentimento verbal. A escolha desta 
metodologia deveu-se a alguns dos objetivos do trabalho. Inicialmente, seria um dado objetivo sobre a presença de asma em adição aos sintomas respiratórios que foram caracterizados através do questionário. Seria também um dado de análise em relação à reatividade brônquica de uma população exposta a um risco respiratório ocupacional. Não encontramos referências na literatura de estudos epidemiológicos de reatividade brônquica em mineiros de carvão. Por último, estava-se interessados em saber como se comporta a queda do $\mathrm{VEF}_{1}$ ao longo do tempo nesta população e sua relação com o grau de hiperreatividade brônquica (HRB).

A droga de escolha foi o Carbacol (Cloreto de Carbamilcolina, Sigma, USA). E um agente colinérgico, não metabolizado pela colinesterase ${ }^{92}$ de ação similar à Metacolina. Tem como vantagens manter-se inalterado em solução por meses ${ }^{159}$, e quando diluído em soluçāo salina apresenta $\mathrm{pH}$ próximo a 6. Consequentemente, é adequado para estudos de campo, além de ser mais barato e não necessitar ser diluído em solução tamponada. Comparativamente à Metacolina, apresentou uma maior especificidade e menor sensibilidade para separar indivíduos normais de asmáticos ${ }^{157}$.

\subsubsection{Aspectos Técnicos}

O método utilizado para a PB foi o de nebulizaçāo contínua através de máscara facial com inspiraçōes normais em Volume Corrente ${ }^{48,117}$. Após uma espirometria basal, os pacientes inalaram solução fisiológica por 2 minutos. Após 30 e 90 segundos obtivemos uma manobra tecnicamente satisfatória do $\mathrm{VEF}_{1}$ (sempre uma só manobra), repetindo-se novas manobras a cada 90" caso necessário. O menor VEF, pós salina foi tomado como referência e caso não caísse mais de $10 \%$ em relação ao $\mathrm{VEF}_{1}$ basal, prosseguíamos a cada 5 minutos com inalaçōes em doses duplas de soluçāo salina de carbacol iniciando-se com uma concentração de $1 \mathrm{mg} / \mathrm{ml}$. O procedimento era repetido, com a medição do $\mathrm{VEF}_{1}$ a 30 e 90 segundos após cada inalação até que houvesse uma queda de $20 \%$ no $\mathrm{VEF}_{1}$, ou que a última concentração fosse inalada $(8 \mathrm{mg} / \mathrm{ml}) . \mathrm{O} \mathrm{VEF}_{\text {}}$, aceito após cada concentração foi o de menor valor. Quando a manobra do VEF, de 90 segundos mostrava uma queda maior do que $3 \%$ em relação aos 30 segundos, a manobra era repetida a cada 90 segundos para verificar se a queda prosseguia, ou até que houvesse estabilização ou recuperação.

Mineiros que apresentaram um VEF, basal inferior a $75 \%$ do valor previsto foram excluídos do teste ${ }^{117}$. Foram também excluídos mineiros com história de 
infecção de vias aéreas superiores (IVAS) ou inferiores nas últimas 6 semanas $^{73}$, hipertensão arterial moderada ou severa $e$ angina ${ }^{7,92}$. Nos casos em que a variação do VEF, pós salina foi maior do que $10 \%$ em relação ao basal o teste também não foi feito ${ }^{97}$ A TABELA 2.9 mostra o número de testes realizados e as causas de exclusões.

TABELA 2.9: Número de Mineiros Submetidos a Provocação Brônquica, Causas de Exclusão e Total de Exames Concluídos

- VEF1 basal < 75q 2 2

- IVAS 3

- H.A. ou Angina 2

- Variação do VEF1 pós salina > 10\& 2

- Incapaz de fazer espirometrias reprodutiveis 3

Os testes foram feitos de manhã ou de tarde, tomando-se a precaução de garantir que o mineiro estivesse em turno que não incluisse a madrugada (6-12h, 12-18h ou 18-24h) há pelo menos 3 dias. Houve somente um caso de PB em mineiro em turno noturno, pelo fato do mesmo trabalhar em turno fixo.

Os resultados foram anotados em folha de registro apropriada (ANEXO 4). As respostas foram expressas através do cálculo da Concentraçāo Provocativa $\left(\mathrm{PC}_{20}\right)$ que produzia uma queda de $20 \%$ no $\mathrm{VEF}_{1}$, derivada através de interpolação linear simples em gráficos monolog dividindo-se as respostas em Positivas $\left(\mathrm{PC}_{20}<=8 \mathrm{mg} / \mathrm{ml}\right)$ e Negativas $\left(\mathrm{PC}_{20}>8 \mathrm{mg} / \mathrm{ml}\right)$.

\subsubsection{Equipamentos e Calibração}

O gás utilizado para a geração do aerosol foi o ar comprimido. Os cilindros foram equipados com uma válvula reguladora de duplo estágio com pressão de 
saída fixada em 50 PSI (White Martins, Modelo R, Brasil), e um fluxômetro acoplado (K. Takaoka, Modelo 3013, Brasil). Utilizamos nebulizadores de jato (NS, Modelo I-205. Brasil).

Os fluxômetros foram aferidos por um rotâmetro eletrônico de baixa resistência (MiniBuck Calibrator, A.P. Buck Inc, USA), para ajuste do fluxo real.

Os nebulizadores foram testados em relação a:

a) Diâmetro das Partículas Geradas: o diâmetro aerodinâmico foi medido através de metodologia desenvolvida na Escola Paulista de Medicina ${ }^{153}$. Em resumo, foi gerado um aerosol radioativo de dietilenotriaminopentacético marcado (DTPA ${ }^{99 \pi} \mathrm{Tc}$ ) a um fluxo conhecido, e as partículas foram depositadas em um impactador em cascata. Através da massa de aerosol medida em cada estágio foi derivado o Diâmetro Mediano de Massa (DMM), que corresponde ao diâmetro aerodinâmico, e o Desvio Padråo Geométrico (DPG). Os resultados mostraram um DMM = 1,6 e um DPG = 3,2, caracterizando portanto um aerosol heterodisperso'. (Para um melhor entendimento do leitor interessado, referimos para a excelente revisão de AGNEW'1)

b) Débito dos Nebulizadores: Os débitos foram calculados para cada nebulizador individualmente. Selecionamos como adequados, nebulizadores que gerassem entre 0,12 a $0,16 \mathrm{ml} / \mathrm{min}^{97}$ a um fluxo real fixo de $31 / \mathrm{min}$, medidos em balança de precisão (Sartorius, Sartorius GMBH, Alemanha) ${ }^{208}$.

c) Reprodutibilidade: $O$ débito de cada nebulizador foi medido no mínimo 4 vezes. Somente nebulizadores cujos débitos apresentavam um coeficiente de variação inferior a $10 \%$ foram aceitos para os testes de PB.

Os fluxômetros utilizados para o cálculo do débito dos nebulizadores (Oftec, Modelo 18B, Brasil) foram diferentes dos fluxômetros levados a campo. Por puro acaso, quando se iniciava um novo trabalho na nossa instituição, ao se recalcular os débitos dos nebulizadores, notou-se que os fluxômetros utilizados no trabalho possuiam um fluxo que variava de acordo com a resistência ao mesmo, ou seja, o fluxo indicado na escala não era o efetivo. Teve-se então que calcular os débitos pelos 2 fluxômetros para cada nebulizador. Em média, os débitos foram 1,5 vezes menores do que os previstos. Os 
resultados referentes ao $\mathrm{DP}_{15}$ e $\mathrm{DP}_{20}$ foram entāo ajustados, pois eram dependentes do débito. A PC $_{20}$ refere-se a concentração e, portanto, não foi alterada.

\subsection{Radiologia}

Em 1984, as empresas envolvidas no trabalho ticaram responsáveis pelo envio das radiografias dos mineiros participantes da amostra. Na ocasiāo, de um total de 956 mineiros obteve-se $708(74 \%)$ radiografias interpretáveis, $140(15 \%)$ radiografias não enviadas e $108(11 \%)$ radiografias qualidade 4 (consideradas como inadequadas para interpretaçāo).

Em 1989 o exame radiológico foi mais cuidadoso. Os mineiros foram radiografados em 2 serviços de radiologia que são referência para toda a região. Os números da avaliaçāo radiológica estão na TABELA 2.10.

TABELA 2.10: Avaliação Radiológica da Coorte, 1984 e 1989, e Causas de Exclusão

Radiografias Interpretadas

224

Radiografias Qualidade 4

25

A técnica radiológica empregada em 1989 foi a constante na versão de 1980 da Classificaçāo Internacional de Radiografias de Pneumoconioses ${ }^{112}$. Foram utilizadas telas intensificadoras de média velocidade (Kodak X-Omatic Regular, Kodak, USA) e filmes de média sensibilidade (Kodak X-Omat K, Kodak, USA). As radiografias consideradas inadequadas para interpretaçăo (qualidade 4) foram repetidas sempre que possível. 
As radiografias foram interpretadas independentemente por 3 leitores (sempre 2 pneumologistas c um radiologista), todos com experiência na versão de 1980 da classificação $^{112}$. Em 1984 dois radiologistas dividiram-se como o Leitor 3, e em 1989 um outro radiologista analisou todo o grupo (Leitor 3). Dois leitores, Leitor $1 \mathrm{e} \mathrm{Leitor} \mathrm{2,} \mathrm{foram}$ os mesmos em 1984 e 1989. Os resultados foram registrados em folhas de leitura apropriadas, uma para cada leitor (ANEXO 4).

Os resultados foram expressos atraves da mediana das 3 leituras para a profusão de pequenas opacidades ${ }^{45}$. Este método, comparativamente à média, tem a vantagem de conferir dentro da escala de 12 pontos um valor real a cada radiografia. Além disto, a mediana elimina sistematicamente leitores tendenciosos.

Para a forma e tamanho das pequenas opacidades utilizou-se um método de pontuação, no qual para cada forma e tamanho mencionados em primeiro lugar é dado o peso 2 e peso 1 para a segunda menção; ds menções com maior soma de pesos é atribuída a forma e tamanho finais ${ }^{4 ?}$. Não houve leituras de grandes opacidades nos mineiros da coorte.

Um "índice de regularidade" das radiografias foi também derivacio com as mesmas finalidades acima ${ }^{45,47}$. A cada uma das chapas foi atribuído o índice de 1 a 4, segundo o critério a seguir:

IR1. Se ambas as formas e tamanhos mencionados fossem regulares (p, $q, r)$.

IR2. Se a primeira menção fosse regular $(p, q, r)$ e a segunda irregular $(s, t, u)$.

IR3. Se a primeira menção fosse irregular e a segunda regular.

IR4. Se ambas as menções fossem irregulares.

O diâmetro traqueal (DT) foi medido na avaliação de 1989, dentro da técnica descrita na literatura ${ }^{238}$, pelo Leitor 1 . Das 277 radiografias, conseguiu-se medir em $239(86,3 \%)$. Este dado será utilizado para análises de correlação com ocorrência de pneumoconiose, sintomas respiratórios, e parâmetros funcionais. 
A progressão radiológica entre as duas investigações foi analisada dentro da escala de 12 pontos da OIT, classificando-se o mineiro como apresentando progressão se o Rx avançasse uma ou mais subcategorias entre 1984 e 1989, estável caso permanecesse na mesma subcategoria nas 2 ocasiões e apresentando regressão, caso retroagisse uma ou mais subcategorias em 1989.

\subsection{Computação e Análises Estatísticas}

Todos os dados referentes à identificação dos 280 mineiros, história ocupacional, questionário de sintomas respiratórios, espirometria, broncoprovocação e radiologia foram digitados e transferidos em fita magnética para um computador de grande porte (Borroughs 7900-CCE-USP). Estes mesmos dados foram transferidos para disquetes flexíveis, compatíveis com leitura em microcomputadores da linha IBM-PC.

As análises foram efetuadas utilizando-se o programa BMDP para computador de grande porte ${ }^{24}$. Algumas foram feitas em microcomputador, com os programas Stat Pack ${ }^{228}$, e houve também um considerável trabalho com calculadora científica de bolso 229 .

Os métodos estatísticos empregados podem ser divididos em análises descritivas, tabelas de associaçāo, análises de variância, e regressōes.

Para o estudo de associações entre variáveis categóricas utilizamos os testes de Qui-Quadrado em tabelas de contingência adotando como nível de rejeição para a hipótese de nulidade o corte de $5 \%(p<=0,05)$. Para as tabelas $2 \times 2$, todos os valores do $\mathrm{x}^{2}$ foram calculados com a correção de Yates, independente dos números nas caselas ${ }^{11}$.

A Análise de Variância (ANOVA) foi empregada para a comparação de médias de variáveis contínuas, referentes a grupos que serão referidos no texto. De maneira geral, elas se referem aos índices funcionais respiratórios, aos índices de exposição, e outras variáveis, admitindo-se o pressuposto de pertecerem a uma distribuição normal. A diferença entre as médias de dois grupos foi calculada pelo valor de "p" diretamente da tabela da análise de variância. Quando o número de grupos era maior que 2 , e o valor de $\mathrm{p}$ inferior a $5 \%$, as diferenças entre os grupos foram calculadas através do método de contrastes de Scheffé ${ }^{212}$ ou, no caso de pequenos números em algum dos 
grupos, pelos testes "t" múltiplos, de Bonferronio (quando o " $n$ " em um dos grupos er: igual ou inferior a $10 \%$ do outro grupo).

Para a análise de múltiplas associaçōes, utilizamos o método d regressão linear múltipla, quando a variável dependente era contínua, e regressão logística quando a variável dependente assumia um valor dicotômico. A primeira delas foi usad: basicamente para o cálculo das equações de predição dos índices funcionais respiratórios, ‘ para correlações de variáveis contínuas.

A regressão logística foi largamente utilizada em virtude da natureza dos dados, pois frequentemente o evento final de interesse era uma variável binária e c período de observação para todos os membros da coorte era semelhante ${ }^{56}$. O modelc logístico mede o risco de determinado evento de forma probabilística $(\mathrm{P})$ que varia na faix: de 0 a 1 , conforme o modelo abaixo.

Probabilidade de um evento $(P)=$ 1 $1+e^{-(a+b i x i+\ldots .+b+b r x)}$

onde $r$ reflete o número de variáveis independentes, a é a constante da equação, e $b_{1}$...b] são as constantes estimadas para cada uma das variáveis regressoras; $x 1 . . x r$ denotam 0 : valores individuais de cada uma das variáveis ${ }^{123}$.

A regra de entrada de uma determinada variável no modelo foi fixad: através de uma significância estatística ao nível de 0,10 , isto é, somente entram no modelc variáveis cuja probabilidade associada seja inferior a $10 \%$. Para variáveis categóricas c número de coeficientes é igual ao número de categorias menos 1 . Em todas as regressõe: logísticas que serão apresentadas apenas os grupos de tabagismo (NF, F e EF) e a PE (Positiva e Negativa) serão as variáveis categóricas. Portanto, para os grupos de tabagismc teremos 2 coeficientes, que serão denominados (1) e (2). Para se obter o resultado de equação deve-se multiplicá-los pelos seguintes valores:

(1) (2)

NF $\quad-1 \quad-1$

F $\quad 0 \quad 1$

EF $\quad 1 \quad 0$

Para a PB há 1 coeficiente que deverá ser multiplicado por: 
(1)

PB Positiva -1

PB Negativa 1

Com os dados gerados no modelo logístico calcula-se o logaritmo da razão de chance (log odds) de um determinado evento, a razão de chance (odds ratio $\mathrm{OR}$ ) associada à equação, e a probabilidade (P) de um evento. Estes dados podem tanto ser apresentados de forma tabular, quanto gráfica. Os OR foram calculados somente em análises transversais. Os intervalos de confiança do OR foram estimados de acordo com o método de Brown ${ }^{26}$.

Para algumas análises transversais, como medida de associação obteve-se a razão de prevalência (PR), que é similar ao cálculo do risco relativo (RR) ${ }^{133}$. Os intervalos de confiança de $95 \%$ para a PR foram calculados de acordo com as séries de Taylor $^{130}$. 


\section{SEÇĀO 3}

RESULTADOS E COMENTÁRIOS 


\section{RESULTADOS E COMENTÁRIOS}

\subsection{Dados Gerais}

A coorte foi composta por 280 mineiros investigados em 1984 e 1989 , que em ambas as ocasióes realizaram espirometrias satisfatórias. Todos os mineiros eram do sexo masculino sendo $252(90,0 \%)$ brancos. A média e o desvio-padrão da idade em 1984 eram de 30,1 $\pm 5,1$ anos e em 1989 de 34,9 \pm 5,1 anos. Em 1989, $270(96,4 \%)$ continuavam empregados nas minas, $6(2,2 \%)$ estavam aposentados e $4(1,4 \%)$ demitidos. A média do tempo de afastamento das minas era de 2,6 anos entre os aposentados e demitidos. Para a finalidade de análises estes 10 mineiros não foram retirados da coorte, pois os motivos que os levaram a afastar-se da atividade não foram médicos, além do que, o tempo de afastamento da mineração era relativamente pequeno. A TABELA 3.1 traz as variáveis estudadas neste trabalho, na forma de prevalências pontuais, ou médias. 
TABELA 3.1: Prevalência e Médias com os Respectivos Desvios-Padrão das Variáveis Analisadas na Coorte em 1984 e 1989.

Exposicão Ocupacional

SANO

SANOAJ
$5,6 \pm 4,0$
$15,8 \pm 13,9$

$7,8 \pm 11,3$

$28,9 \%$

$58,6 \%$

$12,5 \%$
$10,4 \pm 3,9$

$31,5 \pm 16,5$

Tabagismo

AM

Grupos NF

EF
$31,1 \%$

$38,9 \%$

$12,5 \%$

$13,6 \%$

$--$

$$
\begin{aligned}
& 8,9 \pm 9,2 \\
& 19,6 \% \\
& 58,6 \% \\
& 21,8 \%
\end{aligned}
$$

\section{Sintomas Respiratórios}

Tosse

Catarro

Chiado

$\mathrm{BC}$

Radiologia

$\begin{array}{llr}\text { Profusão } & 0 / 0 & 86,2 \% \\ & 0 / 1 & 8,5 \% \\ \text { DT (mm) } & 1 / 0 \text { ou mais } & 5,4 \% \\ & & -\end{array}$

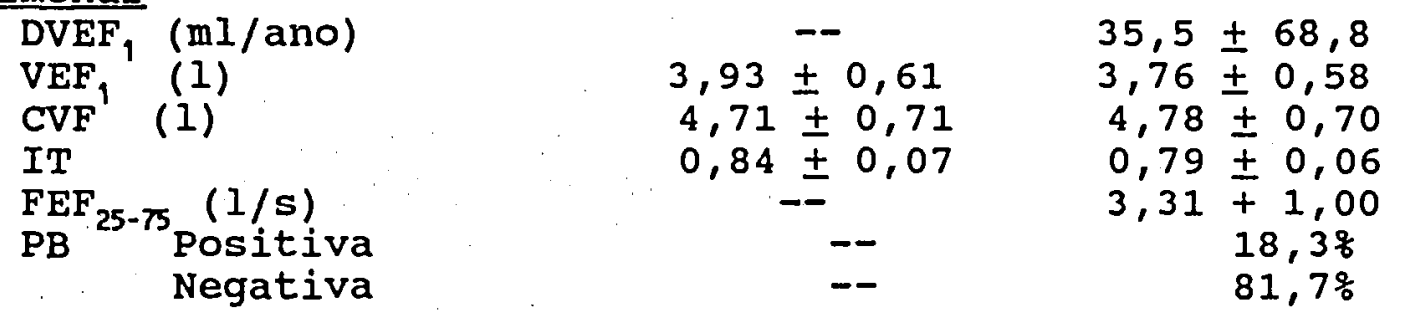

Funcão Pulmonar

A estrutura básica desta seção está dividida em análises que contemplam fundamentalmente três aspectos: sintomas respiratórios, radiologia e função pulmonar. Naturalmente haverá. uma farta correlação entre os mesmos. De maneira geral, a metodologia de análise empregada será similar dentre eles, porém, para algumas 
particularidades, e para melhor entendimento do leitor, variações de análise ou interpretação serão mencionadas no texto, quando necessário.

\subsection{Sintomas Respiratórios}

\subsubsection{Prevalência e Evolução}

Os sintomas respiratórios analisados através da aplicação do questionário de sintomas respiratórios estão descritos na seção de MÉTODOS. As prevalências pontuais dos 4 sintomas estão nas TABELAS 2.7 e 3.1. A TABELA 3.2 traz os intervalos de confiança para a prevalência de cada sintoma em 1984 e 1989.

TABELA 3.2: Intervalo de Confiança (95\%) Calculado para a Prevalência dos Sintomas Respiratórios em 1984 e 1989.

$\begin{array}{lll} & \\ \text { Tosse } & 0,20 !--! 0,42 & 0,30 !--! 0,41 \\ \text { Catarro } & 0,33 !--! 0,44 & 0,31 !--! 0,42 \\ \text { Dispnéia } & 0,09 !--! 0,16 & 0,08 !--! 0,15 \\ \text { Chiado* } & 0,09 !-! 0,17 & 0,18 !--! 0,28\end{array}$

* $\mathrm{p}<0,01$

O sintoma Chiado é o único que apresentou uma diferença estatisticamente significante de 1984 a 1989 (os intervalos de 1984 e 1989 não possuem valores comuns).

As TABELAS 3.3 a 3.6 mostram a distribuição das respostas aos 4 sintomas analisados em 1984 e 1989. Para analisar as mudanças ocorridas nas 2 investigaçōes utilizamos a técnica de MacNemar para o cálculo do $x^{2}$. 
TABELA 3.3: Distribuição de Mineiros Segundo a Presença de Tosse em 1984 e 1989.

\begin{tabular}{|c|c|c|c|c|}
\hline & \multicolumn{3}{|c|}{ TOSSE $(84)$} & \multirow[t]{2}{*}{ TOTAI } \\
\hline & & Sim & Não & \\
\hline \multirow{4}{*}{ TOSSE (89) } & sim & 52 & 48 & 100 \\
\hline & Não & 35 & 145 & 180 \\
\hline & --- & - & --- & $--\infty$ \\
\hline & $\mathbf{T}$ & 87 & 193 & 280 \\
\hline
\end{tabular}

TABELA 3.4: Distribuiçāo de Mineiros Segundo a Presença de Catarro em 1984 e 1989.

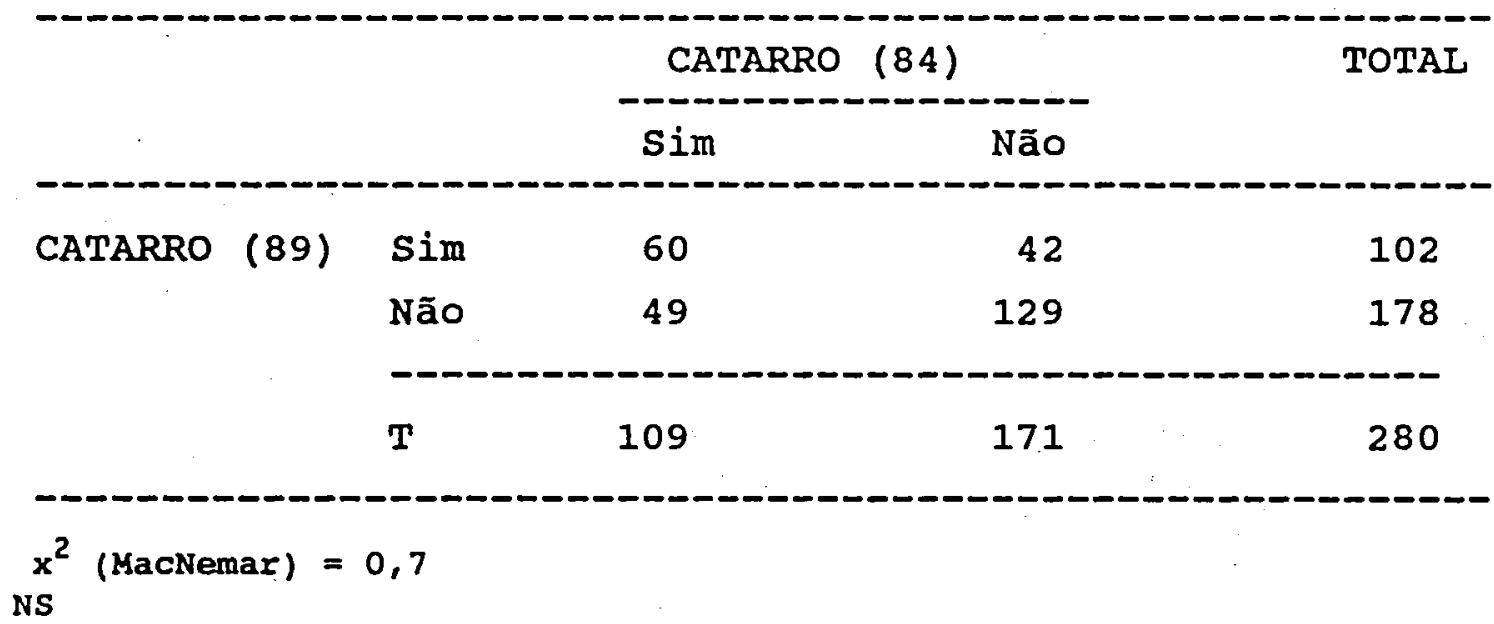

TABELA 3.5. Distribuição de Mineiros Segundo a Presença de Dispnéia em 1984 e 1989.




TABELA 3.6. Distribuiçāo de Mineiros Segundo a Presença de Chiado em 1984 e 1989.

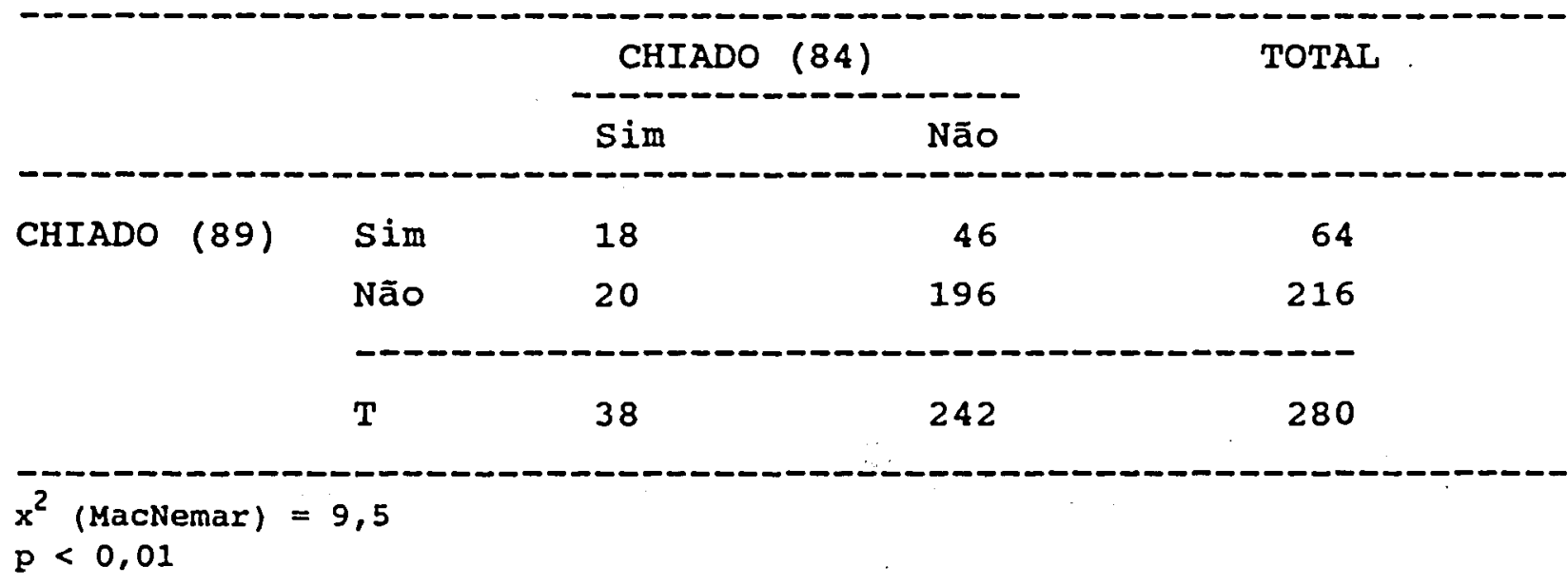

A evoluçāo dos 4 sintomas foi estudada através de uma estratificação dos mineiros em, regressão (apresentavam o sintoma em 1984 e o negavam em 1989), estabilidade (apresentavam ou negavam o sintoma em 1984 e mantinham-se iguais em 1989) e progressão (negavam o sintoma em 1984 e o referiam em 1989). Os números de regressão (R), estabilidade (E) e progressão (P) estão na TABELA 3.7.

TABELA 3.7. Número de Mineiros Segundo a Evolução dos Sintomas Respiratórios 1984-1989

$\begin{array}{llll} & * \mathrm{R} & * \mathrm{E} & \text { *P } \\ \text { Tosse } & 35 & 197 & 48 \\ \text { Catarro } & 49 & 189 & 42 \\ \text { Dispnéia } & 25 & 233 & 22 \\ \text { Chiado } & 20 & 214 & 46\end{array}$

* $R=$ Regressão

$E=$ Estabilidade

$P=$ Progre日são

Os fatores reiacionados com a evoluçāo dos sintomas foram analisados através de análise de variância, para variáveis contínuas, e de tabelas de 
contingência para variáveis categóricas. A influência do SANO, SANOAJ, DVEF, Tabagismo e PB estão nas TABELAS 3.8 a 3.10.

TABELA 3.8: Análise de Variância dos fndices de Exposição (SANO E SANOAJ) nos Grupos de Regressão (R), Estabilidade (E) e Progressão (P) de Sintomas Respiratorios.

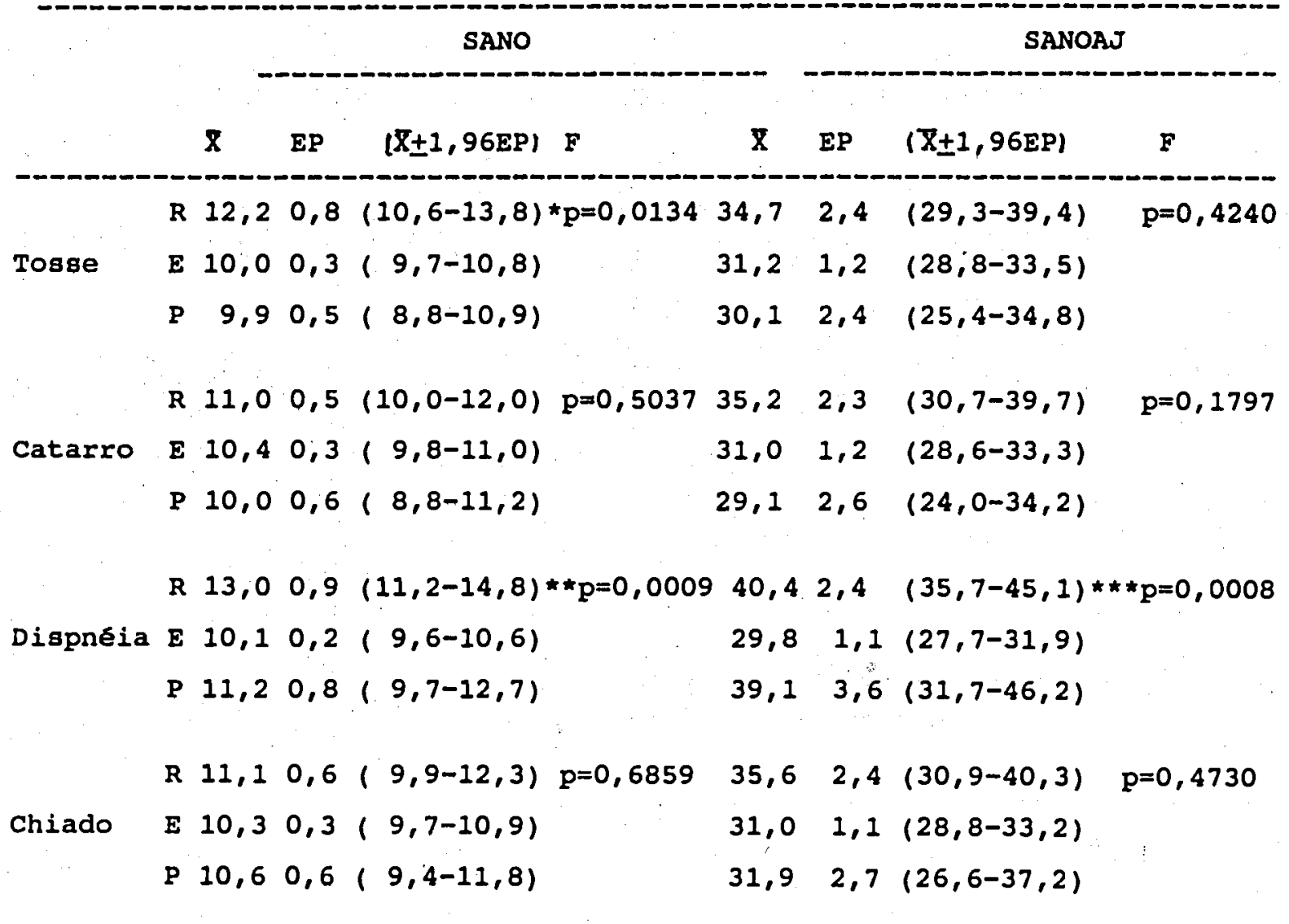

* Média da SANO do grupo de Regressão significativamente maior do que Estabilidade e Progressão

* Média da SANo do grupo de Regressão significativamente maior do que Estabilidade

*** Média da SANOAJ dos grupos de Regressão e Progressão significativamente maior do que Estabilidade 
TABELA 3.9: Análise de Variância do DVEF, nos Grupos de Regressão (R), Estabilidade (E) e Progressão (P) de Sintomas Respiratórios.

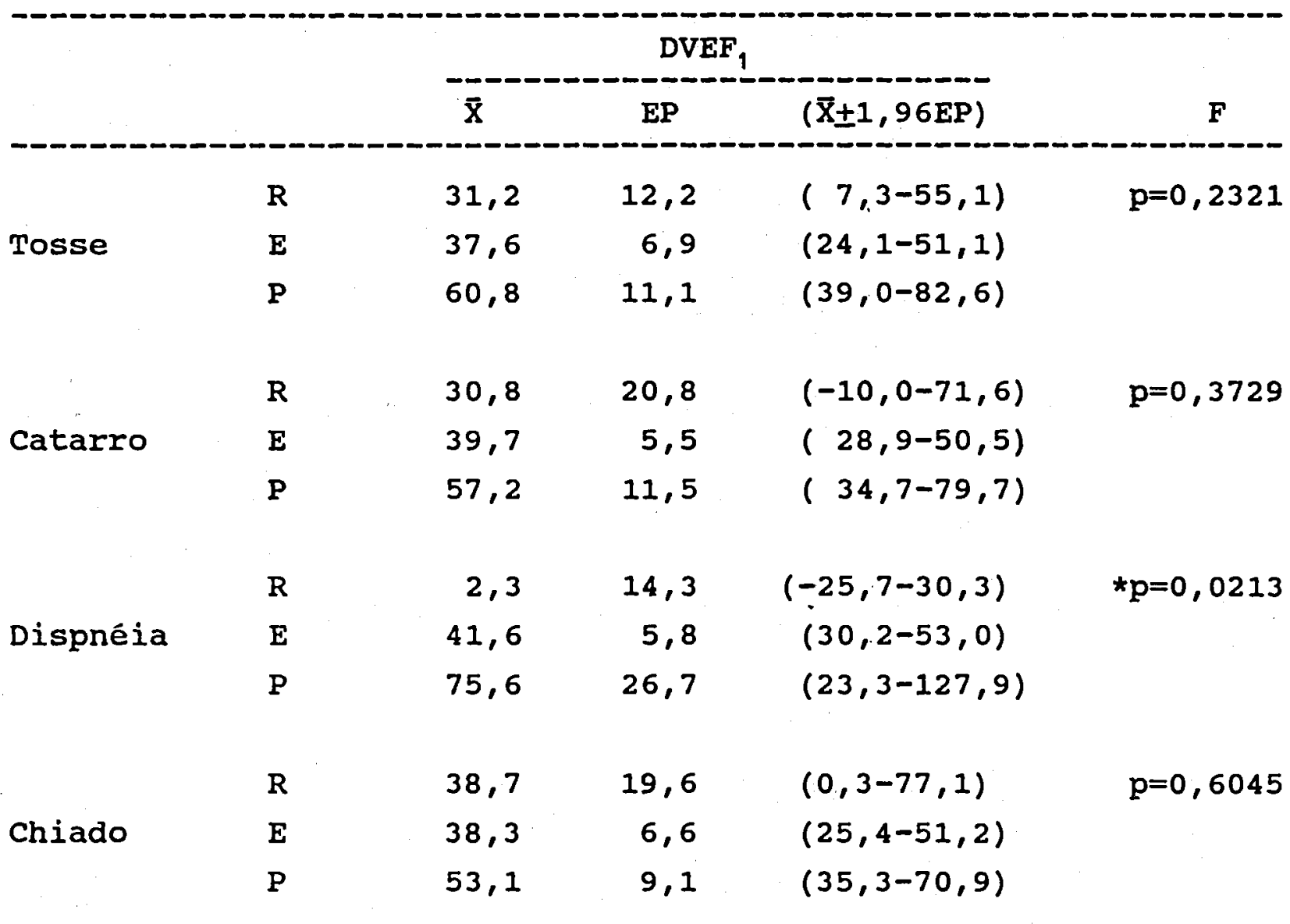

* Média do DVEF, do Grupo de Progressāo e Estáveis significativamente maior que de Regressão 
TABELA 3.10: Tabelas de Contingência (Qui-quadrado) de Tabagismo (Grupos) e Provocação Brônquica (PB) nos Grupos de Evolução dos Sintomas Respiratórios.



* P significante

Em relação ao sintoma tosse, observamos que os mineiros que regrediram foram significativamente mais expostos que os que permaneceram estáveis ou progrediram $(p=0,0134)$, porém isto não foi confirmado pelo SANOAJ; ainda, havia significativamente mais fumantes entre os que progrediram, comparados aos que regrediram ou permaneceram estáveis $(p=0,0003)$. $O$ sintoma catarro não estava associado a nenhuma das variáveis. Quanto ao sintoma dispnéia, os mineiros que regrediram foram 
significativamente mais expostos que os estáveis $(p=0,0008$ para SANOAJ e $p=0,0009$ para SANO) e o $D V_{1}$ foi significativamente maior nos que progrediram e permaneceram estáveis do que naqueles que regrediram. A respeito do sintoma chiado, notou-se que os que progrediram apresentavam uma positividade significativamente maior à PB que os que regrediram ou permaneceram estáveis $(p=0,0000)$. E interessante notar, na TABELA 3.9, que a média do declínio anual do $\mathrm{VEF}_{1}$ é sempre maior no grupo de progressão para cada um dos 4 sintomas estudados, embora a diferença só tenha sido significante para o sintoma dispnéia.

\subsubsection{Fatores Relacionados com o Desenvolvimento de Sintomas Respiratórios}

Tomando-se os dados de sintomas de 1989, estudaram-se os fatores relacionados com a presença de sintomas. Nestas análises ao invés de tosse e catarro, optou-se por estudar a Bronquite Crônica, já que com o questionário de 1989 era possível inferir este diagnóstico da forma clássica. Dos 280 mineiros, 78 (27,9\%) foram diagnosticados como portadores de BC, 32 (11,4\%) apresentavam dispnéia grau 3 e 64 $(22,8 \%)$ apresentavam chiado. $A$ análise das múltiplas variáveis associadas com os sintomas, foi feita pelo método de regressão logística, já que as variáveis dependentes (sintomas) assumiam um valor dicotômico, presença ou ausência. As variáveis independentes eram de 2 tipos: contínuas (Idade, SANO, SANOAJ, VEF,AJ DVEF, e AM) ou categóricas (PB, Grupos de Fumo). Como a interação entre exposição e tabagismo pareceu de importância para estas análises, foram criadas duas outras variáveis independentes para este fim: SANO X AM e SANOAJ X AM.

A regra de entrada das variáveis independentes no modelo foi fixada tendo como limite superior uma probabilidade ao nível de 10\%. As TABELAS 3.11 a 3.13 mostram os resultados. 
TABELA 3.11: Modelo de Regressão Logística para o Estudo dos Fatores Relacionados à Bronquite Crônica.

\begin{tabular}{|c|c|c|c|c|}
\hline VARIÁVEL & INTERVALO & COEFICIENTE & ERRO PADRÃO & $\mathbf{p}$ \\
\hline Constante & & $-1,530$ & 0,208 & \\
\hline Idade & $26-53$ & - & -- & -- \\
\hline SANO & $4-30$ & -- & -- & - \\
\hline SANOAJ & $5-86$ & -- & -- & -- \\
\hline AM & $0-70$ & -- & -- & - \\
\hline Tabagismo & $\begin{array}{l}(1) \\
(2)\end{array}$ & $\begin{array}{r}0,342 \\
1,110\end{array}$ & $\begin{array}{l}0,302 \\
0,228\end{array}$ & 0,0000 \\
\hline SANO $X$ AM & $0-1960$ & -- & -- & -- \\
\hline SANOAJ $X$ AM & $0-2940$ & -- & -- & -- \\
\hline $\mathrm{VEF}_{1} \mathrm{AJ}$ & $2,24-5,48$ & -- & -- & -- \\
\hline DVEF $_{1}$ & $-103,5 \quad-222,4$ & -- & -- & -- \\
\hline $\mathrm{PB}$ & (1) & - & -- & -- \\
\hline
\end{tabular}

O Tabagismo foi a única variável que se associou significativamente em relação à BC. $O$ cálculo da razão de chances (OR) dos fumantes e ex-fumantes apresentarem BC em relação aos não fumantes pode ser derivado do próprio programa utilizado para o cálculo do modelo de regressão logística, pois ele fornece ao final o logarítmo da chance associada a cada um dos 3 grupos. Porém, para facilidade de entendimento do leitor, estes mesmos cálculos podem ser derivados de tabelas de contingência $2 \times 2$ construindo-se duas tabelas $2 \times 2$ com os dados a seguir:

$$
\begin{array}{ll}
\text { NF com BC }=5 & \text { NF sem } B C=50 \\
F \operatorname{com} B C=65 & F \text { sem } B C=99 \\
E F \operatorname{com} B C=8 & \text { EF sem BC }=53
\end{array}
$$

$\mathrm{OR}_{\mathrm{F} / \mathrm{NF}}=6,6$, Intervalo de Confiança de 95\%: 2,5-17,4

$O R_{E F / M F}=1,5$, Intervalo de Confiança de 95\%: 0,5 - 4,9

Portanto, nota-se que a razão de chances do fumante é significativamente maior que a dos não fumantes, ao passo que os ex-fumantes não diferem dos não fumantes na chance de apresentarem BC. 
TABELA 3.12: Modelo de Regressão Logística para o Estudo dos Fatores Relacionados à Dispnéia.

\begin{tabular}{|c|c|c|c|c|}
\hline VARIAVVEL & INTERVALO & COEFICIENTE & ERRO PADRÃO & $p$ \\
\hline Constante & & $-3,430$ & 0,499 & \\
\hline Idade & $26-53$ & -- & -- & - \\
\hline SANO & $4-30$ & -- & -- & -- \\
\hline SANOAJ & $5-86$ & 0,037 & 0,012 & 0,0011 \\
\hline AM & $0-70$ & -- & -- & -- \\
\hline Tabagismo & $\begin{array}{l}(1) \\
(2)\end{array}$ & $=$ & $=$ & $=-$ \\
\hline SANO $X \mathrm{AM}$ & $0-1960$ & -- & -- & -- \\
\hline SANOAJ X AM & $0-2940$ & -- & -- & -- \\
\hline $\mathrm{VEF}_{1} \mathrm{AJ}$ & $2,24-5,48$ & -- & -- & - \\
\hline DVEF $_{q}$ & $-103,5 \quad-222,4$ & -- & -- & $-\dot{-}$ \\
\hline PB & (1) & -- & -- & -- \\
\hline
\end{tabular}

A SANOAJ associou-se significativamente com a probabilidade de um registro positivo de dispnéia. Devido a ser uma variável contínua, pode-se comparar a chance de um registro positivo do sintoma para dois níveis hipotéticos de exposiçāo. Considere-se, por exemplo, dois mineiros, o primeiro com SANOAJ $=15$ e o segundo com SANOAJ = 45. Para cada unidade da variável, o logarítimo de chance varia em 0,037 , portanto no exemplo, a diferença no logarítimo de chance da SANOAJ é (45-15)X0,037 = 1,11. A razão de chance para uma diferença de 30 na SANOAJ será, $e^{1,11}=3,0.0$ intervalo de confiança para esta situação, utilizando-se o erro padrão para o cálculo, inclui valores de 1,5 a 6,1 .

Todas as outras variáveis não tiveram significância ao nível de $10 \%$. 
TABELA 3.13: Modelo de Regressão Logística para o Estudo dos Fatores Relacionados ao Chiado.

\begin{tabular}{|c|c|c|c|c|}
\hline VARIÁVEL & INTERVALO & COEFICIENTE & ERRO PADRÃO & $p$ \\
\hline Constante & & $-0,898$ & 1,45 & \\
\hline Idade & $26-53$ & -- & -- & -- \\
\hline SANO & $4-30$ & 0,147 & 0,058 & 0,0072 \\
\hline SANOAJ & $5-86$ & -- & -- & -- \\
\hline$A M$ & $0-70$ & 0,143 & 0,051 & 0,0006 \\
\hline Tabagismo & $\begin{array}{l}(1) \\
(2)\end{array}$ & -- & -- & -- \\
\hline SANO $X A M$ & $0-1960$ & $-0,008$ & 0,004 & 0,0021 \\
\hline SANOAJ $X$ AM & $0-2940$ & -- & -- & -- \\
\hline $\mathrm{VEF}_{1} \mathrm{AJ}$ & $2,24-5,48$ & $-0,005$ & 0,003 & 0,1095 \\
\hline $\mathrm{DVEF}_{1}$ & $-103,5-222,4$ & -- & -- & -- \\
\hline PB & (1) & $-0,659$ & 0,173 & 0,0001 \\
\hline
\end{tabular}

Uma série de variáveis associaram-se ao Chiado. A mais importante em magnitude foi a $\mathrm{PB}$, seguida de $\mathrm{AM}$, o produto SANO $\mathrm{X}$ AM, SANO e o VEF,AJ. Fixando-se hipoteticamente as variáveis $A M$ em 20, SANO em 10 e VEF, AJ em 3,5 para dois mineiros; a) com $\mathrm{PB}$ positiva, b) com $\mathrm{PB}$ negativa, a diferença na razāo de chances nos dois casos será:

a) $(0.143 \times 20)+(0.147 \times 10)+(-0.008 \times 10 \times 20)+(0.005 .3,5)+(0.659 \times 1)=3.3715$

b) $(0.143 \times 20)+(0.147 \times 10)+(-0.008 \times 10 \times 20)+(0.005 .3,5)+(0.659 \times-1)=2.0535$

$$
\mathrm{e}^{(a-b)}=3,7 \text {, }
$$

No caso acima, o mineiro com um teste de PB positivo tem uma chance de referir chiado 3,7 vezes maior do que o mineiro com teste negativo, desde que ajustadas as outras variáveis significantes.

\subsubsection{Efeitos da Exposição Ocupacional e do Tabagismo}

A influência das exposições concorrentes (poeiras e fumo) sobre a presença de sintomas respiratórios foi analisada de três formas distintas. Inicialmente, associaram-se em tabelas de contingência, os índices de exposição e o tabagismo com os sintomas, isoladamente, para dados de 1984 e 1989. Posteriormente, utilizando dados de 
1989, estas relações foram analisadas em modelos de regressão logística, incluindo também a Bronquite Crônica. Finalmente, foi construída uma tabela de razões de prevalência por sintomas nos grupos de tabagismo, estratificando os mineiros em mais e menos expostos.

Nas tabelas de contingência os sintomas aparecem como presentes ou ausentes. Para os dados de 1984, as faixas de SANO foram de 0 a 5 e de 6 ou mais anos de exposição. As de SANOAJ foram de 0 a 20 e de 21 ou mais, e as de AM foram 0, 1 a 10, e 11 ou mais. Para dados de 1989, as faixas de SANO e SANOAJ foram de 0 a 7, 8 a 13, e 14 ou mais, e 0 a 20, 21 a 40, e 41 ou mais, respectivamente. As faixas de AM foram 0, 1 a 10, 11 a 20, e 21 ou mais. Os grupos de tabagismo foram de Não Fumantes, Fumantes e ExFumantes. As TABELAS 3.14 e 3.15 mostram os resultados resumidos destas tabelas.

TABELA 3.14: Qui-Quadrado e Probabilidade das Associações Simples entre Sintomas Respiratórios, Exposição (SANO E SANOAJ) e Tabagismo (AM e Grupos), 1984.

\begin{tabular}{|c|c|c|c|c|}
\hline & TOSSE & CATARRO & DISPNEIA & CHIADO \\
\hline & $a_{G L=1}$ & $G L=1$ & $G L=1$ & $\mathrm{GL}=1$ \\
\hline \multirow[t]{3}{*}{ SANO } & $x^{2}=6,849$ & $x^{2}=5,911$ & $x^{2}=8,935$ & $x^{2}=4,200$ \\
\hline & $\star p=0,009$ & ${ }^{*} p=0,015$ & $* p=0,003$ & $\star p=0,040$ \\
\hline & $G L=1$ & $G L=1$ & $G L=1$ & $G L=1$ \\
\hline \multirow[t]{3}{*}{ SANOAJ } & $x^{2}=5,181$ & $x^{2}=8,118$ & $x^{2}=6,159$ & $x^{2}=2,810$ \\
\hline & $\star p=0,023$ & $* p=0,004$ & $\star p=0,013$ & $p=0,094$ \\
\hline & $G L=2$ & $G L=2$ & $G L=2$ & $G L=2$ \\
\hline \multirow[t]{2}{*}{$A M$} & $x^{2}=8,766$ & $x^{2}=10,669$ & $x^{2}=1,828$ & $x^{2}=5,752$ \\
\hline & $* p=0,012$ & $* p=0,003$ & $p=0,401$ & $p=0,056$ \\
\hline \multirow{3}{*}{$\begin{array}{l}\text { Grupos de } \\
\text { Tabagismo }\end{array}$} & $G L=2$ & $\mathrm{GL}=2$ & $G L=2$ & $\mathrm{GL}=2$ \\
\hline & $x^{2}=8,833$ & $x^{2}=13,613$ & $x^{2}=1,553$ & $x^{2}=5,330$ \\
\hline & ${ }^{\star} p=0,012$ & $* p=0,001$ & $p=0,4601$ & $p=0,070$ \\
\hline
\end{tabular}

GL = Graus de Liberdade

* p significante 
TABELA 3.15: Qui Quadrado e Probabilidade das Associaçōes Simples entre Sintomas Respiratórios, Exposiçāo (SANO e SANOAJ) e Tabagismo (AM e Grupos), 1989.

\begin{tabular}{|c|c|c|c|c|}
\hline & TOSSE & CATARRO & DISPNEIA & CHIADO \\
\hline & $e_{G L=2}$ & $G L=2$ & $G L=2$ & $G I=2$ \\
\hline \multirow[t]{3}{*}{ SANO } & $x^{2}=0,3915$ & $x^{2}=2,616$ & $x^{2}=3,466$ & $x^{2}=12,097$ \\
\hline & $p=0,821$ & $p=0,270$ & $p=0,177$ & $\star p=0,002$ \\
\hline & $G L=2$ & $G L=2$ & $G L=2$ & $\mathrm{GL}=2$ \\
\hline \multirow[t]{3}{*}{ SANOAJ } & $x^{2}=1,690$ & $x^{2}=2,979$ & $x^{2}=10,979$ & $x^{2}=6,295$ \\
\hline & $p=0,430$ & $p=0,225$ & $\star p=0,0041$ & ${ }^{\star} p=0,0430$ \\
\hline & $\mathrm{GL}=3$ & $\mathrm{GL}=3$ & $\mathrm{GL}=3$ & $\mathrm{GL}=3$ \\
\hline \multirow[t]{2}{*}{$A M$} & $x^{2}=20,964$ & $x^{2}=11,917$ & $x^{2}=4,031$ & $x^{2}=9,256$ \\
\hline & $\star p=0,000$ & ${ }^{\star} p=0,007$ & $p=0,258$ & $\star p=0,026$ \\
\hline \multirow{3}{*}{$\begin{array}{l}\text { Grupos de } \\
\text { Tabagismo }\end{array}$} & $G L=2$ & $\mathrm{GL}=2$ & $\mathrm{GL}=2$ & $\mathrm{GL}=2$ \\
\hline & $x^{2}=28,070$ & $x^{2}=26,386$ & $x^{2}=2,660$ & $x^{2}=3,973$ \\
\hline & $\star p=0,000$ & $\star p=0,000$ & $p=0,2641$ & $p=0,137$ \\
\hline
\end{tabular}

a $\mathrm{GL}=$ Graus de Liberdade

* p significante

Em 1984, todos os sintomas associaram-se significativamente com a SANO e, também, com excessão do chiado, com a SANOAJ. Apenas tosse e catarro associaram-se significativamente com o tabagismo. Em 1989, os achados em relação ao tabagismo foram os mesmos, porém apenas o chiado associou-se significativamente com a exposição (SANO e SANOAJ) e com o índice quantitativo de tabagismo (AM), sendo que a dispnéia associou-se apenas com a SANOAJ.

Estes mesmos fatores de risco foram analisados de forma conjunta, com base nos dados de 1989. Dois índices de exposição (SANO e SANOAJ) e dois índices de tabagismo (AM e grupos de tabagismo) foram colocados como variáveis independentes 
em análises de regressão logística, tendo como variável dependente a presença ou ausência do sintoma. A regra de entrada das variáveis independentes, foi fixada tendo como limite superior uma probabilidade ao nível de $10 \%$. Portanto, somente as variáveis significantes a este nivel constarão dos resultados. As TABELAS 3.16 a 3.19 mostram os resultados destas análises.

TABELA 3.16: Modelo de Regressão Logística para o Estudo da Influência da Exposição Ocupacional (SANO e SANOAJ) e do Tabagismo (AM e Grupos) sobre o Sintoma Tosse $(n=280)$.

\begin{tabular}{lcccc}
\hline VARIÁVEL & INTERVALO & COEFICIENTE & ERRO PADRÃO & p \\
Constante & & $-1,10$ & 0,179 \\
SANO & $4-30$ & -10 & -- \\
SANOAJ & $5-86$ & - & -- & - \\
AM & $0-70$ & $-0,186$ & 0,254 & 0,0000 \\
Tabagismo & $(1)$ & 1,01 & 0,200 &
\end{tabular}

TABELA 3.17: Modelo de Regressão Logística para o Estudo da Influência da Exposição Ocupacional (SANO e SANOAJ) e do Tabagismo (AM e Grupos) sobre o Sintoma Catarro $(n=280)$.

\begin{tabular}{|c|c|c|c|c|}
\hline VARIÁVEL & INTERVALO & COEFICIENTE & ERRO PADRÃO & $p$ \\
\hline Constante & & $-1,03$ & 0,171 & \\
\hline SANO & $4-30$ & -- & -- & -- \\
\hline SANOAJ & $5-86$ & -- & -- & -- \\
\hline $\mathrm{AM}$ & $0-70$ & -- & -- & -- \\
\hline Tabagismo & $\begin{array}{l}(1) \\
(2)\end{array}$ & $\begin{array}{r}-0,360 \\
0,964\end{array}$ & $\begin{array}{l}0,253 \\
0,193\end{array}$ & 0,0000 \\
\hline
\end{tabular}


TABELA 3.18: Modelo de Regressão Logística para o Estudo da Influência da Exposição Ocupacional (SANO e SANOAJ) e do Tabagismo (AM e Grupos) sobre o Sintoma Dispnéia $(n=280)$.

\begin{tabular}{lcccc}
\hline VARIAVEL & INTERVALO & COEFICIENTE & ERRO PADRÃ & $p$ \\
Constante & & $-3,43$ & 0,499 \\
SANO & $4-30$ & - & - & - \\
SANOAJ & $5-86$ & 0,037 & 0,012 & 0,0011 \\
AM & $0-70$ & - & - & -- \\
Tabagismo & $(1)$ & - & - & --
\end{tabular}

TABELA 3.19: Modelo de Regressão Logística para o Estudo da Influência da Exposição Ocupacional (SANO e SANOAJ) e do Tabagismo (AM e Grupos) sobre o Sintoma Chiado $(\mathrm{n}=280)$.

\begin{tabular}{|c|c|c|c|c|}
\hline VARIÁVEL & INTERVALO & COEFICIENTE & ERRO PADRÃO & $p$ \\
\hline Constante & & $-1,80$ & 0,328 & \\
\hline SANO & $4-30$ & -- & -- & -- \\
\hline SANOAJ & $5-86$ & 0,017 & 0,009 & 0,0454 \\
\hline$A M$ & $0-70$ & -- & -- & -- \\
\hline Tabagismo & $\begin{array}{l}(1) \\
(2)\end{array}$ & -- & -- & -- \\
\hline
\end{tabular}

Para os sintomas tosse e catarro, o tabagismo associou-se significativamente com a probabilidade de um registro positivo. A exposição ocupacional ajustada (SANOAJ) associou-se significativamente com a probabilidade de um registro positivo de dispnéia e de chiado. A variável AM foi de significância marginal em relação ao chiado ( $p=0,1060)$, não tendo sido incluida na equação por este motivo.

Estas mesmas análises foram efetuadas para a presença de BC. Os resultados estão na TABELA 3.20 . 
TABELA 3.20: Modelo de Regressão Logística para o Estudo da Influência da Exposição Ocupacional (SANO e SANOAJ) e do Tabagismo (AM e Grupos) sobre o Sintoma Bronquite Crônica $(n=280)$.

\begin{tabular}{lcccr}
\hline VARIAVEL & INTERVALO & COEFICIENTE & ERRO PADRÃO \\
\hline Constante & & $-1,53$ & 0,208 \\
SANO & $4-30$ & - & - & - \\
SANOAJ & $5-86$ & - & - & - \\
AM & $0-70$ & - & - & - \\
Tabagismo & $(1)$ & $-0,342$ & 0,302 & 0,0000 \\
& $(2)$ & 1,110 & 0,228 & -
\end{tabular}

Os resultados mostram efeitos semelhantes aos sintomas tosse e catarro, com os grupos de tabagismo associando-se significativamente com a Bronquite Crônica.

Para se analisar um possível efeito sinérgico ou aditivo do fumo e da exposição, em relação aos sintomas e à presença de $\mathrm{BC}$, ajustaram-se às mesmas equações das TABELAS 3.16 a 3.20 as variáveis SANO X AM e SANOAJ X AM, ou SANO + AM e SANOAJ + AM. A adiçāo destes efeitos combinados não alterou os resultados obtidos acima, e, portanto, eles não serão incluídos no texto.

Concluindo, calculou-se a prevalência de sintomas por grupos de tabagismo, estratificada pela variável SANOAJ, tendo como ponto de corte a mediana das observações (SANOAJ $=30$ ) em Mais Expostos, SANOAJ > 30 e Menos Expostos, SANOAJ $<=30$. Na TABELA 3.21 são observadas as razōes de prevalência (PR) dos sintomas dos Fumantes e Ex-Fumantes para os Não Fumantes nos dois grupos de exposiçāo. 
TABELA 3.21: Porcentagem de Sintomas Respiratórios em Mineiros de Subsolo, Estratificados por Exposição e Tabagismo, Razões de Prevalência e Intervalos de Confiança

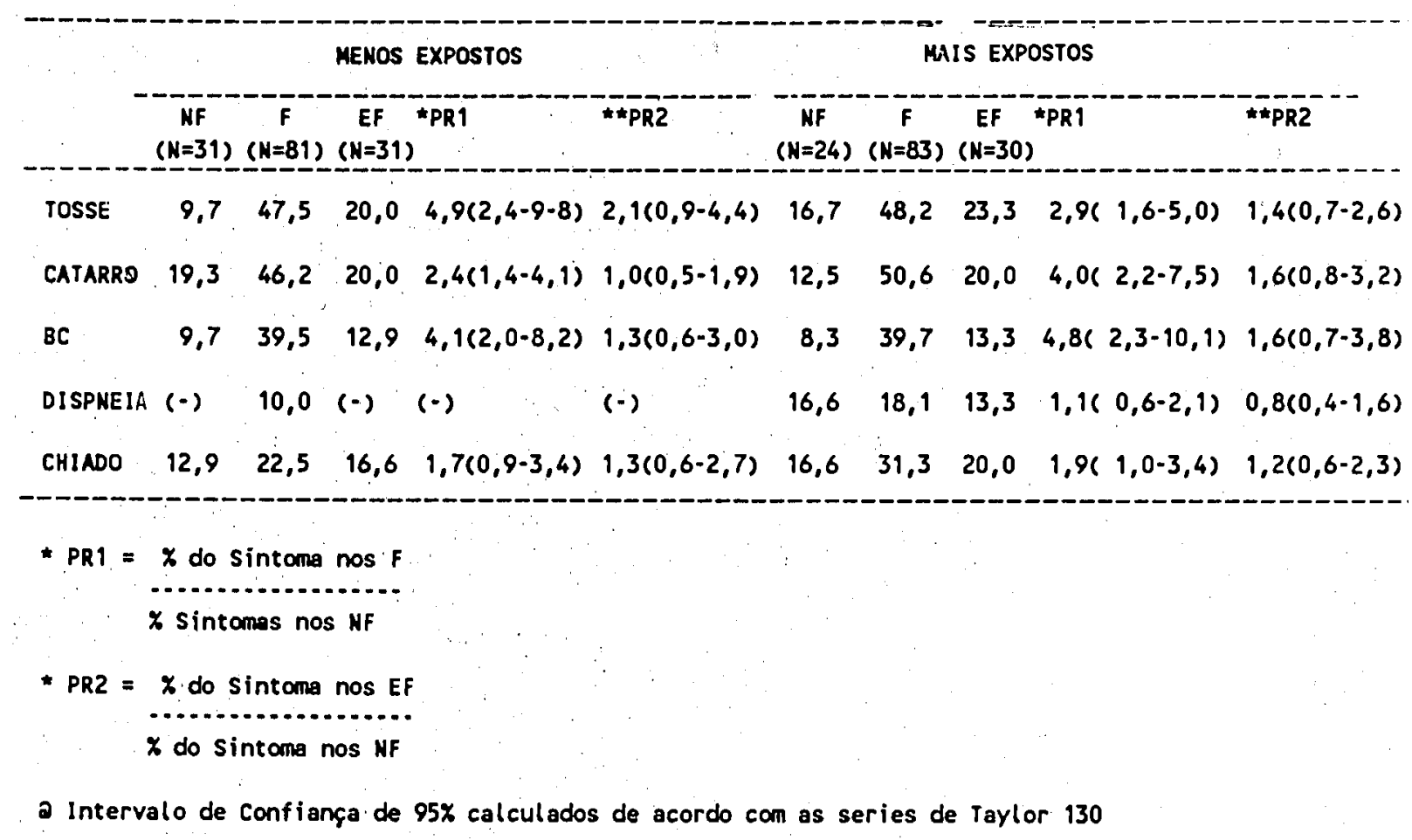

A TABELA 3.21 mostra que em relação aos sintomas respiratórios $\epsilon$ à $\mathrm{BC}$, os EF comportam-se similarmente aos NF, isto é, aparentemente há uma reversibilidade nos sintomas após a cessação do tabagismo. Mineiros fumantes tem razões de prevalência significativamente maiores do que os não fumantes de tosse, catarro e $\mathrm{BC}$. Além disso, mineiros fumantes mais expostos apresentam a razão de prevalência de chiado significativamente maior do que os NF. 


\subsubsection{Reatividade Brônquica, Exposições de Risco e Sintomas Respiratórios}

Em 1989, 268 mineiros da coorte completaram satisfatóriamente um teste de PB com carbacol. Os detalhes técnicos encontram-se em MÉTODOS. Aqui interessam as relações entre a reatividade brônquica, os sintomas respiratórios e as exposições de risco, para o cálculo das razões de prevalência (PR). Outros aspectos serão analisados mais adiante. As relações entre $\mathrm{PB}$, exposição ocupacional e tabagismo são mostradas nas TABELAS 3.22 e 3.23 .

TABELA 3.22: Associação entre Provocação Brônquica,SANO, e SANOAJ

PB
Pegativa
Posiva

TABELA 3.23: Associação entre Provocação Brônquica e Tabagismo.

\begin{tabular}{|c|c|c|c|c|}
\hline & $\mathrm{NF}$ & $\mathrm{F}$ & $\mathrm{EF}$ & TOTAL \\
\hline Positiva & 12 & 29 & 8 & 49 \\
\hline \multicolumn{5}{|l|}{$\mathrm{PB}$} \\
\hline Negativa & 41 & 127 & 51 & 219 \\
\hline TOTAL & 53 & 156 & 59 & 268 \\
\hline
\end{tabular}


A TABELA 3.22 mostra que os índices de exposição ocupacional não estavam associados com a resposta à $\mathrm{PB}$. Mais interessante é a independência entre os grupos de tabagismo e a PB: De fato, $22,6 \%$ nos NF foram positivos, comparativamente a $18,6 \%$ dos $F$ e $13,6 \%$ dos EF (TABELA 3.23).

As relaçōes entre a $\mathrm{PB}$ e os sintomas respiratórios estão na TABELA 3.24. Estudaram-se as razões de prevalência da $\mathrm{PB}$ em grupos sintomáticos, mutuamente exclusivos, definidos na seção de METODOS, estratificados pelos grupos de tabagismo. Observou-se que mineiros assintomáticos não diferiram quanto à resposta à $\mathrm{PB}$ nos diferentes grupos de tabagismo. Mineiros bronquíticos não fumantes apresentaram uma razão de prevalência significativamente maior de PB positivas. Mineiros chiadores apresentaram, independentemente do grupo de tabagismo, razōes de prevalência significativamente maiores de $\mathrm{PB}$ positivas.

TABELA 3.24: Grupos Sintomáticos em Mineiros de Subsolo, Estratificados por Tabagismo e Provocação Brônquica, Razōes de Prevalência e Intervalos de Confiança@

\begin{tabular}{|c|c|c|c|c|c|c|c|c|}
\hline & \multicolumn{3}{|c|}{ NF } & \multicolumn{3}{|c|}{$\mathbf{F}$} & \multicolumn{2}{|r|}{$E F$} \\
\hline & $\begin{array}{c}\mathrm{PB}+ \\
(n=12)\end{array}$ & $\begin{array}{l}\text { PB- } \\
(n=41)\end{array}$ & $P R^{\star}$ & $\begin{array}{c}P B+ \\
(n=29)\end{array}$ & $\begin{array}{l}\text { PB- } \\
(n=27)\end{array}$ & $P R^{*}$ & $\begin{array}{c}P B+ \\
(n=8)\end{array}$ & $\begin{array}{l}P B- \\
(n=51)\end{array}$ \\
\hline $\begin{array}{l}\text { ASSINTOMATICOS } \\
(N=154)\end{array}$ & 33,3 & 85,3 & $0,4(0,3-0,6)$ & 34,5 & 49,6 & $0,7(0,4=1,1)$ & 50,0 & $74,50,7(0,5-1,0)$ \\
\hline $\begin{array}{l}\text { BRONQUITICOS } \\
(N=43)\end{array}$ & 16,7 & 4,9 & $3,4(1,2-9,3)$ & 13,8 & 26,0 & $0,5(0,3-1,0)$ & $(-)$ & $3,9(-)$ \\
\hline $\begin{array}{l}\text { CHIADORES } \\
(N=60)\end{array}$ & 41,7 & 7,3 & $5,7(2,6-12,5$ & 51,7 & 19,7 & $2,6(1,6-4,4)$ & 50,0 & $15,73,2(1,8-5,6)$ \\
\hline $\begin{array}{l}\text { DISPNEICOS } \\
(N=11)\end{array}$ & 8,3 & 2,4 & $3,5(0,8-14,5$ & $(-)$ & 4,7 & $(-)$ & $(-)$ & $5,9(-)$ \\
\hline
\end{tabular}

$\quad P R=x \operatorname{com} P B+$
$x \operatorname{com} P B$

a Intervalos de Confiança de $95 \%$ calculados de acordo com as series de Taylor 130 


\subsubsection{Qcorrência de Asma Brônquica}

As TABELAS 3.1 e 3.2 mostram que o chiado foi o único sintoma a mostrar uma evolução significante durante os 5 anos de observação. $O$ diagnóstico de Asma Brônquica aqui utilizado é baseado nas respostas às questōes 5.2 e 5.6 e/ou 5.8 (1989), calcado na presença de episódios de chiado com dispnéia, com fatores desencadeantes extrínsecos observados. Este critério é subjetivo, pois, como já mencionado anteriormente, exclui os casos de crises sem fatores desencadeantes nítidos, o que acontece com frequência em pacientes asmáticos. Apesar disto, optou-se por este critério, por não se tratar de um diagnóstico clínico, e sim epidemiológico, na presente investigaçāo. Dos 64 casos com menção de episódios de chiado, 51 referiram desencadeamento por exposições na mineração ou ambientais. Todos estes últimos referiram também desencadeamento por fatores presentes na mineração. A TABELA 3.25 mostra as relaçōes entre os mineiros com mençāo de episódios de chiado, $\mathrm{PB}$, e início dos sintomas anteriores ou posteriores ao trabalho em mina de subsolo.

TABELA 3.25. Relações entre a Presença de Episódios de Chiado e Dispnéia, Broncoprovocação e Início dos Sintomas.

* Antes
*Após

Notou-se que $46 / 64(71,9 \%)$ mineiros começaram a apresentar sintomas após a entrada na mineração e 26/64 (40,6\%) apresentavam PB positiva. 
Assumindo, conforme o critério, que $51(18,2 \%)$ eram casos efetivos de Asma Brônquica, prosseguiu-se a análise no sentido de detectar casos de Asma Ocupacional. Os 51 casos foram restritos aos 46 que apresentavam o início dos sintomas após a experiência ocupacional em minas de carvão de subsolo, aliados a uma referência de melhọa clínica ou nāo com o afastamento do trabalho (questão 5.7, 1989). A TABELA 3.26 resume os achados.

TABELA 3.26: Relações entre a Presença de Episódios de Chiado com Dispnéia, Broncoprovocação e Efeito do Afastamento sobre os Sintomas.

\begin{tabular}{|c|c|c|c|}
\hline  & $\begin{array}{c}\text { CHIADO } \\
\text { Sem Fatores } \\
\text { Desencadeantes }\end{array}$ & $\begin{array}{l}\text { DISPNEIA } \\
\text { Com Fatores } \\
\text { Desencadeantes }\end{array}$ & TOTAL \\
\hline \multicolumn{4}{|l|}{ PB Positiva } \\
\hline Melhora com Afastamento & - & 15 & 15 \\
\hline $\begin{array}{l}\text { Não Melhora } \\
\text { PB Negativa }\end{array}$ & 2 & 5 & 7 \\
\hline Melhora com Afastamento & - & 19 & 19 \\
\hline Não Melhora & 4 & 1 & 5 \\
\hline TOTAL & 6 & 40 & 46 \\
\hline
\end{tabular}

Portanto, 34 (12,1\% da coorte) mineiros apresen-taram sintomas ao questionário com características de asma ocupacional, episódios de chiado com dispnéia com fatores desencadeantes de início após a entrada em mineração de carvão, com melhora dos sintomas nos fins de semana ou nas férias. Destes 34 mineiros, 15 apresentavam $\mathrm{PB}$ positiva.

Os fatores desencadeantes mencionados foram 5: fumaça de explosivos $(44,8 \%)$, poeira $(34,5 \%)$, fumos de diesel $(10,3 \%)$, fumos de solda $(5,7 \%)$ e esforço físico $(4,6 \%)$. Estas porcentagens correspondem à soma de todas as menções individuais do questionário (questão 5.6 - 1989). 


\subsection{Radiologia}

\subsubsection{Prevalência de Pneumoconiose}

Em 1984, no estudo transversal original envolvendo 956 mineiros, foram interpretados 708 radiografias, mostrando uma prevalência pontual de pneumoconiose de $5,6 \%$, isto $\varepsilon$, mineiros com radiografias classificadas como $1 / 0$ ou mais. $\mathrm{Na}$ mesma amostra, $80(11,3 \%)$ mineiros tiveram as suas radiografias interpretadas como suspeitas, $0 / 1$, e os $588(83,1 \%)$ restantes foram considerados normais. Na coorte deste estudo, composta por 280 mineiros vindos do estudo original, os números são apresentados na TABELA 3.27.

TABELA 3.27: Prevaiencia ae Alteraçoes Kaaıoıgıcas na Coorte ae $\angle 80$ mıneıros em 1984 e 1989.

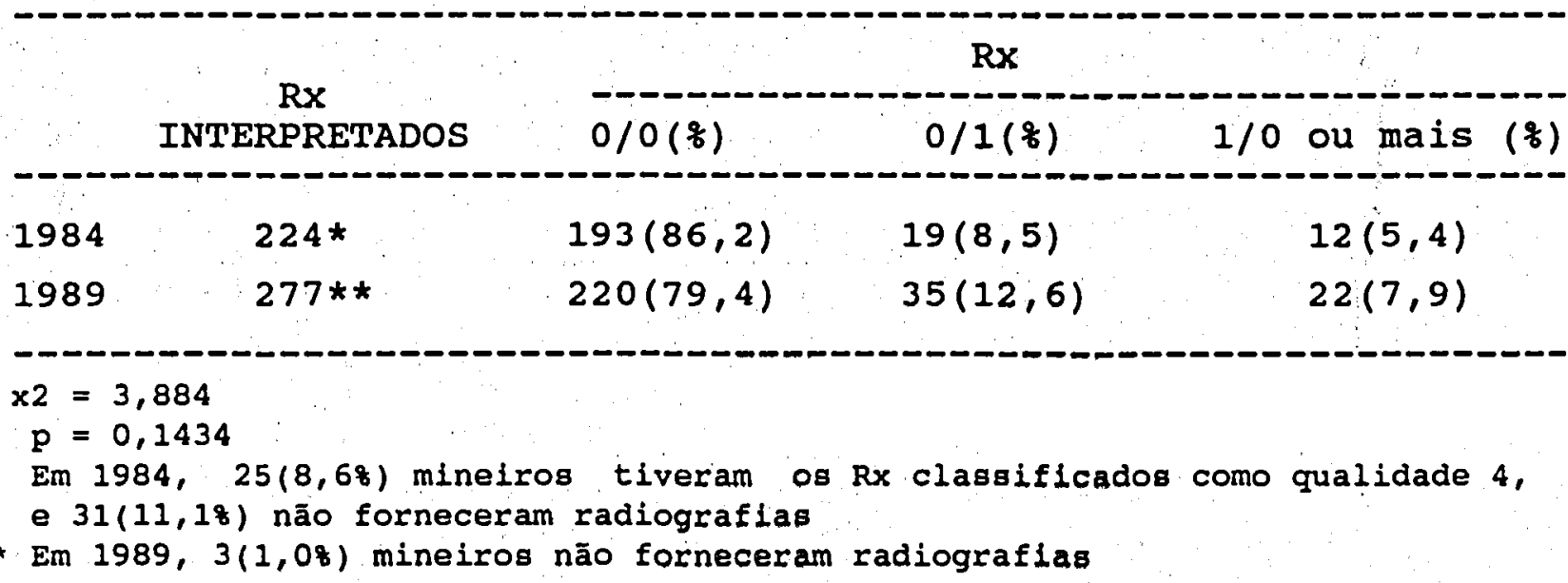

Comparando-se os dados de 1984 da TABELA 3.27 com os dados da amostra do estudo original ${ }^{4}$, não houve diferenças estatisticamente significantes entre as porcentagens de normais, suspeitos e pneumoconióticos $\left(x^{2}=1,494, p=0,4738\right)$. A análise da TABELA 3.27 mostra também que não houve diferença estatística entre os achados radiológicas de 1984 e de 1989 da coorte, embora haja uma tendência à evolução radiológica em 1989. 
As relações entre as alteraçōes radiológicas e a exposição a poeiras, medida através de análise de variância da SANO e SANOAJ, podem ser vistas na TABELA 3.28.

TABELA 3.28: Análises de Variância dos fndices de Exposição (SANO e SANOAJ) Relacionados às Leituras Radiológicas de 1984 e 1989.

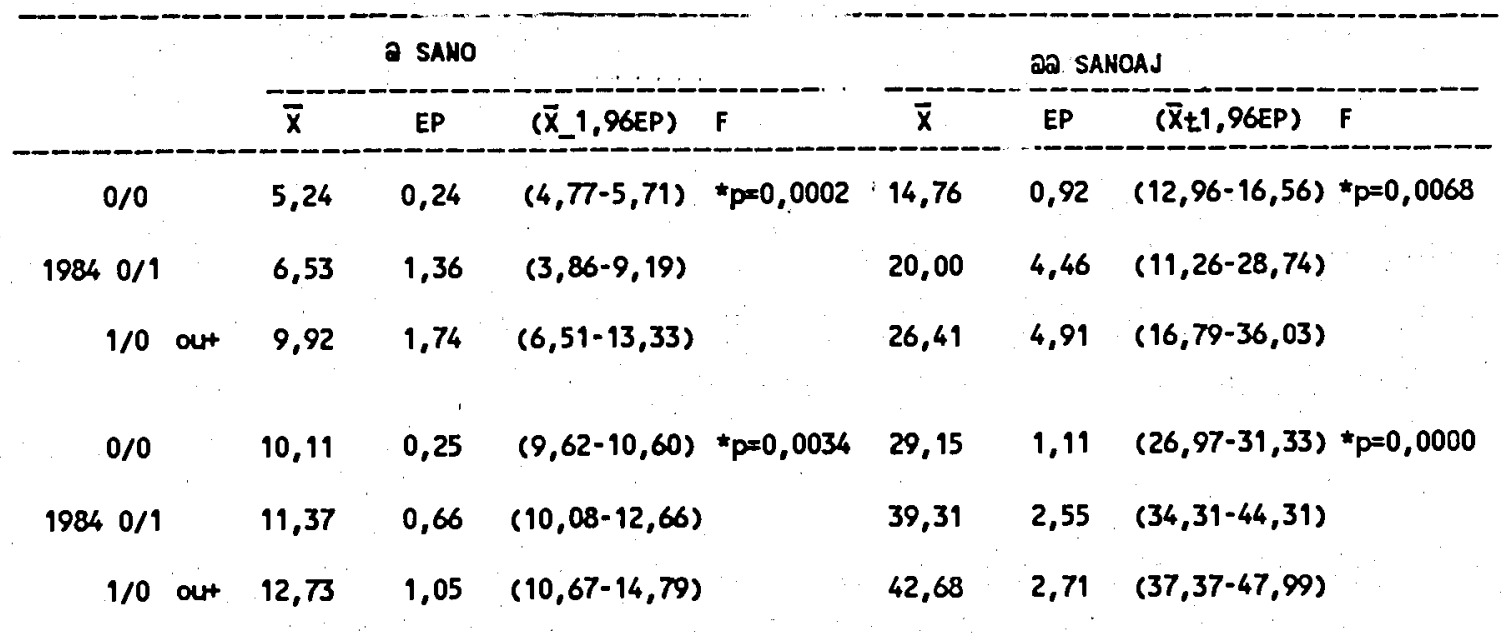

- P significante

a Em 1984 e 1989, medias do grupo $1 / 0$ significativanente maiores que do grupo $0 / 0$

2a Em 1984 medias do grupo 1/0 significativamente maiores do que do grupo 0/0 e em 1989, medias dos grupos $0 / 1$ e 1/0 significativamente maiores do que do grupo $0 / 0$

Ambas as variáveis de exposição, SANO e SANOAJ mostraram uma associação positiva significativa com subcategorias crescentes da classificação radiológica. Para estudar qual destes índices apresentou melhor ajuste em relação à presença ou ausência de pneumoconiose, eles foram colocados como variáveis independentes em um modelo de regressão logística, tendo como variável dependente a presença ou ausência de pneumoconiose. Para isto utilizaram-se dados de 1989 , por se possuir um maior número de observações, e também um maior número de casos de pneumoconiose. Os resultados estão na TABELA 3.29. 
TABELA 3.29: Modelo de Regressão Logística para o Estudo do Melhor Ajuste dos Indices de Exposição Relacionados à Pneumoconiose.

\begin{tabular}{lcccc}
\hline VARIÁVEL & INTERVALO & COEFICIENTE & ERRO PADRÃo & p \\
\hline Constante & - & $-3,920$ & 0,639 & - \\
SANO & $4-30$ & - & - & 0,0037 \\
SANOAJ & $5-86$ & 0,042 & 0,015 & 0.5
\end{tabular}

O SANOAJ mostrou-se um melhor índice para predição da probabilidade do diagnóstico de pneumoconiose ao Rx. Este resultado é um dado que aponta satisfatoriamente para o critério subjetivo adotado para o cálculo deste índice, uma vez que há uma clara relação dose-resposta entre exposição ocupacional em minas de carvão e pneumoconiose.

Uma das preocupações do estudo era que metade dos mineiros de carvão referia exposiçōes inalatórias em outras indústrias (dados retirados das questões 9.1 e 9.2 do questionário de 1989). Dos 280 mineiros, 130 (46,4\%) referiam outras exposições, notadamente em serrarias, cerâmicas, outros tipos de mineração, metalúrgicas e siderúrgicas. De maneira geral estas exposições adicionais foram de curta duração. A prevalência de pneumoconiose foi de $8,4 \%$ nos mineiros com exposições fora da mineração de carvão e $7,3 \%$ nos restantes $\left(x^{2}=0,022, p=0,8817\right)$. 


\subsubsection{Progressão Radiológica}

Para o estudo da progressão radiológica foram analisados 223 pares de $R x$ (mineiros que possuiam radiografias interpretadas em 1984 e 1989).

O período de $\supset$ anos entre os dois estudos é relativamente curto para a observação de uma progressão radiológica substancial na coorte, porém era de se esperar que ocorresse. Efetivamente, esta observaçāo é prontamente visualizada na TABELA 3.30.

TABELA 3.30: Progressāo Radiológica Entre 1984 e 1989 ( $n=223$ ).

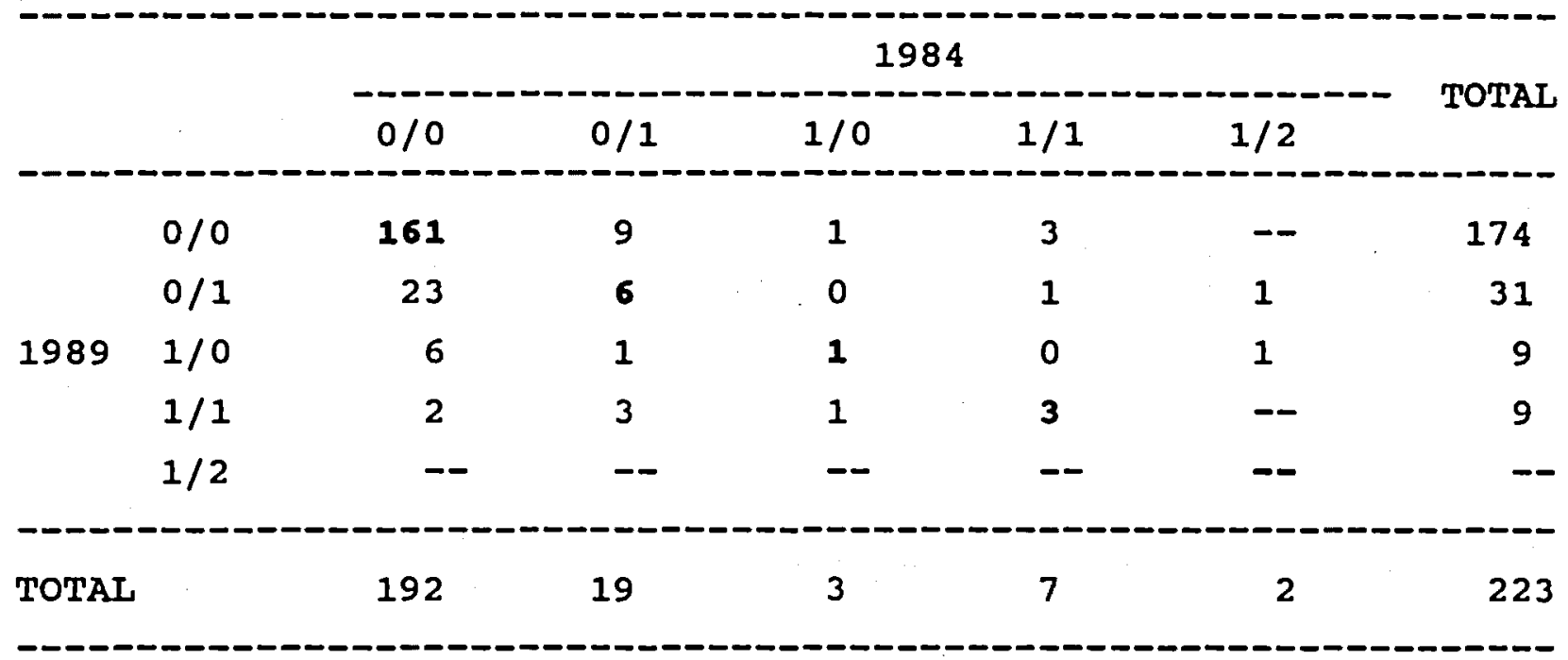

Abaixo da diagonal estão os casos de "progressão" radiológica em número de 36, acima da diagonal estão os casos de "regressāo" em número de 16, e ao longo da mesma encontram-se 171 mineiros radiológicamente estáveis. Referimo-nos à "progressão" e "regressão" entre aspas pois, na verdade, ambas podem dar-se dentro de uma mesma categoria de pneumoconiose. De fato, atentando-se para os casos de "progressão", dos 36 mineiros 23 passaram de normais à suspeitos (0/1) e 1 passou de $1 / 0$ para 1/1. Houve mudança de categoria em 12 mineiros que passaram de normais ou suspeitos para categoria 1 . Dentre os 16 "regressores", 9 passaram de suspeitos para normais e 1 passou de $1 / 2$ para $1 / 0$, sendo que 6 passaram de categoria 1 para normais ou suspeitos. Estes últimos são os casos temidos do ponto de vista legal e social, pois são 
mineiros "anormais" em 1984 que passaram a "normais" em 1989 dentro de uma escala subjetiva de classificação.

Retirando-se dos 223 casos da TABELA 3.30 os 12 mineiros diagnosticados como 1/0 ou mais em 1984, sobram 211 mineiros em risco dos quais 12 foram classificados como $1 / 0$ ou mais em 1989. Estes números são uma expressão da incidência de pneumoconiose no período de observação de 5 anos, isto é, 57/1.000 mineiros ativos, com uma média de 10 anos de exposição, desenvolveram pneumoconiose em 5 anos de observação.

Similarmente aos resultados da evolução dos sintomas respiratórios, algumas variáveis que poderiam influir na progressão radiológica foram analisadas. A associação dos índices de exposição SANO e SANOAJ, Tabagismo, $\mathrm{VEF}_{1}$ e o $\mathrm{DVEF}_{1}$ de 1989 com os grupos de regressão, estabilidade e progressão radiológica encontram-se nas TABELAS 3.31 e 3.32 .

TABELA 3.31: Análise de Variância dos Índices de Exposição (SANO e SANOAJ) do DVEF, e do VEF 1 AJ nos Grupos de Regressão, Progressão e Estabilidade Radiológicas.

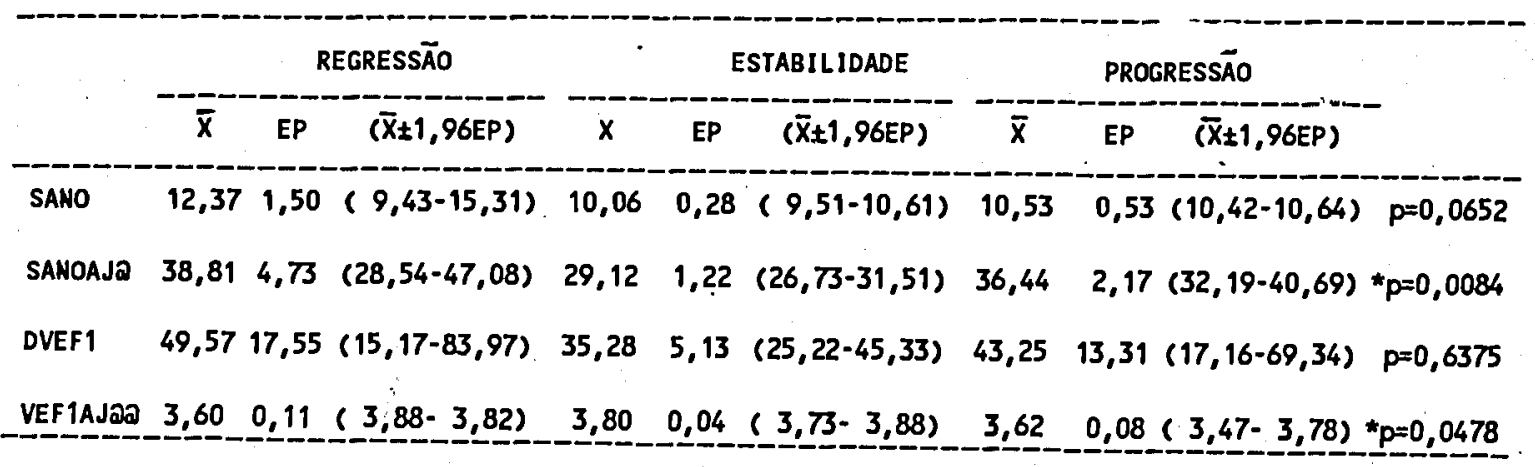

* $p$ significante

a Média do Grupo de Progressăo significativamente maior do que de Estabilidade

aa Média do Grupo de Estabilidade significativamente maior do que de Progressão 
TABELA 3.32: Tabela de Contingência do Tabagismo nos Grupos de Regressão, Progressão e Estabilidade Radiológica.

\begin{tabular}{lrrrr} 
& & & & \\
& TABAGISMO & & TOTAL \\
Regressão & 3 & FF & \\
Estabilidade & 41 & 91 & 39 & 161 \\
Progressão & 2 & 28 & 6 & 36 \\
\hline TOTAL & 46 & 128 & 49 & 223 \\
\hdashline$x^{2}=8,633$ & & & & \\
$\mathrm{p}=0,0709$ & & &
\end{tabular}

Os resultados das TABELAS 3.31 mostram que os progrediram apresentaram uma maior exposição ajustada que os estáveis e também um VEF, ajustado significativamente menor do que os estáveis. Houve uma tendência não significante de haver mais mineiros fumantes entre os que progrediram (TABELA 3.32). Eliminando-se a coluna dos ex-fumantes dos dados da TABELA 3.32, os fumantes apresentaram uma progressão radiológica significantemente maior que os não fumantes $\left(x^{2}=7,493, p=\right.$ 0,0236). Esta significância persiste mesmo juntando-se os grupos de fumantes e exfumantes, e comparando-se com os não fumantes $\left(x^{2}=6,201, p=0,0450\right)$

A evolução radiológica foi ainda analisada em um modelo de regressão logística, tendo como variável a progressão (assumindo o valor 1) e a estabilidade (assumindo o valor 0). Eliminou-se o grupo de regressão destas análises pela necessidade de se trabalhar com uma variável dependente dicotômica. Neste modelo incluiu-se como variáveis independentes a idade, os índices de exposiçāo e de tabagismo, os efeitos combinados da exposição e tabagismo, o $\mathrm{VEF}_{1}$ ajustado e o $\mathrm{DVEF}_{1}$. Os resultados estão na TABELA 3.33 . 
TABELA 3.33: Modelo de Regressão Logística para o Estudo das Variáveis Associadas a Progressão Radiológica $(n=207)$, Progressores $=1$ Estáveis $=0$.

\begin{tabular}{|c|c|c|c|c|}
\hline VARIÁVEL & INTERVALO & COEFICIENTE & ERRO PADRÃO & p \\
\hline Constante & & $-1,90$ & 1,810 & \\
\hline SANO & $4-30$ & -- & -- & -- \\
\hline SANOAJ & $5-68$ & 0,072 & 0,019 & 0,0000 \\
\hline $\mathrm{AM}$ & $0-37$ & 0,307 & 0,077 & 0,0000 \\
\hline Tabagismo & (1) & -- & -- & -- \\
\hline & (2) & -- & -- & -- \\
\hline SANO $X$ AM & $0-750$ & $-0,022$ & 0,006 & 0,0001 \\
\hline SANOAJ $X$ AM & $0-2368$ & -- & -- & -- \\
\hline VEF, $A J$ & $2,24-5,30$ & $-0,008$ & 0,004 & 0,0736 \\
\hline DVEF $_{q}$ & $-102-222,4$ & -- & -- & -- \\
\hline
\end{tabular}

Há uma significativa dependência da progressão à exposição ocupacional (SANOAJ) e tabagismo quantitativo (AM). O VEF, $A J$ mostrou uma relação inversa significativa, ou seja, quanto menor $0 \mathrm{VEF}_{1}$ maior a tendência à progressão radiológica. A combinação de efeitos da exposição ocupacional com o tabagismo (SANO X AM) mostra curiosamente um sinal negativo. À primeira inspeção tem-se a impressão de que há um efeito sinérgico negativo em relação à progressão radiológica, o que não teria qualquer plausibilidade biológica. Procedeu-se então a análises de modelos complementares, retirando algumas das variáveis e modificando a varíavel de efeitos combinados para somatória (SANO + AM), no sentido de melhor compreender o resultado. Os achados confirmaram a mesma estrutura de dependência das variáveis, mostrando que a componente que envolve a interação das duas variáveis é estatisticamente significante, e que representa apenas uma "dedução" ou "desconto" dos efeitos isolados da exposiçāo e do tabagismo, que já haviam sido computados nos coeficientes de AM e SANO (este último não aparece por não ter tido significância, $\mathrm{p}>0,100$ ). 


\subsubsection{Indice de Regularidade}

Conforme descrito em MÉTODOS, calculou-se um índice de regularidade (IR) para cada radiografia que tivesse menção de forma e tamanho em 1989. Portanto, das 277 radiografias interpretadas, 35 foram classificadas como $0 / 1$ e 22 como 1/0 ou mais, obtendo-se um total de 57 mençōes de forma e tamanho. Destas, 12 foram classificadas como índice 1 (regular, regular), 18 como índice 2 (regular, irregular), 14 como índice 3 (irregular, regular), e 13 como índice 4 (irregular, irregular). Estes índices foram relacionados com os sintomas respiratórios, tabagismo e índices funcionais. A razão destas análises é o fato que a presença de opacidades irregulares em exposições que causam fibrose nodular, frequentemente sāo associadas com a presença de outras patologias respiratórias, notadamente o enfisema pulmonar ${ }^{3,47}$. A TABELA 3.34 mostra os resultados obtidos para as variáveis categóricas, e a TABELA 3.35 mostra os resultados para as variáveis contínuas (índices funcionais).

TABELA 3.34: Qui-Quadrado e Probabilidade das Tabelas de Contingência do Índice de Regularidade (IR) com Sintomas Respiratórios e Tabagismo (Grupos).

IR

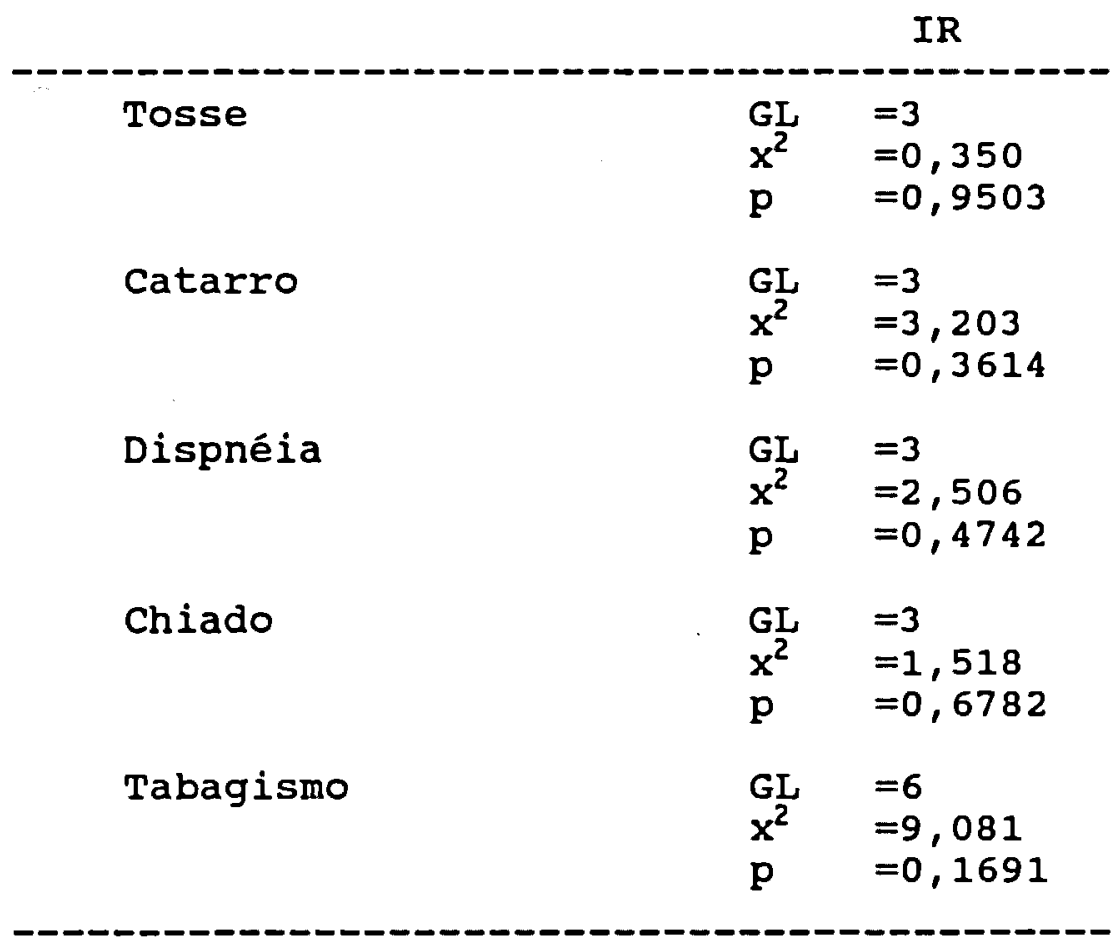


TABELA 3.35: Análise de Variância dos Indices Funcionais nos Grupos do f́ndice de Regularidade

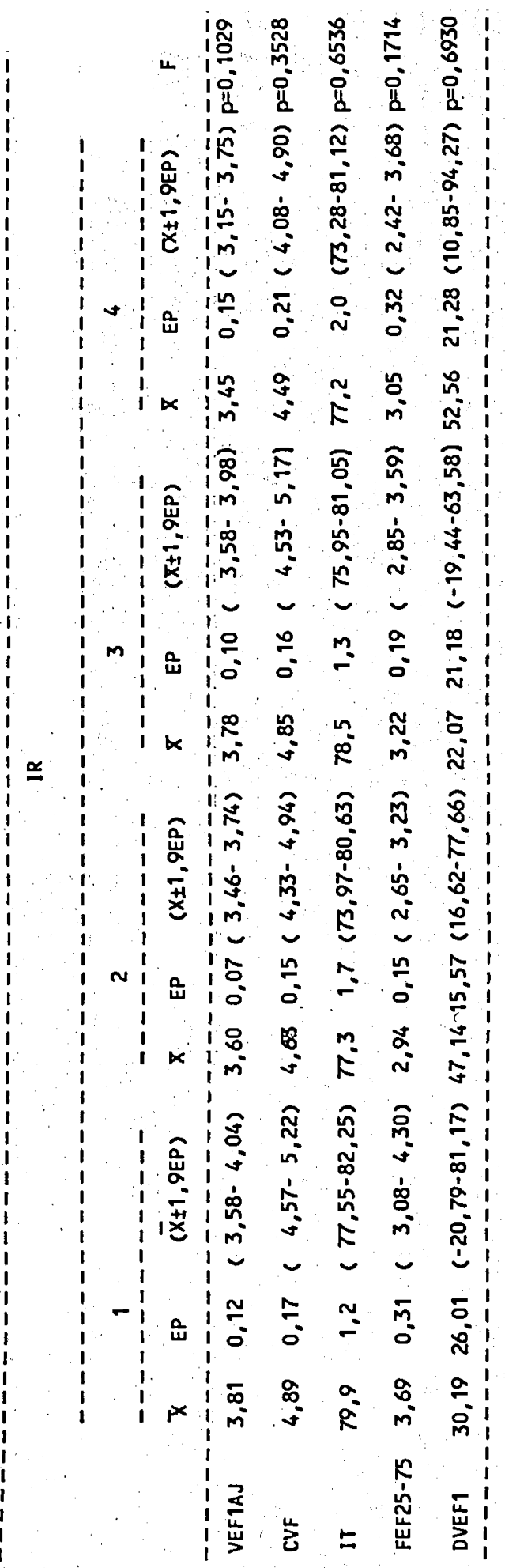


O IR nāo mostrou qualquer associação significante com sintomas respiratórios ou tabagismo, e as análises de variância dos índices funcionais respiratórios não foram significantes entre os diferentes IR. Porém é interessante notar que houve uma tendência de médias mais baixas do VEF, $A J, C V F, I T$, e $F_{25 F}$, maior do VEF1 (DVEF $)$ em mineiros com IR 4 comparados com IR 1.

\subsubsection{Diâmetro Traqueal}

$\mathrm{Na}$ investigação de 1989, o DT foi medido em 239 radiografias. A média do DT foi de $19,45 \pm 2,14 \mathrm{~mm}$ (13 !---! 26). Tomando-se a média do DT dividiu-se esta variável em 2 grupos: 126 mineiros com DT $<=19,45$ e 113 mineiros com $>19,45$ e relacionou-se com os sintomas respiratórios, profusão de pequenas opacidades e índices funcionais. A razão destas análises é que o DT, que é uma característica anatômica, pode influenciar na penetração e deposição de aerosóis em vias aéreas e parênquima pulmonar. Este fato poderia ter expressão através destas variáveis estudadas. As associaçōes do DT com as variáveis categóricas sintomas e profusão de pequenas opacidades (divididas por $0 / 0,0 / 1$ e $1 / 0$ ou mais) encontram-se na TABELA 3.36 e com os índices funcionais na TABELA 3.37.

TABELA 3.36: Qui Quadrado e Probabilidade das Tabelas de Contingência do Diâmetro Traqueal (DT) com Sintomas Respiratórios e Profusão de Pequenas Opacidades.

\begin{tabular}{|c|c|c|}
\hline \multicolumn{3}{|c|}{ DT } \\
\hline Tosse & $\begin{array}{l}\text { GL } \\
x^{2} \\
p\end{array}$ & $\begin{array}{l}=1 \\
=0,194 \\
=0,6600\end{array}$ \\
\hline Catarro & $\begin{array}{l}\mathrm{GL} \\
\mathrm{x}^{2} \\
\mathrm{p}\end{array}$ & $\begin{array}{l}=1 \\
=0,246 \\
=0,6196\end{array}$ \\
\hline$B C$ & $\begin{array}{l}\text { GL } \\
x^{2} \\
p\end{array}$ & $\begin{array}{l}=1 \\
=0,052 \\
=0,8193\end{array}$ \\
\hline Dispnéia & $\begin{array}{l}\text { GL } \\
x^{2} \\
p\end{array}$ & $\begin{array}{l}=1 \\
=2,947 \\
=0,0860\end{array}$ \\
\hline Chiado & $\begin{array}{l}\mathrm{GL} \\
\mathrm{x}^{2} \\
\mathrm{p}\end{array}$ & $\begin{array}{l}=1 \\
=0,396 \\
=0,5291\end{array}$ \\
\hline Profusão & $\begin{array}{l}\text { GL } \\
x^{2} \\
p\end{array}$ & $\begin{array}{l}=2 \\
=1,292 \\
=0,5242\end{array}$ \\
\hline
\end{tabular}


TABELA 3.37: Análise de Variância dos Índices Funcionais nos Grupos de Diâmetro Traqueal.

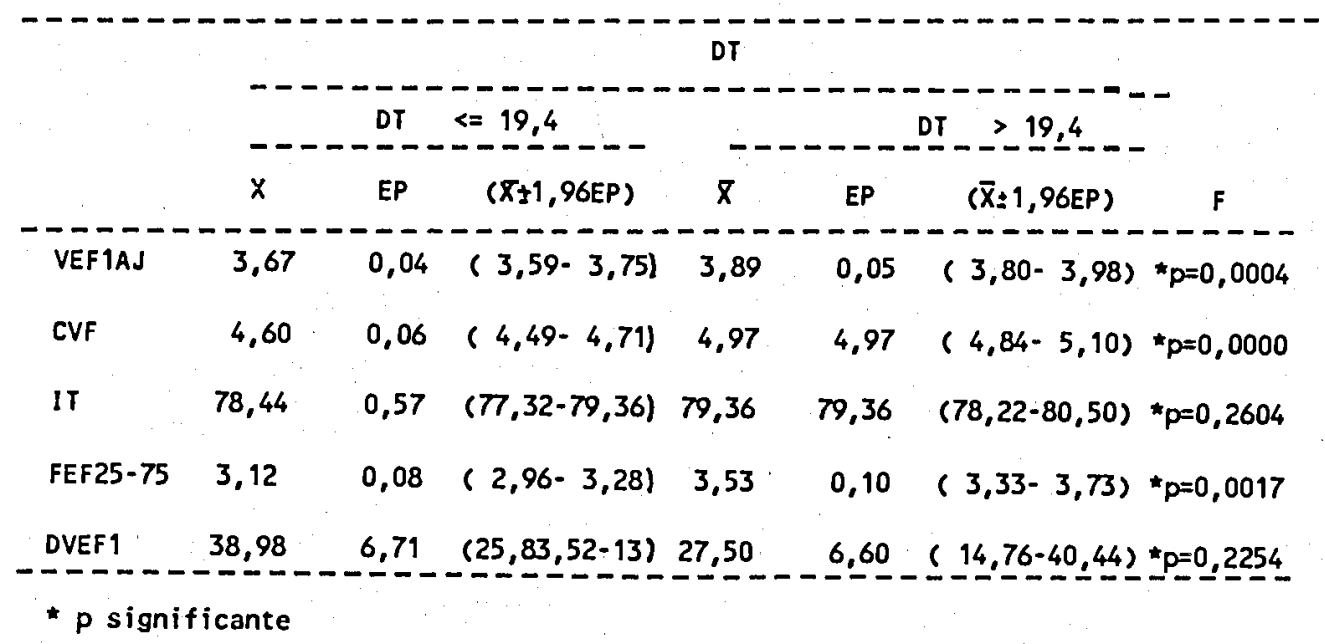

Não houve associação entre mineiros com traquéias menores e maiores e sintomas respiratórios ou prevalência de pneumoconiose. O IT também não mostrou diferenças significantes. A queda anual do $\mathrm{VEF}_{1}$ foi maior em mineiros com DT menor, entretanto não houve diferença estatística significante. $O V E F_{1} A J, a C V F$, e o $\mathrm{FEF}_{25-75}$ foram significativamente maiores em mineiros com DT maior.

\subsubsection{Fatores Associados à Presença de Pneumoconiose}

No estudo de 1989, que gerou a presente coorte, foram analisados diversos fatores associados à presença de pneumoconiose através de regressão por probitos. Houve uma significativa associação da SANO, Dispnéia, VEF, (correlação negativa) e do IT (correlação positiva) ${ }^{4}$. Na presente coorte procedemos a uma análise relativamente similar nos 277 mineiros com radiografias interpretadas em 1989.

A associação entre os índices de exposição e a profusão de pequenos opacidades em 1989 já foi analisada na TABELA 3.28. Os sintomas respiratórios, tosse, catarro, dispnéia e chiado, colocados como presentes ou ausentes, não se associaram significativamente com a presença ou ausência de pneumoconiose ao $\mathrm{Rx}$ em tabelas $2 \times 2$ (Tosse: $\mathrm{x}^{2}=0,087 \mathrm{p}=0,7677$; Catarro: $\mathrm{x}^{2}=0,049 \mathrm{p}=0,8252$; Dispnéia: $\mathrm{x}^{2}=0,001 \mathrm{p}=$ 0,9770; Chiado: $x^{2}=1,624 p=0,2026$ ). As médias dos índices funcionais, $\mathrm{VEF}_{1}, \mathrm{VEF}_{1} \mathrm{AJ}$, $\mathrm{CVF}$, IT e $\mathrm{FEF}_{25-75}$ também não diferiram em análises de variância nos grupos de normais $(0 / 0)$, suspeitos (0/1) e pneumoconióticos (1/0 ou mais). 
Para se estudar os efeitos conjuntos destas variáveis e o Tabagismo, utilizou-se o modelo de regressão logística. Tendo como variável dependente a presença (1/0 ou mais) ou ausência (categoria 0 ) de pneumoconiose ao $\mathbf{R x}$, inicialmente procedeuse a um ajuste dos índices de exposição (SANO e SANOAJ), Tabagismo (AM e Grupos), efeitos combinados de exposição e fumo (SANO X AM e SANOAJ X AM), sintomas respiratórios, VEF,AJ, IT, e Idade. Após eliminar-se uma série de variáveis, que não apresentavam significância, chegou-se ao modelo apresentado na TABELA 3.38. Observese que a variável SANOAJ foi dividida em faixas. A SANO foi eliminada devida à sua colinearidade com SANOAJ.

TABELA 3.38: Modelo de Regressão Logística para o Estudo de Variáveis Associadas à Pneumoconiose.

$\begin{array}{lcccc}\text { VARIÁVEL } & \text { INTERVALO } & \text { COEFICIENTE } & \text { ERRO PADRÃO } \\ \text { Constante } & (1) & -2,74 & 0,299 \\ \text { SANOAJ } & (2) & 1,32 & 0,342 & 0,0001 \\ \text { Idade } & 26-50 & -0,282 & 0,399 & - \\ \text { Tabagismo } & (1) & - & -- & - \\ \text { VEF,AJ } & (2) & - & - & - \\ \text { IT } & 2,24-5,49 & - & - & - \\ \end{array}$

* sanoaj está dividida em 3 faixas: $0-20,21-40$ e 41 ou mais

Os resultados acima mostram que o efeito da exposição, medida pela SANOAJ, é a única variável significativamente associada com a presença de pneumoconiose. A Idade, pela alta colinearidade com SANOAJ, perdeu sua significância após a inclusão desta no modelo. O que é visto na TABELA 3.38 confirma os achados isolados já anteriormente mencionados.

A probabilidade do evento "pneumoconiose" pode ser derivada graficamente do modelo logístico da TABELA 3.38, através da equaçāo descrita no item 
2.7 de MÉTODOS. Os coeficientes (1) e (2) da SANOAJ deverão ser multiplicados pelos seguintes fatores:

$\begin{array}{lcc}0-20 & -1 & -1 \\ 21-40 & 0 & 1 \\ 41-+ & 1 & 0\end{array}$

A FIGURA 3.1 mostra os resultados.

FIGURA 3.1: Probabilidade de Pneumoconiose por Faixas de Exposição Ajustada.






\subsection{Função Pulmonar}

\subsubsection{Dados Descritivos dos Parâmetros Funcionais}

Os parâmetros funcionais foram obtidos em espirometros secos de fole, conforme a descriçāo em MÉTODOS, e os dados volumétricos corrigidos para BTPS. Os dados médios de 1984 (VEF, CVF, IT) e os de 1989 ((VEF, CVF, IT e $\mathrm{FEF}_{25-75}$ ) encontram-se na TABELA 3.1, juntamente com o DVEF ${ }_{1}$. As FIGURAS 3.2 e 3.3 mostram o $\mathrm{VEF}_{1}$ médio por faixas etárias. As TABELAS 3.39 e 3.40 mostram os dados de forma tabular para a CVF,IT e o $\mathrm{FEF}_{25-75}$.

TABELA 3.39: CVF (em litros) e IT Médios por Faixas Etárias e Desvios Padrāo (DP), 1984.

\begin{tabular}{|c|c|c|c|c|}
\hline FAIXA ETÁRIA & $\mathrm{CVF}$ & (DP) & IT & (DP) \\
\hline 21 a $25 \quad(n=55)$ & 4,86 & $(0,68)$ & 0,87 & $(0,06)$ \\
\hline 26 a $30 \quad(n=101)$ & 4,70 & $(0,82)$ & 0,84 & $(0 ; 06)$ \\
\hline $31135 \quad(n=75)$ & 4,72 & $(0,63)$ & 0,82 & $(0,08)$ \\
\hline 36. a $40 \quad(n=43)$ & 4,56 & $(0,60)$ & 0,82 & $(0,07)$ \\
\hline 41 ou $+(n=6)$ & 4,43 & $(0,40)$ & 0,83 & $(0,03)$ \\
\hline
\end{tabular}

TABELA 3.40: CVF (em litros), IT e $\mathrm{FEF}_{25-75}$ (em litros por segundo) Médios por Faixas Etárias e Desvios Padräo (DP), 1989.

\begin{tabular}{|c|c|c|c|c|c|c|}
\hline FAIXA ETÁRIA & CVF & $(D P)$ & IT & (DP) & $\mathrm{FEF}_{25-75}$ & (DP) \\
\hline 26 a $30 \quad(n=60)$ & 5,03 & $(0,67)$ & 0,80 & $(0,06)$ & 3,66 & $(1,03)$ \\
\hline 31 a $35 \quad(n=100)$ & 4,76 & $(0,77)$ & 0,79 & $(0,06)$ & 3,37 & $(0,99)$ \\
\hline 36 a $40 \quad(n=77)$ & 4,78 & $(0,61)$ & 0,78 & $(0,05)$ & 3,14 & $(0,88)$ \\
\hline 41 a $45 \quad(n=34)$ & 4,52 & $(0,64)$ & 0,78 & $(0,08)$ & 2,95 & $(1,04)$ \\
\hline 45 ou $+(n=9)$ & 4,50 & $(0,50)$ & 0,77 & $(0,07)$ & 2,97 & $(1,01)$ \\
\hline
\end{tabular}


FICIIRA 3.2: VFF. Médio por Faixas Etárias - 1984.




FIGURA 3.3: VEF1 Médio por Faixas Etárias - 1989.

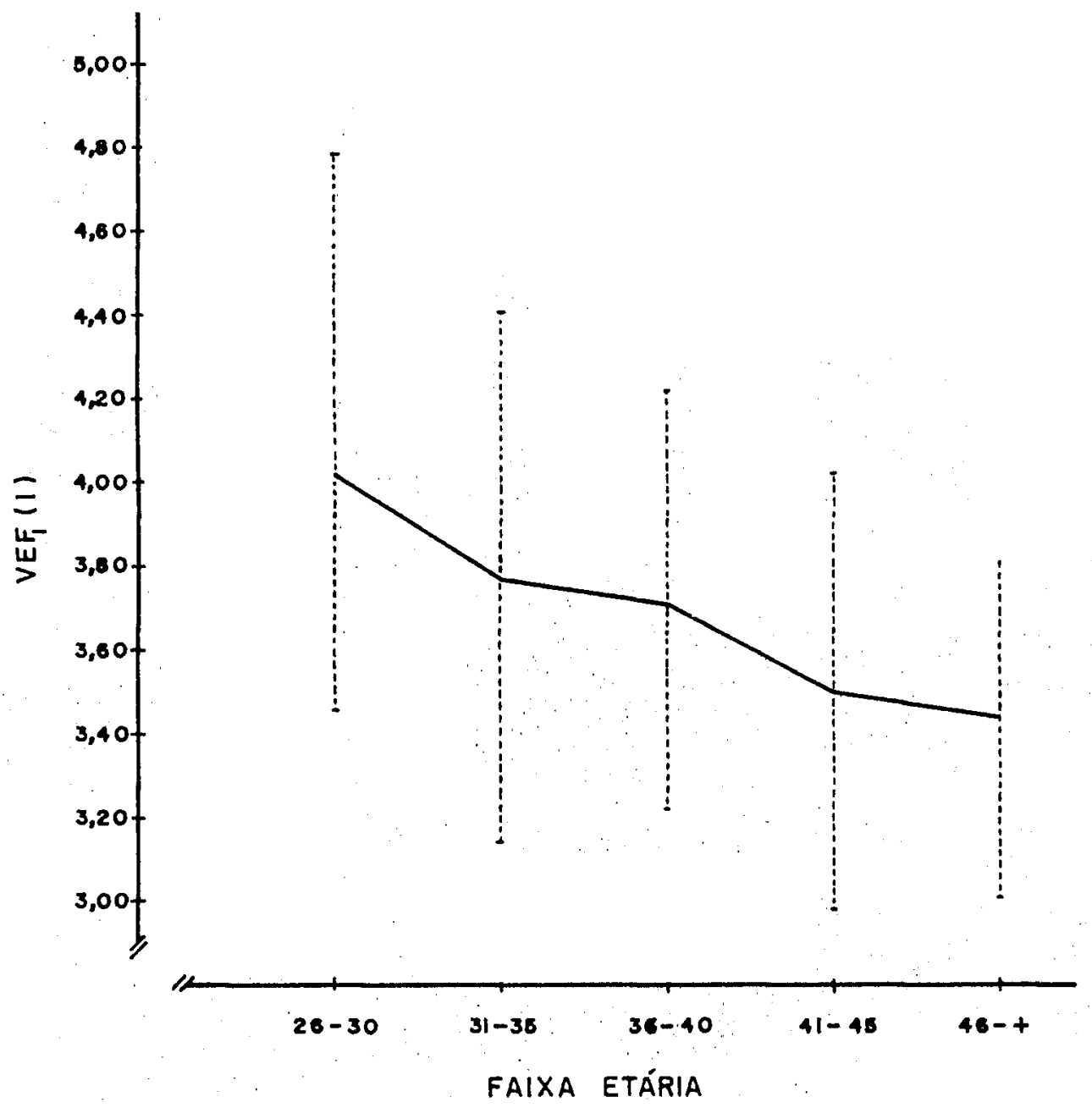


Os parâmetros funcionais mostram uma queda paulatina com a idade E interessante notar que a CVF média de 1989 e superior a de 1984 (TABELA 3.1). Estє achado será discutido mais adiante.

Os dados de 1984 e 1989 para o VEF, e o CVF foram colocados en um modelo de regressão linear múltipla como variáveis dependentes, tendo como variávei independentes a altura e a idade, para a obtenção das equações de regressão da coorte. $O$ ؛ resultados estão na TABELA 3.41.

TABELA 3.41. Modelo de Regressão Linear Múltipla para o VEF, e a CVF, 1984 e 1989

$$
(\mathrm{n}=280)
$$

$\begin{array}{lllll} & & \text { COEFICIENTES } & \\ & \text { CONSTANTE } & \text { Altura (m) } & \text { Idade (anos) } & \\ 1984 & & & & \\ \mathrm{VEF}_{1} & -2,7085 & 4,4031 & -0,0265 & 0,504 \\ \mathrm{CVF} & -4,7850 & 5,8799 & 0,0146 & 0,518\end{array}$

$\underline{1989}$

\begin{tabular}{lrrrr}
$\mathrm{VEF}_{1}$ & $-3,3190$ & 4,7499 & $-0,0274$ & 0,495 \\
$\mathrm{CVF}$ & $-5,8879$ & 6,7602 & $-0,0220$ & 0,535 \\
\hline
\end{tabular}

As equaçōes obtidas em 1984 e 1989 podem ser vistas graficamente nas FIGURAS 3.4 e 3.5, comparando-as com equaçōes de uso habitual no nosso meio, como as de KNUDSON e col. ${ }^{131}$, CRAPO e col. $^{57}$ e MORRIS e col. ${ }^{175}$. 
FIGURA 3.4: Equações de Regressão para o $\mathrm{VEF}_{1}$ (Altura fixada em 1,70 m).

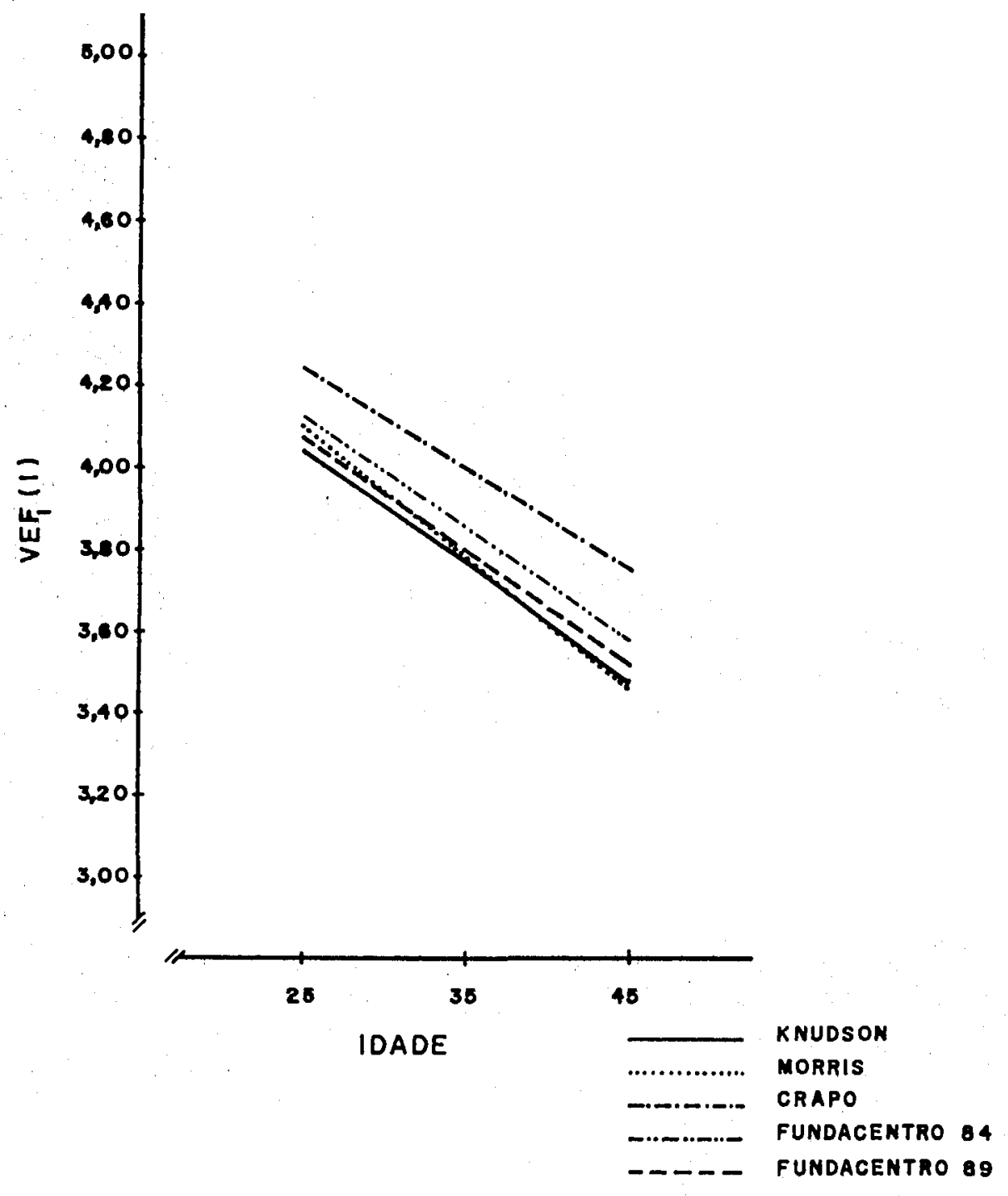


FIGURA 3.5: Equações de Regressão para o CVF (Altura fixada de 1,70 m).

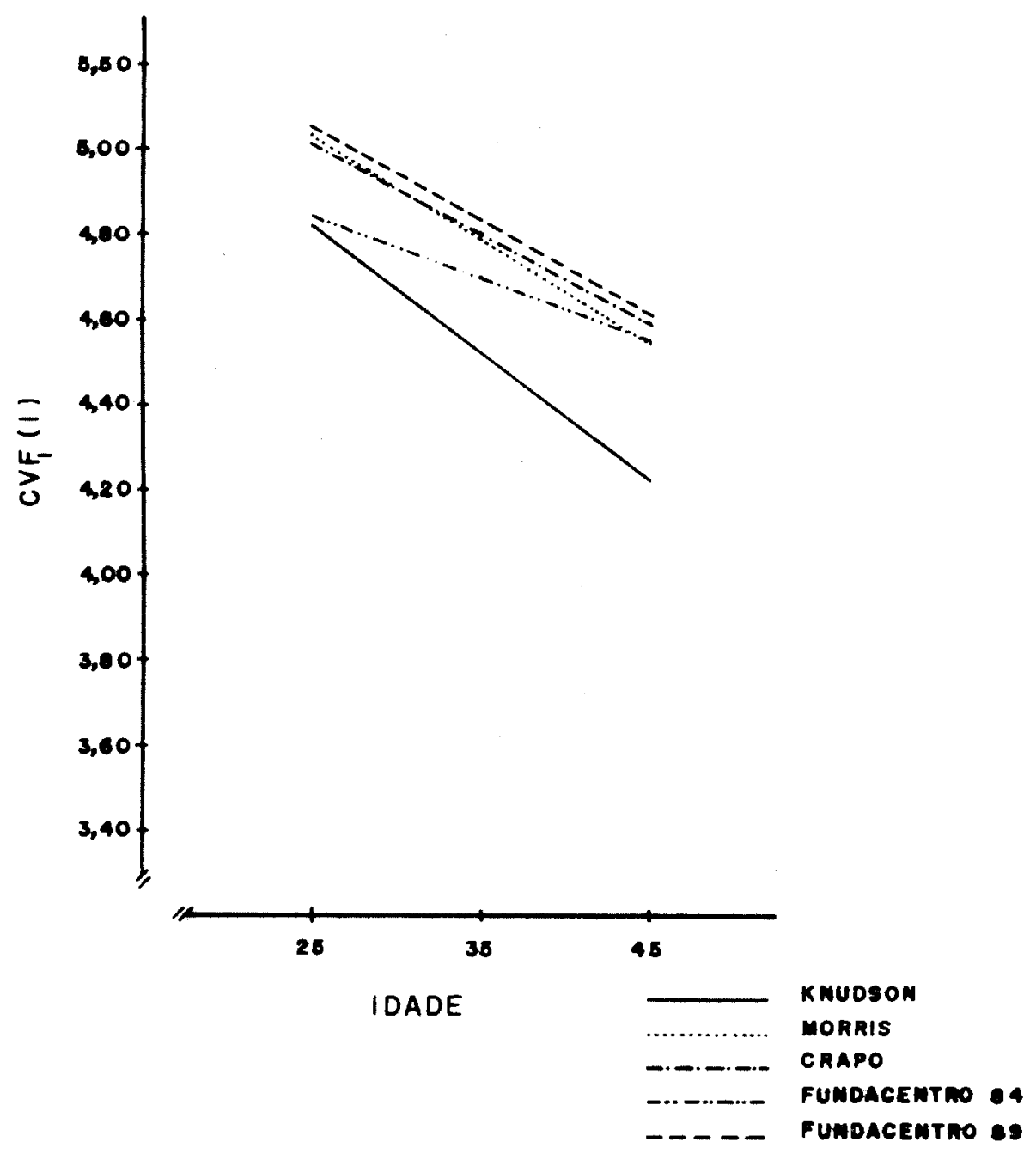

Comparativamente às equações das FIGURAS 3.4 e 3.5 , os coeficientes de idade são relativamente semelhantes para o $\mathrm{VEF}_{1}$ nas equações da coorte, porém bem menores em relação à CVF. 
Nos modelos de regressão linear múltipla de 1984 e 1989, alguns termos foram incluídos para responder a questões específicas. Primeiramente, os índices de exposição SANO e SANOAJ na equação do $\mathrm{VEF}_{1}$. Não houve inclusão dos mesmos no modelo, devido à baixa explicaçāo adicional das variáveis dependentes. Posteriormente, estudou-se o efeito da Idade e exponenciais, Idade e Idade $^{3}$. Para esta análise, ajustou-se o $\mathrm{VEF}_{1}$ para altura segundo a fórmula $\mathrm{VEF}_{1} .(1,69)^{2} / \mathrm{Alt}^{2}$, e incluiu-se como variáveis independentes a Idade, Idade ${ }^{2}$ Idade ${ }^{3}$. O único termo significante foi a Idade, sendo que seus exponenciais não foram significantes. Isto mostrou que, na coorte em estudo, o efeito negativo da idade sobre o VEF, tende a ser linear e não exponencial.

Como parâmetros de normalidade para o cálculo de valores previstos do $\mathrm{VEF}_{1}, \mathrm{CVF}$, IT e $\mathrm{FEF}_{25-75}$, adotou-se o trabalho de KNUDSON e col. ${ }^{131}$, com os respectivos valores do $95^{\circ}$ percentil, como limites de normalidade/anormalidade. A TABELA 3.42 traz as médias dos índices em porcentagem do valor previsto.

TABELA 3.42: Médias das Porcentagens e Desvios Padrāo do Previsto Para os Índices Funcionais Respiratórios, 1984 e 1989.

\begin{tabular}{|c|c|c|c|c|}
\hline & \multicolumn{2}{|c|}{1984} & \multicolumn{2}{|c|}{1989} \\
\hline & $\overline{\mathrm{x}}$ & (DP) & $\overline{\mathrm{X}}$ & (DP) \\
\hline $\mathrm{VEF}_{1}$ & 102,5 & $(14,2)$ & 102,6 & $(13,6)$ \\
\hline$C V F$ & 103,2 & $(14,0)$ & 108,8 & $(13,2)$ \\
\hline IT & 99,9 & $(8,1)$ & 94,9 & $(7,3)$ \\
\hline $\mathrm{FEF}_{25-\pi 5}$ & - & - & 83,2 & $(24,6)$ \\
\hline
\end{tabular}

A TABELA 3.43 traz o número de mineiros classificados como normais ou alterados em 1984 e 1989. 
TABELA 3.43: Mineiros com Parametros Funcionais Normais e Alterados Segundo os Valores Previstos de KNUDSON e col. ${ }^{131}$.

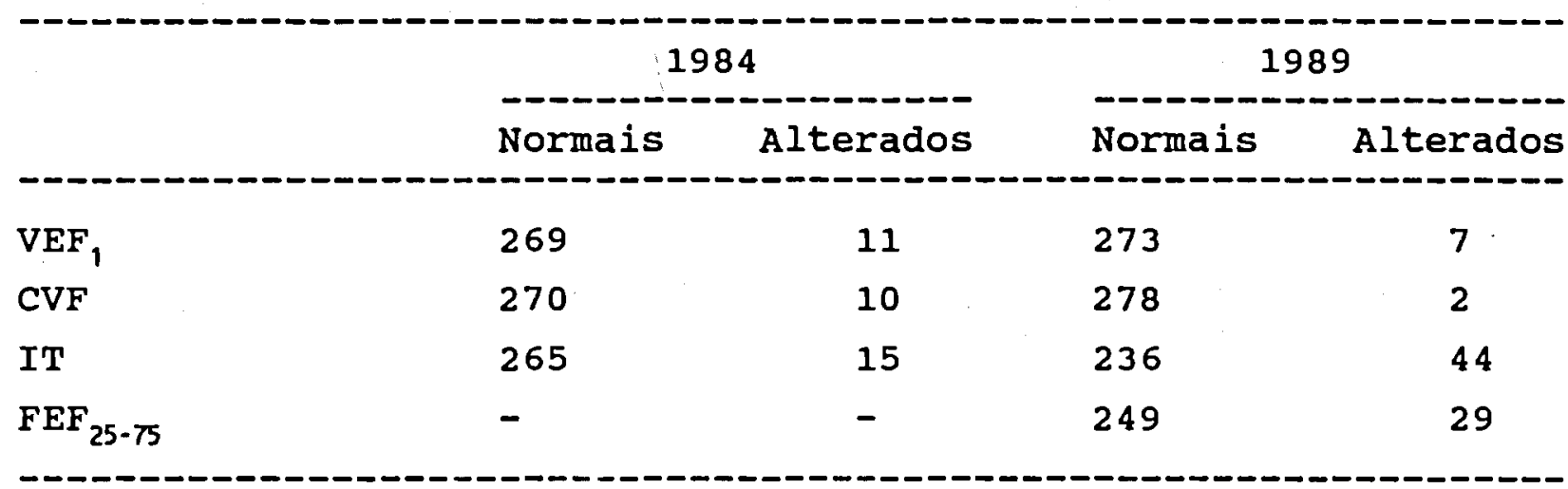

A TABELA 3.43 mostrou que, entre 1984 e 1989 apenas o IT apresentou uma evolução importante. Calculando-se os Intervalos de Confiança de $95 \%$ para IT e a probabilidade associada às diferenças entre as porcentagens de IT alterados em 1984 e 1989, concluiu-se que em 1989 havia um número significativamente maior de mineiros com IT alterado ( $p<0,001)$.

\subsubsection{Dimensões de Vias Aéreas e Espirometria}

No item 3.2.4 foram apresentadas uma série de análises referentes ao DT. Chamou a atenção que indivíduos com DT maior apresentavam fluxos e volumes significativamente maiores (TABELA 3.37). As únicas excessões eram o IT, e o DVEF,

O diâmetro traqueal frontal, que eram juntamente com o comprimento da traquéia as únicas medições possíveis no $\mathrm{Rx}$ de tórax frontal, foi medido de acordo com uma técnica conhecida ${ }^{238}$. Restringindo a coorte aos 239 mineiros que tiveram o DT medido, estudou-se qual seria a contribuição desta medida nas equações de regressão das variáveis espirométricas. A TABELA 3.44 mostra os resultados. 
TABELA 3.44: Coeficientes de Correlação Múltipla ( $r$ ) das Equações de Regressão da Espirometria Fơrçada (Variável Dependente) com Indices Antropométricos e Diâmetro Traqueal $(\mathrm{n}=239)$.

$\begin{array}{lcc}\text { VARIAVEI DEPENDENTE } & \text { VARIAVEIS INDEPENDENTES } \\ \text { VEF } & \\ \text { CVF } & 0,50 & 0,54 * * \\ \text { IT* } & 0,53 & 0,56 * * \\ \text { FEF }_{25-75} & 0,19 & - \\ & 0,31 & 0,36 * *\end{array}$

* Apenas a Idade entrou como variável independente na equaçāo de regressão do IT, à semelhança da equação de KNUDSON.

**p<0,001 para a contribuição de DT na equação

O fato do DT não ter entrado na equação de predição do IT já era antecipado pelos resultados da TABELA 3.37. Em relação ao $\mathrm{VEF}_{1}, \mathrm{CVF}_{\text {e }} \mathrm{FEF}_{25-75}$, DT trouxe uma contribuição significativa com coeficientes positivos para as equaçōes, porém todas com aumentos muito diṣcretos nos coeficientes de correlação.

\subsubsection{Declínio do VEF}

Um dos objetivos do presente trabalho era a análise do comportamento longitudinal do $\mathrm{VEF}_{1}$ ao longo dos 5 anos. Cada um dos 280 mineiros da coorte possuia medições em 2 pontos, 1984 e 1989. A média do declínio do DVEF, na coorte foi de 35,46 ml/ano $\pm 68,83(-103,46 !---! 222,44)$, mostrando uma grande dispersão dos valores em torno da média. Em 1984, 55 mineiros tinham entre 21 a 25 anos, que é uma faixa admitida como de crescimento longitudinal do VEF, ${ }^{30,131}$. O DVEF, destes mineiros foi calculado e como a média não diferia dos outros 225 eles foram incluidos nas análises que serão aqui comentadas. A FIGURA 3.6 mostra o $\mathrm{DVEF}_{1}$ médio por faixas etárias. A idade de cada mineiro foi calculada como a idade média exata entre os 2 estudos. Na faixa de 21 a 25 anos o número de mineiros foi igual a 12. 
FIGURA 3.6: DVEF, Médio (ml/ano) por Faixas Etárias e Desvios Padrão.

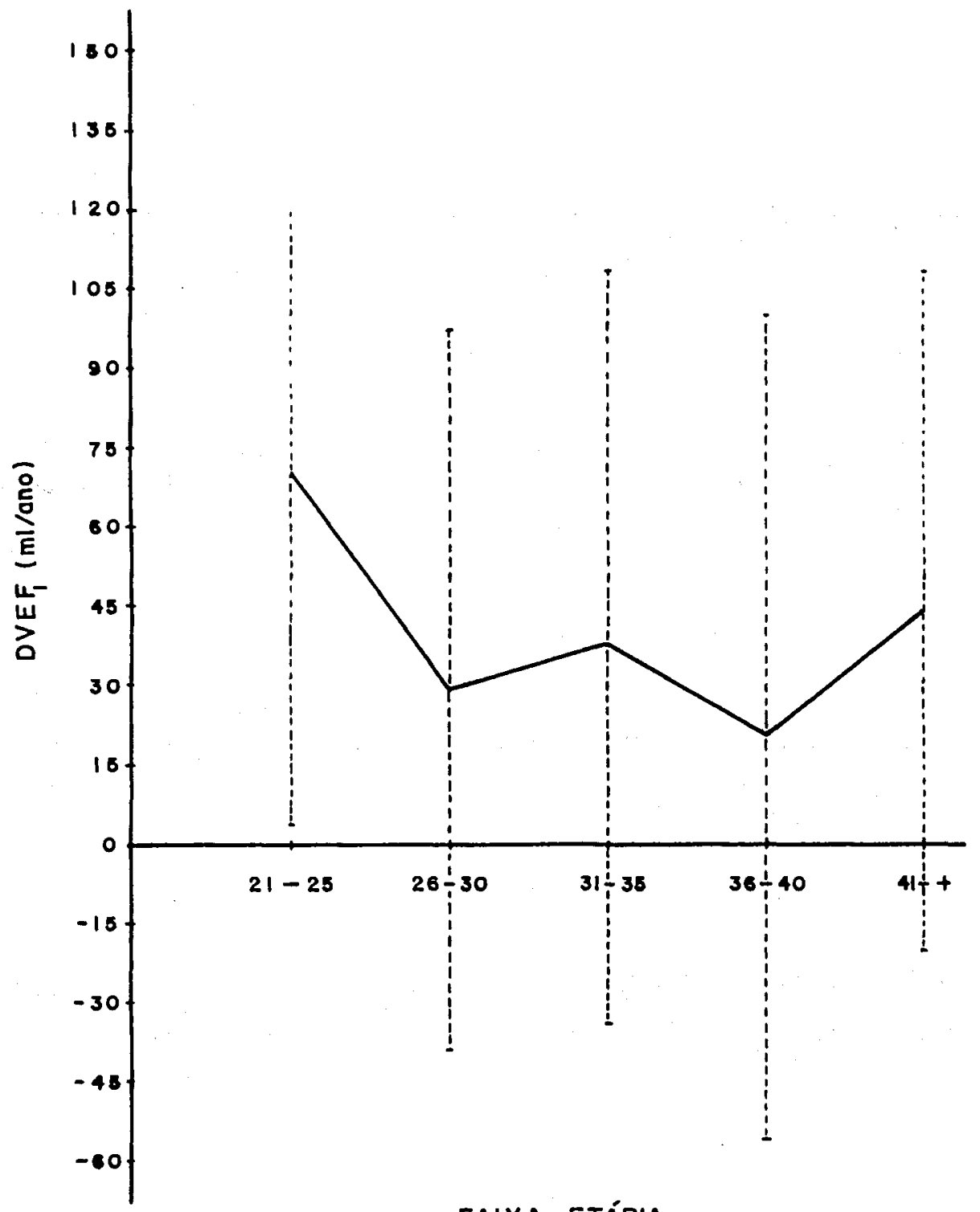

FAIXA ETÁRIA

$\mathrm{O}$ declínio do $\mathrm{VEF}_{1}$, baseado em idade, pode ser analisado de duas formas: através dos coeficientes de idade derivados das equações de regressão múltipla (TABELA 3.41) ou calculando-se o coeficiente médio das mudanças individuais de cada um dos mineiros (há um chamado declínio transversal, estimado pontualmente, e um 
declínio longitudinal que pode ser calculado quando se tem dois ou mais pontos no tempo). A TABELA 3.45 traz os coeficientes de 84 e 89 , o coeficiente longitudinal e uma estimativa percentual de declínio em relação ao $\mathrm{VEF}_{1}$ médio.

TABELA 3.45: Declínio Anual do VEF, em ml e Percentual Anual em Relação ao VEF ${ }^{*}$.

$\begin{array}{lcc} & \text { COEFICIENTE } & \% \\ \text { Transversal } 1984 & 26,5 & 0,7 \\ \text { Transversal } 1989 & 27,4 & 0,7 \\ \text { Longitudinal } 1984-1989 & 35,5 & 0,9\end{array}$

* $0 \mathrm{VEF}_{1}$ é a média do $\mathrm{VEF}_{1}$ de 1984 e 1989 para os coeficientes transversais, e a média do $\mathrm{VEF}_{1} 1984$ - 1989 para o coeficiente longitudinal.

É interessante notar que o declínio estimado longitudinalmente é maior do que as estimativas transversais, isto é, $25,3 \%$ maior do que a estimativa de 1984, e $22,8 \%$ maior do que 1989 , que é o oposto ao descrito na literatura ${ }^{30,91}$.

A equação de KNUDSON ${ }^{131}$, tem um coeficiente de idade negativo, igual a 29,2 para indivíduos com 25 anos ou mais. Tomando-se este valor como base, os mineiros da coorte foram divididos em dois grupos: um chamado de declínio lento (DVEF $<=29 \mathrm{ml} /$ ano, $\mathrm{n}=123)$ e um grupo chamado de declínio rápido $\left(\mathrm{DVEF}_{1}>29 \mathrm{ml} / \mathrm{ano}, \mathrm{n}\right.$ = 157). Através de análises de variância e tabelas de associação, estudaram-se algumas variáveis de interesse. Os resultados estão nas TABELAS 3.46 e 3.47. 
TABELA 3.46: Análises de Variância dos Índices de Exposiçāo (SANO e SANOAJ), Idade e Tabagismo Quantitativo, Relacionados ao Declínio Lento ou Rápido do $\mathrm{VEF}_{\text {, }}$

\begin{tabular}{|c|c|c|c|c|c|c|c|}
\hline & \multicolumn{3}{|c|}{$\star D L$} & \multicolumn{3}{|c|}{$\star D R$} & \multirow[b]{2}{*}{$\mathbf{F}$} \\
\hline & $\bar{x}$ & EP & $(\vec{x} \pm 1,96 \mathrm{EP})$ & $\bar{x}$ & EP & $|\bar{x} \pm 1,96 \mathrm{EP}\rangle$ & \\
\hline SANO & 10,39 & 0,31 & $(9,78-11,00)$ & 10,49 & 0,34 & $(9,82-11,16)$ & $=0,8307$ \\
\hline SANOAJ & 32,40 & 1,39 & $(29,68-35,12)$ & 30,73 & 1,39 & $(28,01-33,45)$ & $=0,4025$ \\
\hline Idade & 34,52 & 0,43 & $(33 ; 68-35,36)$ & 35,27 & 0,43 & $(34,43-36,11)$ & $p=0,2280$ \\
\hline MM & 8,02 & 0,67 & $(6,71-9,33)$ & 9,57 & 0,82 & $(7,96-11,18)$ & $D=0,1598$ \\
\hline
\end{tabular}

TABELA 3.47: Qui-Quadrado e Probabilidade das Tabelas de Contingência do Declínio do VEF, (Lento ou Rápido) com Tabagismo (Grupos) e PB.

\begin{tabular}{|c|c|}
\hline & [NIO DO VEF \\
\hline Tabagismo & $\begin{array}{l}\mathrm{GL}=3 \\
\mathrm{x}^{2}=0,531 \\
\mathrm{p}=0,7669\end{array}$ \\
\hline PB & $\begin{array}{l}\mathrm{GL}=2 \\
\mathrm{x}^{2}=2,326 \\
\mathrm{p}=0,1272\end{array}$ \\
\hline
\end{tabular}

As TABELAS 3.46 e 3.47 não mostram relação do declínio do $\mathrm{VEF}_{1}$, dividido em Lento e Rápido, com Índices de Exposição, Idade, Tabagismo, e PB, ò que, de certa forma, foi um resultado inesperado. Mineiros com PB positiva tenderam a apresentar um declínio rápido do $\mathrm{VEF}_{1}$, embora nesta tabela de associação simples, este achado não fosse significante. 
Para uma melhor análise das relações entre o $\mathrm{DVEF}_{1}$ e a $\mathrm{PB}$, utilizou-se um modelo de regressão linear, com o $\mathrm{DVEF}_{1}$ como variável dependente e a PB (dicotômica) como variável independente. Os resultados estão na TABELA 3.48.

TABELA 3.48: Modelo de Regressão Linear para DVEF, Variável Independente PB (Positiva $=-1$, Negativa $=1$ ).

\begin{tabular}{|c|c|c|c|}
\hline V.DEPENDENTE & CONSTANTE & COEFICIENTE & $\mathrm{r}$ \\
\hline$D F_{1}$ & 97,0413 & $-31,4202$ & 0,14 \\
\hline
\end{tabular}

Embora a variável PB fosse significante $(\mathrm{F}=5,28,0,01<\mathrm{p}<0,025)$, ela forneceu uma explicação mínima (coefi-ciente de determinação múltiplo de 0,02). Este dado, apesar das restrições acima, vem de encontro a dados de literatura que mostram uma correlação entre estas variáveis, embora a relação causa-efeito não possa ser discernida.

Para uma análise da influência da Exposição e do Tabagismo no declínio do $\mathrm{VEF}_{1}$, foi construida uma tabela de razões de prevalência, estratificando os mineiros por tabagismo e exposição, à semelhança à TABELA 3.21. Os resultados estão na TABELA 3.49 . 
TABELA 3.49: Porcentagem de Mineiros com Declínio Lento (DL) ou Rápido (DR) do VEF, Estratificados por Tabagismo e Exposição, Razōes de Prevalência e Intervalos de Confiança@.

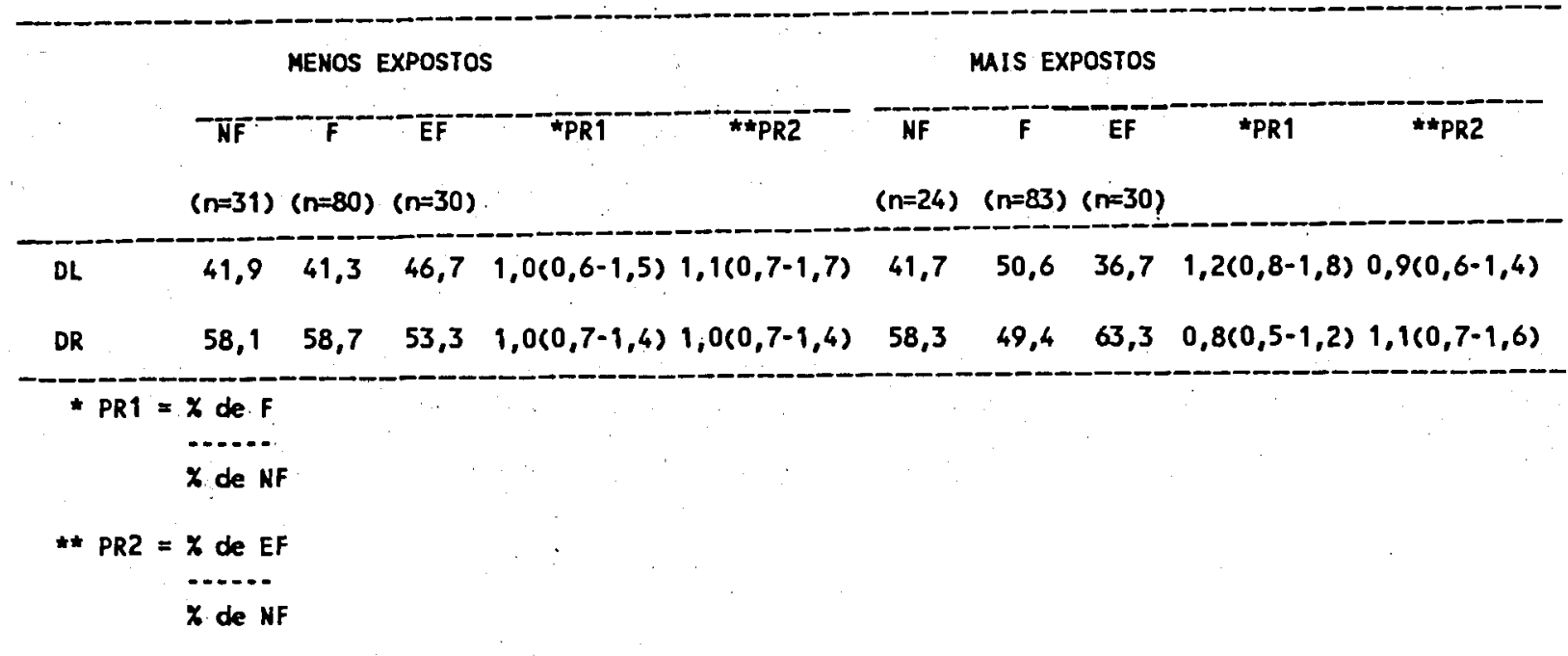

a Intervalos de Confianca de $95 \%$ calculados de acordo con as series de Taytor 130

As razões de prevalência de DL e DR de mineiros Fumantes e ExFumantes, para Não Fumantes, foram próximas ao valor unitário, tanto no grupo de menor exposição, quanto no grupo mais exposto. Todos os intervalos de confiança incluiram valores abaixo de 1 , mostrando não haver diferenças significantes da queda do $\mathrm{VEF}_{\text {, }}$, estratificada por tabagismo e exposição.

Com o objetivo de analisar a tendência do $\mathrm{DVEF}_{1}$ com a idade, procurando-se estudar o momento (idade) em que os indivíduos da coorte passavam de uma tendência de crescimento ou estabilidade, a declínio, estas duas variáveis (DVEF/ variável dependente) foram correlacionadas em um modelo de regressão linear (de acordo com o trabalho de BURROWS e col. ${ }^{30}$ ). Os resultados foram não significantes, não havendo a inclusão do termo Idade no modelo $(F=0,33, \mathrm{p}>0,55)$. 


\subsubsection{Obstrucão de Vias Áereas, Bronquite Crônica. Exposição Ocupacionale Tabagismo}

Queixas compativeis com BC foram regıstrados em $\delta \mathrm{U}(20,0 \%)$ mineiros da coorte. Uma série de características da $\mathrm{BC}$ já foram descritas anteriormente (subitens 3.2.2 e 3.2.3). Alguns aspectos da relação entre BC e função de vias aéreas também foram comentados na Introduçāo (subiten 1.2.3).

Inıcıalmente, procurou-se caracterızar a presença ae odsuruçao de vias aéreas através do VEF, utilizando-se do $95^{\circ}$ percentil para separar os mineiros em normais e alterados. A TABELA 3.42 mostrou que, em 1989, apenas 7 mineiros apresentavam VEF, anormal. Ao mesmo tempo, 44 apresentavam o IT anormal. A TABELA 3.50 tráz estes casos estratificados pela variável BC.

TABELA 3.50: VEF, e IT Normais e Alterados e Bronquite Crônica.

\begin{tabular}{|c|c|c|c|c|c|c|c|c|c|}
\hline & \multicolumn{4}{|c|}{ BC - } & \multicolumn{4}{|c|}{$\mathrm{BC}+$} & \multirow[b]{2}{*}{$\mathrm{T}$} \\
\hline & $\star N$ & (z) & $\star A$ & $(z)$ & $\star N$ & (\%) & $\star_{A}$ & $\left(\frac{8}{6}\right)$ & \\
\hline$V E F_{1}$ & 197 & $(70,4)$ & 3 & $(1,1)$ & 76 & $(27,1)$ & 4 & $(1,4)$ & 280 \\
\hline IT & 171 & $(61,1)$ & 29 & $(10,4)$ & 65 & $(23,1)$ & 15 & $(5,4)$ & 280 \\
\hline
\end{tabular}

* $\mathrm{N}=$ Indice Funcloral acima do $95^{\circ}$ percentil previsto

$A=$ Indice Funcional igual ou abaixo do $95^{\circ}$ percentil previsto

Utilizando-se o VEF, como critério para a classificação da Bronquite Crônica em BC sem obstrução e BC com obstrução, os pequenos números impedem uma análise estatística adequada. Optou-se, portanto, por analisar os grupos classificados pelo IT. Através de análise de variância, as médias dos índices de exposição, tabagismo quantitativo e índices funcionais foram comparadas nestes grupos. Os resultados estão na TABELA 3.51. 
TABELA 3.51: Análises de Variância dos Índices de Exposição, Tabagismo e Índices ıncionais em Mineiros Classificados de Acordo com a Presença de onquite Crônica, Com e Sem Obstruçāo.

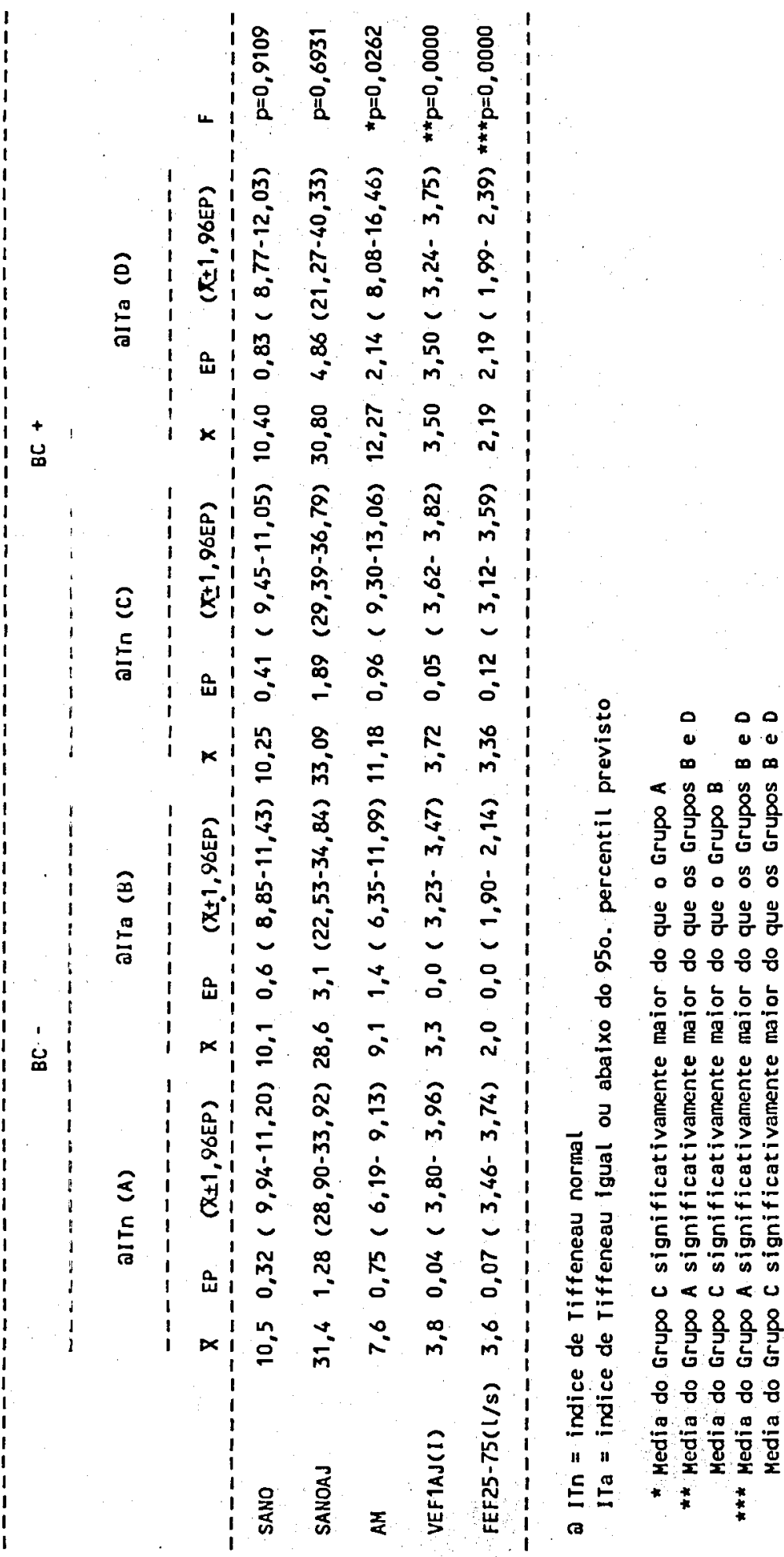


Os números da TABELA 3.51 mostram que o tabagismo quantitativo diferencia apenas a presença de $\mathrm{BC}$. $\mathrm{O} \mathrm{VEF}_{1} \mathrm{AJ}_{\mathrm{J}}$ e $\circ \mathrm{FEF}_{25-75}$ (principalmente) estão associados com o IT e não diferenciam a presença de BC.

'A influência da Exposição Ocupacional e Tabagismo em relação a obstrução de vias aéreas, foi analisada através de úm modelo de regressão logística e do cálculo de razões de prevalência. Na primeira análise, a variável dependente dicotômica foi o IT normal ou alterado; as variáveis independentes foram o SANO, SANOAJ, AM, Grupos de Tabagismo, e os produtos SANO X AM e SANOAJ X AM. Os resultados estão na TABELA 3.52.

TABELA 3.52: Modelo de Regressāo Logística para o Estudo da Influência da Exposição Ocupacional e do Tabagismo sobre o Índice de Tiffeneau.

\begin{tabular}{|c|c|c|c|c|}
\hline VARIÁVEL & INTERVALO & COEFICIENTE & ERRO-PADRĀO & $p$ \\
\hline Constante & & $-3,01$ & 0,578 & \\
\hline SANO & $4-30$ & -- & -- & -- \\
\hline SANOAJ & $5-86$ & -- & -- & -- \\
\hline AM* & Faixas & 0,718 & 0,277 & 0,0104 \\
\hline \multirow[t]{2}{*}{ Tabagismo } & (1) & -- & -- & -- \\
\hline & (2) & -- & -- & -- \\
\hline SANO $X \quad A M$ & 0 a 1960 & -- & -- & -- \\
\hline SANOAJ X AM & 0 a 2940 & $-0,001$ & 0,001 & 0,0826 \\
\hline
\end{tabular}

É interessante notar que a variável quantitativa de fumo correlacionase melhor com o IT que os grupos de tabagismo. A componente sinérgica de exposição e tabagismo, representada por SANOAJ X AM também correlacionou-se significativamente com o IT, embora na direção inversa ao AM. A interpretação deste efeito é, do ponto de vista matemático, análoga à da TABELA 3.33, ou seja, como o efeito isolado do AM já foi computado, pois foi a primeira variável a entrar na equação, há uma "dedução" ponderada de efeitos da variável SANOAJ X AM, para não computar-se os efeitos de AM duas vezes. 
A TABELA 3.53 traz as razões de prevalência do achado de IT normal ou alterado, estratificadas por tabagismo e exposição. Esta última é dividida em mineiros menos expostos (SANOAJ $<=30$ ) e mais expostos (SANOAJ > 30), como nas TABELAS 3.21 e 3.49 .

TABELA 3.53: Porcentagem de Mineiros Apresentando IT Normal ou Alterado, Estratificados por Exposição e Tabagismo, Razōes de Prevalência e Intervalos de Confiança@.

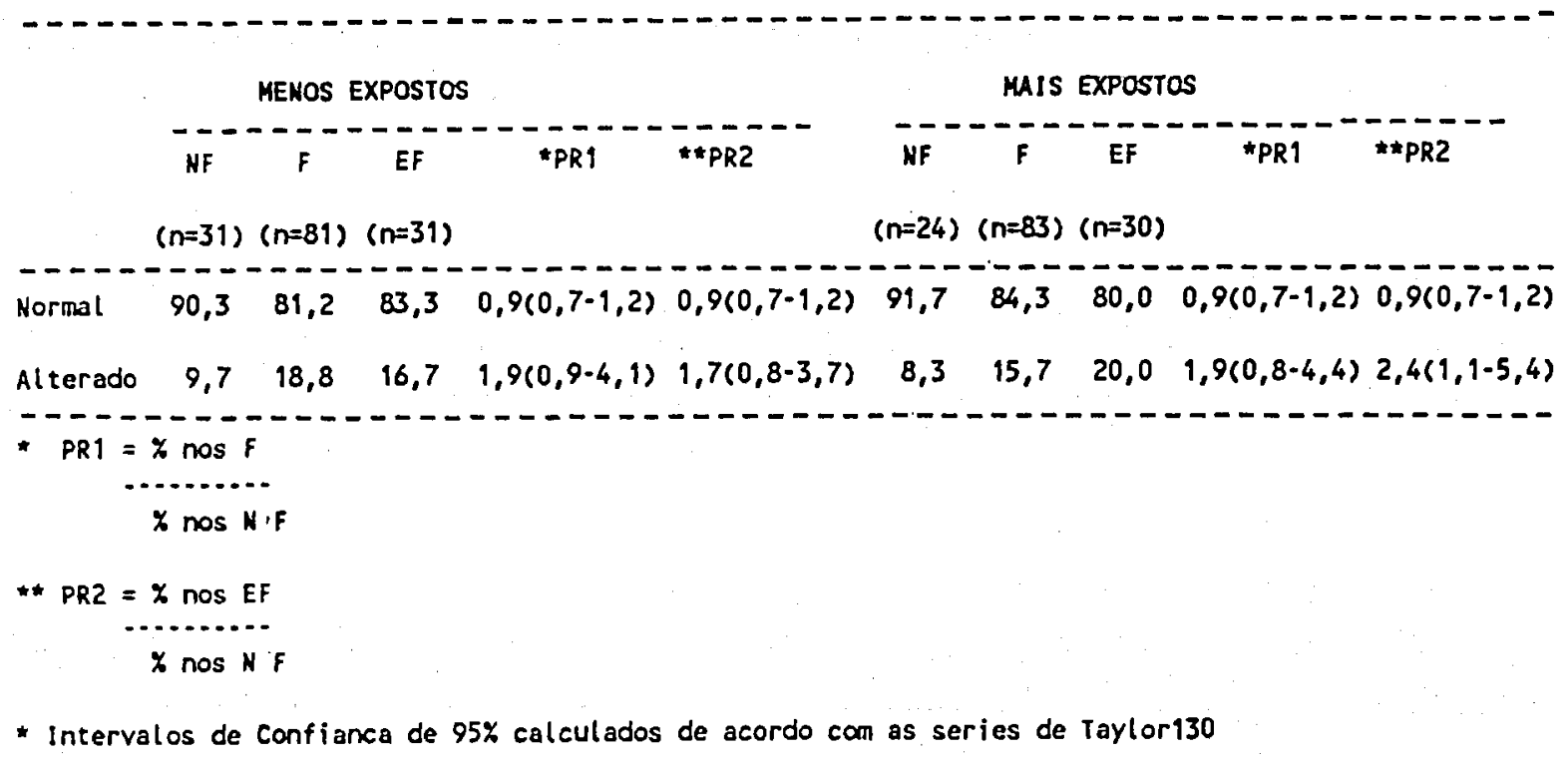

A única razão de prevalência significante foi a PR2 de mineiros com IT alterado no grupo mais exposto. Os resultados dos fumantes e ex-fumantes foram muito semelhantes, mostrando que do ponto de vista funcional, os fumantes e ex-fumantes tem comportamento semelhante.

Portanto, as TABELAS 3.52 e 3.53 mostram duas diferenças importantes no comportamento dos índices funcionais em comparação com os sintomas respiratórios. Nestes últimos, o grupo de tabagismo a que o mineiro pertencia associou-se mais fortemente com os sintomas, e os ex-fumantes comportavam-se como não fumantes.

Tabelas semelhantes à TABELA 3.53 foram construídas para o VEF, a CVF, e o $\mathrm{FEF}_{25 \cdot 75}$. Como para os dois primeiros havia diversas caselas com $\mathrm{n}=0 \mathrm{a}$ apresentação será omitida, porém vale salientar que todos os 7 mineiros com VEF, 
anormal e os 2 mineiros com CVF anormal (vide TABELA 3.42) encontravam-se entre os mais expostos. Os resultados para o $\mathrm{FEF}_{25-75}$ envolviam 29 mineiros com exames alterados e foram semelhantes aos da TABELA 3.53 .

\subsubsection{Provocacão Brônquica}

Dos 268 testes concluidos, 49 (18,3\%) foram considerados positivos. As associaçōes da PB com os Índices de Exposiçāo, Tabagismo e Grupos Sintomáticos estão no subitem 3.2.4. A TABELA 3.54 mostra os valores médios do $\mathrm{VEF}_{1}, \mathrm{VEF}_{1} \%$, $\mathrm{VEF}_{1} \mathrm{AJ}$ e do $\mathrm{DVEF}_{1}$, nos grupos de $\mathrm{PB}$ positiva e negativa.

TABELA 3.54: Análise de Variância dos Índices do VEF, Relacionados à PB

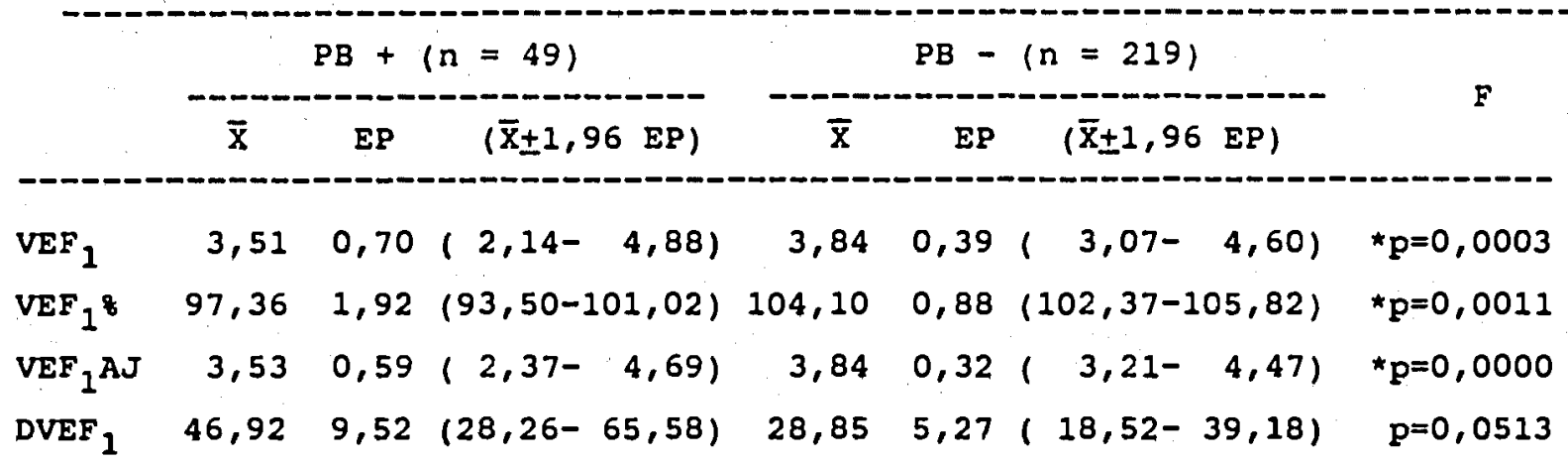

* p Bignificante

Mineiros com PB positiva apresentaram um $\mathrm{VEF}_{1}$ basal significativamente menor do que mineiros com $\mathrm{PB}$ negativa. A queda do $\mathrm{VEF}_{1}$ também foi maior em mineiros com PB positiva, embora a significância desta associação fosse marginal. $O$ índice do $\mathrm{VEF}_{\text {q }}$ que melhor se associou com a $\mathrm{PB}$ foi o VEF, $\mathrm{AJ}$. Através de dados derivados de um modelo de regressão por logitos, a probabilidade de um mineiro apresentar um teste de $\mathrm{PB}$ positivo relacionada ao $\mathrm{VEF}_{1} \mathrm{AJ}$ está ilustrado na FIGURA 3.7, conforme a equação descrita em MÉTODOS. 
FIGURA 3.7: Probabilidade de um Registro Positivo de PB em Função de VEF ${ }_{1} A J$ Basal (Modelo de Regressão Logística, $p=0,0008$ ).

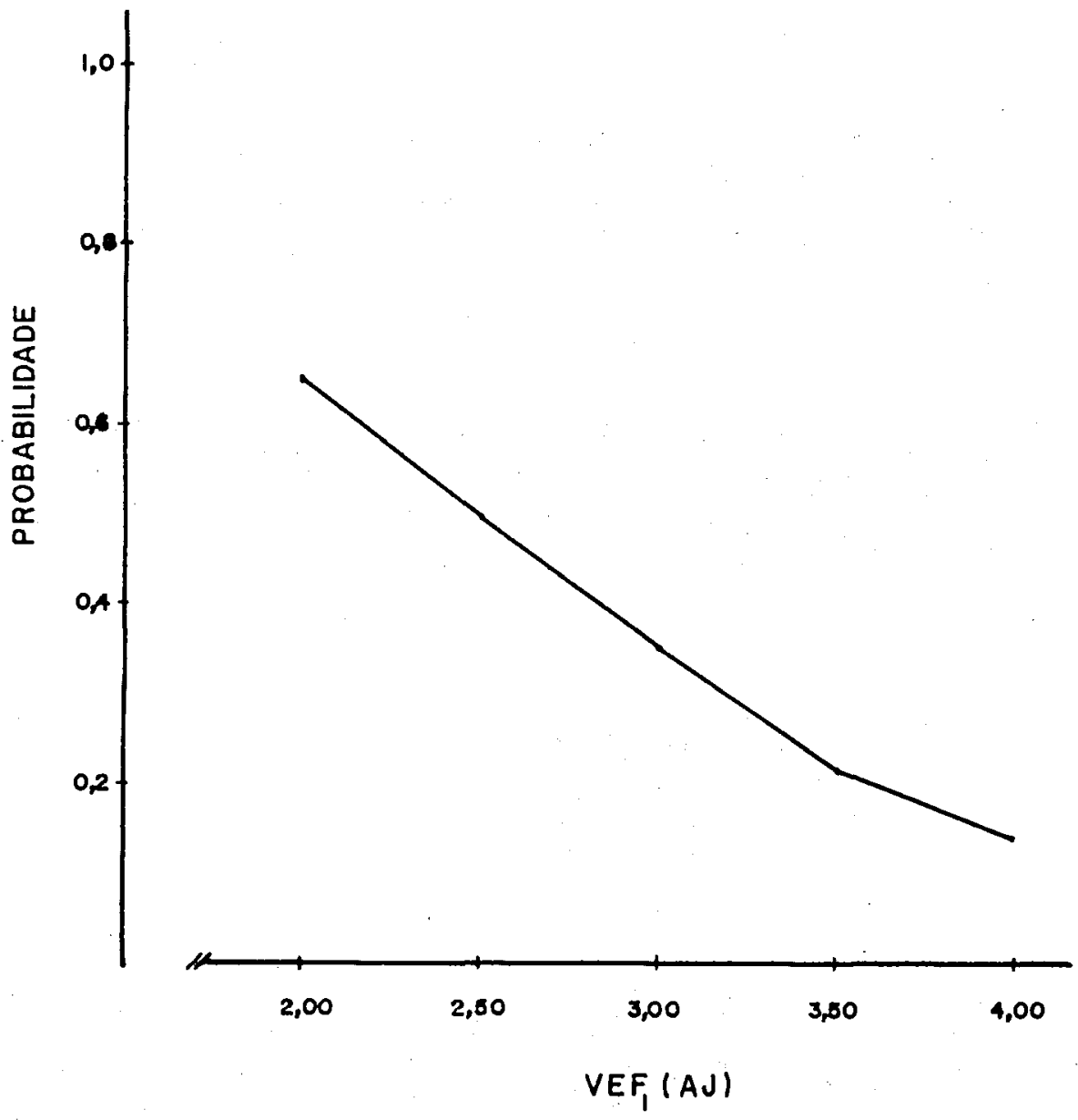

\subsubsection{Modelos de Relações de Efeitos - Análise de Resíduos}

Para uma complementação de análises, estudamos como variáveis adicionais os resíduos do $\mathrm{VEF}_{1}$ e do IT de 1989. Através das equações de predição utilizadas, para cada mineiro calculamos a diferença entre o parametro observado e o previsto. Para o $\mathrm{VEF}_{1}$ ajustamos os resíduos para altura, através da fórmula: $\mathrm{VEF}_{1} \mathrm{AJ}$ obs, predito $=\frac{\text { VEF } 1}{\text { Altura }^{2}} \cdot 1,69^{2}$ 
Os resíduos do $\mathrm{VEF}_{1} \mathrm{AJ}$ e do IT distribuiram-se de forma simétrica, sem que houvesse valores extremos, a não ser uma discreta tendência a uma cauda mais longa nos valores de resíduos positivos do $\mathrm{VEF}_{1}$. A TABELA 3.55 traz os resultados obtidos.

TABELA 3.55: Distribuição dos Resíduos do VEF AJ e do IT, $1989(n=280)$.

\begin{tabular}{|c|c|c|c|c|c|}
\hline & $\overline{\mathrm{X}}$ & $S D$ & EP & INTERVALO & RESIDUOS NEGATIVOS(n) \\
\hline $\mathrm{VEF}, \mathrm{AJ}$ & 7,88 & 49,35 & 2,95 & $-115,46-175,97$ & 122 \\
\hline$I T$ & $-4,21$ & 6,05 & 0,36 & $-20,96-20,17$ & 211 \\
\hline
\end{tabular}

Os resíduos do $\mathrm{VEF}_{1} \mathrm{AJ}$ distribuiram-se de forma ampla, com uma média positiva. O IT, ao contrário apresentou uma média negativa. Estes resultados já eram esperados pela análise dos dados da TABELA 3.42.

Dividindo-se os resíduos em Positivos e Negativos, 158 mineiros eram Positivos e 122 Negativos para o VEF, AJ. Para o IT, 69 eram Positivos e 211 Negativos. Relacionaram-se estes grupos, em tabelas de contigência, com a SANO ( 0 a 7, 8 a 13, e 14 ou mais), SANOAJ (0 a 20, 21 a 40, e 41 ou mais), AM (0,1 a 10, 11 a 20, e 21 ou mais) e Grupos de Tabagismo (NF, F, EF). Os resultados estão na TABELA 3.56. 
TABELA 3.56: Qui-Quadrado e Probabilidades das Tabelas de Contin-gência entre os Resíduos Positivos ou Negativos do $\mathrm{VEF}_{\mathfrak{1}} \mathrm{AJ}$ e do IT com Exposição (SANO, SANOAJ) e Tabagismo (AM, Grupos)

\begin{tabular}{|c|c|c|c|}
\hline \multirow[t]{2}{*}{ VARIÁVEL } & \multicolumn{3}{|c|}{ RESIDUOS } \\
\hline & $V E F_{1} A J$ & IT & \\
\hline & $G L=2$ & GL & $=2$ \\
\hline \multirow[t]{2}{*}{ SANO } & $x^{2}=3,129$ & $x^{2}$ & $=0,348$ \\
\hline & $\mathrm{p}=0,2092$ & $\mathbf{p}$ & $=0,8402$ \\
\hline & GL $=2$ & GL & $=2$ \\
\hline \multirow[t]{3}{*}{ SANOAJ } & $x^{2}=3,882$ & $x^{2}$ & $=0,281$ \\
\hline & $p=0,1435$ & $\mathrm{p}$ & $=0,8688$ \\
\hline & $\mathbf{G L}=3$ & GL & $=3$ \\
\hline \multirow[t]{3}{*}{$A M$} & $x^{2}=2,367$ & $x^{2}$ & $=6,836$ \\
\hline & $p=0,4998$ & $\mathbf{p}$ & $=0,0773$ \\
\hline & GL $=2$ & GL & $=2$ \\
\hline \multirow[t]{2}{*}{ Tabagismo } & $x^{2}=4,370$ & $x^{2}$ & $=01,885$ \\
\hline & $p=0,1125$ & $p$ & $=0,3896$ \\
\hline
\end{tabular}

Portanto, não houve associação entre a exposição, tabagismo, e resíduos positivo ou negativo do $\mathrm{VEF}_{1} \mathrm{AJ}$ e IT, embora houvesse uma tendência a encontrarmos mais fumantes no grupo de resíduo negativo do $\mathrm{VEF}_{\mathfrak{q}} \mathrm{AJ}$, e maior número de mineiros com $\mathrm{AM}>10$ no grupo de resíduo negativo do IT (dados numéricos omitidos).

Os efeitos da exposição e tabagismo foram também analisados em um modelo de regressão por logitos, tendo como variável dependente o resíduo dicotomizado em Negativo (probabilidade igual a 1) e Positivo (probabilidade igual a 0). Incluimos como variáveis independentes SANO, SANOAJ, AM, Grupos de Tabagismo, e os efeitos combinados SANO X AM e SANOAJ X AM. Os resultados para os resíduos do VEF 1 AJ estāo na TABELA 3.57 e para o IT na TABELA 3.58. 
TABELA 3.57: Modelo de Regressão Logística para o Estudo dos Efeitos da Exposiçāo (SANO e SANOAJ), Tabagismo (AM e Grupos), e Efeitos Combinados (SANO X AM, SANOAJ X AM) sobre os Resíduos do VEF, AJ.

\begin{tabular}{lcccc}
\hline VARIAVEL & INTERVALO & COEFICIENTE & ERRO-PADRĀO \\
\hline Constante & & $-0,405$ & 0,140 \\
SANO & $4-30$ & - & - & - \\
SANOAJ & $5-86$ & - & - & - \\
AM & $0-70$ & - & - & - \\
Tabagismo & $(1)$ & $-0,214$ & 0,210 & 0,0892 \\
& $(2)$ & 0,368 & 0,167 & \\
SANO X AM & 0 a 1960 & - & - & - \\
SANOAJ X AM & 0 a 2940 & - & - & - \\
-
\end{tabular}

TABELA 3.58: Modelo de Regressão Logística para o Estudo dos Efeitos da Exposição (SANO e SANOAJ), Tabagismo (AM e Grupos), e Efeitos Combinados (SANO X AM, SANOAJ X AM) sobre os Resíduos do IT.

$\begin{array}{lcccc}\text { VARIÁVEL } & \text { INTERVALO } & \text { COEFICIENTE } & \text { ERRO-PADRÃO } & \text { p } \\ \text { Constante } & & 0,712 & 0,194 & - \\ \text { SANO } & 4-30 & -- & - & - \\ \text { SANOAJ } & 5-86 & - & - & 0,0107 \\ \text { AM } & 0-70 & 0,049 & 0,019 & - \\ \text { Tabagismo } & (1) & -- & - & - \\ & (2) & - & - & - \\ \text { SANO X AM } & 0 \text { a } 1960 & - & - & - \\ \text { SANOAJ X AM } & 0 \text { a } 2940 & - & -\end{array}$


O Tabagismo foi a variável mais importante relacionada aos resíduos do VEF,AJ (Grupos) e IT (AM). A análise (cálculos) dos dados da TABELA 3.57 mostra que $O \mathrm{OR}$ de um resíduo negativo de $\mathrm{VEF}_{1} \mathrm{AJ}$ de fumantes para não fumantes é de 1,68 $(1,16-3,57)$ e de ex-fumantes para não fumantes de 0,94 (0,18-1,70). A TABELA 3.58 mostra que o OR de um resíduo negativo do IT de um mineiro que fumou 20 AM para um mineiro nāo fumante é de $2,67(1,26-5,61)$.

Finalmente, a variável PB (positiva ou negativa) foi inclúda nos modelos apresentados nas TABELAS 3.57 e 3.58. Em ambos os modelos, a PB foi significante e entrou nas equaçōes $\left(p=0,0196\right.$ na equação do resíduo do $V E F_{1} A J$ e $p=$ 0,0314 na equação do resíduo do IT).

A FIGURA 3.8 mostra as probabilidades de um resíduo negativo do $\mathrm{VEF}_{1} \mathrm{AJ}$ associada ao grupo de tabagismo a PB.Mineiros não fumantes e ex-fumantes comportaram-se de forma semelhante em relação aos residuos do $\mathrm{VEF}_{1} \mathrm{AJ}$.

A FIGURA 3.9 mostra duas curvas de probabilidade de um resíduo negativo do IT em mineiros com $\mathrm{PB}$ positiva ou negativa.Mineiros com $\mathrm{PB}$ positiva tendem significativamente a apresentar resíduos negativos do IT. Esta probabilidade acentua-se à medida que aumenta o número de AM. 
FIGURA 3.8: Probabilidade de um Resíduo Negativo do VEF 1 AJ em Mineiros com PB Positiva ou Negativa.

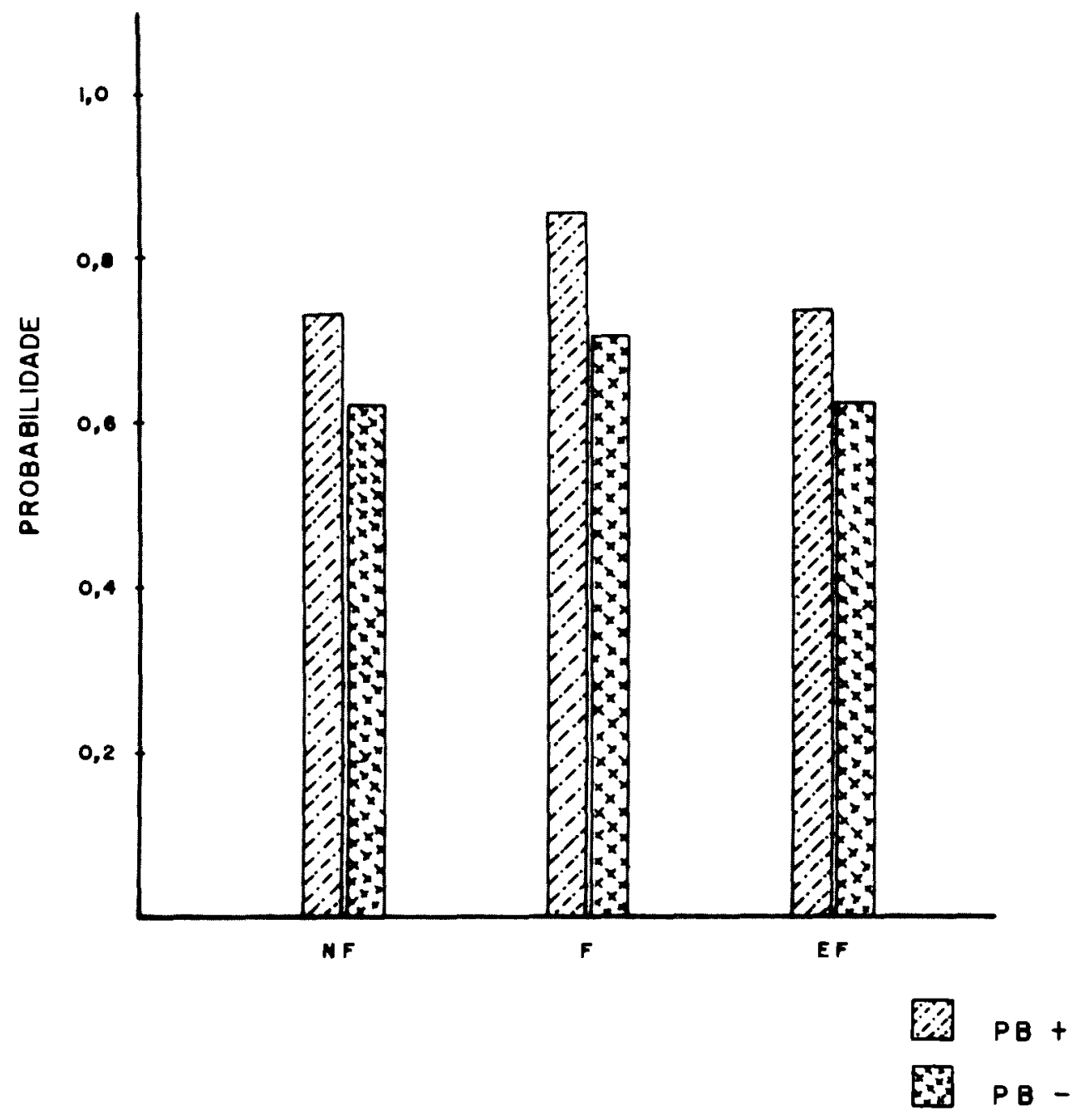


FIGURA 3.9: Probabilidade de um Resíduo Negativo do IT em Mineiros com PB Positiva ou Negativa.

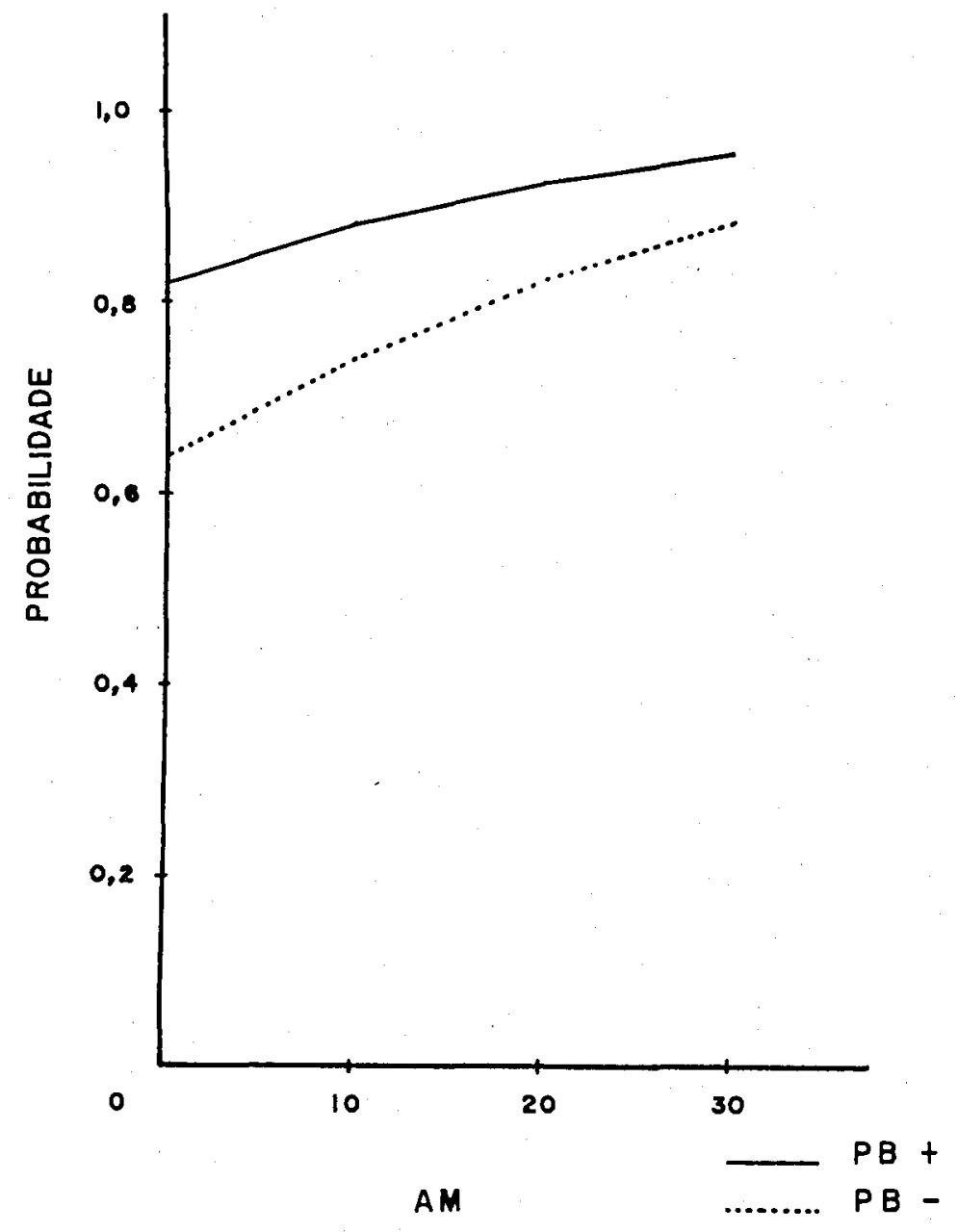


SEÇÃO 4 DISCUSSÃO 


\section{DISCUSSÃO}

\subsection{Aspectos Relativos ao Desenho Epidemiológico e à Amostra}

O tipo de estudo descrito neste trabalho foi fundamentalmente prospectivo analítico, onde os objetivos principais foram identificar fatores de risco, $\varepsilon$ estimar a sua contribuição para alguns eventos finais. Houve também um componente descritivo, relacionado a aspectos que se tinha pouco conhecimento prévio, como a análise da ocorrência de asma brônquica e da utilização da PB como um método investigativo em mineiros de carvão de subsolo.

A amostra inicial de 1984 foi constituida por mineiros ativos de 6 grandes empresas mineradoras, retirados de minas com tipos de operação distintos e amostrados sistematicamente. Através das listagens fornecidas pelas empresas, foram amostrados sistematicamente 1 em cada 2 mineiros dentro de cada função específica, ora todos os pares, ora todos os ímpares. $\mathrm{Na}$ ocasião esta amostra englobou cerca de $10 \%$ de todos o mineiros de subsolo da bacia carbonífera catarinense. Os mineiros que não compareceram por férias, doença ou recusa, não foram repostos pois a amostra era grande. O não comparecimento por doença $€$ uma causa de viés e a sua reposição por indivíduos não doentes, acentuaria ainda mais este problema.

Em 1989, os mineiros que tivessem uma espirometria e/ou uma radiografia interpretada em 1984 foram convocados para um novo exame. Como mencionado em MÉTODOS, o critério para participação na coorte era a existência da primeira exigência acima, porém, como existe a intenção de um futuro retorno para um terceiro exame, mineiros que não conseguiram espirometrias satisfatórias em 1984 foram incluidos, com a intenção que, no próximo seguimento, passem a integrar a coorte.

Desta forma a coorte é originária de uma amostra que foi "restrita" em dois níveis, primeiramente uma "restriçāo completa" por uma circunscrição geográfica, limitando o estudo à bacia carbonífera catarinense e, num segundo nível, uma "restrição parcial" à mineiros que completaram espirometrias satisfatórias nos dois exames (pareamento por uma variável) ${ }^{130}$. 
Estas restrições podem ser fontes de viés. O subitem 1.3.1 da INTRODUÇÃO traz algumas informações sobre a indústria carbonífera brasileira. Apesar do Rio Grande do Sul possuir quase 90\% das reservas do país (TABELA 1.1), a maior atividade extrativa ocorre em Santa Catarina (TABELA 1.2). O carvão encontrado em ambos os estados é do tipo betuminoso ${ }^{147}$, porém, apesar do menor poder calorífico do carvão rio-grandense, não há dados de literatura que diferenciem riscos referentes a carvão betuminoso com diferentes graus de poder calorífico. Há sim, diferença entre o carvão antracitoso e o betuminoso; o primeiro deles é geologicamente mais antigo, possui um conteúdo de carbono mais elevado, e, quando minerado, gera uma maior quantidade de partículas respiráveis ${ }^{114,216,241}$. A forma de mineração no Rio Grande do Sul é predominante manual e semi-mecanizada, o que está representado na amostra. Portanto, a circunscrição geográfica da coorte não deve ter implicaçōes em relação a se estender os resultados para outras regiōes produtoras de carvão.

A restrição da coorte a mineiros que tenham completado espirometrias satisfatórias nas duas investigações envolve uma discussão detalhada. A inabilidade em produzir curvas espirométricas reprodutíveis, segundo os critérios sugeridos pela $\mathrm{ATS}^{8,9}$, leva à exclusāo de indivíduos com mais sintomas respiratórios ${ }^{69,70,122}$, mais doenças respiratórias ocupacionais ${ }^{69}$, e uma queda mais acelerada do $\mathrm{VEF}_{1}{ }^{71,134}$. A TABELA 2.6 mostrou que os mineiros excluídos da coorte por não terem espirometrias reprodutíveis em 1984 apresentavam, em 1989, uma prevalência significativamente maior de tosse e dispnéia. A presença de catarro, BC, chiado, e a SANO eram também maiores, embora as diferenças não fossem significantes. Um fato interessante é que o $\mathrm{VEF}_{1}$, mesmo quando ajustado para altura, foi maior no grupo dos excluídos do que na coorte $(p=0,0001)$.

Em uma recente revisão sobre o tema ${ }^{21}$, concluiu-se que a exclusão da análise de indivíduos ocupacionalmente expostos a riscos respiratórios que não alcançam os critérios da ATS leva, efetivamente, a um viés em direção a hipótese de nulidade, subestimando assim os efeitos deletérios da exposição ocupacional. Neste trabalho ${ }^{21}$ a importância da inspiração máxima em indivíduos que apresentam HRB como causa de variabilidade de medidas é mencionada. Como curiosidade, no presente estudo, a frequência de $\mathrm{PB}$ positiva nos mineiros excluidos foi de $13,2 \%$, e, nos mineiros da coorte, de $18,3 \%$ (dados não mencionados).

A frequência de espirometrias rejeitadas em investigaçōes epidemiológicas foi de $15,7 \%$ em trabalhadores de algodã $0^{69}, 17,7 \%$ em maquinistas de 
trem ${ }^{69}, 8,9 \%$ na primeira avaliação do estudo das seis cidades, $\mathrm{EUA}^{70}$, e $10 \%$ na primeira avaliação de mineiros de carvão nos $E^{122}$. Neste último, os $10 \% \$$ correspondem a mineiros com uma diferença de até $200 \mathrm{ml}$ para o $\mathrm{VEF}_{\mathfrak{q}}$, portanto esta porcentagem, segundo os critérios atuais da ATS, deve ser maior. Reportando-se aos dados do presente trabalho, em 1984 houve 30,7\% de provas rejeitadas e, em 1989 0,5\%. Estes números estão mostrando duas situaçōes distintas: uma clara falha nos exames de 1984, consequente ao treinamento e supervisāo inadequados das espirometrias, e uma provável seleção de população reexaminada em 1989, composta por indivíduos "sobreviventes" mais sadios, e, portanto, menos inclinados a uma espirometria inadequada, aliado a uma supervisão constante de todas as espirometrias efetuadas. Também, como curiosidade deve-se mencionar que dos três médicos que participaram da supervisão e do trabalho de campo em 1984 , um deles teve $25 \%$ de suas espirometrias aceitas, o segundo $58,1 \%$ e o terceiro, que é pneumologista, $100 \%$. Em 1989, os três médicos que participaram e supervisionaram o trabalho de campo eram pneumologistas.

Portanto, a segunda restrição da amostra tem um potencial de viés em direçāo a uma subestimação dos efeitos respiratórios causados pela exposição ocupacional. Este aspecto será futuramente analisado, pois há a intenção de continuar o trabalho no futuro, o que certamente trará mais elementos para esclarecer estes pontos.

Além da seleção pela espirometria, não se conseguiu examinar um número adequado de ex-mineiros devido ao não comparecimento. A comparação de mineiros ativos com ex-mineiros seria útil, no sentido de se analisar os efeitos respiratórios causados pela exposição ocupacional de uma forma ampla, e passível de generalização para a população mineira.

A TABELA 2.4 compara as características dos mineiros que compareceram em 1989 com as dos não respondentes. Eles diferiram apenas na idade, os não respondentes sendo mais velhos. Isto porém dá apenas uma idéia de que os dois grupos eram semelhantes em um ponto no tempo. Não se pode inferir que a evolução sintomática, radiológica e funcional, tenha sido semelhante nos dois grupos.

$\mathrm{Na}$ Grã-Bretanha, as estimativas de incidência de FMP foram comparadas em mineiros ativos e ex-mineiros. Demonstrou-se que, quando baseadas somente em mineiros ativos, elas seriam uma subestimativa da incidência real da doença ${ }^{146}$. Um outro estudo identificou ex-mineiros que se aposentaram antes da idade prevista e que 
apresentaram respostas orgânicas acentuadas à exposição cumulativa a poeiras ${ }^{110}$. Neste material, embora fossem uma minoria, fica a mensagem que, efetivamente, há respostas acentuadas à exposição ocupacional, relacionadas com o motivo de saída antecipada da indústria, e passíveis de levar à incapacidade funcional respiratória.

A perda de indivíduos ocorrida de 1984 a 1989 foi maior do que se esperava no planejamento do seguimento (FiGURA 2.1). Os motivos são diversos:

a) houve uma falha técnica, no sentido de, durante o período de 1985 ao início de 1989 , não se manteve contato com os membros da amostra. Isto deveria ter sido previsto no planejamento da primeira investigaçāo, conforme sugerido na literatura ${ }^{86}$. Na verdade, como a SANO média era baixa em 1984, era de se esperar que a maioria dos mineiros ainda estivessem trabalhando em 1989, além de que havia uma previsāo de crescimento da produção de carvão. Infelizmente isto não ocorreu, bavendo inclusive diminuição da mão de obra empregada nos anos que se seguiram (TABELA 1.2).

b) Chamou a atenção o fato de que quase todos os mineiros que compareceram em 1989 conheciam nomes das listagens dos ex-mineiros. Apesar do comparecimento dos exmineiros ter sido mínimo, nenhum deles veio através do contato com mineiros e sim, pelos outros meios de divulgaçāo. Os sindicatos da categoria também não auxiliaram de forma importante, apesar dos contatos efetuados. Esta "resistência" pode ter duas facetas opostas. Havia certamente ex-mineiros demitidos aguardando uma nova oportunidade de trabalho na indústria carbonífera. Para estes, um possível diagnóstico de uma patologia relacionada ao trabalho seria prejudicial, pois talvez temessem uma divulgação pública dos resultados. Por outro lado, havia ex-mineiros aposentados, que não mais dependiam da indústria carbonífera, e para os quais o diagnóstico de uma patologia ocupacional poderia inclusive trazer benefícios pevidenciários.

c) O sistema de saúde nacional não está preparado para este tipo de investigações, com os seus problemas intrínsecos envolvidos. Em países onde há serviços de saúde organizados, todo cidadão tem algum tipo de identificação que o acompanha até o fim de sua vida. A tarefa de rastrear pessoas, inclusive eventos na sua história médica, fica incrivelmente facilitada. Estas considerações são no presente momento utópicas dentro do sistema de saúde brasileiro, porém, sentimos que esta menção é importante e acreditamos que inúmeros pesquisadores envolvidos com investigações de coorte já tenham passado por experiências semelhantes. 
Resumindo, este trabalho representa uma análise dos efeitos respiratórios da exposição em minas de carvão de subsolo em uma população selecionada através de critérios naturais e funcionais respiratórios e, deve tratar-se de uma estimativa extremamente conservadora dos reais efeitos deste risco sobre toda a população mineira da bacia carbonífera brasileira.

\subsection{Alguns Pontos Referentes aos Instrumentos de Investigação}

\subsubsection{Questionários}

Os questionários utilizados em 1984 e 1989 obedeceram a mesma estrutura básica. Ambos são derivados do questionário do Medical Research Council ${ }^{86}$. ampliados para contemplar aspectos referentes à investigação epidemiológica em doenças ocupacionais pulmonares. A estrutura de ambos e o vínculo com o questionário do MRC já foram apresentados no item 2.2.

A utilização de questionários, como instrumento de coleta de dados, deve obedecer a alguns princípios: as questões devem ter sua validade e confiabilidade (repetibilidade) medidas ${ }^{23,86}$. A validade é medida usualmente através do cálculo de sensibilidade e especificidade. Na literatura, apenas as questões referentes ao catarro foram adequadamente validadas $^{85}$. Questões referentes a dispnéia, que é um sintoma extremamente subjetivo, tosse e chiado, não tem uma validade estabelecida, porém como a intenção do questionário é epidemiológica, e não clínica, as discrepâncias entre diagnósticos clínicos e respostas sāo esperadas ${ }^{211}$.

A confiabilidade é, em resumo, a consistência das respostas a uma mesma pergunta, feita por dois questionários. Na prática, uma forma de analisarmos a confiabilidade é através da análise das respostas às mesmas questões em duas ocasiōes diferentes.

Embora os sintomas respiratórios não sejam estáticos em estudos longitudinais ${ }^{81,218}$, notadamente a tosse e o catarro, que relacionam-se fortemente com o grupo de tabagismo a que o indivíduo pertence, as TABELAS 3.3 a 3.6 mostram uma franca 
tendência à manutenção das respostas obtidas num intervalo de tempo de 5 anos, com excessão do chiado.

As questōes novas sobre chiado foram as mais problemáticas. Elas foram elaboradas no sentido de melhor analisar as relaçōes entre chiado, dispnéia e trabalho. Em 1984 conseguiu-se aproveitar apenas as questōes de chiado traduzidas do questionário do MRC devido a inconsistência das outras respostas. Em 1989, o treinamento dos entrevistadores foi cuidadoso, porém, mesmo deixando as questōes em aberto para posterior codificação, teve-se que descartar a questão 5.5, pois não havia uma forma de colocação padronizada, ficando sujeita a um critério subjetivo de interpretação.

$\mathrm{Na}$ excelente revisão de SAMET ${ }^{211}$, o autor coloca uma série de fontes de viés na aplicação de questionários: devidas ao entrevistador, devidas à estação do ano em que o questionário é aplicado, devidas a modificações do questionário (já comentado), e ao modo de administração. O treinamento dos técnicos que auxiliaram no trabalham de campo, foi feito através de aplicaçāo conjunta de questionários e folheto de instruções. Em 1984, em algumas minas, a supervisão dos técnicos foi feita, em parte, por médicos não habituados ao questionário. Em 1989, a supervisão foi feita por três pneumologistas habituados à sua aplicação. A única forma para avaliar os resultados é a comparação da prevalência pontual de sintomas e de dados da história de tabagismo. A primeira delas está colocada na TABELA 2.7 e, afora o registro do chiado, que evoluiu da primeira para a segunda avaliação, não há dados díspares. A história de tabagismo foi também comparada; notou-se que houve $3(1,1 \%)$ casos discrepantes: 2 fumantes em 1984 que passaram a não fumantes em 1989 e 1 ex-fumante que passou a não fumante; o que pareceu perfeitamente aceitável (dados omitidos de RESULTADOS).

Não foram feitas análises referentes ao registro de sintomas de acordo com a época do ano neste material. Há uma tendência a uma maior positividade de relatos de sintomas respiratórios nos meses de inverno, porém não há elementos palpáveis que confirmem diferenças significantes nas respostas obtidas em inquéritos epidemiológicos aplicados em diferentes épocas do ano ${ }^{211}$. 


\subsubsection{Exposicão Ocupacional}

Uma das forma de expressão da exposição ocupacional às poeiras é a medida quantitativa cumulativa. Isto é obtido através de amostragem contínua (ou, alternativamente, peródica) de poeiras respiráveis em pontos estratégicos, que possibilitem o cálculo da exposição para diferentes funçōes na mineração. A exposição a poeiras significa a quantidade de poeira respirável que é passível de inalação por um mineiro em determinada função. A dose significa a quantidade de poeira que é efetivamente inalada e depositada. Uma parte da poeira inalada é depositada a qualquer nível do sistema respiratório. A deposição é uma função do diâmetro aerodinâmico das partículas, da densidade, da velocidade do fluxo aéreo, do tempo de parada inspiratória, e da anatomia das vias aéreas, entre outros ${ }^{1}$. A resposta orgânica é determinada basicamente pelo "clearence" das partículas depositadas que depende da função dos macrófagos alveolares, e do sistema mucociliar. A interação entre a deposição e o "clearence" determinam o tempo de residência da poeira nos pulmōes. Portanto, quando se mede exposição ocupacional através da exposição cumulativa, este é apenas um dos fatores relacionados com o binômio dose/resposta e, no presente momento, é a melhor forma de expressar exposição.

A TABELA 4.1 mostra exemplos de diferentes formas de expressão da exposição ocupacional em mineiros de carvão.É interessante notar que também a Idade é utilizada como medida de exposição ${ }^{129,139}$, pois sua colinearidade com Anos de Exposição costuma ser alta. Infelizmente, não dispomos de medidas quantitativas que nos permitiriam calcular exposição cumulativa. Há, sim, dados pontuais, já discutidos no subitem 1.3.3, que autorizam a dizer que a quantidade de poeira respirável é grande, e que a quantidade de quartzo é grande 235 . 
TABELA 4.1: Diferentes Formas de Expressão de Exposição Ocupacional em Mineiros de Carvão

\begin{tabular}{|c|c|c|c|}
\hline PAIS & VARIÁVEIS ANALISADAS & $\begin{array}{l}\text { MEDIDAS DE } \\
\text { EXPOSIÇÃO }\end{array}$ & REFERENCIA \\
\hline$B$ & $\begin{array}{l}\text { Prevalência e Probabili- } \\
\text { dade de Pneumoconiose }\end{array}$ & $* g \cdot h \cdot m^{-3}$ & $113,114,223$ \\
\hline B & $\mathrm{BC}$ & $* g \cdot h \cdot m^{-3}$ & 197 \\
\hline GB & $\mathrm{BC}$ & $* g \cdot h \cdot m^{-3}$ & 204 \\
\hline lemanha & $\begin{array}{l}\text { Prevalência de Pneumoco- } \\
\text { niose } \\
\text { Progressão Radiológica }\end{array}$ & $\begin{array}{l}\mathrm{mg} \cdot \text { Turnos } \cdot \mathrm{m}^{-3} \\
\mathrm{mg} \cdot \text { Turnos. } \mathrm{m}^{-3}\end{array}$ & $\begin{array}{l}200 \\
199\end{array}$ \\
\hline UA & $\begin{array}{c}\text { BC } \\
\text { obstrução de Vias Aéreas }\end{array}$ & $\begin{array}{l}\text { Idade, Anos de } \\
\text { Exposição, Funções } \\
\text { no Subsolo }\end{array}$ & 129 \\
\hline UA & Curva Fluxo-Volume & $\begin{array}{l}\text { Anos de Exposição } \\
\text { Funções no Subsolo }\end{array}$ & 95 \\
\hline élgica & $\mathrm{BC}$ & $\begin{array}{l}\text { Anos de Exposição } \\
\text { Particulas. } \mathrm{Cm}^{-3}\end{array}$ & 139 \\
\hline ralia & $B C$ & Idade & 139 \\
\hline
\end{tabular}

$\star g \cdot h \cdot m^{-3}=\frac{\text { gramas/hora }}{m^{3}}$

A utilização de dois índices de exposição, SANO e SANOAJ, justificase na medida em que a SANO é uma medida objetiva, de fácil obtenção e que se correlaciona bem com parâmetros radiológicos ${ }^{4,173}$, sintomas respiratórios ${ }^{129,161} \mathrm{e}$ alterações funcionais ${ }^{95}$. O cálculo da SANOAJ foi feito através de um critério misto de dados objetivos ${ }^{235}$ e subjetivos (relatos de mineiros e de técnicos de fiscalização). A prevalência de pneumoconiose associa-se muito bem com os diferentes índices de exposição, e trabalhos de correlação radiológica-anatomopatológica mostram que, em mineiros de carvão, a quantidade de poeira total nos pulmões reflete bem a categoria radiológica ${ }^{205}$. Assim sendo, associou-se os dois índices com a presença/ausência de pneumoconiose ao $\mathrm{Rx}$ 
em 1989, em um modelo de regressāo por logitos (TABELA 3.29), e os resultados foram significativos para ambos os índices dos quais SANOAJ foi o primeiro a entrar na equaçāo, devido ao maior qui-quadrado $(8,42$ contra 3,18$)$. Após a entrada da SANOAJ na equaçāo, por efeito de colinearidade entre os dois índices, a SANO perdeu sua associação com 0 modelo. Assim, a variável de exposição ajustada por função no subsolo aparenta ser um razóável critério de trabalho.

\subsubsection{Espirometria}

Dois aspectos metodológicos relacionados a espirometria merecem menção:

a) Inicialmente, o trabalho de KNUDSON e col. ${ }^{131}$ foi escolhido como referência para valores previstos e critérios de normalidade, por alguns motivos. A publicação é relativamente recente (1983). Apesar disto, ela se refere a espirometrias feitas entré 1972 e 1975, tendo portanto uma diferença média de 14,5 anos com os dados colhidos no nosso trabalho. Analisando os diversos trabalhos que forneceram dados para o cálculo de valores previstos de espirometria, GLINDMEYER e col. ${ }^{91}$ demonstraram um nítido "efeito de coorte", o que significa que, há uma tendência secular a um aumento na capacidade vital ajustada para a altura. Comparando-se dados de uma população de referência com diversas equaçōes de regressão publicadas, LEBOWITZ e. col. ${ }^{138}$ concluiram não ser recomendável que se utilizem dados de referência obtidos há mais de 12 a 15 anos. Através do critério nāo paramétrico de utilizar o $95^{\circ}$ percentil para separar indivíduos normais de anormais, estes autores concluiram que, em uma amostra de comunidade sem sintomas respiratórios e sem diagnóstico de doenças pulmonares, o máximo de valores anormais do $\mathrm{VEF}_{1}$ era de 4,5\%, e o mínimo de 3,8\%, utilizando-se diversas equações de referência. $O 95^{\circ}$ percentil classificou no mínimo $95,5 \%$ de espirometrias como normais, e teve melhor especificidade do que o Intervalo de Confiança 95\%.

b) $\mathrm{Na}$ investigação de 1984 as espirometrias foram feitas nas minas. É muito provável que os mineiros submeteram-se aos exames em diversos pontos da jornada de trabalho - antes, após e durante a jornada; havendo, possivelmente exames realizados em mineiros imediatamente saídos do turno noturno. Em 1989 adotou-se o critério de examiná-los durante $o$ dia (entre 8 e $17 \mathrm{~h}$ ), e não incluir mineiros de turno noturno. Estes foram examinados apenas 3 dias após terem passado para um dos turnos diurnos. Houve 
diversos casos de exames feitos à tarde em mineiros que trabalharam no turno diurno matinal ( 6 às $12 \mathrm{~h}$ ). Há dados de literatura sobre efeitos agudos da exposição a poeiras em minas de carvão. McKERROW e col. ${ }^{151}$ demonstraram um aumento de $6 \%$ na resistência das vias aéreas ao longo da jornada de trabalho. LAPP e col. ${ }^{135}$, analisaram o declínio no $\mathrm{VEF}_{1}$ ao longo da jornada, mostrando que este guardava uma relação positiva com valores crescentes de poeira respirável. LOVE ${ }^{143}$ demonstrou reduções importantes nos parâmetros funcionais de mineiros de turno noturno, durante a jornada de trabalho, e reduções mais modestas em mineiros de turno vespertino. Estes últimos achados não foram justificados pela exposição ocupacional, nem pelo tabagismo. Há dados em estudos de exposição a poeiras de grāos ${ }^{65}$, algodão ${ }^{151,182}$, indústria de papel ${ }^{75}$, madeira $^{35}$, e na indústria de borracha ${ }^{94}$. Embora sejam estudos lidando com diferentes objetivos, todos eles apresentaram algum efeito deletério no $\mathrm{VEF}_{1}$ em medições pré e pós turno de trabalho (com exceção dos trabalhadores expostos a poeiras de madeira). A maior parte das exposições acima mencionadas (grãos, algodão, e diversos produtos químicos encontrados na indústria de borracha) são relacionadas, tanto à asma ocupacional quanto a doenças crônicas de vias aéreas, predominantemente.

c) Além do possível efeito do turno de trabalho sobre as vias aéreas em mineiros de carvão, há também a própria exaustão muscular, pois se trata de uma atividade física pesada, o que eventualmente também pode contribuir para desvios dos valores fisiológicos em condições ideais.

\subsubsection{Provocação Brônquica}

$O$ fato que os fluxômetros não registravam o fluxo de ar efetivo (subitem 2.5.2), leva a uma análise das possíveis implicações que poderiam derivar de provas efetuadas com débitos dos nebulizadores abaixo do ideal.

O nebulizadores utilizados tinham débitos que variavam de 0,12 a 0,16 $\mathrm{ml} / \mathrm{min}$. a um fluxo real de 3 litros/min, correspondendo a doses máximas de carbacol de 3,84 a 5,12 mg. Com a correção efetuada (dividindo-se as doses por um fator de 1,5) as doses efetivas variaram entre 2,56 a $3,41 \mathrm{mg}$.

Em um trabalho efetuado em nossa instituição, compararam-se as respostas à metacolina e ao carbacol em indivíduos normais e asmáticos ${ }^{157}$. Através de 
análise discriminante, as doses de corte de normais e asmáticos foram calculadas para diferentes índices da curva dose-resposta de ambas as drogas ( $\mathrm{DP}_{15}, \mathrm{DP}_{20}, \mathrm{PC}_{15}$ e $\left.\mathrm{PC}_{20}\right)$, entrando ainda na equaçāo um índice de sintomas respiratórios (SR), de 0 a 4 (soma-se 1 ponto para a presença de tosse e/ou catarro e/ou dispnéia e/ou chiado).

$$
\begin{aligned}
& \text { A função para o } \mathrm{DP}_{20} \text { do carbacol foi expressa pela equação: } \\
& \mathrm{F}=-1,54666+0,620567 . \mathrm{DP}_{20}-0,516306 . \mathrm{SR}
\end{aligned}
$$

aonde $\mathrm{F}$ assume valores positivos (indivíduos normais), ou negativos (asmáticos). Quando $\mathrm{F}$ $=0$, obtem-se o valor de corte entre normais e asmáticos. Assumindo $F=0$, calcula-se as doses de corte do $\mathrm{DP}_{20}$ para os diferentes valores de $\mathrm{SR}$ que foram de $2,49,3,32,4,15,4,99$ e $5,82 \mathrm{mg}$ respectivamente. Portanto, as doses efetivas incluiram parcialmente as doses de corte.

Prosseguindo o raciocínio, 158 mineiros eram assintomáticos (TABELA 2.8), tendo portanto 0 pontos no índice de sintomas respiratórios, e consequentemente uma dose de corte de $2,49 \mathrm{mg}$ de carbacol. Na pior das hipóteses (em que os 122 mineiros restantes tivessem pelo menos 2 sintomas respiratórios), pelo menos $60 \%$ da coorte recebeu uma dose adequada da droga.

Há ainda dois aspectos a serem comentados: primeiramente, se uma população receber uma dose mais baixa de carbacol, isto tenderá a aumentar a especificidade do teste, pois serão detectados os individuos com HRB moderada ou acentuada e diminuirá o número de falsos positivos. Em segundo lugar fica a questão: será que a resposta dose-dependente ou concentração-dependente? Uma resposta direta a esta questão não é encontrada na literatura. Sabe-se, entretanto, que os dois métodos padronizados de PB, através de inalações controladas por dosímetro e através de nebulização contínua e inspiraçōes a volume corrente, produzem resultados altamente correlacionados $^{209}$. O método de nebulização contínua não permite um controle efetivo da dose inalada, pois tanto o volume corrente quanto a frequência respiratória variam entre indivíduos. Este fato indica que talvez a concentração seja mais importante, porém isto é especulativo e baseado em dados indiretos, e, salvo novas informaçōes na literatura, devemos trabalhar com equipamentos e técnicas que já são rotina ${ }^{97}$. 


\subsection{Sintomas Respiratórios}

O inquérito sobre sintomas respiratórios, por meio da aplicação de questionários, faz parte da metodologia de investigação epidemiológica de doenças respiratórias crônicas ${ }^{80,86}$. Através das respostas obtidas, podem-se comparar prevalências de sintomas dentro da comunidade, assim como entre comunidades e, no neste caso específico, avaliar alguns dos efeitos não pneumoconióticos da exposição ocupacional.

Como já mencionado no início do trabalho (sub item 1.4.1), não há dados de prevalência de sintomas respiratórios na comunidade local, para comparar com os números obtidos. Não há justificativa em compará-los com dados comunitários, ou de populaçōes de classe trabalhadora publicados, uma vez que a zona carbonífera estudada está situada numa área suspeita de alta poluição ambiental ${ }^{4}$. Os dados da literatura serāo mencionados com o intuito de analisar alguns aspectos específicos, fazer uma comparaçāo da coorte através da análise da evoluçāo dos sintomas e estudar fatores relacionados com a presença de sintomas.

As TABELAS 3.1 e 3.2 mostraram a prevalência pontual dos quatro sintomas, nas duas investigaçōes, e os intervalos de confiança, respectivamente. É interessante notar que o chiado apresentou uma evolução significativa entre 1984 e 1989, enquanto as prevalências dos outros sintomas permaneceram estáveis.

PETERSEN e col. ${ }^{193}$ estudaram 1.372 trabalhadores não expostos a riscos respiratórios ocupacionais sabidos, no estado de Carolina do Norte, EUA (a expressão "blue collar workers" não tem uma tradução definida para a língua portuguesa: refere-se basicamente à população operária de produção). Foram analisados 9 sintomas, entre os quais 4 são os mesmos aqui estudados, com os mesmos critérios de definição, e ainda a BC, cuja definição foi um pouco diferente, utilizando-se um questionário semelhante ao aqui empregado. As proporçōes para a faixa etária de 20 a 69 anos, foram de 0,181, 0,170, 0,079, 0,082 , e 0,106 , para tosse, catarro, BC, dispnéia grau 3 e chiado, respectivamente. Quando os dados foram estratificados por grupo de tabagismo, observou-se que os não-fumantes e o exfumantes comportavam-se de forma semelhante e diferenciavam-se dos fumantes em relação à tosse, catarro, e $\mathrm{BC}$, nāo havendo diferenças, entretanto, para dispnéia e chiado. A TABELA 3.21 mostrou que, na coorte, este comportamento é o mesmo. 
HIGGINS e col. ${ }^{103}$, estudando cinco comunidades mineiras da Virgínia, EUA; mostraram também um comportamento semelhante de não fumantes e ex-fumantes em relaçāo à tosse, catarro, e tosse com catarro. Neste trabalho, as prevalências destes três sintomas e o chiado (não encontramos os critérios de definição dos sintomas) não diferiram quando mineiros e ex-mineiros de carvão foram comparadas com não mineiros.

A evolução dos sintomas apresentou dados que merecem análise.A TABELA 3.1 mostrou que as prevalências de tosse, catarro e dispnéia, mantiveram-se estáveis no período de 5 anos entre as duas investigaçōes. A TABELA 3.7 indica que a regressão dos sintomas foi acompanhada de uma maior SANO (TABELA 3.8), embora isto só fosse significante para a tosse e o inverso ocorresse para a SANOAJ. Estes achados foram inesperados; as explicaçōes possíveis são, em primeiro lugar uma provável adaptação longitudinal ao pó, ou seja, mineiros com uma média de SANO ao redor de 5 anos (1984), que permaneceram na indústria, foram paulatinamente adequando as respostas brônquicas à deposiçāo de poeiras, através de mecanismos de defesa habituais, provavelmente do "clearence" mucociliar. Em segundo lugar, é possível que exista um viés subjetivo de valorização dos sintomas: à medida em que passam os anos na mineração, sintomas que eram inicialmente valorizados passam a uma "rotina de observação" e deixam de se tornar queixas importantes. No nosso material, os mineiros que passaram a apresentar dispnéia, e os que não mais referiram este sintoma apresentaram uma SANOAJ significativamente maior do que os que permaneceram estáveis (TABELA 3.8). Infelizmente, os dados do questionário de 1984 não permitiram aferir a prevalência de BC para se analisar a sua evolução.

HIGGINS $^{104}$ mostrou que, tanto na Grã-Bretanha quanto nos EUA, houve uma tendência a um aumento nas proporções de $\mathrm{BC}$ e dispnéia relacionadas com anos de exposição, em mineiros de carvão. Dois estudos publicados, o primeiro em mineiros de ouro ${ }^{243}$, e o segundo em mineiros de carvão ${ }^{149}$, mostraram resultados semelhantes em relação à $B C$. Em mineiros de ouro, o aumento da prevalência de $B C$ e alterações no VEF, e no $\mathrm{FEF}_{25-75}$ ocorreram até uma dada exposição quantitativa, após o que, as proporções de anormalidade mantiveram-se estáveis. Em mineiros de carvão de faixa etária avançada (55 a 64 anos), não houve efeitos da exposição cumulativa em relação a BC, diferentemente do que se observou em faixas etárias menores. Os autores de ambos os trabalhos interpretaram os achados de uma forma semelhante, sugerindo que após uma certa exposição, ou idade (que são variáveis com alta colinearidade), há um "esgotamento de susceptíveis" aos efeitos da exposição ocupacional. Portanto, o resultado de uma independência entre os 
sintomas tosse e catarro e a exposição ocupacional, em 1989, pode representar, ou um processo de adaptaçāo longitudinal, ou um fenômeno semelhante ao descrito nestes outros estudos.

Durante os 5 anos, os números referentes ao tabagismo tiveram algumas alteraçōes. A proporção de fumantes foi exatamente a mesma em 1984 e 1989 , porém houve uma diminuição dı s não fumantes, com um consequente aumento dos exfumantes (TABELA 3.1). Houve ı ma significativa associação entre a progressão da tosse e o status de fumante, e uma tendên cia não significante à progressão do sintoma catarro nos fumantes (TABELA 3.10). Em duis trabalhos epidemiológicos, um referente a um estudo comunitário $^{81}$, e outro a uma população operária ${ }^{218}$, a prevalência de sintomas respiratórios inespecíficos e de BC diminuiram em um período de observaçāo de 6 e 7 anos, respectivamente. Ambos os autores consideraram que o principal fator responsável foi a mudança nos hábitos de fumar, em relação à tosse, catarro e BC. A dispnéia e o chiado por sua vez mostraram-se independentes da cessaçāo do fumo ${ }^{218}$. Os achados aqui descritos estão de acordo com estes estudos, porém, como não houve uma diminuição na proporção de fumantes, as proporçōes de tosse e catarro mantiveram-se estáveis.

A queda do $\mathrm{VEF}_{1}\left(\mathrm{DVEF}_{1}\right)$ foi maior em todos os grupos de progressão de sintomas, porém somente para o sintoma dispnéia foi estatisticamente significante (TABELA 3.9). Este dado é importante, pois mostra uma tendência a uma deterioração funcional mais rápida em indivíduos que apresentam sintomas respiratórios. Como a medida do $\mathrm{DVEF}_{1}$ baseada em 2 pontos apresentou uma grande variação, é possível que no futuro, com mais dados espirométricos, se possa estudar melhor estas associações.

Os testes de $\mathrm{PB}$ positivos associaram-se fortemente à progressão do chiado (TABELA 3.10). Embora o valor preditivo da resposta das vias aéreas à PB não seja alto em indivíduos com sintomas de chiado ao questionário $58,50 \%$ dos mineiros que relataram uma progressāo do chiado em 1989 apresentaram PB positiva. Estes aspectos serāo comentados adiante, de forma mais detalhada.

Com dados transversais de 1989 , os fatores relacionados aos sintomas foram analisados em modelos de regressão logística. Estes resultados, expressos nas TABELAS 3.11 a 3.13, confirmaram os achados das associações simples descritas anteriormente permitindo calcular as razões de chance associadas às equações. Nestas 
análises, os termos combinados de tabagismo e exposição ocupacional foram incluídos, na tentativa de avaliar uma possível ação aditiva ou sinérgica dos mesmos. $O$ tabagismo associou-se significativamente à presença de BC (TABELA 3.11), OR $=6,6(2,5-17,4)$, ao passo que mineiros ex-fumantes não apresentaram diferenças significantes em relação aos não-fumantes, $\mathrm{OR}=1,5(0,5-4,9)$. A SANOAJ associou-se significativamente à dispnéia (TABELA 3.12) e uma série de variáveis associaram-se ao chiado, sendo a $\mathrm{PB}$ a mais importante delas (TABELA 3.13. Todos estes dados confirmaram as diferentes estruturas de dependência dos sintomas, mostrando mais uma vez que a tosse e o catarro crônicos dependem fundamentalmente do grupo tabágico a que o indivíduo pertence, mais do que da medida quantitativa do fumo (AM) e que estes sintomas são reversíveis após a cessação do fumo. Por sua vez, a dispnéia associou-se significativamente a SANOAJ, apenas, mostrando que mineiros com maior soma ajustada de anos de experiência de subsolo tendem a apresentar mais queixas de dispnéia grau 3. No modelo do sintoma chiado, mineiros com o sintoma presente tenderam a apresentar PB positiva, AM maior, SANO maior e VEF, menor. Ainda, a combinação de efeitos da exposição e do tabagismo estava significativamente associada ao chiado.

Portanto, as estruturas de dependência dos modelos de sintomas confirmam dados de literatura citados anteriormente, e apontam para diferentes mecanismos patogênicos atuando na gênese e evolução dos mesmos. É necessário que se façam estudos mais aprofundados sobre este tema, uma vez que há poucos dados de literatura e, podem contribuir para um melhor entendimento da história natural das doenças respiratórias (notadamente das vias aéreas).

Para complementar, uma questão fica "sub judice". As prevalências de sintomas encontrados neste grupo são maiores do que na população geral? Estudos comunitários são mais adequados para responder a esta questão, uma vez que eliminam o viés de seleção de grupos ocupacionais expostos a riscos respiratórios. As prevalências de tosse, catarro, tosse e catarro, e dispnéia, referidas por HIGGINS ${ }^{103}$ para mineiros e exmineiros de carvão, foram absolutamente superponíveis às aqui descritas. Apenas a de chiado foi maior, mas não há informaçōes da questāo utilizada para este cálculo. Quando comparada à população não exposta, não houve diferenças significativas em relação aos 5 sintomas. 
Em um outro estudo do mesmo autor ${ }^{104}$, as razōes de prevalência de $\mathrm{BC}$ de mineiros e ex-mineiros para nāo mineiros variaram de 1,2 a 6,4, e, de dispnéia, de 1,0 a 9,3, em 5 comunidades distintas (GB e EUA).

LEBOWITZ $^{137}$ encontrou uma maior prevalência de sintomas respiratórios em indivíduos que referiram exposição importante à silica, fibras de vidro, e gases de motores de combustão, em um estudo populacional. KORN e col. ${ }^{132}$ mostraram achados semelhantes em um estudo populacional de maior dimensão, relatando razōes de chance entre 1,32 e 1,60 para tosse, catarro, dispnéia, e chiado, em grupos que referiram exposição a poeiras, fumos e gases comparados a indivíduos não expostos.

Pode-se levantar a hipótese que, na coorte, provavelmente os sintomas dispnéia e chiado são mais prevalentes do que na população geral, uma vez que o primeiro não apresentou relação com o tabagismo, e o segundo mostrou uma evolução ao longo do período de observação. Em relação à tosse, catarro e $\mathrm{BC}$, uma vez que são dependentes do tabagismo, há necessidade de um estudo amplo para concluir adequadamente se há um excesso dos mesmos.

\subsection{Reatividade Brônquica e Asma}

A medida da reatividade brônquica, através de testes de PB com agentes colinérgicos ou histamina, tem sido utilizada em estudos epidemiológicos, tanto em estudos populacionais ${ }^{184,203,226,237}$, como em alguns grupos ocupacionais ${ }^{74,168,194,239}$. Neste trabalho, os testes foram feitos com a finalidade de investigar a ocorrência de asma e, de analisar as relações entre HRB e declínio funcional longitudinal.

A HRB não se associou com os índices de exposição ocupacional (TABELA 3.22), nem com os grupos de tabagismo (TABELA 3.23). Mineiros de ferro com PB positiva não apresentaram diferenças em relação ao tempo de mineração comparados com os de $\mathrm{PB}$ negativa ${ }^{194}$. Em um grupo de trabalhadores de silos de grãos, a positividade da $\mathrm{PB}$ não se associou significativamente com o tempo de exposição ${ }^{168}$. Em um grupo de 227 trabalhadores de serrarias de cedro vermelho, um acompanhamento longitudinal mostrou que o tempo de exposição não se associou com os resultados da PB, porém, trabalhadores com $\mathrm{PB}$ persistentemente positiva no seguimento, apresentaram uma maior exposiçāo cumulativa a poeira total ${ }^{239}$. 
A influência do tabagismo sobre a HRB é controversa. Alguns trabalhos apontam para uma maior prevalência de HRB em fumantes ${ }^{28,226}$, enquanto a maioria das publicaçōes não relatam uma associação entre o tabagismo e a resposta à

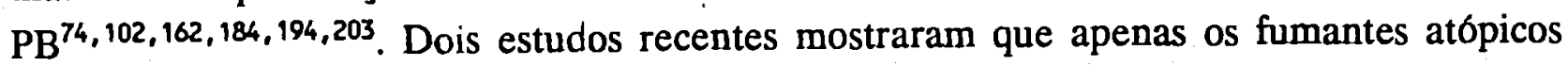
tem prevalência aumentada de $H_{R B}{ }^{128,184}$. Por outro lado, em portadores de LCFA induzida pelo tabagismo, a geometria alterada das vias aéreas facilita a resposta à inalação de drogas broncoconstritoras ${ }^{169}$.

Parte destes estudos mencionados leva a crer que há duas vertentes em direção à LCFA: por um lado a atopia, e por outro, as alteraçōes estruturais de vias aéreas causadas predominantemente pelo tabagismo, o que não reforça a "hipótese holandesa" da LCFA $^{187 *}$. Estes aspectos foram brilhantemente comentados por BURROWS ${ }^{31}$.

Sintomas respiratórios relacionam-se com a reatividade brônquica $^{74,194,203,226}$. As TABELAS 3.11 a 3.13 mostraram a análise de alguns fatores (variáveis independentes) em relaçāo ao relato de $B C$, dispnéia e chiado, em modelos de regressão logística. A HRB estava associada significativamente ao chiado. Dividindo-se a coorte em grupos sintomáticos mutuamente exclusivos, estratificados pelo tabagismo, calculamos as razōes de prevalência de PB positiva para PB negativa (TABELA 3.24). Mineiros com chiado apresentaram PR(s) significantes, independentemente do tabagismo. Apenas mineiros com BC comportaram-se de forma distinta, com os não fumantes apresentando uma PR significante. PHAM e col. ${ }^{194}$ demonstraram, em um estudo transversal, que um teste de $\mathrm{PB}$ (com acetilcolina) positivo relacionava-se à presença de $\mathrm{BC}$, asma e dispnéia em 1.109 mineiros de ferro; destes, 820 foram seguidos longitudinalmente e, nos mineiros com PB positiva na primiera avaliação, estes sintomas persistiam, além de ter havido uma maior perda de mineiros com $\mathrm{PB}$ positiva no seguimento. ENARSON e col. ${ }^{74}$ descreveram os resultados das medidas de $\mathrm{PB}$ e a presença de sintomas relacionados à asma e à BC em 1392 trabalhadores de diversas indústrias. A proporção de trabalhadores assintomáticos respiratórios foi de $54,6 \%$, comparável aos $55 \%$ da coorte aqui descrita. A HRB associou-se melhor com sintomas relacionados à asma, porém para o grupo considerado como HRB leve ( $\mathrm{PC}_{20}$ de metacolina entre 2 e $8 \mathrm{mg} / \mathrm{ml}$ ), a positividade à $\mathrm{PB}$ foi igual em trabalhadores apresentando $\mathrm{BC}$ ou com um diagnóstico médico de asma.

"A "hipótese holandesa" associa fatores ambientais como o tabagismo e a poluiçảo atmosférica com a BC, porém a "tendência asmática", medida como HRB, ć o principal fator levando à LCFA. 
Dois estudos populacionais recentes relacionaram medidas de HRB com sintomas respiratórios. SPARROW e col. ${ }^{226}$, apresentaram resultados de 458 indivíduos do sexo masculino, entre 41 a 86 anos de idade, mostrando uma associação significativa entre $\mathrm{PB}$ positiva e respostas afirmativas às questões de chiado. Houve também uma associação marginal entre PB positiva e tosse crônica. RIJCKEN e col. ${ }^{203}$, em um estudo mais amplo, demonstraram uma associação significante entre PB positiva e tosse, catarro, episódios agudos de bronquite nos últimos 3 anos, dispnéia grau 3, chiado persistente e crises asmáticas.

Estes trabalhos epidemiológicos utilizaram-se de metodologias distintas para o teste de PB e para a classificação da PB em positiva ou negativa. E provável que alguns resultados discordantes sejam fruto das diferentes padronizaçōes metodológicas. Nestes estudos, há uma forte associação entre sintomas, notadamente o chiado, e hiperreatividade brônquica. Porém, o fato que em estudos populacionais, mesmo em indivíduos assintomáticos, há uma proporção de positivos e a distribuição de respostas entre os grupos sintomáticos são sobrepostas, diferentemente de estudos de PB que enfocam o binômio normais-asmáticos, é possível que seja mais conveniente sumarizar os resultados da $\mathrm{PB}$ como uma variável contínua e não dicotômica ${ }^{185,202}$. Isto eliminaria o viés causado pela fixação de um ponto arbitrário de corte, que normalmente é estabelecido para se classificar um indivíduo como positivo ou negativo. Uma outra opção, seria adotar um corte mais liberal, como o $\mathrm{PC}_{15}{ }^{78}$, o que aumentaria a sensibilidade dos resultados sem afetar a sua reprodutibilidade.

Mineiros com PB positiva apresentaram diferenças significativas na espirometria basal. A TABELA 3.54 mostrou que o $\mathrm{VEF}_{1}$, tanto em valor absoluto, como ajustado para altura, ou para percentagem do previsto, foi mais baixo neste grupo. $O$ declínio do $\mathrm{VEF}_{1}$ foi mais acentuado em mineiros com $\mathrm{PB}$ positiva, porém a diferença foi de significância marginal. MINETTE e col. ${ }^{162}$, em um estudo caso-controle de mineiros de carvão sintomáticos, originários de internações hospitalares, nāo encontrou diferenças significantes entre o VEF, basal nos grupos de $\mathrm{PB}$ positiva ou negativa, estratificados por tabagismo. No estudo de PHAM e col. ${ }^{194}$ mineiros de ferro com PB positiva apresentavam um VEF, basal e um IT mais baixos, e a evolução de ambos os parâmetros no seguimento foi mais acentuada (declínio rápido) em mineiros com $\mathrm{PB}$ positiva no primeiro exame. Em trabalhadores de cedro vermelho ${ }^{239}$ o $\mathrm{VEF}_{1}$ basal foi significativamente menor no grupo de $\mathrm{PB}$ positiva e, na evoluçāo, aqueles que persistiram com $\mathrm{PB}$ positiva mantiveram-se com 
valores mais baixos de $\mathrm{VEF}_{1}$. E interessante notar que no seguimento, trabalhadores que passaram a não responder à $\mathrm{PB}$ apresentaram uma melhora funcional pulmonar. SPARROW e col. ${ }^{226}$ encontraram razōes de prevalência de PB (positiva/negativa) significativas em indivíduos com $\mathrm{VEF}_{1} \mathrm{e} \mathrm{FEF}_{25-\pi 3}$ anormal nos grupos de não fumantes e exfumantes. Curiosamente, no grupo de fumantes, as razōes de prevalência não foram significativas para o estes mesmos parâmteros.

A TABELA 3.48 mostrou um modelo de regressāo linear entre o DVEF, e o resultado da PB. Houve correlaçāo significante, porém fornecendo uma explicaçāo mínima ao modelo $\left(r=0,14, r^{2}=0,02\right)$, Estes resultados são compatíveis com a literatura já comentada e, também, com dados dos estudos populacionais de doenças pulmonares obstrutivas crônicas feitos na Holanda ${ }^{237}$, e de envelhecimento feitos nos EUA $^{188}$.

Estudos específicos de reatividade brônquica em mineiros de carvâo foram efetuados por MINETE na Bélgica ${ }^{162,163,164}$ e por HUDGEL e col. nos EUA ${ }^{108}$. Os primeiros, não demonstraram associaçāo entre a presença de pneumoconiose e HRB, nem entre a gravidade do quadro de $\mathrm{BC}$ e a $\mathrm{HRB}$, porém, mineiros com PB positiva apresentaram um declínio funcional significativamente maior, em um período de observaçāo de 4 a 5 anos. Os autores do segundo trabalho compararam resultados de PB em 22 mineiros de uma determinada mina, não fumantes e ex-fumantes, com um grupo controle, sendo que a positividade foi de $41 \%$ e $20 \%$, respectivamente. Este trabalho foi interrompido devido ao fechamento da mina e o grupo de "casos" ficou restrito. Mesmo assim, os autores sugeriram que a PB poderia ser utilizada para identificar mineiros em risco de evoluirem com uma deterioração acelerada da função pulmonar.

A análise das TABELAS 3.25 e 3.26 mostrou que 51 mineiros da coorte referiram dados, ao questionário, compatíveis com o diagnóstico de asma, aqui utilizado. Restringindo estes 51 casos ao início dos sintomas após entrarem nas minas, aliado a uma melhora com o afastamento do trabalho, 34 apresentaram sintomas compatíveis com asma de característica ocupacional. O critério do diagnóstico de asma utilizado já foi comentado anteriormente; ele é compatível com a categoria "asma atual questionável" (Classe 3) do estudo epidemiológico sobre a história natural da asma, desenvolvido nos EUA ${ }^{107,232}$. A maior parte dos mineiros com uma resposta positiva à questāo $5.2 \mathrm{em} 1989$ apresentou o início dos sintomas após entrar na mina (TABELA 3.25). Como já mencionado, o chiado foi o único sintoma que evoluiu significativamente entre 1984 e 1989, além do que a exposição a 
poeiras foi significativamente associada ao chiado (TABELAS 3.13 e 3.15). Portanto, há dados numéricos que mostram uma evolução do chiado, associada à exposição ocupacional, em um período de oḅservação de 5 anos.

Mineiros de carvão apresentam uma diminuição nos índices de expiraçāo forçada, particularmente no fluxo a volumes pulmonares baixos e no VEF, ao longo da jornada de trabalho ${ }^{135,143}$. Embora ambas as citações discordem em relação a um efeito da exposição ocupacional sobre estes achados, o fato é que estas alterações vão em direção contrária à cronobiologia das vias aéreas (elas são observáveis tanto em mineiros de turno diurno como em mineiros de turno noturno fixo), comprometendo também a porção da curva fluxo-volume independente de esforço.

Estes dados, sugestivos de reatividade brôquica aumentada ${ }^{108}$, associados a dados de uma deterioração funcional ao longo do turno de trabalho ${ }^{135,143}$, são indicativos de uma labilidade aumentada das vias aéreas neste grupo ocupacional. Nossos achados de evolução do chiado e de sua relação com a exposição ocupacional reforçam a suspeita de que, efetivamente, a prevalência de asma é maior em mineiros de carvão.

Hoje, há uma tendência em associar-se o diagnóstico de asma brônquica com hiperreatividade brônquica. Como então conciliar o diagnóstico de asma (51 casos), ou asma ocupacional (34 casos), com os achados de PB? A TABELA 3.25 mostrou que 22/51 (43,1\%) apresentaram PB positiva, e a TABELA 3.26 mostrou que $15 / 34(44,1 \%)$ apresentaram $\mathrm{PB}$ positiva.

Em um excelente editorial sobre reatividade brônquica, COCKROFT e HARGREAVE ${ }^{49}$ discutem uma série de aspectos sobre asma e HRB. A asma brônquica é uma doença que pode manifestar-se de forma episódica, não sendo necessário que a reatividade brônquica permaneça anormal constantemente. Em um recente estudo populacional transversal, PATTEMORE e col. ${ }^{190}$ encontram uma positividade à PB de 52\%, em crianças com referência de asma ao questionário. É possível que nos $48 \%$ restantes haja diagnósticos errôneos, mas muitas das crianças poderiam efetivamente estar em um período assintomático ou paucissintomático. $O$ que não se espera é uma reatividade brônquica normal em indivíduos com asma, durante um período sintomático.

Quando se aborda mais especificamente em asma ocupacional, algumas de suas características são peculiares. E possível encontrarmos asmáticos 
ocupacionais sem $\mathrm{HRB}^{98,148}$ e, comumente, encontramos asmáticos não atópicos ${ }^{34}$. Há dados que sugerem que na asma ocupacional, a reatividade brônquica é mais uma consequência da ação do agente do que a causa da doença ${ }^{98}$. Crises de broncoespasmo com dispnéia podem ser desencadeadas por mecanismos irritativos de vias aéreas, resolvendo de forma rápida com o afastamento da exposição. Embora este não seja o mecanismo mais comum em asma ocupacional ${ }^{34,87}$, os fatores desencadeantes mais frequentemente mencionados pelos mineiros poderiam perfeitamente atuar desta forma, com períodos transitórios de aumento da reatividade brônquica. Para se avaliar adequadamente o diagnóstico de asma ocupacional nos mineiros de carvão, a PB deveria ser feita nos períodos de manifestaçōes clínicas presentes.

Resumindo, a prevalência de sintomas compatíveis com asma classe $3^{107}$ foi de $18,2 \%$, e de asma ocupacional, $12,1 \%$. Embora este estudo não seja conclusivo, pelos aspectos discutidos acima, acreditamos que os dados apresentados constituem uma indicação para incluir a asma entre as patologias associadas à exposição ocupacionạl em mineiros de carvão.

\subsection{Prevalência de Pneumoconiose, Evolução Radiológica e Fatores de Risco}

A prevalência pontual de pneumoconiose foi de 5,4 e 7,9\%, em 1984 e 1989, respectivamente (TABELA 3.27). Embora em 1989 houvesse mais mineiros com radiografias suspeitas e anormais, as diferenças não foram estatisticamente significantes. A prevalência pontual real de pneumoconiose deve ser considerada tomando-se como base 0 trabalho de 1984. Naquela ocasiāo, na amostra original de 956 mineiros era de 5,6\%4. Isto porque, a coorte do presente estudo foi selecionada com base em critérios já discutidos, e portanto os dados de 1989 certamente não representam a população de mineiros de carvão.

Qual é a importância destes números? Vamos tomar como base a prevalência de 5,64, ou mesmo 5,4\% (TABELA 3.27). Em um estudo de prevalência nacional nos EUA no início da década de 80, a prevalência de PMC foi de 4,5\% ${ }^{158}$. A média aproximada de anos de exposição de mineiros com $\mathrm{PMC}$ foi de 24 (calculado da referência 158, TABELA II-24, pg 350). Na GB, dados oficiais encontram-se sumarizados por PARKES $^{189}$. Em 1978, a prevalência de PMC era de 5,2\%. Não há dados para se deduzir o tempo médio de exposição, pois na GB o índice de exposição atualmente utilizado é o 
cumulativo, porém a probabilidade de se adquir PMC categoria 2 ou mais, nos limites permitidos de poeira, é próximo a 4,5\% após 35 anos de trabalho no subsolo ${ }^{113}$.

O tempo médio de exposição de mineiros com PMC em 1984, foi de 8,4 anos ${ }^{4}$. Os dados da coorte de 1984 mostraram que o tempo médio foi de 9,9 anos (TABELA 3.28). Portanto, embora os números de prevalência sejam semelhantes, salta aos olhos a diferença quanto ao tempo de exposição médio para se adquirir a PMC. Se se pensar que, no Brasil, a maior parte dos mineiros de subsolo tem aposentadoria especial após 15 anos, qualquer estudo nacional em mineiros ativos será uma subestimativa real da prevalência da PMC, uma vez que a doença pode manifestar-se após os 15 anos de trabalho independente de exposição.

As TABELAS 3.28 e 3.29 mostraram a associação da PMC com os índices de exposiçāo e um modelo de regressão logística para o estudo do melhor ajuste dos mesmos, respectivamente. Há um gradiente de médias dos índices, tanto para a SANO quanto para a SANOAJ. Este último, apresentou um melhor ajuste com a presença de pneumoconiose no Rx. Nesta análise, casos com uma mediana de leituras $0 / 1$ foram incluídos como "pneumoconiose ausente". A PMC é uma patologia de cunho puramente ocupacional e, basicamente, é uma função da exposição a poeiras. Em um estudo sobre a PMC em ex-mineiros as estimativas de prevalência de PMC, calculadas com base na exposição cumulativa de mineiros, descreveram adequadamente os achados radiológicos ${ }^{223}$. A exposição cumulativa, utilizada principalmente na GB e Alemanha (TABELA 4.1), associou-se melhor com a PMC do que o índice "anos de exposição"223 e há dados de literatura mostrando que, além da exposição cumulativa, há um efeito do "tempo de residência" da poeira nos pulmões ${ }^{111,200}$.

Além das evidências em estudos de populações expostas, há dados de correlaçōes anatomo-patológicas que também trazem um substrato para estes achados. Logo no início da utilização da escala radiológica de 12 pontos da OIT, ROSSITER ${ }^{205}$ mostrou que havia uma relação linear significativa entre a quantidade de carbono nos pulmões e a aparência radiológica. Dois estudos publicados pelo grupo do IOM, mostraram uma boa correlação entre poeira total nos pulmões e imagem radiológica, além do que, em mineiros trabalhando em minas de carvão de baixo teor de carbono, a melhor associação dos achados radiológicos era com o conteúdo de cinzas no pulmão, enquanto que em minas de carvão alto teor de carbono a aparência radiológica associava-se tanto ao conteúdo de cinzas quanto ao carbono ${ }^{207}$. A correlação entre a quantidade total de poeira e a profusão é melhor 
para radiografias apresentando opacidades do tipo "p"79. Ambos os estudos sugerem que as opacidades maiores, notadamente as " $\mathrm{r}$ ", associam-se a lesões fibróticas maiores, indicando a possibilidade de lesōes silicóticas.

Os dados publicados em outros países sobre o papel do quartzo nas curvas de probabilidade de pneumoconiose em mineiros de carvão devem ser tomados com cautela, uma vez que tanto em minas britânicas como alemãs a concentração média de quartzo na poeira respirável não ultrapassa 7,5\%. As pequenas flutuaçōes encontradas dentro desta faixa não modificam as curvas de probabilidade ${ }^{223}$, contudo há dados de um estudo caso-controle que mostra haver uma rápida progressão de imagens radiológicas associada a quantidades maiores de quartzo na poeira respirável ${ }^{115}$. E provável que as curvas de probabilidade da PMC para as minas brasileiras sejam distintas dos dados conhecidos de literatura, uma vez que os níveis de quartzo respirável sāo altos ${ }^{235}$ e o quartzo é muito mais fibrogênico que o carbono.

A progressão radiológica observada nos 223 mineiros com $\mathbf{R x}$ interpretados em 1984 e 1989 foi discreta (TABELAS 3.27 e 3.30). A progressão foi aqui definida como uma mediana de leitura de 1989 superior em 1 subcategoria em relação à mediana de 1984. Será que este critério é válido? Será que o tempo de observação de 5 anos é adequado para se analisar progressão? Será que o método de leitura radiológica utilizado é o mais adequado para o estudo de progressão?

Há poucos estudos sobre progressão radiológica em mineiros de carvão na literatura. JACOBSEN e col. ${ }^{115}$ publicaram um estudo caso-controle sobre "progressāo rápida" em mineiros de carvão. O critério utilizado foi de progressão de duas ou mais subcategorias em um período de aproximadamente 10 anos, por pelo menos 3 de 5 leitores, analisando-se as radiografias pareadamente, isto é, com diferentes $\mathrm{Rx}$ do mesmo mineiro analisados em conjunto. ATTFIELD e col. ${ }^{12}$ analisaram dados longitudinais de 1252 mineiros de carvão nos EUA. Em um período de observação de 9 anos, 43 mineiros progrediram, 23 regrediram e 1186 permaneceram estáveis.

Em um estudo volumoso sobre seguimento radiológico de operários expostos ao asbesto, WERNER ${ }^{242}$ mostrou que, de um total de 6.369 pares de radiografias, 1.339 involuiram e 510 progrediram em um período médio de 3,5 anos entre as radiografias. Estes achados discrepantes foram atribuídos a alguns fatores, entre os quais a falta de intercâmbio e de sessōes conjuntas entre os leitores, o método de leituras independentes e o 
próprio fato dos dados terem sido gerados de 1972 a 1978. Em 1972, a escala de 12 pontos era muito recente e fica notório pela análise da TABELA 2 do estudo de WERNER ${ }^{242}$, que o número de radiografias consideradas anormais caiu expressivamente com o passar dos anos.

LIDELL e col. ${ }^{141}$ publicaram uma excelente revisão sobre os métodos de avaliaçāo de radiografias seriadas. Através de análises de 7 estudos epidemiológicos, medindo-se a consistência, o "ruído", a especificidade e as correlações entre os métodos de leitura conjunta e independente, os autores concluiram que a leitura conjunta tem melhor especificidade que a leitura independente, embora não houvesse evidências de uma diferença consistente de resultados entre os dois métodos.

Apesar de se conhecer previamente estas referências, não houve possibilidade de interpretação conjunta dos 223 pares de radiografias, pois não se estava de posse das radiografias de 1984. Antes de iniciar as leituras em 1989, houve uma sessão conjunta de leitura entre o Leitor 1 e o Leitor 2, e entre o Leitor 1 e o Leitor 3 (o Leitor 1 é um Leitor B-NIOSH), com o objetivo de "ajustar" as interpretações. Houve em uma boa concordância de leituras (aqui definida como interpretações dentro de mais ou menos 1 subcategoria): $87,9 \%$ entre o Leitor 1 e o Leitor 2, 91,2\% entre o Leitor 1 e o Leitor 3 e $87,9 \%$ entre o Leitor 2 e o Leitor 3. O período de observação de 5 anos entre as radiografias foi menor do que no estudo caso-controle descrito ${ }^{115}$, mas semelhante aos estudos comentados na revisão de LIDELL e col. ${ }^{14}$. O intervalo de 4 anos entre as interpretações de 1984 e 1989 tráz um possível viés que não há como analisar, no entanto a inspeção da TABELA 3.30 indica que os dados radiológicos são consistentes pela sua distribuição no tempo.

Considera-se também, que o achado de involução radiológica para 0 normal em 6 mineiros, (2,7\%) é um número baixo, inferior aos $10,1 \%$ do estudo de WERNER $^{242}$, porém superior aos $0,8 \%$ do estudo de ATTFIELD e col. ${ }^{12}$, e é um evento típico da interpretação de radiografias pelo método de leitura independente.

Mineiros com progressão ao Rx apresentaram uma média de SANOAJ significativamente maior que os mineiros que permaneceram com a mesma leitura, e um $\mathrm{VEF}_{1} \mathrm{AJ}$ significativamente menor (TABELA 3.31). O modelo de regressão logística (TABELA 3.33), comparando apenas os grupos de progressão e estáveis confirmou os mesmos achados e, ainda, acrescentou o tabagismo quantitativo (AM) e um efeito 
combinado sinérgico da exposiçāo com o tabagismo (SANO X AM) como significativamente relacionados com a progressão. Portanto, além da exposição ocupacional, o VEF, e o tabagismo foram importantes preditores da progressão radiológica. Em relação ao primeiro, $\varepsilon$ interessante notar que, embora o $\mathrm{DVEF}_{1}$ fosse maior nos que progrediram, não houve significância estatística. É possível, então, que mineiros com VEF, mais baixo ao iniciar a pesquisa fossem passíveis de progressão radiológica. Efetivamente, foi notado no estudo original de $1984^{4}$ que mineiros com pneumoconiose, naquela ocasião, apresentavam um $\mathrm{VEF}_{1}$ mais baixo.

A incidência de pneumoconiose no período entre 1984 e 1989 foi de $57 / 1.000$, dando uma média de 11,4 casos anuais por 1.000 mineiros em risco. MUIR e col. $^{177}$ publicaram dados referentes às décadas de 50 e 60 na $\mathrm{GB}$, onde a incidência de pneumoconiose foi de 77/1.000 num período de 10 anos, ou seja, 7,7 casos anuais por 1.000 mineiros em risco. Dados inferidos da TABELA 8.2 da publicação de PARKES ${ }^{189}$ mostram que o pico de incidência de PMC na GB foi por volta de 7,5/1.000, no ano de 1955. Nos EUA, dados publicados por ATTFIELD e col. ${ }^{12}$ mostram que a incidência de pneumoconiose na década de 70 foi de aproximadamente 25,8/1.000 em um período de observação de 9 anos (2,9 casos anuais por 1.000 mineiros).

Pequenas opacidades foram registradas em 57 radiografias (35 com profusāo $0 / 1$ e 22 com 1/0 ou mais). Estas distribuiam-se quase que perfeitamente pelos 4 índices de regularidade. $O$ IR não se associou a sintomas respiratórios, nem ao tabagismo. Houve uma tendência estatisticamente nāo significante, a que mineiros com IR igual a 4 apresentassem os índices funcionais respiratórios diminuídos (TABELA 3.35).

Opacidades irregulares não são as mais frequentes na PMC. Tem havido uma série de debates em relação à sua significância em mineiros de carvão. Dois trabalhos britânicos mostraram que elas são mais prevalentes com o passar dos anos de seguimento ${ }^{45,144}$. O substrato anatomopatológico é de uma fibrose intersticial não delimitada em nódulos, e é tipicamente a opacidade prevalente na asbestose. LYONS e col. ${ }^{144}$ publicaram em 1974 o primeiro estudo referente à significância das opacidades irregulares na PMC. Eles demonstraram que, a medida em que passam os anos de seguimento, elas se tornam mais prevalentes. A presença das mesmas correlacionou-se significativamente com a presença de enfisema na autópsia e com um $\mathrm{VEF}_{\mathbf{q}}$ mais baixo. AMANDUS e col. ${ }^{6}$, descreveram os achados clínicos e fisiológicos em mineiros de carvão, concluindo que a presença de opacidades irregulares era associada ao tabagismo, BC, idade 
e anos de exposição. O VEF médio, o IT e a Capacidade Pulmonar Total (CPT) eram também mais baixos, comparados com mineiros apresentando opacidades regulares. A influência da idade e da exposição ocupacional foi também encontrada em estudos utilizando anos de exposição ${ }^{45}$, ou exposição cumulativa ${ }^{52}$. Neste último estudo, que envolveu uma amostra grande, a presença de opacidades irregulares associou-se a déficits do VEF, e do CVF. A difusão do monóxido de carbono também se altera em mineiros com opacidades irregulares ${ }^{47,60}$.

Os achados da TABELA 3.35, embora não significantes, indicam uma tendência a uma pior função pulmonar em mineiros com opacidades irregulares ao Rx. Provavelmente, elas são associadas à presença de enfisema pulmonar, ou fibrose intersticial (R10), e indicam um prognóstico clínico mais grave do que mineiros com opacidades predominantemente regulares.

O tabagismo não exerceu influência sobre a presença de pneumoconiose em 1989 (TABELA 3.38), porém foi importante em relação à progressão radiológica, apresentando um efeito isolado, e também sinérgico com anos de exposição (TABELA 3.33). Os dados de literatura são controversos em relação a associação entre PMC e tabagismo. O tabagismo foi significativamente associado à presença de opacidades irregulares $^{6,45}$. Outros trabalhos não demonstraram associação entre tabagismo e opacidades irregulares ${ }^{52}$, nem entre o tabagismo e a $\mathrm{PMC}^{140}$. E possível que, efetivamente, a presença de opacidades irregulares associe-se com o tabagismo, uma vez que este último se associa ao enfisema pulmonar.

\subsection{Espirometria e Dimensões de Vias Aéreas}

Os dados espirométricos de 1984 e 1989 foram mostrados de forma gráfica (FIGURAS 3.2 e 3.3) e tabular (TABELAS 3.39 e 3.40). Para o VEF, CVF e FEF $_{25}$. ${ }_{75}$, houve uma queda gradual por faixa etária. Isto não é claramente observado para o IT, onde apenas em 1984 há uma queda mais acentuada dos 21 a 25 anos para a faixa seguinte (TABELA 3.39). Os valores médios do $\mathrm{VEF}_{1}$ e do IT, declinaram significativamente entre 1984 e 1989 (TABELA 3.1). Isto não foi visto para a CVF, que apresentou crescimento médio no período de observação (TABELA 3.1). 
Estudos populacionais mostram que a CVF apresenta uma curva de crescimento discretamente diferente do VEF, em indivíduos normais do sexo masculino ${ }^{32}$. Há uma clara dependência da altura dos 12 até os 18-19 anos, com um componente de idade discreto. Entre os 18 e os 35 anos há ưm aumento leve, seguido de uma queda leve, que não são significantes e independem da altura. $O$ treinamento muscular da cintura escapular tem uma influência positiva sobre o crescimento da CVF através de uma melhor função da musculatura acessória inspiratória ${ }^{55}$. Este efeito pode ser avaliado após o período de dependência da CVF em relação à altura. Alguns estudos epidemiológicos sobre mineiros de carvão mostram que a CVF nāo costuma ser afetada em mineiros ativos. JAIN e col. ${ }^{116}$ estudaram 675 mineiros de carvão na Nigéria; a CVF média do grupo era normal e mineiros de frente de serviço apresentavam valores médios discretamente acima do previsto, porém com fluxos expiratórios diminuídos. ZICHENG ${ }^{244}$ não mostrou diferenças na $\mathrm{CVF}$ em mineiros de carvão com mais de 10 anos de subsolo, sem pneumoconiose, ou com pneumoconiose simples, comparados com um pequeno grupo controle. NEMERY e col. ${ }^{181}$ compararam um grupo de mineiros de carvão não fumantes com um grupo de operários de siderúrgica não fumantes, pareados pela idade. Os mineiros de carvão apresentaram um $\mathrm{VEF}_{1}$ e uma $\mathrm{PaO}_{2}$ significativamente menores, e uma diferença alvéolo-arterial de $\mathrm{O}_{2}$ maior. A CVF foi semelhante nos dois grupos.

O comportamento da CVF em mineiros de carvão pode portanto apresentar algumas peculiaridades. A atividade exige um considerável esforço muscular da cintura escapular, principalmente na frente de trabalho, levando a um treinamento muscular contínuo. O discreto aumento da CVF média durante o período de observação pode ser justificado por este treinamento e pela média de idade da coorte, ainda dentro do período de estabilidade da CVF.

O próprio comportamento do IT reforça esta hipótese. Na TABELA 3.39, como já mencionado, há uma queda acentuada do IT na faixa dos 26 a 30 anos, comparada com a faixa anterior. É muito provável que os mineiros mais velhos tivessem uma SANO maior e, consequentemente, um maior treinamento muscular, levando a uma diminuição relativa do $\mathrm{VEF}_{1}$ para a CVF.

$\mathrm{O} \mathrm{VEF}_{1}$ no sexo masculino, por sua vez, alcança um valor de pico por volta dos 19 anos, com mínimas modificações até os 27 anos $^{32}$. Nāo há influência do 
treinamento muscular sobre o seu comportamento sendo considerado um indicador muito mais sensível que a CVF para fatores de riscos ocupacionais.

As equações de regressão para o $V F_{1}$ e a CVF na TABELA 3.41 mostram também um comportamento diferenciado dos dois índices em relação a Idade. Os coeficientes de idade do VEF, sāo semelhantes em 1984 e 1989 e aumentam para o CVF (todos sempre na mesma direção). Provavelmente trata-se de um "efeito de coorte", pois as equaçōes de 1984 refletem valores de mineiros com uma média de idade mais baixa. É possível que equações de regressão para o CVF em 1984, por faixas etárias distintas, mostrem inclusive um coeficiente positivo para idade, na primeira faixa etária.

Nos modelos de regressão linear múltipla do $\mathrm{VEF}_{1}$ não houve a entrada das variáveis de exposiçāo (SANO ou SANOAJ). Com dados gerados no trabalho longitudinal britânico de mineiros de carvão,"'Pneumoconioses Field Research"' MARINE e col. $^{149}$ derivaram uma equação interna de predição do $\mathrm{VEF}_{\uparrow}$, aonde houve a inclusão do termo "poeira", expresso em exposição cumulativa (g.h.m ${ }^{-3}$ ), que foi significante. É possível que os índices de exposição aqui utilizados não sejam suficientemente precisos para descrever correlações com os parâmetros funcionais. Pode ser, também, que os efeitos da exposição sobre os parâmetros ocorram mais lentamente e a análise de mineiros com 10 anos de exposição é ainda insuficiente para detectar estes efeitos.

Da mesma forma, não houve inclusão de exponenciais de Idade $\left(I^{2} \mathrm{e}\right.$ $\mathrm{I}^{3}$ ). Em populaçōes adultas normais, a variável Idade tem uma relação linear com o $\mathrm{VEF}_{1} \mathrm{e}$ a CVF, mas em fumantes e em grupos ocupacionalmente expostos observa-se, com frequência, um efeito exponencial de Idade ${ }^{215}$. Um acompanhamento longitudinal de grupos controle e ocupacionalmente expostos a poeiras de grãos, confirmou estes achados ${ }^{214}$. $O$ efeito exponencial da idade sobre o declínio do $\mathrm{VEF}_{\text {, }}$ pode ser entendido como uma somatória ao processo de envelhecimento, de exposições ocupacionais cumulativas. $\mathrm{Na}$ coorte, estes efeitos não foram detectados. As considerações do parágrafo acima, referentes ao tempo de acompanhamento destes mineiros em relação à exposição ocupacional, aplicam-se também aos efeitos da idade, pois são variáveis colineares.

A TABELA 3.42 mostrou os parâmetros funcionais de forma percentual em relação aos valores previstos utilizados ${ }^{131}$ e a TABELA 3.43 classificou os mineiros como normais e alterados, através do critério do $95^{\circ}$ percentil. $O$ pequeno número de mineiros com $\mathrm{VEF}_{1}$ e CVF alterados em 1989 chama a atenção. As modificações 
longitudinais do CVF já foram discutidas anteriormente. Não se esperava encontrar um número tão baixo de mineiros com $\mathrm{VEF}_{1}$ alterado em 1989, mesmo porque, em 1984, já havia 11 alterados. Alguns fatores podem ter influenciado estes achados e serão comentados a seguir.

Em '1984, as espirometrias foram feitas nas minas, em diferentes fases de turnos de trabalho. Estes aspectos já foram abordados no subitem 4.2.3. Talvez isto tenha influenciado nas manobras do $V E F_{1}$ levando à obtençāo de resultados que não refletiram a condiçāo basal ideal.

Em estudos longitudinais de função pulmonar é comum observarmos o fenômeno de "regressão em direção à média", ou "efeitos de aprendizado"29,30, que pode ser resumido como o resultado do aprendizado de manobras corretas de espirometria, levando a obtençāo de valores melhores em repetições das provas. Não acreditamos que isto tenha sido importante na coorte, porque as provas foram feitas com um intervalo de 5 anos. Poucos mineiros fizeram espirometria neste intervalo de tempo, além do que durante o trabalho de campo a impressão era semelhante a se estar testando indivíduos pela primeira vez.

Este debate leva a algumas considerações de ordem prática. É comum em pneumologia ocupacional, utilizar-se a espirometria em exames pré-admissionais, ou em projetos específicos, esperando que haja um número de indivíduos anormais, ou mesmo que o VEF, seja um indicador sensível para o diagnóstico precoce de algumas patologias. Isto não ocorre de fato, pois rotineiramente acompanha-se uma população operária fisicamente selecionada e, portanto, tendendo a apresentar exames normais (com excessão de algumas patologias ocupacionais agudas de vias aéreas como a asma). Os efeitos crônicos da exposição a poeiras sobre as vias aéreas manifestam-se paulatinamente e, de maneira geral, dentro de um período prolongado. O que se pode encontrar é um declínio anormal do VEF, ao longo do tempo e, mesmo assim, os pontos do $\mathrm{VEF}_{1}$ podem ainda manter-se dentro da faixa de normalidade adotada. Obviamente para que isto seja observado e valorizado, as espirometrias tem que ser técnicamente perfeitas, com equipamentos bem calibrados que atendam às especificações da ATS'.

PETERSEN e col. ${ }^{192}$ estudaram valores normais de espirometria em operários ("blue-collar workers"), procurando comparar os resultados com dados de referência clássicos ${ }^{57,131,175}$. Homens brancos apresentaram um $V_{E F}$ médio superior aos 
previstos por KNUDSON e col. ${ }^{131}(p<0,05)$, porém as diferenças entre a CVF e o IT não foram significantes. Apesar de ser um trabalho com um número de normais relativamente pequeno, houve a tentativa de demonstrar possíveis diferenças espirométricas, comparandose com dados derivados de comunidade. Estas diferenças foram discretas. Infelizmente, a discussão do trabalho é muito pobre em relação ao que se deduzia de sua introdução e, ao final, o leitor fica com as mesmas dúvidas iniciais, pois os autores não se aprofundam na análise dos resultados e, principalmente, na problemática de seleçāo, que ao nosso ver era o objetivo principal do trabalho.

Devido aos achados da TABELA 3.43, algumas análises utilizando mineiros com VEF, normal e alterado nāo puderam ser feitas. Optou-se, portanto, por trabalhar com o IT como índice de normalidade/anormalidade, além de se analisar o declínio longitudinal do $\mathrm{VEF}_{1}$, e os resíduos do $\mathrm{VEF}_{1}$ e do IT. A utilização do IT como índice de obstrução é mais adequado do que o $\mathrm{VEF}_{1}$, inclusive associando-se melhor com o declínio longitudinal do $\mathrm{VEF}_{1}$ do que o $\mathrm{VEF}_{1}$ basal ${ }^{29}$, além do que o $\mathrm{VEF}_{1}$ isolado pode estar diminuido também em processos restritivos. KIBELSTIS e col. também utilizaram o IT como medida de obstrução de vias aéreas em mineiros de carvão nos EUA ${ }^{129}$.

O IT foi o único índice funcional que apresentou um declínio médio entre 1984 a 1989 (TABELAS 3.42 e 3.43). Inicialmente houve a preocupaçāo de que esta evolução do IT fosse apenas uma consequência da evolução da CVF e, na realidade, o IT também não estaria sendo fiel a um processo obstrutivo real. A TABELA 3.51 mostrou que o $\mathrm{FEF}_{25-75}$ associou-se significativamente ao IT, sendo um dado favorável a que os achados em relação ao IT estivessem realmente refletindo uma limitação ao fluxo aéreo.

A análise das dimensōes de vias aéreas centrais surgiu de um resultado curioso em 1984. Mineiros com pneumoconiose apresentavam um VEF, mais baixo e um IT alto ${ }^{4}$. Estes resultados não foram confirmados no presente estudo. No subitem 3.3.4 relacionamos o DT com sintomas respiratórios, pneumoconiose e índices funcionais (TABELAS 3.36 e 3.37). Apenas os índices VEF, AJ, CVF, e $\mathrm{FEF}_{25-75}$ associaram-se significativamente com o DT: mineiros com DT abaixo da média apresentavam volumes e fluxos significativamente menores. É improvável que a altura seja um fator importante nestes resultados, uma vez que o $\mathrm{VEF}_{1}$ ajustado para altura também mostrou diferenças significativas nos dois grupos. O DT nāo se correlacionou com o tamanho dos pulmões. Em uma amostra de 30 radiografias da coorte, correlacionou-se o DT, a área do pulmão direito calculada por planimetria, a altura do pulmão e os diâmetros inferiores e superiores. A área 
do pulmão correlacionou-se muito bem com o produto diâmetro inferior $x$ altura $\left(r^{2}=\right.$ $0,90)^{*}$. O DT não se correlacionou com nenhuma destas medidas. VEDAL e col. ${ }^{238}$, em um grupo de 239 trabalhadores de silos de grāos, encontraram uma correlaçāo fraca, porém significante, do DT com a altura e o $\mathrm{VEF}_{1}$, porém não com o $\mathrm{FEF}_{25-\pi 3}$ e o IT. Neste trabalho, o declínio anual do $\mathrm{VEF}_{1}$ foi significativamente maior em indivíduos com traquéias maiores mesmo após ajuste para idade e tabagismo. $\mathrm{Na}$ coorte, mineiros com traquéias maiores tiveram um declínio anual menor, porém estes resultados não foram significantes.

HOFFSTEIN ${ }^{106}$, utilizando-se da técnica de reflexāo acústica para medir a área da traquéia, não encontrou uma correlação significativa entre a CPT e a área traqueal em homens, mas sim em mulheres. COLLINS e col. ${ }^{53}$, correlacionando medidas radiologicas da traquéia com volumes pulmonares (CPT, diâmetros torácicos, e altura do puilmão), encontraram resultados pouco expressivos em homens e mulheres. A inclusão de medidas de dimensāo traqueal nas equaçōes de prediçāo da CVF, VEF mostrou que, embora alguns resultados fossem significativos, a sua contribuição era negligível do ponto de vista prático. A TABELA 3.44 mostrou os resultados da inclusão do

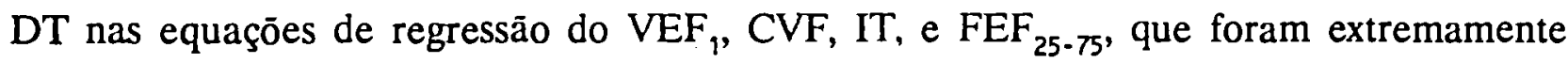
semelhantes aos obtidos no estudo acima citado.

As relaçōes entre as dimensōes de vias aéreas, a penetraçāo e deposição de aerosóis e a ocorrência de doença, sāo complexas e pouco estudadas. BECKLAKE e col. ${ }^{22}$ relataram que trabalhadores de asbesto com traquéias curtas eram mais susceptíveis a desenvolver alterações radiológicas. Teoricamente, vias aéreas maiores facilitam a deposição distal de partículas'. MUIR e col. ${ }^{177}$ estudaram as relaçōes entre pneumoconiose e bronquite crônica, a partir da hipótese que as condiçōes fossem mutuamente exclusivas, uma vez que a obstrução de vias aéreas leva a uma deposição mais central de partículas ${ }^{64}$. Não houve diferenças significantes entre a incidência de pneumoconiose em mineiros com ou sem BC, e alguns resultados aparentemente paradoxais foram constatados: por um lado, mineiros. que referiram catarro no início do seguimento tiveram uma incidência maior de PMC, por outro, mineiros com catarro necessitaram de uma maior exposição cumulativa para manifestarem a doença. Aparentemente este estudo traz um erro implícito na sua formulação, uma vez que interpreta a presença de BC como obstrução de vias aéreas. E possível que uma análise deste tipo, com critérios espirométricos 
para diferenciar indivíduos com e sem obstrução, associados a medidas de dimensões de vias aéreas, traga contribuiçōes importantes para o estudo da fisiopatologia das doenças inalatórias pulmonares.

\subsection{Efeitos da Exposição Ocupacional e do Tabagismo e Declínio Funcional}

A análise dos riscos respiratórios concorrentes, exposição ocupacional e tabagismo foi destacada ao longo deste trabalho. Os efeitos de ambas as exposições no sistema respiratório são múltiplos, envolvendo vias aéreas próximais, distais e parênquima pulmonar. Especificamente em relação a poeiras na mineração de carvão há um farto material bibliográfico sobre as alterações anatomo-patológicas resultantes da exposição.

As alteraçōes originalmente descritas por HEPPLESTON ${ }^{100,101}$ referiam-se a lesões maculares simples e ao enfisema focal ${ }^{101}$. GOUGH ${ }^{93}$ descreveu a FMP em trabalhadores de navios que carregavam carvão. DOUGLAS e col..$^{66}$ encontraram uma relação significante entre a exposição cumulativa a poeiras e um aumento na relação. glândula: parede, em brônquios centrais. Relatos da enfisema associado à exposição a poeiras na mineração de carvão podem ser encontrados nos trabalhos de RYDER e $\operatorname{col}^{210} \mathrm{e}$ RUCKLEY e col. ${ }^{206}$. Recentemente, CHURG e col. ${ }^{38}$ publicaram um trabalho sobre o comprometimento de pequenas vias aéreas e exposição a poeiras minerais. Posteriormente, CHURG e col. ${ }^{37}$ demonstraram que estas lesões associavam-se a alterações significantes nos fluxos expiratórios.

As patologias de vias aéreas causadas pela exposição a poeiras são consideradas, no presente momento, como uma das patologias ocupacionais de maior prevalância ${ }^{25}$. No Brasil, atualmente, as pneumoconioses estāo assumindo um caráter epidêmico, mascarando as outras patologias, que são problemáticas em relação ao estabelecimento do nexo causal. Nesté item será discutido de forma conjunta os efeitos destes riscos respiratórios sobre sintomas e função pulmonar, visando responder a alguns dos objetivos específicos destacados na primeira seção.

Em 1984, a presença de tosse e catarro associou-se de forma positiva significante com os índices de exposição e o tabagismo, enquanto a dispnéia e o chiado 
associou-se com os índices de exposição (TABELA 3.14). Em 1989 algumas mudanças ocorreram: a tosse e o catarro associaram-se apenas com o tabagismo e o chiado associou-se também com o tabagismo quantitativo (TABELA 3.15). Estes achados já foram dicutidos no item 4.3. Os modelos de regressão logística, em que foram utilizados dados de 1989, incluindo a $\mathrm{BC}^{*}$ para o estudo específico da exposição e do tabagismo, confirmaram a estrutura de dependência destas variáveis (TABELAS 3.16 a 3.20), não tendo sido incluídas nos modelos, variáveis combinadas, somatórias ou multiplicativas entre exposição e tabagismo. Através da análise das razōes de prevalência na TABELA 3.21, também pode-se notar a ausência de efeitos combinados da exposição e do tabagismo, com excessão do chiado, para o qual a PR foi marginalmente significante em mineiros fumantes mais expostos.

Assim, os sintomas podem ser divididos dentro de duas classes: uma delas fundamentalmente dependente do tabagismo e reversível após a cessação do fumo incluindo a tosse, catarro e a BC, e uma segunda classe fundamentalmente ligada a exposição ocupacional, que inclui a dispnéia e o chiado.

Estes resultados devem ser interpretados com cautela, pois referem-se a mineiros com uma média de 10 anos de exposição. É perfeitamente possível que num próximo seguimento, haja modificações nestas associações, assim como é possível que a análise de ex-mineiros pudesse nos trazer dados adicionais importantes.

Os efeitos da exposição e do tabagismo sobre a função pulmonar foram analisados de forma semelhante. $O$ modelo de regressão logística, tendo como variável dependente o IT normal ou alterado, mostrou significância do tabagismo quantitativo, e um efeito combinado sinérgico do tabagismo quantitativo com a exposição cumulativa (TABELA 3.52). Entretanto os cálculos das razões de prevalência na TABELA 3.53 mostraram que com excessão dos ex-fumantes mais expostos, a dicotomia de exposição não trouxe contribuiçōes adicionais.

\footnotetext{
- Somente como esclarecimento adicional, no modelo logístico da TABELA 3.20, que analisou os efeitos da exposiçăo e do tabagismo sobre a BC, não se notou o efeito inibitório do tabagismo sobre a exposiçāo, isto ć, uma queda da associaçāo entre exposição e BC após entrar a variável tabagismo na equação. Os valores do qui-quadrado antes da entrada dos grupos de fumo eram: 0,29 para SANO, 0,53 para SANOAJ, 7,97 para AM e 29,77 para os grupos de fumo. Após a entrada de grupos de fumo, o qui-quadrado de AM caiu a nível de não significância.
} 
O que chama a atenção nestes resultados é que 0 IT associou-se melhor com o número de Anos-Maço que com o grupo de tabagismo. Além disso, o comportamento dos ex-fumantes aproximou-se mais dos fumantes, indicando uma perda funcional irreversível após uma dada "exposição" ao fumo. Estes resultados estão de acordo com o trabalho de DOCKERY e col.62. O tabagismo causa perdas funcionais cumulativas irreversíveis ao longo dos anos, com um componente agudo reversível, de menor magnitude.

A presença de $\mathrm{BC}$ associada a obstrução de vias aéreas, medida pelo II alterado, está na TABELA 3.50. Dos mineiros sem BC, 29 (14,5\%) apresentaram $\Pi$ alterado e dos com BC 15 (18,7\%) apresentaram IT alterado. A TABELA 4.2. mostra a prevalência de $\mathrm{BC}$ com ou sem obstrução em alguns estudos epidemiológicos de mineiros de carvão.

TABELA 4.2: Prevalência de BC com ou sem Obstrução em Mineiros de Carvão.

$\begin{array}{lccc} & & \text { BC }\left(\frac{8}{6}\right) \\ \text { PAIS } & \text { REF } & \text { Sem obstrução } & \text { Com Obstrução } \\ \text { GB } & 204 & 29,7 & 6,9 \\ \text { Austrália } & 139 & 13,2 & 3,5 \\ \text { Brasil } & * & 23,1 & 5,4 \\ & & & \end{array}$

* Presente trabalho

A prevalência global de $\mathrm{BC}$ nos EUA foi de $38,4 \%{ }^{95}$ e na Alemanha de $13,0 \%$ 221. Dos trabalhos citados, nenhum se utilizou de um critério semelhante ao deste para classificar o indivíduo como bronquítico, segundo os critérios diagnósticos correntes ${ }^{39}$.

A associação entre $\mathrm{BC}$ e exposição ocupacional em minas de carvão vem sendo mais estudada nos últimos 20 anos. Em 1971, durante um encontro internacional, foram apresentados três trabalhos sobre o tema. MINETTE ${ }^{161}$, estudando três populaçōes distintas: uma comunidade mineira, pacientes de um hospital mineiro e mineiros de uma mina de carvão, concluiu que os sintomas de bronquite eram relacionados ao tabagismo, e a prevalência em mineiros e não mineiros era semelhante, porém após controlar para idade e 
tabagismo, houve uma tendência à associação entre bronquite e número de anos de subsolo. REICHEL e col. ${ }^{198}$, na Alemanha, comentaram brevemente sobre os sintomas tosse e expectoração; ambos tinham sua prevalência dependente da faixa etária. Mineiros com formas radiológicas B e C, curiosamente, apresentavam menos sintomas que mineiros com formas radiológicas simples. Este estudo não controlou os sintomas pelo tabagismo, sendo portanto difícil inferir-se conclusōes mais abrangentes. RAE e col. ${ }^{197}$, em um cuidadoso estudo longitudinal na $\mathrm{GB}$, demonstraram uma associação significante entre níveis crescentes de exposição cumulativa e BC, mesmo em não fumantes, e uma associação de sintomas de BC com a presença de PMC. Estes achados eram marcantes em mineiros nas faixas de $25-34$ e $35-44$ anos.

ROGAN e col. ${ }^{\mathrm{CU}}$, estudando a mesma população de RAE e col. ${ }^{197}$, excluídos mineiros com FMP, menores de 25 anos e maiores de 65 anos, analisaram o VEF mostrando uma associação inversa significante com exposição cumulativa e graus de BC. Não houve associação entre o $\mathrm{VEF}_{1}$ e a categoria radiológica de pneumoconiose, após controlar para exposição e idade. Aparentemente, não houve interação entre os efeitos da exposição e do tabagismo, e os autores concluiram que a perda média do VEF, atribuível à exposição, após 35 anos de subsolo, a uma concentração máxima de $4 \mathrm{mg} / \mathrm{m}^{3}$, seria em torno de $150 \mathrm{ml} \mathrm{e}$, portanto, improvável de se associar a sintomas clínicos importantes.

KIBELSTIS e col. 'cy analisaram a $\mathrm{BC}$ e a espirometria em mineiros de carvão betuminoso nos EUA. A prevalência de BC era uma função de anos de subsolo, e da funçāo no subsolo, além do tabagismo. A função no subsolo, por sua vez, não influiu na presença de obstrução de vias aéreas, medida pelo IT. Somente quando mineiros de superfície não fumantes foram comparados com mineiros de subsolo não fumantes surgiram diferenças, que foram também observadas em relação ao $\mathrm{VEF}_{1}$. Este estudo sugeriu que a exposição ocupacional era principalmente ligada a sintomas de $B C$, e os efeitos sobre a capacidade ventilatória eram modestos, quando comparados aos efeitos do tabagismo.

HANKINSON e col. ${ }^{95}$, estudando as curvas fluxo-volume em 6014 mineiros ativos, encontraram uma correlação negativa significante com anos de exposição para os fluxos máximos a volumes pulmonares altos, em mineiros não fumantes, e uma diminuição global dos fluxos em fumantes. Não houve correlação com categoria radiológica de pneumoconiose, ou com funçắo no subsolo. Estes dados eram indicativos de um comprometimento preferencial de vias aéreas altas nos não fumantes. Em um estudo posterior, HANKINSON e col. ${ }^{96}$ separaram as curvas em grupos de fumantes e não 
fumantes dividos por BC (sim ou não), demonstrando que, eretıvamente, a diminuição dos fluxos altos nos não fumantes está ligada à presença de $\mathrm{BC}^{*}$.

Todos estes estudos levaram ao reconhecimento da BC de causa ocupacional ${ }^{171}$, porém sem indícios de que seus efeitos pudessem ser incapacitantes ${ }^{170,171}$.

Mais recentemente, algumas publicações contestaram o conceito de que os efeitos funcionais da exposição a poeiras fossem modestos. HURLEY e col. ${ }^{110}$ identificaram um grupo de 199 ex-mineiros sintomáticos que abandonaram a indústria por problemas de saúde e apresentaram um declínio excessivo do $\mathrm{VEF}_{1}$ ao longo do tempo, chegando a $800 \mathrm{ml}$ anuais em mineiros mais expostos. MARINE e col. ${ }^{149}$, reanalisando dados de 3380 mineiros originários do estudo do "Pneumoconiosis Field Research", derivaram curvas de prevalência estimada de BC por exposição cumulativa, mostrando que embora houvesse mais casos entre os fumantes, a inclinaçāo da curva (coeficientes) para os não fumantes acompanhava a curva dos fumantes. Além disso, os autores contestaram o conceito que a presença de BC e LCFA são independentes, pois havia mais casos de obstruçāo, definida como $\mathrm{VEF}_{1}<80 \%$ do previsto, entre os sintomáticos independente do efeito da exposiçāo.

$\mathrm{Na}$ coorte, as diferenças entre as porcentagens de IT alterados nos mineiros com e sem $\mathrm{BC}$ não foram significantes (TABELA 3.50). Além disso, não se conseguiu demonstrar diferenças na exposição ocupacional de mineiros com IT normal ou alterado estratificados pela BC (TABELA 3.51).

No trabalho de MARINE e col. ${ }^{149}$, além do grande número de mineiros estudados, a porcentagem com $\mathrm{VEF}_{1}$ inferior a $80 \%$ chegou próximo aos $50 \%$, contrastando com os 2,5\% de $\mathrm{VEF}_{1}$ anormais no nosso trabalho. A BC e a LCFA são condições altamente prevalentes na GB. Além disso, os mineiros analisados por MARINE tinham uma média de

\footnotetext{
- Uma avaliação funcional mais detalhada em ex-mineinos de molibdênio (risco de silicase), que envolveu curvas fluxo-volume. pletismografia e difusāo do monóxido de carbono foi publicada por KREISS e col. ${ }^{133}$. Neste trabalho, a influência da exposição cumulativa a poeiras afetou diferentemente näo fumantes e fumantes. Nos primeiros, a exposiçāo associou-se a volumes pulmonares reduzidos, fluxos aumentados e difusāo aumentada. Nos fumantes, a exposição associou-se a volumes pulmonares aumentados, $e$ diminuiçāo de fluxos e da difusăo. Estes resultados originários de uma metodologia mais complexa, em que os volumes pulmonares foram calculados por pletismografia, mostraram efeitos duradouros da exposição, possivelmente irreversíveis, pois a população analisada foi de ex-mineiros, entre 5 a 11 meses após afastarem-se da exposiçāo. Estes achados estão em desacordo com o trabalho de HANKINSON c col. ${ }^{96}$. Contudo, $\mathrm{em}$ ambos $\propto$ trabalhos, a tendência a uma restrição funcional nos não fumantes ficou bem caracterizada.
} 
idade de 47 anos, e provavelmente uma maior média de exposição. Para tentar suplantar estas diferenças, os resultados do $\mathrm{VEF}_{1}$ e do IT foram analisados através dos resíduos, isto é, da diferença entre os valores obtidos e previstos (obtendo-se desta forma uma variável que foi tratada de forma dicotômica dividindo-se os resultados em resíduos positivos e negativos para o $V_{E F}$ e o IT). Os efeitos da exposição e do tabagismo sobre os resíduos não mostraram resultados significantes nas tabelas de associação simples (TABELA 3.56), porém os modelos de regressão logística mostraram resultados significativos para os grupos de fumo em relaçāo ao $\mathrm{VEF}_{1}$, e do tabagismo quantitativo em relação ao IT (TABELAS 3.57 e 3.58). Nestes modelos, não se observou efeitos significantes da interação entre exposiçāo e tabagismo. Introduzindo a PB nos modelos houve a sua inclusão, mostrando que mineiros com $\mathrm{PB}$ positiva tendem a ter resíduos significantemente maiores (mais negativos) do $\mathrm{VEF}_{1}$ e do IT (FIGURAS 3.8 e 3.9).

O estudo do declínio funcional complementou as análises referentes aos efeitos funcionais da exposição ocupacional e do tabagismo. $O$ interesse dessas análises foi a comparação com valores previstos de declínio rotineiramente empregados, gerados quase sempre de estudos transversais, e também de comparação com dados de estudos longitudinais.

GLINDMEYER e col. ${ }^{91}$ demonstraram que o declínio do $\mathrm{VEF}_{1}$ calculado por regressāo linear, baseada em 5 espirometrias anuais, era menor que os coeficientes de idade das equaçōes de valores previstos publicadas. Mesmo excluindo-se a primeira visita, e analisando-se o declínio longitudinal com quatro espirometrias para cada indivíduo, na tentativa de corrigir o viés de "erros de aprendizado", os resultados permaneceram iguais. BURROWS e col. ${ }^{30}$ chegaram às mesmas conclusōes, estudando adultos com diversas espirometrias ao longo de 11 anos de seguimento. A idade de início de declínio do $\mathrm{VEF}_{1}$, em homens e mulheres, foi calculada em 36,3 e $36,7^{\circ}$ anos, respectivamente. Foi também mostrado graficamente que as equações de valores previstos tendem a subestimar o $\mathrm{VEF}_{\text {, }}$ em faixas etárias mais elevadas, pelo fato dos coeficientes de idade transversais serem maiores do que o declínio calculado longitudinalmente.

Esta particularidade fisiológica pode ser explicada, ao menos parcialmente, por alguns aspectos. Primeiramente, o "efeito de aprendizado" ou "regressão em direção à média" não se observa em estudos transversais ${ }^{30,91}$. Em segundo lugar, os efeitos cumulativos de exposições agressoras em indivíduos idosos são acentuados em análises transversais, e também porque há efeitos agudos sobre os indivíduos em estudo. $\mathrm{O}$ 
seguimento longitudinal tem a possibilidade de eliminar. ou aiustar estes efeitos. adequadamente.

A inclusão de indivíduos jovens nas análises do declínio funcional está, porém, sujeita a críticas. A FIGURA 3.6 mostra que a média de declínio anual foi maior na faixa dos 21 a 25 anos, se bem que apenas 12 mineiros encontravam-se nesta faixa (idade média entre 1984 e 1989). Os valores previstos, utilizados neste trabalho, assumem que o coeficiente de idade passa a ter um sinal negativo aos 25 anos $^{131}$. Por outro lado, trabalhos do mesmo grupo mostram que os valores máximos do $\mathrm{VEF}_{1}$ são alcançádos por volta dos 20 anos no sexo masculino e, até o final da $3^{\text {a }}$ década, há um platô ${ }^{32}$. LAWTHER e col. ${ }^{136}$, acompanhando estudantes de medicina chegou a resultados semelhantes. Em um estudo clássico sobre declínio funcional em mineiros de carvão, ATTFIELD ${ }^{13}$ incluiu mineiros de 20 anos em diante. Por estas razōes, foi considerada aceitável a inclusão de mineiros que estavam na faixa de 21 a 25 anos em 1984.

Um outro ponto que chamou a atenção foi a variabilidade do $\mathrm{DVEF}_{1}$. O desvio padrão foi praticamente o dobro da média. A TABELA 4.3 traz resultados do DVEF, de alguns estudos publicados.

TABELA 4.3: DVEF, Médio em ml/ano e Desvio Padrão em Alguns Estudos Publicados

\begin{tabular}{|c|c|c|c|c|}
\hline REFERENCIA & ANO & GRUPO ALVO & $D \cup E F_{I}(D P)$ & COMENTARIOS \\
\hline BARTER $^{17}$ & 1976 & $\begin{array}{l}34 \text { pacientes com } \\
\text { BC moderada } \\
(45-66 \text { anos })\end{array}$ & $46(57)$ & $\begin{array}{l}6 \text { espirometrias } \\
\text { em } 5 \text { anos de } \\
\text { seguimento }\end{array}$ \\
\hline KAUFFMANN $^{121}$ & 1979 & $\begin{array}{l}575 \text { trabalhadores } \\
\text { de diferentes } \\
\text { indústrias } \\
(30-54 \text { anos })\end{array}$ & 47 (34) & $\begin{array}{l}2 \text { espirometrias } \\
\text { em } 12 \text { anos de } \\
\text { seguimento }\end{array}$ \\
\hline CAMPBELL 33 & 1985 & $\begin{array}{l}66 \text { pacientes com } \\
B C\end{array}$ & $58,6(51,4)$ & $\begin{array}{l}4 \text { a } 6 \text { anos de } \\
\text { seguimento }\end{array}$ \\
\hline BATES $^{18}$ & 1985 & $\begin{array}{l}\text { 397 mineiros de } \\
\text { carvão com sin- } \\
\text { tomas respirató } \\
\text { rios ou PMC }\end{array}$ & $\begin{array}{l}\star 67,8(35,2) \\
\star \star 46,2(28,3) \\
\star \star \star 73,5(46,8) \\
\star \star \star \star 557,6(33,2)\end{array}$ & $\begin{array}{l}\text { seguimento médio } \\
\text { de } 18 \text { anos }-2 \text { a } \\
11 \text { espirometrias }\end{array}$ \\
\hline
\end{tabular}

* Nāo Fumantes falecidos

** Nảo Fumantes vivos

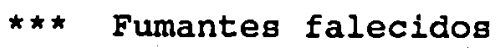

$\star \star \star \star$. Fumantes vivos 
Em todos os trabalhos, a variabilidade do $\mathrm{DVEF}_{1}$ foi grande. KAUFFMANN ${ }^{121}$ ainda indicou que o coeficiente de variaçāo do DVEF, foi de 0,72 (para comparaçāo, o coeficiente de variaçāo do $\mathrm{VEF}_{1}$ era de 0,18 ). Uma das razōes para a grande variabilidade da medida na coorte, pode ser atribuida a apenas 2 pontos de seguimento no tempo ${ }^{30}$.

A comparação do declínio do $\mathrm{VEF}_{1}$, analisado transversalmente e longitudinalmente, foi incluida na TABELA 3.45. O declínio longitudinal foi superior ao declínio calculado separadamente para os dados de 1984 e 1989. Como já comentado no subitem 3.4.3, este achado não coincide com os dados de literatura citados ${ }^{30,91}$. Este declínio é, na média, inferior aos trabalhos citados na TABELA 4.3 e, ao mesmo tempo, superior ao declínio previsto transversalmente, o que aponta para fator(es) agressor(es) de vias aéreas, neste grupo ocupacional. Os valores̀ do $\mathrm{DVEF}_{1}$, não tão acentuados como os da TABELA 4.3, refletem, provavelmente, que os mineiros são mais jovens e mais saudáveis no momento, do que os outros grupos mencionados.

O declínio longitudinal do $V E F$, é uma função positiva da idade $^{13,30,121,142,236}$ e também da altura representada por um modelo proporcional "Idade.Altura ${ }^{3,130,50}$. A FIGURA 3.6 e uma equaçāo de regressão linear representada por $\mathrm{DVEF}_{1}=\mathrm{c}+\mathrm{b}_{1}$.Idade (mencionada ao final do subitem 3.4.3) não mostraram uma correlação entre o declínio e a idade. Talvez isto seja um indício de seleção neste grupo ocupacional, ou seja, a coorte de mineiros ativos representa aqueles indivíduos que não sofreram um declínio acelerado do $\mathrm{VEF}_{1}$, pela somatória de efeitos próprios da Idade associados à exposição ocupacional.

As TABELAS 3.46 e 3.47 mostraram as associaçōes entre o $\mathrm{DVEF}_{1}$, a exposição ocupacional e o tabagismo, em tabelas de contingência. Para isto, os mineiros foram divididos em grupos de declínio rápido e declínio lento, utilizando-se do coeficiente de idade previsto por KNUDSON ${ }^{131}$. Não houve diferenças nas médias de SANO e SANOAJ nos dois grupos. A média de AM de mineiros com declínio rápido foi superior, porém isto não alcançou significância estatística.

Estes resultados foram também inesperados. $\mathrm{O} \mathrm{VEF}_{1}$ cai mais acentuadamente em fumantes ${ }^{84,121,236}$. Mesmo em mineiros de carvão ativos há uma correlaçāo significante entre o tabagismo e o $\mathrm{DVEF}_{1}{ }^{13,142}$. O fato de estar-se analisando 
uma população relativamente jovem (média de idade de 35 anos), cujos fumantes possuem uma média de AM baixa (AM médio de 9) deve ser responsável por estes achados negativos. Os cálculos das PR(s) na TABELA 3.49 mostraram que, efetivamente, não houve influência da .exposição ocupacional e do tabagismo no declínio do $\mathrm{VEF}_{1}$ neste trabalho. Todos os $\mathrm{PR}(\mathrm{s})$ foram próximos ao valor unitário.

Há dois estudos importantes, e extremamente semelhantes, em relação ao declínio longitudinal do VEF, em mineiros de carvão. LOVE e col. ${ }^{142}$ analisaram 1677 mineiros ativos na GB. Utilizando-se de dois pontos no tempo, num intervalo de 11 anos de observação, encontraram um declínio significativamente associado à exposição cumulativa que antecedeu a primeira avaliação. Esta correlação permaneceu significante mesmo após controlar para idade, altura e tabagismo. Os efeitos médios da exposição foram estimados em $1 / 3$ dos efeitos devidos ao tabagismo, porém, em mineiros com exposições maiores, ambos os efeitos eram próximos. ATTFIELD ${ }^{13}$ fez um trabalho igual nos EUA, analisando 1072 mineiros ativos. A diferença era a ausência de dados de exposição cumulativa e a inclusão de mineiros abaixo de 25 anos nas análises. Os efeitos do tabagismo foram mais importantes do que os efeitos da exposição, embora mineiros que trabalhassem 35 anos no subsolo tivessem coeficientes de declínio, ligados aos índices de exposição, semelhantes ao tabagismo. COCHRANE ${ }^{49}$ comentou que o estudo de LOVE e col. ${ }^{142}$ refere-se a uma população sobrevivente constituida por $1 / 3$ da população original. Além disso, a equação de regressão múltipla do $\mathrm{DVEF}_{1}$ apresenta um coeficiente de correlação muito baixo, $6 \%$, incluídas todas as variáveis significantes. No próprio trabalho, esta baixa explicação foi atribuída a possíveis erros de mediçāo no trabalho de campo. Os resultados de ATTFIELD ${ }^{13}$ foram ligeiramente melhores: o coeficiente de correlação explicou $12 \%$ da variação total.

Mesmo que as populaçōes descritas nestes trabalhos fossem sobreviventes, houve uma clara demonstração de um efeito da exposição ocupacional no

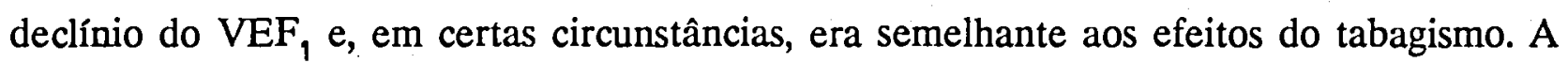
crítica de COCHRANE ${ }^{41}$ indica que os efeitos encontrados são uma subestimativa dos reais efeitos da exposição ocupacional.

As exposiçōes ocupacionais estāo efetivamente relacionadas com um declínio acelerado da função pulmonar, normalmente medida pelo VEF, KAUFFMANN e col. ${ }^{120}$ encontraram resultados significativos da influência da exposição a poeiras minerais e orgânicas, gases (quando associados a poeiras) e calor, no declínio do VEF, em 12 anos de 
seguimento de 556 trabalhadores. Houve também uma correlação com a intensidade da exposição. ENARSON e col. ${ }^{76}$ estudando trabalhadores de silos de grãos, também encontraram efeitos significativos da exposição no declínio do $\mathrm{VEF}_{\uparrow}$.

Estes trabalhos ${ }^{13,76.120 .121,142}$ são uma pequena parte das evidências publicadas sobre a relação entre exposiçōes ocupacionais e limitação crônica ao fluxo aéreo, sumarizadas por BECKLAKE ${ }^{19,20}$.

A influência da hiperreatividade brônquica no declínio funcional foi também analisada. Embora a tabela de contingência mostrasse um maior número de mineiros com PB positiva entre os de declínio rápido, não houve significância estatística (TABELA 3.47), mas, num modelo de regressão linear, houve a inclusão da PB como variável independente, que foi significante, embora com uma baixa explicação da variância da equação (TABELA 3.48).

A associação entre o declínio do $\mathrm{VEF}_{1}$ e a hiperreatividade brônquica vem sendo estudada na comunidade ${ }^{188,231,237}$, em portadores de $\operatorname{LCFA}^{17,33,119,195}$ e em alguns grupos ocupacionais ${ }^{10,76,162,194,230}$. Em todos estes estudos a hiperreatividade associou-se significativamente a um declínio acelerado do $\mathrm{VEF}_{1} . \mathrm{Em}$ indivíduos fumantes esta relação foi mais forte ${ }^{188,230,231,237}$, isto é, a hiperreatividade é um fator de declínio funcional importante em indivíduos fumantes.

Com excessão do estudo de $\mathrm{KANNER}^{119}$ que mediu a hiperreatividade como a resposta ao broncodilatador, todos os trabalhos citados foram feitos com PB. van der LENDE e col. ${ }^{237}$, em um estudo populacional comparando indivíduos de duas comunidades, com a finalidade de analisar os fatores de risco de declínio funcional respiratório (em princípio o tabagismo e a poluição ambiental), submeteram uma parte da amostra a testes de PB com histamina. Embora esta publicação seja apenas uma rápida comunicação de resultados, os autores demonstraram que uma positividade da PB associou-se a um declínio funcional significativamente maior em mulheres e em homens. Nestes últimos, este achado restringiu-se ao grupo dos fumantes. TAYLOR e col. ${ }^{239} \mathrm{em}$ um estudo longitudinal de função pulmonar em 227 homens sem doenças respiratórias ou alterações radiológicas de importância mostraram uma associação significante entre o declínio do $\mathrm{VEF}_{1}$ e a hiperreatividade em fumantes. PARKER e col. ${ }^{188}$ publicaram dados gerados no estudo longitudinal do envelhecimento (Boston-EUA). Entre 790 homens de 40-79 anos, a 
hiperreatividade foi um significante preditor do declínio do $\mathrm{VEF}_{1}$ principalmente em fumantes com testes cutâneos negativos.

Os achados de TAYLOR e col. ${ }^{231}$ e PARKER e col. ${ }^{188}$ persistiram após controlar para outras variáveis de risco. Entretanto, estes dois estudos diferem quanto a influência do VEF, basal. Enquanto TAYLOR não encontrou significância na relação entre o declínio e o VEF, basal, PARKER demonstrou que o VEF, basal tem significancia estatística em uma análise de regressão linear múltipla.

MINETTE e col. ${ }^{162}$, em um estudo longitudinal, notaram que mineiros de carvão com $\mathrm{BC}$ e $\mathrm{PB}$ positiva apresentavam um declínio funcional mais acentuado que mineiros com BC e PB negativa. PHAM e col. ${ }^{194}$, em um estudo longitudinal de 820 mineiros de ferro citaram, de forma breve, que mineiros com $\mathrm{PB}$ positiva apresentaram um declínio do $\mathrm{VEF}_{1}$ significativamente maior. Dois trabalhos sobre o declínio funcional em trabalhadores de silos de grãos foram publicados pelo mesmo grupo ${ }^{76,230}$, mostrando que a hiperreatividade foi um fator significante no declínio do $\mathrm{VEF}_{\uparrow}$, além da variação semanal da espirometria durante um período de trabalho, e medidas quantitativas de exposição a poeiras $^{76}$. ANNESI e col. ${ }^{10}$ chegaram a conclusão que o declínio funcional em fumantes associou-se significativamente à PB positiva e, à rinite alérgica, em 599 trabalhadores. Infelizmente este estudo é pobre na caracterização da parte ocupacional.

É interessante que todos os estudos que fizeram testes cutâneos (pricktests) foram unânimes em afirmar que a atopia expressa por testes cutâneos positivos nāo se relacionou com um declínio acelerado do $\mathrm{VEF}_{1}{ }^{10,33,188,230,231}$.

$\mathrm{Na}$ coorte há fortes indícios de que a hiperreatividade brônquica associa-se a déficits funcionais, expressos pelo VEF, e o IT (FIGURAS 3.8 e 3.9) e a um declínio funcional acelerado do VEF, (TABELA 3.48). Acreditamos que a inexistência de associação entre o DVEF, e a exposição ocupacional deve-se, em grande parte, à baixa média de anos de exposiçāo, pois o tempo de residência da poeira nos pulmōes é um fator significante em relação ao declínio funcional em mineiros de carvão ${ }^{142}$. 
SEÇĀO 5 CONCLUSŌES E RECOMENDAÇÕES 


\section{CONCLUSÕES E RECOMENDAÇÕES}

\subsection{Conclusões}

C1) Os sintomas respiratórios apresentaram um comportamento distinto. A tosse, catarro e a bronquite crônica associaram-se aos grupos de tabagismo, enquanto a dispnéia e o chiado se associaram aos índices de exposição ocupacional. A análise da evolução dos sintomas durante os 5 anos de observação mostrou que apenas o chiado progrediu significantemente neste período. Embora a média da soma de anos de subsolo ajustada fosse maior para os grupos que apresentaram evolução dos quatro sintomas, isto foi significante apenas para a dispnéia. Além disso há dados que sugerem que a tosse e o catarro apresentaram uma "adaptação longitudinal" à exposição ocupacional ao longo do estudo. Com exceção do sintoma chiado, não se deteçtaram efeitos aditivos ou multiplicativos significantes da exposição ocupacional e do tabagismo em relação aos sintomas respiratórios. Houve uma reversibilidade dos sintomas tosse e catarro, e da bronquite crônica, associada à cessação do fumo. Mineiros que tiveram uma evoluçāo dos sintomas, apresentaram um declínio longitudinal do $\mathrm{VEF}_{1}$ maior, embora este resultado fosse significante apenas para a evolução da dispnéia.

C2) A hiperreatividade brônquica não se associou aos índices de exposição, nem aos grupos de tabagismo. Houve uma significativa associação entre HRB e presença do sintoma chiado, mesmo quando controlada para a exposição, o tabagismo e o VEF, basal, e uma associação entre HRB e bronquite crônica entre os mineiros não fumantes. Mineiros com um teste de provocação brônquica positivo apresentaram um $\mathrm{VEF}_{\text {, }}$ basal significantemente menor e um declínio longitudinal do $\mathrm{VEF}_{1}$ mais acentuado.

C3) Sintomas compatíveis com o diagnóstico de asma ocorreram em $18,2 \%$ dos mineiros e de asma com características ocupacionais em $12,1 \%$. A positividade à provocação brônquica foi de $44,1 \%$ neste último grupo, portanto bem maior que na coorte. Estes dados, aliados à evolução do sintoma chiado durante 0 período de observação, sua associação com os índices de exposição, e o início dos sintomas após a entrada na mineração de carvão, na 
maior parte dos casos, são fortes indícios de que a asma é devida, ao menos parcialmente, a fatores ocupacionais, neste grupo em estudo.

C4) A prevalência de pneumoconiose em mineiros ativos foi de 5,6\%, no estudo de 1984. Na coorte, a prevalência foi de 5,4\% em 1984 e 7,9\% em 1989, não havendo diferenças significantes entre estes números. Embora a prevalência pontual não seja aberrante, comparada a estudos em outros países, o tempo médio de exposição de mineiros de carvão com pneumoconiose é muito baixo no Brasil. Além disto, mineiros de frente de serviço tem aposentadoria especial com 15 anos de trabalho no subsolo; isto significa que em avaliações pontuais de mineiros ativos há uma subestimação da prevalência real da doença. A incidência anual de casos de PMC, na coorte, foi de 11,4/1.000 mineiros em risco, o que indica uma condição grave, quando comparada a outros países. É possível que a maior exposição ao quartzo, nas minas de carvāo brasileiras, explique parcialmente estes achados.

C5) A progressão radiológica associou-se significativamente à soma de anos de exposição ajustada. $O$ tabagismo quantitativo também associou-se significativamente, assim como foi detectado um efeito sinérgico da exposição e do tabagismo, e um $\mathrm{VEF}_{1}$ mais baixo entre os mineiros apresentando evoluçāo ao Rx.

C6) Mineiros com opacidades irregulares ao Rx tenderam a apresentar parâmetros funcionais piores. Embora as diferenças entre as médias dos parâmetros, nos diferentes grupos do Indice de Regularidade, nāo tenham sido significantes, estes dados são compatíveis com a literatura existente, e indicam uma provável associação entre a PMC e outras patologias pulmonares (provavelmente enfisema pulmonar).

C7) A análise dos parâmetros espirométricos da coorte mostrou um crescimento longitudinal da CVF média no período de observaçāo. Este fato é atribuível à faixa etária média dos mineiros, assim como a um treinamento muscular contínuo, no exercício da atividade laboral. Os outros índices, VEF, e IT, declinaram com o tempo. Não detectamos efeitos significantes dos índices de exposição ocupacional em relação à equação de regressāo do $\mathrm{VEF}_{\mathfrak{1}}$, nem de exponenciais da Idade. Provavelmente, isto se deve à baixa média de anos de 
exposição da coorte, uma vez que o tempo de residência das poeiras nos pulmōes é um fator importante para a observação destes efeitos. O VEF, detectou um número muito baixo de mineiros com alteraçōes espirométricas. O IT foi o único parâmetro a apresentar evolutivamente um aumento do número de mineiros com valores anormais durante o período de observação, e parece ser um índice mais adequado para o diagnóstico precoce de obstrução de vias aéreas em mineiros de carvão.

C8) A análise dos efeitos da exposição ocupacional e do tabagismo sobre os parâmetros funcionais mostrou que as alterações do IT eram dependentes do tabagismo quantitativo e também de um componente sinérgico entre exposição e tabagismo, embora este último efeito fosse marginalmente significante. Os efeitos do tabagismo sobre a função pulmonar foram distintos dos en̉contrados em relação aos sintomas respiratórios. Nestes últimos, o comportamento dos ex-fumantes aproximou-se dos não fumantes, enquanto que, em relação ao IT, o comportamento dos ex-fumantes foi semelhante ao dos fumantes, indicando uma perda funcional irreversível causada pelo fumo. A análise de resíduos do $\mathrm{VEF}_{1}$ e do IT confirmaram que o tabagismo é o fator de risco respiratório preponderante neste grupo ocupacional, com uma média de 10 anos de exposiçāo. Mineiros com a hiperreatividade brônquica tem uma acentuação significativa dos efeitos do tabagismo sobre os resíduos do $\mathrm{VEF}_{1} \mathrm{e}$ do IT.

C9) O declínio longitudinal do $\mathrm{VEF}_{1}$ apresentou um comportamento inverso ao observado em populaçōes normais. Ele foi superior aos coeficientes de idade das equações de regressão calculadas com dados pontuais, indicando que este grupo ocupacional está sujeito a um declínio acentuado do $\mathrm{VEF}_{\mathrm{\gamma}}$. O fato de nāo termos encontrado efeitos significantes do tabagismo e da idade sobre o $\mathrm{DVEF}_{1}$ são indícios de seleção na coorte, e também da própria variabilidade da medida. Mineiros com hiperreatividade brônquica apresentaram um declínio do $\mathrm{VEF}_{1}$ mais acentuado que mineiros com $\mathrm{PB}$ negativa.

C10) Este estudo reflete a análise de uma coorte de mineiros de carvão ativos. Além da ausência de ex-mineiros em número adequado para algumas análises comparativas, os mineiros participantes foram selecionados com base em critérios espirométricos, o que traz um viés em direçăo a uma 
subestimação dos efeitos da exposiçắo ocupacional sobre o sistema respiratório. Além disso, o treinamento inadequado dos técnicos que participaram do trabalho de campo em 1984 contribuiu para a exclusão de mineiros, na definição da coorte. Portanto, este estudo representa uma análise conservadora dos efeitos respiratórios da exposição ocupacional em mineiros de carvão.

\subsection{Recomendações}

Baseados nestas conclusões, recomendamos que:

R1) Seja institucionalizada uma identificação de todos os trabalhadores na indústria de mineração de carvão. Eles deverão ter uma história ocupacional detalhada em seus registros. Haja um programa de levantamento por amostragem de poeiras na indústria, que permita a derivação de índices de exposição cumulativos fiéis e, também, de exposição ao quartzo.

R2) Seja estruturada uma assistência à saúde adequada para proporcionar um seguimento mínimo a todos os mineiros. $\mathrm{Na}$ prática, é suficiente que cada mineiro seja avaliado a cada 2 anos, do ponto de vista clínico, com ênfase nos sintomas respiratórios, nos exames radiológicos e espirométricos. Estes últimos, necessitam ser realizados com equipamentos e técnicas adequados e interpretados corretamente.

R3) Seja implantado um banco de dados de fácil manejo e acesso, que possa dar suporte às duas recomendaçōes anteriores.

R4) Seja implantado um programa de seguimento de ex-mineiros. De acordo com sua condição clínica o seguimento pode ser anual, bienal ou trienal, e sempre nos mesmos moldes referidos anteriormente.

R5) Sejam procuradas fontes de financiamento para a implantação das recomendações acima. 
R6) Seja implantado um programa de conscientização do hábito de fumar e suas consequências à saúde.

R7) Haja uma continuidade do trabalho aqui apresentado. Embora, em 1989, 404 mineiros fossem examinados, somente 280 foram incluidos nestas análises. Num próximo seguimento poderão ser incluídos todos eles. É recomendável que este estudo prossiga para se poder melhorar as análises dos efeitos devidos à exposição ocupacional, pois pareceu que, na coorte, parte dos resultados de associaçōes estatisticamente não significantes foram devidos ao baixo tempo de anos de exposiçāo e de residência da poeira nos pulmōes. Além disso, o declínio longitudinal do $\mathrm{VEF}_{1}$ e suas relaçōes com a reatividade brônquica poderão ser melhor analisados.

R8) Paralelamente, é fundamental que sejam tomadas medidas de higiene nas minas, visando diminuir a exposição a poeiras respiráveis, que indubitavelmente é excessiva, e ainda se agrava pela existência de teores de quartzo superiores aos encontrados em minerações de carvão de outros países.

R9) Haja, dentro das organizações de trabalhadores, um interesse específico voltado para o acompanhamento da implantação de programas de saúde ocupacional adequados para a realidade regional.

R10)Haja, dentro das empresas mineradoras, um interesse específico voltado para proporcionar condiçōes e ambiente de trabalho adequados, além de uma direta responsabilidade pela ocorrência de doenças ocupacionais em seus trabalhadores. 


\section{REFERÊNCIAS BIBLIOGRÁFICAS}

01. AGNEW, J.E. Physical properties and mechanisms of deposition of aerosols. In: Clarke, W., Pavia, D., eds. Aerosols and the lung. London, Butterworths, 1984. p.49-70.

02. ALGRANTI, E. A case-control study of pneumoconiotic coal miners in Brazil. In: VII th International Pneumoconioses Conference. Proceedings. s.l., s. ed. US Department of Health and Human Services, 1990. p. 1221-1223. (NIOSH Publication nº 90-108 PartII)

03. ALGRANTI, E. Slateworkers' pneumoconiosis. Cardiff, 1982 (Tese de Mestrado-Welsh National School of Medicine, University of Wales).

04. ALGRANTI, E., SOUZA FILHO, A.J. Correlations between radiology, respiratory symptoms and spirometry in active underground coal miners in Brazil. In: VII th International Pneumoconioses Conference. Proceedings. s.l., s. ed. US Department of Health and Human Services, 1990. p. 105-111. (NIOSH Publication n090-108 Part I).

05. ALTHOUSE, R., ATTFIELD, M., KELLIE, S. Use of data from x-ray screening program for coal workers to evaluate the effectiveness of $2 \mathrm{mg} / \mathrm{m}^{3}$ coal dust standard. J. Occup. Med., 28:741-745, 1986.

06. AMANDUS, H.E. et al. Significance of irregular small opacities in radiographs of coalminers in the USA. Br. J. Ind. Med., 33:13-17, 1976.

07. AMANDUS, H.E., PIACITELLI, G. Dust exposure at US surface coal mines in 1982-1983. Arch. Environ. Health, 42:374-380, 1987.

08. AMERICAN THORACIC SOCIETY. ATS statement-Snowbird workshop on standardization of spirometry. Am. Rev. Respir. Dis., 119:831-838, 1979.

09. AMERICAN THORACIC SOCIETY. Standardization of spirometry - 1987 update. Am. Rev. Respir. Dis., 136:1285-1298, 1987. 
10 ANNESI, I. et al. The relevance of hyperresposiveness but not atopy to FEV1 decline. Preliminary results in a working population. Bull. Eur. Physiopatol. Respir., 23:397-400, 1987.

11. ARMITAGE, P. Statistical methods in medical research. Oxford, Blackwell Scientific Publications, 1971.

12. ATTFIELD, M., REGER, R., GLENN, R. The incidence and progression of pneumoconiosis over nine years in US coal miners: I. Principal findings. Am. J. Ind. Med., 6:407-415, 1984.

13. ATTFIELD, M.D. Longitudinal decline in $\mathrm{FEV}_{1}$ in United States coalminers. Thorax, 40:132-137, 1985.

14. ATTFIELD, M. Radiological health of coal miners. Morgantown, NIOSH Report to Coal Council, Inhouse report, 1982.

15. ATUHAIRE, L.K. et al. Mortality of men in the Rhondda Fach 1950-1980. Br. J. Ind. Med., 42:741-745, 1985.

16. BANKS, D.E. et al. Silicosis in surface coalmine drillers. Thorax, 38:275-278, 1983.

17. BARTER, C.E., CAMPBELL, A.H. Relationship of constitutional factors and cigarrete smoking to decrease in 1-second forced expiratory volume. Am. Rev. Respir. Dis., 113:305-314, 1976.

18. BATES, D.V. et al. A longitudinal study of pulmonary function in coal miners in Lorraine, France. Am. J. Ind. Med., 8:21-32, 1985.

19. BECKLAKE, M. Chronic airflow limitation: its rela-tionship to work in dusty occupations. Chest, 88:608-617, 1985. 
20. BECKLAKE, M. Occupational exposures: evidence for a causal association with chronic obstructive pulmonary disease. Am. Rev. Respir. Dis., 140:585-591, 1989.

21. BECKLAKE, M.R. Epidemiology of spirometric test failure (editorial). Br. J. Ind. Med., 47:73-74, 1990.

22. BECKLAKE, M.R. et al. Lung structure as a risk factor in adverse pulmonary responses to asbestos expusure. Am. Rev. Respir. Dis., 128:385-388, 1983.

23. BENNETT, A.E., RITCHIE, K. Questionnaires in medicine. London, Oxford University Press, 1975.

24. BMDP STATISTICAL SOFTWARE. Berkeley, University of California Press, 1981.

25. BROOKS, S.M., KALICA, A.R. Strategies for elucidating the relationship between occupational exposures and chronic airflow obstruction. Am. Rev. Respir. Dis., 135:268-273, 1987.

26. BROWN, C.C. The validity of approximation methods for interval estimation of the odds ratio. Am. J. Epidemiol., 113:474-480, 1981.

27. BUNSE, H.A.W. A mineração de carvão no Rio Grande do Sul. Porto Alegre, Secretaria de Energia, Minas e Telecomunicaçōes (RS), 1984.

28. BURNEY, P.G.J. et al. Descriptive epidemiology of bronchial reactivity in an adult population: results from a community study. Thorax, 42:38-44, 1987.

29. BURROWS, B. et al. The "horse racing effect" and predicting decline in forced expiratory volume in one second from screening spirometry. Am. Rev. Respir. Dis., 135:788-793, 1987.

30. BURROWS, B. et al. Longitudinal changes in forced expiratory volume in one second in adults. Am. Rev. Respir. Dis., 133:974-980, 1986. 
31. BURROWS, B., MARTTNEZ, F.D. Bronchial responsiveness, atopy, smoking, and chronic obstructive pulmonary disease (editorial).Am. Rev. Respir. Dis., 140:1515-1517, 1989.

32. BURROWS, B. et al. A descriptive analysis of the growth and decline of the FVC and $\mathrm{FEV}_{1}$. Chest, 83:717-724, 1983.

33. CAMPBELL, A.H. et al. Factors affecting the decline of ventilatory function in chronic bronchitis. Thorax, 40:741-748, 1985.

34. CHAN-YEUNG, M., LAM, S. Occupational asthma. Am. Rev. Respir. Dis., 133:686-703, 1986.

35. CHAN-YEUNG, M. et al. Epidemiologic health study of grain elevator workers in British Columbia. Am. Rev. Respir. Dis., 121:329-338, 1980.

36. CHAPMAN, R.S., CALAFIORE, D.C., HASSELBLAD, V. Prevalence of persistent cough and phlegm in young adults in relation to long-term ambient sulfur oxide exposure. Am. Rev. Respir. Dis., 132:261-267, 1985.

37. CHURG, A. et al. Small airways disease and mineral dust exposure. Am. Rev. Respir. Dis., 131:139-143, 1985.

38. CHURG, A, WRIGHT, J.L. Small airway disease in persons exposed to nonasbestos mineral.dusts. Hum. Pathol., 14:688-693, 1983.

39. CIBA GEIGY SYMPOSIUM IREPORT. Terminology, definitions and classification of chronic pulmonary emphysema and related conditions. Thorax, 14:286-299, 1959.

40. CIVIL, G.W., HEPPLESTON, A.G., CASWELL, C. The influence of exposure duration and intermittency upon the pulmonary retention and elimination of dusts from high and low rank coal mines. Ann. Occup. Hyg., 17:173-185, 1975. 
41. COCHRANE, A.L. Coal and the lung (letter). Thorax, 38:877-878, 1983.

42. COCHRANE, A.L. Relation between radiographic categories of coalworkers pneumoconiosis and expectation of life. Br. Med. J., 2:532-534, 1973.

43. COCHRANE, A.L. The attack rate of progressive massive fibrosis. Br. J. Ind. Med., 19:52-64, 1962.

44. COCHRANE, A.L. et al. The mortality of miners and ex-miners in the Rhondda Fach. Br. J. Ind. Med., 21:38-45, 1964.

45. COCKROFT, A. et al. Prevalence and relation to underground exposure of radiological irregular opacities in South Wales coal workers with pneumoconiosis. Br. J. Ind. Med., 40:169-172, 1983.

46. COCKROFT, A.E. et al. Post mortem study of emphysema in coal workers and non-coal workers. Lancet, 2:600-603, 1982.

47. COCKROFT, A.E. et al. Irregular opacities in coal workers' pneumoconiosiscorrelation with pulmonary function and pathology. Ann. Occup. Hyg., 26:767-787, 1982.

48. COCKROFT, D.W. Measurement of airway responsiveness to inhaled histamine or methacholine: method of continuous aerosol generation and tidal breathing inhalation. In: Hargreave, F.E., Woolcock, AJ. eds. Airway responsiveness: measurement and interpretation. Astra Pharmaceuticals Ltd, 1985. p.22-28.

49. COCKROFT, D.W., HARGREAVE, F.E. Airway hiperrespon-siveness. Relevance of random population data to clinical usefulness (editorial). Am. Rev. Respir. Dis., 142:497-500, 1990.

50. COLE, T.J. The influence of height on the decline in ventilatory function. Int. J. Epidemiol., 3:145-152, 1974. 
51. COLLET, A. et al. Recherches infra-structurales sur l'evolution des macrophages alvéolaires et leurs réactions aux poussieres minerales. In: Davis, C.N. ed. Inhaled Particles and Vapours II. Oxford, Pergamon Press, 1967. p. 155-162.

52. COLLINS, H.P.R. et al. Irregularly shaped small shadows on chest radiographs, dust exposure, and lung function in coalworkers' pneumoconiosis. Br. J. Ind. Med., 45:43-55, 1988.

53. COLLINS, D.V. et al. Large airway size, lung size, and maximal expiratory flow in healthy nonsmokers. Am. Rev. Respir. Dis., 134:951-955, 1986.

54. COTES, J. E., STEEL, J. Work-related lung disorders. London, Blackwell, 1987.

55. COTES, J.E. Lung function. 3rd ed. London, Blackwell Scientific Publications, 1975.

56. COX, D.R. Analysis of binary data. London, Chapman and Hall, 1980.

57. CRAPO, R.O., MORRIS, A.H., GARDNER, R.M. Reference spirometric values using techniques and equipment that meets ATS reccomendations. Am. Rev. Respir. Dis., 123:659-664, 1981.

58. DALES, R.E. et al. Prediction of airway reactivity from responses to a standardized respiratory symptom questionnaire. Am. Rev. Respir. Dis., 135:817-821, 1987.

59. DAVIS, J.M.G., OTTERY, J., leROUX, A. The effect of quartz and other non coal dust in coalworkers' pneumoconiosis Part II: Lung autopsy studies. In: Walton, W.H., ed. Inhaled Particles IV (2). Oxford, Pergamon Press, 1977. p.691-702.

60. DECHOUX, J. et al. Les petites anomalies radiologiques pulmonaires irrégulieres observées chez les mineurs de charbon lorrains. Rev. Pneumol. Clin, 40:91-97, 1984. 
61. DIVISÃO DE FOMENTO DA PRODUÇÃO MINERAL Higiene nas minas de carvão do estado de Santa Catarina. Rio de Janeiro, 1952. (Boletim 92).

62. DOCKERY, D.W. et al. Cumulative and reversible effects of lifetime smoking on simple tests of lung function in adults. Am. Rev. Respir. Dis., 137:286292, 1988.

63. DOCKERY, D.W. et al. Distribution of forced expiratory volume in one second and forced vital capacity in healthy, white, adult never-smokers in six U.S. cities. Am. Rev. Respir. Dis., 131:511-520, 1985.

64. DOLOVICH, M.B. et al. Aerosol penetrance: a sensitive index of peripheral airways obstruction. J. Appl. Physiol., 40:468-471, 1976.

65. doPICO, G.A. et al. Acute effects of grain dust exposure during a workshift. Am. Rev. Respir. Dis., 128:399-404, 1983.

66. DOUGLAS, A.N., LAMB, D., RUCKLEY, V.A. Bronchial gland dimensions in coalminers: influence of smoking and dust exposure. Thorax, 37:760-764, 1982.

67. DOUGLAS, A.N. et al. Dust exposure, dust recovered from the lung, and associated pathology in a group of British coalminers. Br. J. Ind. Med., 43:795-801, 1986.

68. DUNN, O.J., CLARK, V.A. Applied statistics: analysis of variance and regression. 2nd ed. Nova York, Wiley, 1987.

69. EISEN, E.A. et al. Effects of spirometry standards in two occupational cohorts. Am. Rev. Respir. Dis., 132:120-124, 1985.

70. EISEN, E.A. et al. The association between health status and the performance of excessively variable spirometric tests in a population-based study in six U.S. cities Am. Rev. Respir. Dis., 136:1371-1376, 1987. 
71. EISEN, E.A., WEGMAN, D.H., LOUIS, T.A. Effects of selection in a prospective study of forced expiratory volume in Vermont granite workers. Am. Rev. Respir. Dis., 128:587-591, 1983.

72. ELMES, P.C. Relative importance of cigarette smoking in occupational lung disease. Br. J. Ind. Med., 38:1-13, 1981.

73. EMPEY, D.W. et al. Mechanisms of bronchial hyperreactivity in normal subjects after upper respiratory tract infection. Am. Rev. Respir. Dis., 113:131-139, 1976.

74. ENARSON, D.A. et al. Asthma, asthmalike symptoms, chronic bronchitis, and the degree of bronchial hyperresponsiveness in epidemiologic surveys. Am. Rev. Respir. Dis., 136:613-617, 1987.

75. ENARSON, D.A., YEUNG, M.C. Determinants of changes in $F V_{1}$ over a workshift. Br. J. Ind. Med., 42:202-204, 1985.

76. ENARSON, D., CHAN-YEUNG, M. Rapid decline in $\mathrm{FEV}_{1}$ in grainhadlers: relation to level of exposure. Am. Rev. Respir. Dis., 36:A157, 1987. (Resumo)

77. ENARSON, D.A. et al. Summarizing methacholine bronchoprovocation data in epidemiological surveys. Bull. Eur. Physiopath. Respir., 23:387-389, 1987.

78. ERNST, P. et al. Relation of airway responsiveness to duration of work in a dusty environment. Thorax, 44:116-120, 1989.

79. FERNIE, J.M., RUCKLEY, V.A. Coalworkers pneumoconiosis: correlation between opacities profusion and number and type of dust lesions with special reference to opacity type. Br. J. Ind. Med., 44:273-277, 1987.

80. FERRIS Jr, B.G. Stadardization epidemiology project. Am. Rev. Respir. Dis., 118:1-120, 1978. 
81. FERRIS Jr, B.G. et al. Chronic non-specific respiratory disease in Berlin, New Hampshire, 1961 to 1967. Am. Rev. Respir. Dis., 107:110-122, 1973.

82. FLETCHER, C.M. Pneumoconiosis of coal-miners. Br. Med. J., 1:1015-1022 e 1065-1074, 1948.

83. FLETCHER, C., PETO, R. The natural history of chronic airflow obstruction. Br. Med. J., 1:1645-1648, 1977.

84. FLETCHER, C.M. et al. The natural history of chronic bronchitis and emphysema. London, Oxford University Press, 1976.

85. FLETCHER, C.M. et al. The significance of respiratory symptoms and the diagnosis of chronic bronchitis in a working population. Br. Med. J., 2:257266, 1959.

86. FLOREY, C.V., LEEDER, S.R. Methods for cohort studies of chronic airflow limitation. Copenhagem, WHO Regional Publications, 1982. (European Series $\left.N^{0} 12\right)$.

87. GANDEVIA, B. Occupational asthma I. Med. J. Aust., 2:232-335, 1970.

88. GIGLIO, J.S. Pneumotórax bilateral espontâneo por pneumoconiose. Rev. Med. Paraná, 10:208-240, 1941.

89. GILSON, J.C. Occupational bronchitis? Proc. Roy. Soc. Med., 63:35-42, 1970.

90. GILSON, J.C., HUGH-JONES, P. Lung function in coal workers pneumoconiosis. Medical Research Council. London, HMSO, 1955. (Special Report Series no 290).

91. GLINDMEYER, H.W. et al. Noncomparability of longitudinally and crosssectionally determined annual change in spirometry. Am. Rev. Respir. Dis., 125:544-548, 1982. 
92. GOODMAN, L.S., GILMAN, A.G. The pharmacological basis of therapeutics. $5^{\text {th }}$ ed. New York, Macmillan, 1975.

93. GOUGH, J. Pneumoconiosis of coal trimmers. J. Pathol. Bacteriol., 51:277-287, 1940.

94. GOVERNA, M. et al. Ventilatory function in rubber processing workers: acute changes over the workshift. Br. J. Ind. Med., 44:83-89, 1987.

95. HANKINSON, J. et al. Factors influencing expiratory flow rates in coal miners. In. Walton, W.H., ed. Inhaled Particles IV (2). Oxford, Pergamon Press, 1977. p.737-752.

96. HANKINSON, J.L., REGER, R.B., MORGAN, W.K.C. Maximal expiratory flows in coalminers. Am. Rev. Respir. Dis., 116:175-180, 1977.

97. HARGREAVE, F.E. et al. Inhalation provocation tests. Sem. Respir. Med., IV:224-234, 1983.

98. HARGREAVE, F.E., RAMSDALE, E.H., PUGSLEY, S.O. Occupational asthma without bronchial hyperresponsiveness. Am. Rev. Respir. Dis., 130:513-515, 1984.

99. HARRINGTON, J.S. Investigative" techniques in the laboratory study of coal worker's pneumoconiosis: recent advances at cellular level. Ann. N. Y. Acad. Sci., 200:817-834, 1972.

100. HEPPLESTON, A.G. Essencial lesions of pneumoconiosis in welsh coal workers. J. Pathol. Bacteriol., 59:453-460, 1947.

101. HEPPLESTON, A.G. The patological anatomy of simple pneumoconiosis in coal workers. J. Pathol. Bacteriol., 66:235-246, 1953.

102. HIGGENBOTTAM, T.W., HAMILTON, D., CLARK, T.J.H. Changes in airway size and bronchial response to inhaled histamine in smokers and non-smokers. Clin. Sci., 54:11p, 1978. (Resumo) 
103. HIGGINS, I.T.T. et al. Chronic respiratory disease in mining communities in Marion County, West Virginia. Br. J. Ind. Med., 25:165-175, 1968.

104. HIGGINS, I.T.T. Chronic respiratory disease in mining comunities. Ann. N. Y. Acad. Sci., 200:197-210, 1972.

105. HIGGINS, I.T.T. et al. Respiratory symptoms and pulmonary disability in an industrial town. Br. J. Ind. Med., 2:904-910, 1956.

106. HOFFESTEIN, V. Relationship between lung volume, maxi-mal expiratory flow, forced expiratory volume in one second, and tracheal area in normal men and women. Am. Rev. Respir. Dis., 134:956-961, 1986.

107. HOPP, R.J. et al. The presence of airway reactivity before the development of asthma. Am. Rev. Respir. Dis., 141:2-8, 1990.

108. HUDGEL, D.W., ROE, R. Nonspecific airway hyper-reactivity in nonsmoking bituminous coal miners demonstrated by quantitative methacholine inhalation challenge. J. Lab. Clin. Med., 111:684-691, 1988.

109. HURLEY, J.F. et al. Exposure to respirable coalmine dust and incidence of progressive massive fibrosis. Br. J. Ind. Med., 44:661-672, 1987.

110. HURLEY, J.F., SOUTAR, C.A. Can exposure to coalmine dust cause a severe impairment of lung function? Br. J. Ind. Med., 43:150-157, 1986.

111. HURLEY, J.F. et al. Coalworkers simple pneumoconiosis and exposure to dust at 10 British coalmines. Br. J. Ind. Med., 39:120-127, 1982.

112. INTERNATIONAL LABOUR OFFICE. Guidelines for the use of ILO International Classification of Radiographs of Pneumoconiosis. Revised Edition 1980, Geneva, ILO, 1980. (Occupational Safety and Health Series no 22). 
113. JACOBSEN, M. New data on the relationship between simple pneumoconiosis and exposure to coal mine dust. Chest, 78(Supl):408-410, 1980.

114. JACOBSEN, $M$. et al. The relation between pneumoconiosis and dust exposure in British coal mines. In: Walton, W.H. ed. Inhaled Particles III (2). Old Woking, Surrey, Unwin, 1971. p.903-917.

115. JACOBSEN, M., MACLAREN, W.M. Unusual pulmonary observations and exposure to coalmine dust: a case-control study. Ann. Occup. Hyg., 26:753$765,1982$.

116. JAIN, B.L., PATRICK, J.M. Ventilatory function in Nigerian coal miners. Br. J. Ind. Med., 38:275-280, 1981.

117. JUNIPER, E.F. et al. Reproducibility and comparison of responses to inhaled histamine and methacholine. Thorax, 33:705-710, 1978.

118. KAMBUROFF, P.L., WOITOWITZ, H.H., WOITOWITZ, R.H. Prediction of spirometric indices. Buckingham, England: Vitalograph Ltd. Respir. News. Bull., 17:1-4, 1973.

119. KANNER, R.E. The relationship between airways responsiveness and chronic airflow limitation. Chest, 86:54-57, 1984.

120. KAUFFMANN, F. et al. Occupational exposure and 12-year spirometric changes among Paris area workers. Br. J. Ind. Med., 39:221-232, 1982.

121. KAUFFMANN, F. et al. Twelve years spirometric changes among Paris area workers. Int. J. Epidemiol., 8:201-211, 1979.

122. KELLIE, S.E. et al. Spirometric variability criteria-association with respiratory morbidity and mortality in a cohort of coal miners. Am. J. Epidemiol., 125:437-444, 1987.

123. KELSEY, J.L., THOMPSON, D.W., EVANS, A.S. Methods in observational epidemiology, New York, Oxford University Press, , 1986. 
124. KENNEDY, M.C.S. Coal and the lung (letter). Thorax, 38:877, 1983.

125. KENNEDY, M.C.S. Nitrous fumes and coalminers with emphysema. Ann. Occup. Hyg., 15:285-300, 1972.

126. KENNEDY, M.C.S. Emphysema: beginning of an understanding. Br. Med. J., 281:388-389, 1980.

127. KENNEDY, S.M. et al. Pulmonary function and peripheral airway disease in patients with mineral dust disease and fume exposure. Am. Rev. Respir. Dis., 132:1294-1299, 1985.

128. KENNEDY, S. et al. Bronchial hyper-responsiveness, once adjusted for FEV1 level, is not increased in non-atopic subjects. Am. Rev. Respir. Dis., 137:31, 1988. (Resumo)

129. KIBELSTIS, J.A. et al. Prevalence of bronchitis and airway obstruction in american bituminous coal miners. Am. Rev. Respir. Dis., 108:886-893, 1973.

130. KLEINENBAUM, D.G., KUPPER, L.L., MORGENSTERN, H. Epidemiologic research. Principles and quantitative methods. Belmont, California, Lifetime Learning Publications, 1982.

131. KNUDSON, R.J. et al. Changes in the normal maximal expiratory flow-volume curve with growth and aging. Am. Rev. Respir. Dis., 127:725-734, 1983.

132. KORN, R.J. et al. Occupational exposures and chronic respiratory symptoms. Am. Rev. Respir. Dis., 136:298-304, 1987.

133. KREISS, $\mathrm{K}$. et al. Hard-rock mining exposures affect smokers and nonsmokers differently. Am. Rev. Respir. Dis., 139:1487-1493, 1989.

134. KRZYZANOWSKY, M., JEDRYCHOWSKI, W., WYSOCKI, W. Significance of spirometry repeatability criteria for the assessment of lung 
function level and changes over 13 years. Am. Rev. Respir. Dis., 139:256, 1988. (Resumo)

135. LAPP, N.L. et al. Changes in ventilatory function in coal miners after a workshift. Arch. Environ. Health, 24:204-208, 1972.

136. LAWTHER, P.J., BROOKS, A.G.F., WALLER, R.E. Respiratory function measurements in a cohort of medical students: a ten-year follow-up. Thorax, 33:773-778, 1978.

137. LEBOWITZ, M.D. Occupational exposures in relation to symptomatology and lung function in a community population. Environ. Res., 14:39-67, 1977.

138. LEBOWITZ, M.D., HOLBERG, C.J. Comparisons of spirometric reference values and the proportions of abnormal subjects among male smokers and those symptomatic in a community population. Am. Rev. Respir. Dis., 141:1491-1496, 1990.

139. LEIGH, J., WILES , A.N., GLICK, M. Total population study of factors affecting chronic bronchitis prevalence in the coal mining industry of New South Wales, Australia. Br. J. Ind. Med., 43:263-271, 1986.

140. LEIGH, J. et al. Quantified pathology of emphysema, pneumoconiosis and chronic bronchitis in coal workers. Br. J. Ind. Med., 40:258-263, 1983.

141. LIDELL, F.D.K., MORGAN, W.K.C. Methods of assessing serial films of the pneumoconioses: a review. J. Soc. Occup. Med., 28:6-15, 1978.

142. LOVE, R.G., MILLER, B.G. Longitudinal studies on lung function in coalminers. Thorax, 37:193-197, 1982.

143. LOVE, R.G. Lung function before and after a work shift. Br. J. Ind. Med., 40:153-159, 1983.

144. LYONS, J.P. et al. Significance of irregular opacities in the radiology of coalworkers pneumoconiosis. Br. J. Ind. Med., 31:36-44, 1974. 
145. LYONS, J.P., CAMPBELL, H. Evolution of disability in coalworkers pneumoconiosis. Thorax, 31:527-533, 1976.

146. MACLAREN, W.M., SOUTAR, C.A. Progressive massive fibrosis and simple pneumoconiosis in ex-miners. Br. J. Ind. Med., 42:734-740, 1985.

147. MALDONADO, J.M.S.V. Economia política do setor carbonffero no Brasil: o carvão energético. s.l., s. ed., 1985. (Mimeografado).

148. MAPP, C.E. et al. Toluene diisocyanate-induced asthma without airway. hyperresponsiveness. Eur. J. Respir. Dis., 68:89-95, 1986.

149. MARINE, W.M., GURR, D., JACOBSEN, M. Clinically important respiratory effects of dust exposure and smoking in British coal miners. Am. Rev. Respir. Dis., 137:106-112, 1988.

150. MARTIN, J.C. et al. The role of quartz in the development of coal workers pneumoconiosis. Ann. N. Y. Acad. Sci, 200:127-141, 1972.

151. McKERROW, C.B. et al. Respiratory function during the day in cotton workers: a study in byssinosis. Br. J. Ind. Med., 15:75-83, 1958.

152. McLINTOCK, J.S., RAE, S., JACOBSEN, M. The attack rate of progressive massive fibrosis in British coalminers. In: Walton, W.H., ed. Inhaled Particles III (2). Old Woking, Surrey, Unwin, 1971. p.933-950.

153. MEDEIROS, R.B. et al. Descrição de um sistema de medida do diâmetro aerodinâmico mediano de massa (DMM) de radioaerosois produzidos por nebulização. In: $4^{a}$ Reunião Anual da Federaçāo da Sociedade de Biologia Experimental. Anais s.l,, s. ed. Editora Legis Summa, 1989.p. 87.

154. MEDICAL RESEARCH COUNCIL. Chronic bronchitis and occupation. Br. Med. J., 1:101-102, 1966. 
155. MEDICAL RESEARCH COUNCIL. Chronic pulmonary disease in South Wales coalminers. I-Medical studies. London, H.M.S.O., 1942, (Special. Report Series No 243).

156. MENDES, R. Pneumoconioses, bibliografia brasileira comentada, 1886-1976. Rev. Ass. Med. Bras., 25:406-410, 1979.

157. MENDONÇA, E.M.C. et al. Comparaçāo entre as respostas inalatórias à metacolina e ao carbacol em indivíduos normais e asmáticos. J. Pneumol., 16 (Supl 1):6, 1990. (Resumo)

158. MERCHANT, J.A. Occupational respiratory diseases. Washington, US Department of Health and Human Services, 1986. (NIOSH Publication $\mathrm{n}^{\mathrm{O}}$ 86-102).

159. MERCK INDEX. 9th ed. Rahway, Merck and Co, Inc, 1976. p.1777.

160. MILLER, B.G., JACOBSEN, M. Dust exposure, pneumoconiosis and mortality of coalminers. Br. J. Ind. Med., 42:723-733, 1985.

161. MINETTE, A. Role de l'empoussierage professionnel dans la production des bronchites chroniques des mineurs de charbon. In: Walton, W.H. ed. Inhaled Particles II(2). Old Woking, Surrey, Unwin, 1971. p.873-881.

162. MINETTE, A., MARCQ, M., GEPTS, L. Prognostic value of a positive acetylcholine test regarding $\mathrm{VC}$ and $\mathrm{FEV}_{1}$ in coal-miners with a history of chronic bronchitis. Bull. Europ. Physiopath. Resp., 14:167-175, 1978.

163. MINETTE, A. Valeur prognostique de la sensibilité respiratoire à l'acétylcholine dans un groupe de mineurs de charbon. Rev. Inst. Hyg. Mines., 28:147-152, 1973.

164. MINETTE, A. Valeur pronostique de l'hyperréactivité bronchique pour l'acétylcholine au cours de la bronchite cronique des mineurs de charbon. Bronches, 18:466-488, 1968. 
165. MINISTÉRIO DE MINAS E ENERGIA, Departamento Nacional da Produção Mineral. Informativo anual da indústria carbonifera 1987. Brasília, 1988.

166. MINISTÉRIO DE MINAS E ENERGIA, Departamento Nacional da Produção Mineral. Informativo anual da indústria carbonífera 1986. Brasília, 1987.

167. MINISTÉRIO DE MINAS E ENERGIA, Departamento Nacional da Produção Mineral. Informativo anual da indústria carbonífera 1985. Brasília, 1986.

168. MINK, J.T. et al. Increased bronchial reactivity to inhaled histamine in nonsmoking grain workers with normal lung function. Chest, 77:28-31, 1980.

169. MORENO, R.H., HOGG, J.C., PARÉ, P.D. Mechanics of airway narrowing. Am. Rev. Respir. Dis., 133:1171-1180, 1986.

170. MORGAN, W.K.C. On dust, disability, and death (editorial). Am. Rev. Respir. Med., 134:639-641, 1986.

171. MORGAN, W.K.C. Industrial bronchitis. Br. J. Ind. Med., 35:285-291, 1978.

172. MORGAN, W.K.C. The prevalence of coal workers' pneumoconiosis. Am. Rev. Respir. Dis., 98:306-310, 1968.

173. MORGAN. W.K.C. et al. The prevalence of coal workers pneumoconiosis in US coal miners. Arch. Environ. Health, 27:221-226, 1973.

174. MORGAN, W.K.C., LAPP, N.L. Respiratory disease in coal miners. Am. Rev. Respir. Dis., 113:531-559, 1976.

175. MORRIS, J.F., KOSKI, A., JOHNSON, L.C. Spirometric standards for healthy nonsmoking adults. Am. Rev. Respir. Dis., 103:57-67, 1971. 
176. MUIR, D.C.F. Dust inhalation, retention and elimination. In: Rogan, J.M. ed. Medicine in the mining industries. Philadelphia, F.A. Davis Company, 1972.

177. MUIR, D.C.F. et al. Pneumocoiosis and chronic bronchitis, Br. Med. J., 2:424$427,1977$.

178. NATIONAL COAL BOARD MEDICAL SERVICE. Annual report 1983-4. London, N.C.B., 1985.

179. NATIONAL COAL BOARD MEDICAL SERVICE. Annual report 1982-3, London, N.C.B., 1984.

180. NAVRÁTIL, M., WIDMISKY, J., KASALICKY, J. Relationships of pulmonary haemodynamics and ventilation and distribution in silicosis. Bull. Eur. Physiopath. Respir., 4:349-359, 1968.

181. NEMERY, B. et al. Impairment of ventilatory function and pulmonary gas exchange in non-smoking coalminers. Lancet, 2:1427-1429, 1987.

182. NOGUEIRA, D.P. et al. Lung function tests and early prediction of byssinosis. Med. Lav., 74:129-136, 1983.

183. NUNN, J.F. Applied respiratory physiology. $3^{\text {rd }}$ ed. Cambridge, Butterworths, 1987.

184. O'CONNOR, G.T. et al. Smoking, atopy, and methacoline airway responsiveness among middle-aged and elderly men. Am. Rev. Respir. Dis., 140:1520-1526, 1989.

185. O'CONNOR, G. et al. Analysis of dose-response curves to methacholine. Am. Rev. Respir. Dis., 136:1412-1417, 1987.

186. OREHECK, J. et al. Effect of short-term, low-level nitrogen dioxide exposure on bronchial sensitivity of asthmatic patients. J. Clin. Invest., 57:301-307, 1976. 
187. ORIE, N.G. et al. The host factor in bronchitis. In: Orie, N.G., Sluiter, H.J., eds. Bronchitis. Assen, Royal Vangorcum, 1961. p.43-59.

188. PARKER, D.R. et al. The relationship of nonspecific airway responsiveness and atopy to the rate of decline of lung function. Am. Rev. Respir. Dis., 141:589-594, 1990.

189. PARKES, W.R. Occupational lung disorders. $2^{\text {nd }}$ ed. London, Butterwoths, 1982.

190. PATTEMORE, P.K. et al. The interrelationship among bronchial hyperresponsiveness, the diagnosis of asthma, and asthma symptoms. Am. Rev. Respir. Dis., 142:549-554, 1990.

191. PEREIRA, M.F., FIRMEZA, H. Condiçōes de trabalho nas minas de São Jerônimo e Butiá. Bol. Min. Trab. Ind. Com., 10:195-224, 1943.

192. PETERSEN, M., HANKINSON, J. Spirometry reference values for nonexposed blue-collar workers. J. Occup. Med., 27:644-650, 1985.

193. PETERSEN, M., CASTELLAN, R.M. Prevalence of chest symptoms in nonexposed blue-collar workers. J. Occup. Med., 26:367-373, 1984.

194. PHAM, Q.T. et al. Prognostic value of acetylcholine challenge test: a prospective study. Br. J. Ind. Med., 41:267-271, 1984.

195. POSTMA, D.S. et al. Independent influence of reversibility of air-flow obstruction and nonspecific hyperreactivity on the long term course of lung function and chronic airflow obstruction. Am. Rev. Respir. Dis., 134:276-280, 1986.

196. PRYS-ROBERTS, C. Principles of treatment of poisoning by higher oxides of nitrogen. Br. J. Anaesth., 39:432-439, 1967. 
197. RAE, S., WALKER, D.D., ATTFIELD, M.D. Chronic bronchitis and dust exposure in British coalminers. In: Walton, W.H. ed. Inhaled Particles III(2). Old Wolking, Surrey, Unwin, 1971. p.883-894.

198. REICHEL, G., ULMER, W.T. The interrelationship of coalminers pneumoconiosis and bronchitis. In: Walton, W.H. ed. Inhaled Particles III(2). Old Woking, Surrey, Unwin, 1971. p.897-900.

199. REISNER, M.T.R. Results of epidemiologic studies on the progression of coal workers pneumoconiosis. Chest, 78(Supl):406-407, 1980.

200. REISNER, M.T.R. Results of epidemiological studies of pneumoconiosis in West German coal mines. In: Walton, W.H. ed. Inhaled Particles III(2). Old Woking, Surrey, Unwin, 1971.p.921-929.

201. REISNER, M.T.R., ROBOCK, K. Results of epidemiological, mineralogical and cytotoxicological studies on the pathogenicity of coal mine dust. In: Walton, W.H., ed. Inhaled Particles IV(2). Oxford, Pergamon Press, 1977. p.703-715.

202. RIJCKEN, B. et al. The distribution of bronchial responsiveness to histamine in symptomatic and asymptomatic subjects. Am. Rev. Respir. Dis., 140:615$623,1989$.

203. RIJCKEN, B. et al. The relationship of nonspecific bronchial responsiveness to respiratory symptoms in a randon population sample. Am. Rev. Respir. Dis., 136:62-68, 1987.

204. ROGAN, J.M. et al. Role of dust in the working environment in development of chronic bronchitis in Bristish coal miners. Br. J. Ind. Med., 30:217-226, 1973.

205. ROSSITER, C.E. Relation between content and composition of coalworkers lungs and radiological appearances. Br. J. Ind. Med., 29:31-44, 1972. 
206. RUCKLEY, V.A. et al. Emphysema and dust exposure in a group of coal workers. Am. Rev. Respir. Dis., 129:528-532, 1984.

207. RUCKLEY, V.A. et al. Comparison of radiographic appearences with associated pathology and lung dust content in a group of coalworkers. Br. J. Ind. Med., 41:459-467, 1984.

208. RYAN, G. et al. Standardization of inhalation provocation tests: influence of nebulizer output, particle size, and method of inhalation. J. Allergy. Clin. Immunol., 67:156-161, 1981.

209. RYAN, G. et al. Standardization of inhalation provocation tests;:two techniques of aerosol generation and inhalation compared. Am. Rev. Respir. Dis., 123:195-199, 1981.

210. RYDER, R. et al. Emphysema in coal workers pneumoconiosis. Br. Med. J., 3:481-487, 1970.

211. SAMET, J.H. A historical and epidemiologic perspective on respiratory symptoms questionnaires. Am. J. Epidemiol., 108:435-446, 1978.

212. SCHEFFÉ, H. Judging all contrasts in the analysis of variance. Biometrika, 40:87-104, 1953.

213. SCHILING, R.S.F. et al. Disagreement between observers in an epidemiological study of respiratory disease. Br. Med. J., 1:65-68, 1955.

214. SCHULZER, M., ENARSON, D.A., YEUNG, M.C. Analyzing cross-sectional and longitudinal lung function measurements: the effect of age. Can. J. Stat., 13:7-15, 1985.

215. SCHULZER, M., YEUNG, M.C., TAN, F. On the possible significance of the quadratic effect of age on lung function measurements. Can. J. Stat., 10:293-303, 1982.

216. SEATON, A. Coal and the lung (editorial). Thorax, 38:241-243, 1983. 
217. SEATON, A. et al. Quartz and pneumoconiosis in coalminers. Lancet, 2:12721275, 1981.

218. SHARP, J.T. et al. A longitudinal study of bronchitis symptoms and spirometry in a middle-aged, male, industrial population. Am. Rev. Respir. Dis., 108:1066-1077, 1973.

219. SHEPPARD, D. et al. Exercise increases sulfur dioxide-induced bronchoconstriction in asthmatic subjects. Am. Rev. Respir. Dis., 123:486$491,1981$.

220. SHEPPARD, D. et al. Lower treshold and greater bronchomotor responsiveness of asthmatic subjects to sulfur dioxide. Am. Rev. Respir. Dis., 122:873-878, 1980.

221. SMIDT, U. Dust and non-specific respiratory disorders in foundry workers and coal miners in the Rhine-Ruhr area. Rev. Inst. Hyg. Mines., 34:70-76, 1979.

222. SOUTAR, C.A. Occupational bronchitis. In: Harrington, J.M., ed. Recent Advances in Occupational Health. London, Churchill Livingstone, 1987. Number 3.

223. SOUTAR, C.A. et al. Quantitative relations between exposure to respirable coalmine dust and coalworkers simple pneumoconiosis in men who have worked as miners but have left the coal industry. Br. J. Ind. Med., 43:29$36,1986$.

224. SOUTAR, C.A., HURLEY, J.F. Relationships between dust exposure and lung function in miners and ex-miners. Br. J. Ind. Med., 43:307-320, 1986.

225. SOUZA FILHO, A.J., ALICE, S.H., LUCA, V. Pneumoconiose dos trabalhadores das minas de carvão. J. Pneumol., 7:57-66, 1981. 
226. SPARROW, D. et al. The relationship of nonspecific bronchial responsiveness to the occurence of respiratory symptoms and decreased levels of pulmonary function. Am. Rev. Respir. Dis., 135:1255-1260, 1987.

227. SRISKANDAN, K. PETTINGALE, K.W. "Numismatist's pneumonitis". A case of acute nitrogen dioxide poisoning. Post. Med. J., 61:819-821, 1985.

228. STAT PACK - STATISTICAL PACKAGE. Walonick Associates Inc., University of Manitoba. Canada, 1982.

229. SWINSCOW, T.D.V. Statistics at square one. 7th ed. London. The British Medical Journal, 1980.

230. TABONA, M. et al. Host factors affecting longitudinal decline in lung spirometry among grain elevator workers. Chest, 85:782-786, 1984.

231. TAYLOR, R.G. et al. Bronchial reactivity to inhaled histamine and annual rate of decline in FEV, in male smokers and ex-smokers. Thorax, 40:9-16, 1985.

232. TOWNLEY, R.G. et al. Methacholine inhalation challenge studies. J. Allergy. Clin. Immunol., 64:569-574, 1979.

233. TSCHIEDEL, S.V. Avaliação do dano pulmonar na pneumoconiose do trabalhador de carvão. Porto Alegre, 1982 (Tese de Mestrado Universidade Federal do Rio Grande do Sul).

234. TSCHIEDEL, S.B., MARTINEZ, D., RIGATTO, M. Importância do diagnóstico precoce na pneumoconiose do mineiro de carvão - avaliação do binômio exposição-transtorno respiratório. J. Pneumol., 6 Supl.:51, 1980. (Resumo)

235. VALENTI, I.F. Levantamento das condiçōes de segurança e higiene das indústrias carboníferas (SC). Porto Alegre, FUNDACENTRO, 1985. (Relatório Técnico). 
236. van der LENDE, R. et al. Decreases in $\mathrm{VC}$ and $\mathrm{FEV}_{1}$ with time: indicators for effects of smoking and air pollution. Bull. Eur. Physiopath. Respir., 17:775-792, 1981.

237. van der LENDE, R., RIJCKEN, B., SCHOUTEN, J.P. Longitudinal versus cross-sectional studies in measuring effects of smoking air pollution and hyperreactivity on VC and FEV . Bull. Eur. Physiopath. Resp., 19:84P, 1983.

238. VEDAL, S., ENARSON, D.A., CHAN-YEUNG, M. Airway size and the rate of pulmonary function decline in grain handlers. Am. Rev. Respir. Dis., 138:1584-1588, 1988.

239. VEDAL, S. et al. A longitudinal study of the occurence of bronchial hyperresponsiveness in western red cedar workers. Am. Rev. Respir. Dis., 137:651-655, 1988.

240. VOLPATO, T.G. A pirita humana. Florianópolis, Universidade Federal de Santa Catarina/Assembléia Legislativa do Estado de Santa Catarina, 1984.

241. WALTON, W.H. et al. The effect of quartz and other non-coal dusts in coalworkers pneumoconiosis Part I: Epidemiological studies. In Walton, W.H., ed. Inhaled Particles IV(2). Oxford, Pergamon Press, 1977. p.669688.

242. WERNER, J.B. Problems with the measurement of radiological changes, In: Biological effects of mineral fibres. Lyon, 1980. p. 571-577. (IARC Scientific Publications $n^{0} 30$ )

243. WILES, F.J., FAURE, M.H. Chronic obstructive lung disease in gold miners. In: Walton, W.H. ed. Inhaled Particles IV(2). Oxford, Pergamon Press, 1977. p.727-734.

244. ZICHENG, S. A study of lung function in coalworkers pneumoconiosis. Br. J. Ind. Med., 43:644-645, 1986. 


\section{ANEXO 1}

Funções no Subsolo:

Agrupamentos e Códigos 
GRUPO SUPERVISÃO (01 a 09)

01 - Supervisão (sem diferenciação)

GRUPO FRENTE DE TRABALHO (11 a 39)

11 - Mineiro, puxador, produção, frente de serviço, langol

12 - Operador de cortadeira

13 - Operador de perfuratrizes (frente), furador de frente

14 - Operador de perfuratrizes (teto), furador de teto

Operador de Stoper

15 - Operador de Bob Cat

16 - Operador de Loader

17 - Operador de correias transportadoras e chutes

18 - Detonadores

19 - Escoramento

20 - Transporte I (Motoristas, Madeireiros, Manobreiros,

Trilheiros, Guincheiros, Cabistas)

21 - Transporte II (Shuttle Car)

22 - Limpeza

23 - Alimentadores

24 - Responsáveis pela produção, encarregados de produção, encarregados.

25 - Marteleiros

26 - Operadores de máquinas não especificados

27 - Operador de máquina I

28 - Operador de máquina II

29 - Serventes, Serviços Gerais

30 - Manutenção em turno de produção

31 - Encarregados de transporte

32 - Lubrificadores

GRUPO MANUTENÇÃO (41 a 49)

41 - Manutenção (fora de turno de produção)

GRUPO SUPERFÍCIE (51 a 59)

51 - Atividades de superfície quando o trabalho for poeirento 
ANEXO 2

Questionário de Sintomas Respiratórios e

Exposiçōes Inalatórias Ocupacionais - 1984 
QUESTIONARIO DE SINTOMAS RESPIRATORIOS

E EXPOSICCOES INALATORIAS OCUPACIONAIS

NOME

ENDEREÇO TELEFONE

SEXO

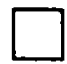

COR

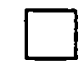

DATA DE MASCIMENTO

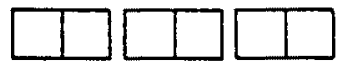

IDADE

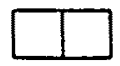

ESTADO CIVIL<smiles>C1CCC1</smiles>

HISTORIA PROFISSIONAL

DATA DO QUESTIONARIO

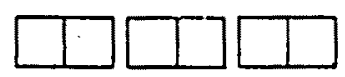

ENTREVISTADOR

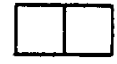

Adaptado do Questionārio de Sintomas Respiratórios

Medical Research Council - Grā Brotanha - 1976 
Coloque as questões, conformo a relação abaixo. Assinale 1 - Sin, 2 - Nāo, ou outros cōdigo, conforme indicado nos boxes. Quarido em dưvida assinale Não.

Informe ao entrevistado sobre

o questionärio, orientando-o para responder, Sim ou Nāo toda vez que possivel

Tosse

1. Vocè geralmente tosse ao acordar?

Caso Nāo para 1

2. Voce geralmente tosse ao acordar no inverno?

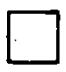

3. Você geralmente tosse du rante o dia ou a noite?

4. Voce tosse por pelo menos 3 meses por ano ao acordar?

\section{Catarro}

5. Vocē geralmente escarm ao acordar (catarro de vias aéreas inferiores)?

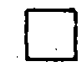

6. Você geralmente escarra a ocordar no imverno?

7. Você geralmente escarra du rante $\circ$ dia ou a noite?

Caso $\mathrm{Sin}$ para 5,6 ou 7

8. Vocẽ geralmente escarra pe 10 mens 3 meses por am ao acordar?

\section{Dispnēia}

9. Vocë sente falta de ar a andar no plano normal?

10. Vocē sente falta de ar ao andar apressado ou numa subida leve?

11. Você consegue acompanhar o passo de pessoas de sua idade, andando no plano?

12. Você tem de parar para descansar quando anda no plano em passo nor mal?

\section{Chiado}

13. Voce jā motou "chiado", "apitos" ou "miados" no seu peito?

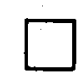

Caso Sim para 13

14. Você jâ apresentou algun episódio de chiado e falta de ar?

Caso Sim para 14, prossiga com as ques tōes referentes a chiado

15. Sua respiração é normal entre estes episôdios?

16. En relação a jornada de trabalho, você chia preferencialmente

No começo do dia $(=1)$

No final do dia $(=2)$

0 dia todo ( $(-3)$

No começo da $\operatorname{semana~(=1)}$

No final da semana (dias üteis) $(=2)$

Dias de semana $(=1)$

Fins de semana $(=2)$ 
Dor Toräcica

17. Você sente dor no tórax ao respirar ou a tossir?

\section{Caso $\mathrm{Sin}$ para 17}

18. En que locais

9. Vocē sente dor no tórax ao fazer esforços físicos?

Caso Sim para 19

20. En que locais?

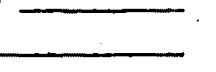

\section{Doencas Respiratórias Recentes}

21. Durante os ültimos 3 anos você apresentou alguma doença respi ratória que o afastasse das atividades por pelo menos 1 se mana?

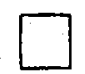

Caso Sim para 21

22. Neste episódio, aumenta a quan tidade de escarro?

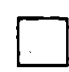

23. Quantos episödios semelhantes a penül tima questão nos ultimos 3 anos?

\section{Qutras Doencas Respiratōrias ou}

Correlacionadas

24. Vocē apresenta (ou)

Trauna de Törax

Fraturas de Costela $\quad(=02)$

Cirurgias Toräcicas $(=03)$

Bronquite Crânica $(=04)$

Asma Brōnquica $\quad(=05)$

Enfisema

Tuberculose

Preunonia

Pleurisia
Hipertensāo Arterial (=10)

Doença Coronariana

Insuficiência Cardíaca $(=12)$

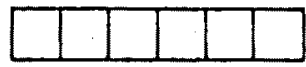

\section{Tabagismo}

25. Você fuma?

Caso kào para 25

26. Você jā fumou pelo menos 1 cigar ro ao dia por 1 ano?

Caso Não para 26, omita questōes res tantes referentes ao fumo

27. Quantos ${ }^{\circ}$ igarros por dia?

28. Com que idade começou a fumar?

29. Você diria que traga(va) a fuma ça?

No Traga $\quad(=0)$
Levemente $\quad(=1)$
Noderadamente $\quad(=2)$
Profundamente $\quad(=3)$

30. Você fuma(va) cigarıos com fil tro?

31. Quais as marcas que vocẽ costu ma(va) fumar?

32. Você funa cigarros feitos em casa?

33. Qual a quantidade de fumo se maral? (em gramas)

34. Você fuma cachimbo?

35. Você diria que inala fumaça de cachimbo?
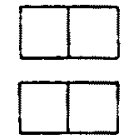
36. Qual a quantidade de fumo se manal? (em gramas)

37. Você fuma charutos?

38. Quantos charutos por dia?

$\underline{\text { Para ex-fumantes }}$

39. Hā quanto termpo parou de fumar?

Exposição a Gases, Vapores ou Fumos

40. Vocē trabalho diretamente exposto ou próximo a emissāo de gases, va pores ou fumos?

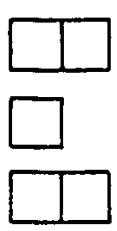

47. Quais?
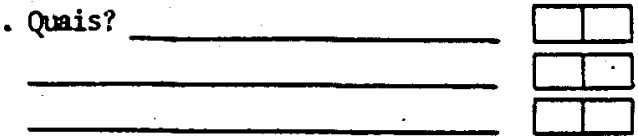

Você costuma lidar com:

48. Colas ou solventes

49. Tintas

50. Soldas

51. Cerâmica

52. Qutros

Especificar

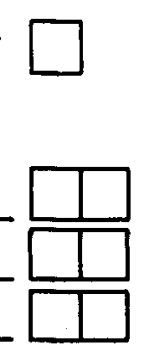

Caso Sin para 40

41. Quais?

COMENTARIOS ADICIONAIS

Exposiçāo a Poeiras Orgânicas e Inorgânicas

42. Você trabalha diretamente exposto ou próximo a emissão de poeiras?

Caso Sim para 42

43. Quais?

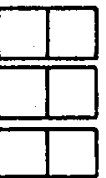

Exposiçōes Inadvertidas

44. Você cria animais domésticos?

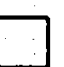

Caso $\mathrm{Sin}$ para 44

45. Quais?



46. Seu companheiro(a) trabalha exposto a poeiras? 
ANEXO 3

Questionário de Sintomas Respiratórios e

Exposiçōes Inalatórias Ocupacionais - 1989 
Whootration

IFUNDACENTRO

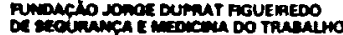

QUESTIONARIO DE SINTOMAS RESPIRATORIOS

E EXPOSICOES INALATORIAS OCUPACIONAIS

NONE

ENCEREPO

TELEFONE

SEXO

COR

DATA DE NASCIMENTO



IDADE

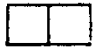

ESTADO CIVIL

INDiSTRIA

HISTÉRIA PROFISSIONAL

DATA DO QUESTIONARTO



ENTEVISTADOR

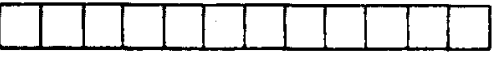

Adaptado do Questionārio de Sintomas Respiratórios

Medical Research Council - Grā Bretanha - 1976 


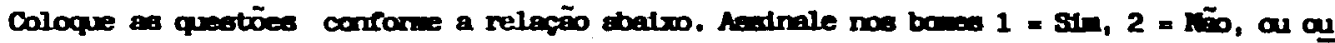



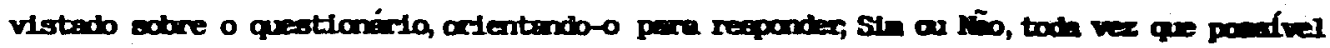

1. Toose

1.1. Você geralmente tosse ao acor dar?

1.2. Você geralmente tosse durente o dia ou a nolte?

Coso Stan pare 1.1 on 1.2

1.3. Você tosse pelo menos 3 meses por ano a acordar?

\section{Catacro}

2.1. Você geralmente escarra $\quad$ : acordar?

2.2. Você geralmente escarra cura te o dila ou a nolte?

Caso sin para 2.1 a 2.2

2.3. Você escarra pelo menos 3 ne ses por ano ao acordar?

\section{Tose e Catarro}

(En caso de questões 1.3 e 2.3 se rem positivas)

3.1. Há quantos anos você apresen ta tosse e catarro matinals?

4. Dispréla

Caso o Entrevistado tenha una lifi tagēo a deembulação por problemes que nẽo sejen de crden pulnonar ou cardisca, assinale "1" e onta bs questióes de n's 10, 11 e 12

4.1. Vocé sente falta de ar ao an dar apressado no plano ou nu ma sublda leve?

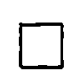


5.8. Relação com determinas subs tânclas ou atividades fora do emblente do trabalho:

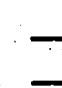

\section{Doenges Bexpiratióriss Hecentes}

6.1. Durante os úlimos 3 anos vo cê apresentou alguma doença resplratórla que 0 : afastasse das atividades por pelo menos 1 semana?

\section{Caco sil para 6.1}

6.2. Neste episódio, aumentou quantidade de escarro?

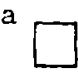

6.3. Quantos episódios semelhantes a periil tima questão nos illt mos 3 anos?

7. Ortras Doengas Reeplratiórias ar Cosralacionadas

7.1. Vocé apresenta(ou): Trauma de Tórax $(=1)$ Fratura de Costela $(=2)$

- Cirurglas Torácicas $(=3)$. Bronquilte Crânica

Agma Brânquilca

Enrisema

Tuberculose

$(=7)$

Preumania

$(=8)$

Derrane Pleural

(=9)

\section{Dadeos}

\subsection{Você suma?}

8.2. Você já lnmou pelo menos 1 cl garro ao dia por 1 eno?
Cano háo para 8.2, cuita as ques töes restantes refertantes ao fur

8.3. Quantos clgarros por dia

8.4. Com que 1dade começous a fumar?

8.5. Tabagismo em anos/maço?

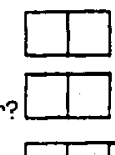

\section{Para ex-numantes}

8.6. Há quantos anos parou de fu mar?

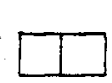

9. Exposiçäo a Pbeiras Orgânicas e Inorgânicas (em autros elpregos)

9.1. Você já trabaihou diretamente exposto ou próximo a emissão de poeiras?

\section{Caso Sim para 31}

9.2. Quais:
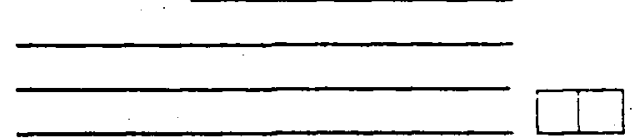

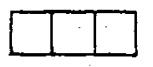

Peso (4):

Altura (cm):

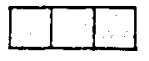

Prova de Angão Rulmanar

$\mathrm{VEF}_{1}$ (1)

CVF (1)

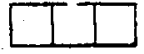

CVE (1)

FEF $(1 / s)$

PEAK-FLON $(1 / \mathrm{m})$

A9

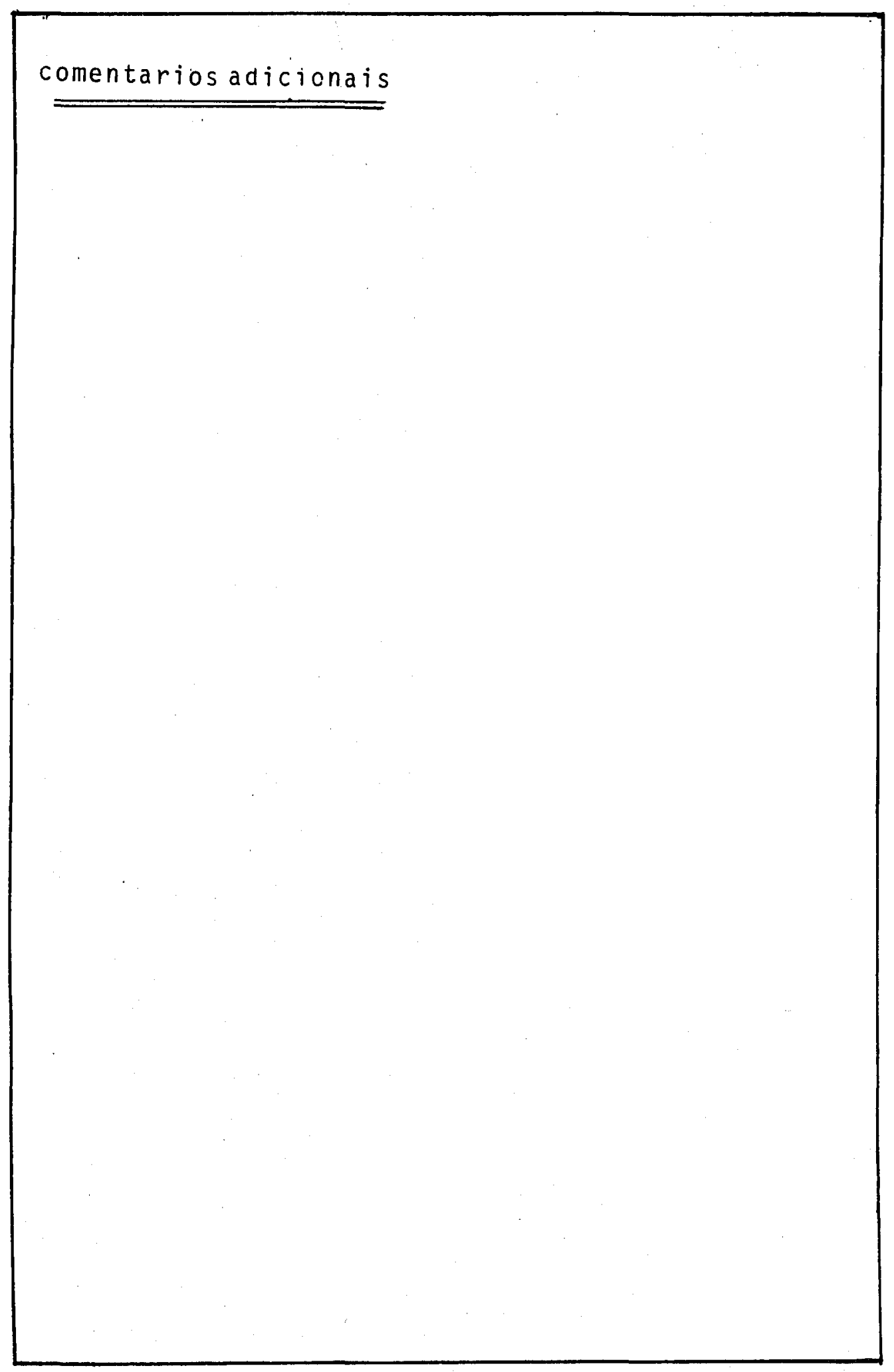


ANEXO 4

Folha de Resultados de Provocaçáo Brónquica 


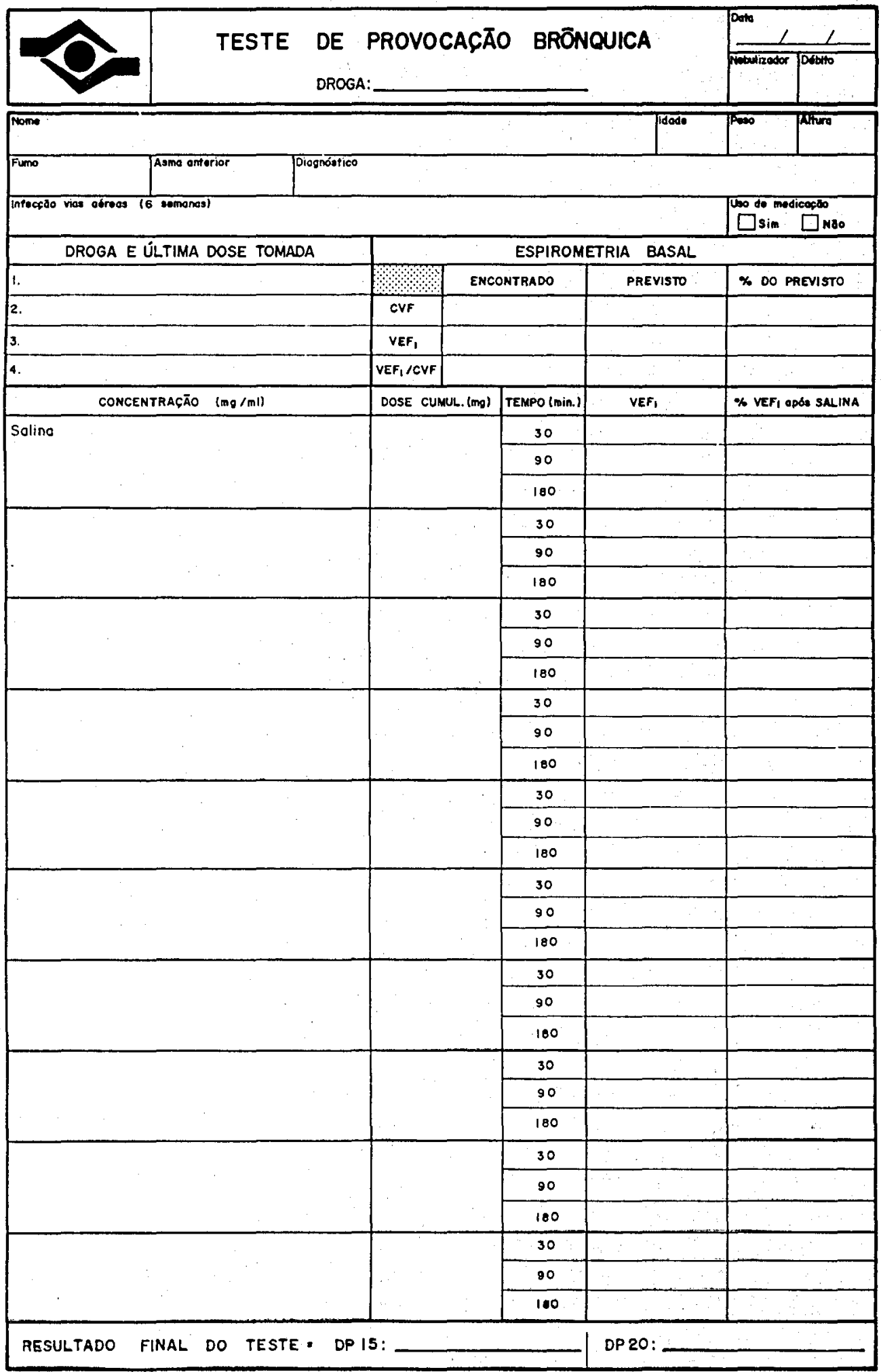


ANEXO 5

Folha de Leitura Radiologica 


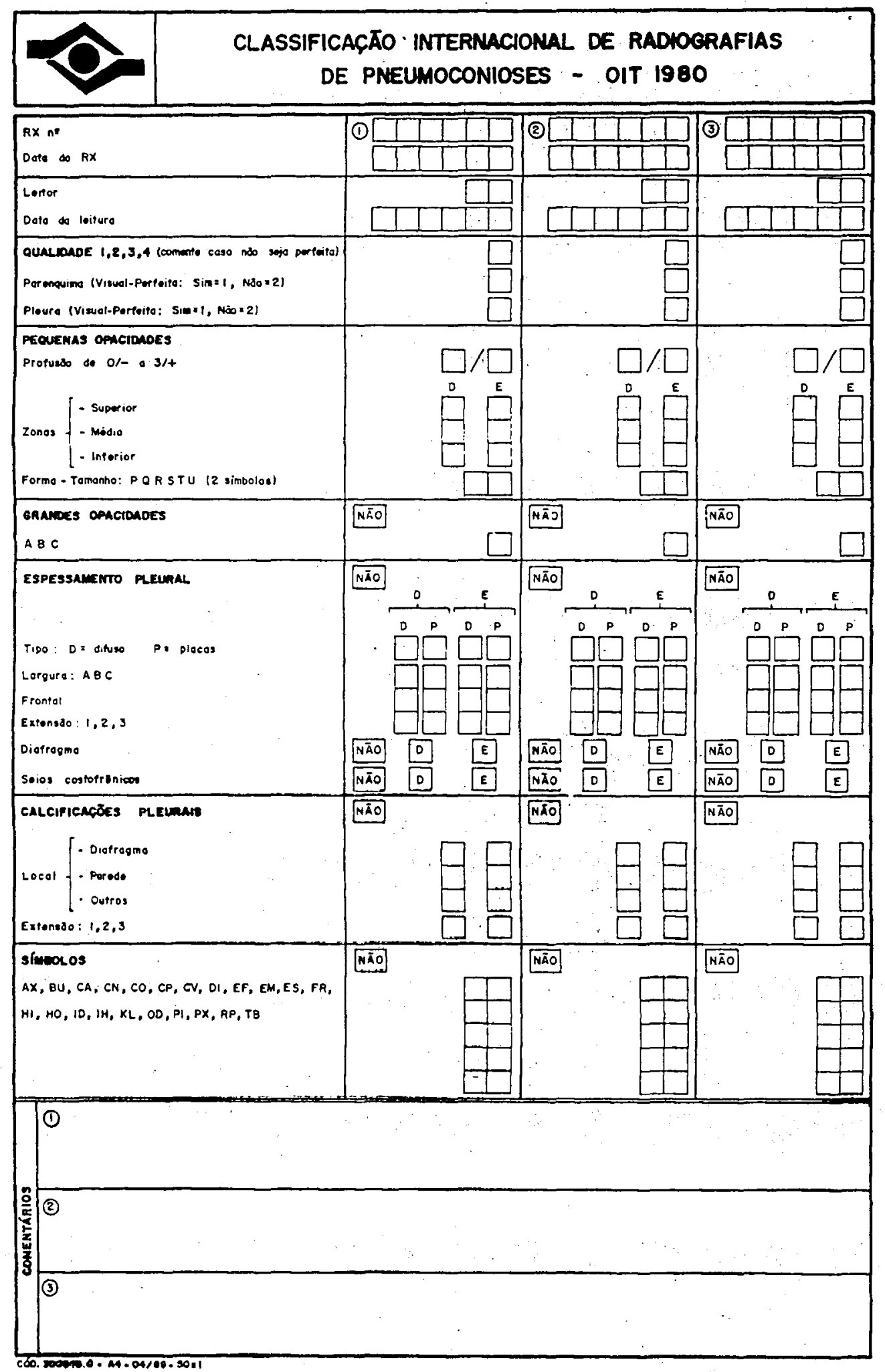

